\title{
Charakterisierung von Leupaxin und seiner Interaktionspartner in Karzinomzellen
}

\author{
Dissertation \\ zur Erlangung des mathematisch-naturwissenschaftlichen Doktorgrades \\ ,Doctor rerum naturalium ${ }^{66}$ \\ der Georg-August-Universität Göttingen
}

\author{
vorgelegt von \\ Sandra Gräfin von Hardenberg, \\ geb. Beckemeyer \\ aus \\ Minden
}

Göttingen, 2010 
Referent: $\quad$ Prof. Dr. Dr. W. Engel

Korreferent: Prof. Dr. S. Hoyer-Fender

Tag der Disputation : 07. Juli 2010 


\section{Inhaltsverzeichnis}

Fachwortverzeichnis

1.1 Leupaxin - Ein Mitglied der Paxillin-Proteinfamilie 1

1.2 Zur Expression und Lokalisation von LPXN 2

1.3 Zur Funktion von LPXN 4

1.4 Zur Funktion von LPXN im Prostatakarzinom 5

1.5 Ziele der Arbeit 7

2 Material und Methoden 9

2.1 Chemikalien und Reagenzien 9

2.2 Biochemikalien und Enzyme 11

$\begin{array}{lll}2.3 \text { Gebrauchswaren } & 12\end{array}$

$\begin{array}{lll}2.4 & \text { Sterilisationsverfahren } & 13\end{array}$

2.5 Gebrauchsfertige Reaktionssysteme 13

2.6 Lösungen 14

2.7 Medien, Antibiotika, Agarplatten 17

$\begin{array}{ll}\text { 2.7.1 Medien für Bakterien } & 17\end{array}$

$\begin{array}{lll}2.7 .2 & \text { Agarplatten } & 18\end{array}$

2.7.3 Medien für eukaryontische Zellkulturen 18

$\begin{array}{lll}2.8 & \text { Biologisches Material } & 19\end{array}$

$\begin{array}{ll}2.8 .1 \quad \text { Bakterienstämme } & 19\end{array}$

2.8.2 Eukaryontische Zellinien 19

$\begin{array}{lll}2.8 .3 & \text { Mausstämme } 20\end{array}$

$\begin{array}{ll}\text { 2.8.4 Synthetische Oligonukleotide } & 20\end{array}$ 
2.8.4.1 Synthetische DNA-Oligonukleotide

2.8.4.2 Synthetische RNA-Oligonukleotide 25

2.8.5 Antikörper 27

2.8.6 Plasmide und Vektoren 29

2.8.7 Verwendete Konstrukte und Plasmide 29

2.8.8 Datenbanken 30

2.9 Isolierung und Aufreinigung von Nukleinsäuren 30

2.9.1 Minipräparation von Plasmid-DNA 30

2.9.2 Herstellung von Bakterien-Glycerin-Stocks 31

2.9.3 Midipräparation von Plasmid-DNA 31

2.9.4 Ethanolfällung von DNA aus wässrigen Lösungen 31

2.9.5 Phenol/Chloroform- Aufreinigung von Nukleinsäuren 32

2.9.6 Isolierung von Gesamt-RNA aus Zellkulturen 32

2.9.7 Isolierung von Gesamt-RNA aus Organen der Maus 32

2.9.8 Konzentrationsbestimmung von Nukleinsäuren 32

2.10 Klonierungstechniken 33

2.10.1 Spaltung von DNA mit Restriktionsendonukleasen 33

2.10.2 Isolierung von DNA-Fragmenten aus Agarosegelen 33

2.10.3 Dephosphorylierung von Plasmid-DNA 34

2.10.4 Ligation von DNA-Fragmenten 34

2.10.5 Subklonierung von PCR- und RT-PCR-Produkten 34

2.11 Gelelektrophorese 35

2.11.1 Gelelektrophorese von DNA 35

2.11.2 Gelelektrophorese von RNA 36

2.11.3 Längenstandards 36

2.12 Transfertechniken von Nukleinsäuren $\quad 37$

2.12.1 Northern Blot-Analysen 37

2.12.2 Radioaktive Markierung von DNA und Hybridisierung membrangebundener RNA 37

2.12.3 Random Prime-Markierung 37

2.12.4 Hybridisierung membrangebundener RNA mit radioaktiv markierten $\begin{array}{ll}\text { DNA-Sonden } & 38\end{array}$

2.13 Polymerase-Kettenreaktion (PCR) 38

2.13.1 PCR an Plasmid-DNA 39 
2.13.2 Reverse Transkription

2.13.3 Quantitative real time PCR-Analysen 40

$\begin{array}{lll}2.14 & \text { Sequenzanalyse } & 43\end{array}$

2.15 Proteinchemische Techniken 44

2.15.1 Isolierung von Gesamtprotein aus Zellkulturen 44

2.15.2 Isolierung von Gesamt-Protein aus Organen der Maus 44

2.15.3 Konzentrationsbestimmung von Proteinen 45

2.15.4 SDS-Polyacrylamidgelelektrophorese (SDS-PAGE) 45

2.15.5 Western Blot-Analysen von Proteinen auf PVDF-Membranen 46

2.15.6 Färbung von Polyacrylamidgelen 46

2.15.7 Inkubation von membrangebundenen Proteinen mit Antikörpern 46

2.15.8 Densitometrische Auswertung 48

2.16 Aufreinigung eines TAT-Transduktionsproteins 48

2.16.1 Expression des TAT-LPXN-Fusionsproteins 48

2.16.2 Herstellung von Proteinlysaten aus Bakterien und Aufreinigung des Fusionsproteins $\quad 48$

$\begin{array}{lll}\text { 2.16.3 Transduktion des TAT-Fusionsproteins } & 50\end{array}$

2.17 Zellbiologische Methoden 50

2.17.1 Zellkultur eukaryontischer Zellen $\quad 50$

2.17.2 Isolierung von Primärzellen aus murinen Prostatakarzinomen 51

2.17.3 Zellkultur eukaryontischer muriner Primärzellen 51

2.17.4 Kryokonservierung und Revitalisierung von eukaryontischen Zellen $\quad 52$

2.17.5 Transfektion eukaryontischer Zellen 52

2.17.6 Anfertigung von Zytospin-Präparaten 53

2.17.7 Collagen-Aufreinigung aus Rattenschwänzen 53

2.18 Invasionsassay 53

2.19 Proliferationsassay 54

2.20 Assay zur Bestimmung der Adhäsion von Zellen 55

2.21 Bestimmung der Migrationsfähigkeit von Zellen 55

2.22 Herunterregulierung der Genexpression mittels RNA-Interferenz 56

2.22.1 Überblick über den Mechanismus von RNAi 57

2.22.2 Transfektion eukaryontischer Zellen mit siRNAs 58

2.23 Methoden zur subzellulären Lokalisierung eines Proteins 59

2.23.1 Immunzytochemische Färbung eukaryontischer Zellen 59 
2.23.2 Subzelluläre Lokalisation von Fusionsproteinen

2.24 Histologische Techniken

2.24.1 Fixierung des Gewebes

2.24.2 Vorbehandlung der Objektträger

2.24.3 Herstellung der Paraffinschnitte

2.24.4 Immunlokalisierung von Proteinen in Paraffingewebeschnitten

2.25 Whole Genome cDNA-Array

2.25.1 Vorbereitung der Gewebeproben

2.25.2 Isolierung der RNA

2.25.3 Labeling und Hybridisierung der Proben

2.25.4 Auswertung des Microarrays

2.26 Kinex $^{\mathrm{TM}}$ Antikörper-Array 66

2.27 GST-Pulldown 66

2.27.1 Aufreinigung der Glutathionsepharose 4-Beads

2.27.2 GST-Pulldown-Experiment zum Interaktionsnachweis von Caldesmon und LPXN

2.27.3 GST-Pulldown-Experiment zum Nachweis der LPXN-abhängigen Aktivierung von RhoA und Rac

2.27.4 In vitro Aktivierung von RhoA und Rac durch GTP $\gamma \mathrm{S}$

2.27.5 Regenerierung der Glutathionsepharose 4 Beads

3.1 Einfluss von LPXN auf die Progression von Prostatakarzinomen in einem Mausmodel

3.1.1 Analyse von doppelt transgenen LPXN/TRAMP-Mäusen

3.1.1.1 Endogenes LPXN spielt keine Rolle bei der Entwicklung des TRAMP-Tumors

3.1.1.2 Analyse der Tumormasse doppelt transgener LPXN/TRAMPund einfach transgener TRAMP-Mäuse

3.1.1.3 Analyse der Morphologie der Prostatae doppelt transgener LPXN/TRAMP- und einfach transgener TRAMP-Mäuse 
3.1.1.4 Analyse zur Bildung von Fernmetastasen in doppelt transgenen LPXN/TRAMP- und einfach transgenen TRAMP-Mäusen 76

3.1.2 LPXN erhöht die Progression von Prostatakarzinomen in kastrierten TRAMP-Mäusen

3.1.2.1 Überprüfung der Expression des transgenen SV40 T-Ag in den kastrierten Mäusen als Indiz für den Erfolg der Kastration

3.1.2.2 Analyse der Tumorentwicklung in kastrierten doppelt transgenen LPXN/TRAMP-Mäusen

3.2 Einfluss von LPXN auf das Migrations- und Invasionsverhalten von primären Prostatakarzinomzellen

3.2.1 Etablierung einer Primärzellkultur aus Prostatatumoren doppelt transgener LPXN/TRAMP- und einfach transgener TRAMP-Mäuse

3.2.2 LPXN erhöht das Migrations- und Invasionsverhalten von primären PCa-Zellen

3.3 LPXN reguliert die Expression von verschiedenen Genen

3.3.1 Die Expression des Zelladhäsions-Moleküls p120CTN korreliert negativ mit der LPXN-Expression

3.3.1.1 Überexpression von LPXN in PCa-Zelllinien korreliert mit der Expressionsabnahme von p120CTN 89

3.3.1.2 Expression von p120CTN im LPXN/TRAMP-Mausmodell

3.3.1.3 Expression von p120CTN in Primärzellen von LPXN/TRAMPTumoren

3.3.2 Analysen zur Funktion von p120CTN

3.3.2.1 Herunterregulierung von p120CTN in den PCa-Zelllinien mittels RNA-Interferenz

3.3.2.2 Verstärkte Migration und Invasion nach Herunterregulierung der p120CTN-Expression

3.3.2.3 Änderung der subzellulären Lokalisation von $\beta$-Catenin nach Herunterregulierung der LPXN- und p120CTN-Expression

3.3.2.4 Herunterregulierung der LPXN-Expression vermindert die Expression des $\beta$-Catenin Zielgens MMP-7

3.3.2.5 Überexpression von LPXN erhöht die Expression des $\beta$-Catenin Zielgens MMP-7 
3.3.3 Whole genome expression microarray zur Ermittlung von

Kandidatengenen, welche durch LPXN während der

Tumorprogression reguliert werden

3.4 Caldesmon als Interaktionspartner von LPXN

3.4.1 Expression von Caldesmon in PCa-Zelllinien

3.4.2 Untersuchung der subzellulären Lokalisation von Caldesmon in den

PCa-Zellen PC-3

3.4.3. Subzelluläre Kolokalisation von LPXN und Caldesmon in den

PCa-Zellen PC-3

3.4.4. Interaktionsnachweis von LPXN und Caldesmon durch ein

GST-Pulldown-Experiment

3.4.5 Analysen zur Funktion von Caldesmon

3.4.5.1 Herunterregulierung der Expression von Caldesmon in PCa-Zelllinien mittels RNA-Interferenz

3.4.5.2. Verstärkte Zellmigration von PC-3 und DU 145 PCa-Zellen nach Herunterregulierung der Caldesmon-Expression

3.4.5.3 Caldesmon hat keinen Einfluss auf die Proliferation von PCa-Zellen

3.4.6 Analysen zur Expression von Caldesmon in Abhängigkeit der

LPXN-Expression

3.4.7 Analysen zur Phosphorylierung von Caldesmon in Abhängigkeit zur LPXN-Expression

3.5 LPXN beeinflusst die Zelladhäsion und die Zytoskelett-Organisation

3.5.1 Analyse der Zelladhäsion und -organisation nach LPXN-Herunterregulierung in vitro

3.5.1.1 Verringerte Zelladhäsion und Zellzahl nach Herunterregulierung der LPXN-Expression

3.5.1.2 Verringerte Bildung von focal adhesion sites nach Herunterregulierung der LPXN-Expression

3.5.1.3 „Blebbing“ der Zellen nach Herunterregulierung der LPXNExpression

3.5.2 Analyse der Zelladhäsion und -organisation bei LPXN Überexpression ex vivo

3.5.2.1. Erhöhte Zelladhäsion nach Überexpression von LPXN ex vivo 
3.5.2.2. Verstärkte Bildung von focal adhesion sites nach LPXN-

Überexpression

3.5.3 GST-Pulldown zur Analyse der Aktivität der Rho-GTPasen

RhoA und Rac

3.5.3.1 Aufreinigung der GST-Fusionsproteine

3.5.3.2 GST-Pulldown mit den aufgereinigten GST-Fusionsproteinen

3.6 Analysen zum Einfluss von LPXN auf die Phosphorylierung und

Expression weiterer Gene

3.6.1 Durchführung eines Antikörper-Arrays

3.6.2 Überprüfung der Daten des Antikörper-Arrays

3.6.3 Analyse der TAK1-vermittelten Signalwege

3.6.4 Analyse der SRC-vermittelten Signalwege

4.1 Zusammenfassung der Ergebnisse

4.2 Zur Bedeutung von LPXN in der Progression von Prostatakarzinomen

4.3 Molekulare Mechanismen der Tumorprogression

4.3.1 Zelladhäsionsmoleküle in der Tumorprogression

4.3.2 Matrix-Metalloproteinasen in der Tumorprogression

4.3.3 Wachstumsfaktoren in der Tumorprogression

4.4 LPXN im Netzwerk der progressionsrelevanten Moleküle 161

4.4.1 LPXN-vermittelte Progression durch Zelladhäsionsmoleküle $\quad 161$

4.4.2 LPXN-vermittelte Progression durch Caldesmon 166

$\begin{array}{lll}\text { 4.4.3 Weitere LPXN-vermittelte Signalwege } & 169\end{array}$

4.5 Perspektiven 


\section{Abkürzungsverzeichnis}

\begin{tabular}{|c|c|}
\hline Abb. & Abbildung \\
\hline Amp & Ampicillin \\
\hline As & Aminosäure \\
\hline ATP & Adenosintriphosphat \\
\hline $\mathrm{bp}$ & Basenpaar \\
\hline bzw. & beziehungsweise \\
\hline${ }^{\circ} \mathrm{C}$ & Grad Celsius \\
\hline ca. & circa (ungefähr) \\
\hline cDNA & komplementäre DNA \\
\hline $\mathrm{cm}$ & Zentimeter \\
\hline c.off & Cut off \\
\hline DAPI & $4^{\prime}, 6^{\prime}$-Diamidino-2-Phenylindol \\
\hline dATP & Desoxyadenosintriphosphat \\
\hline $\mathrm{dCTP}$ & Desoxycytosintriphosphat \\
\hline dGTP & Desoxyguanosintriphosphat \\
\hline DEPC & Diethylpyrocarbonat \\
\hline DMSO & Dimethylsulfoxid \\
\hline DNA & Desoxyribonukleinsäure \\
\hline dNTPs & Desoxynukleotidtriphosphate \\
\hline ds & doppelsträngig \\
\hline DTT & 1,4-Dithiothreitol \\
\hline dTTP & Desoxythymidintriphosphat \\
\hline $\mathrm{ECM}$ & Extrazelluläre Matrix \\
\hline EDTA & Ethylendiamintetraessigsäure \\
\hline EGTA & Ethylenglycol-bis $(\beta$-aminoethyl)-N,N,N',N'-tetraacetat \\
\hline et al. & et alteri (und andere) \\
\hline FISH & Fluoreszenz in situ Hybridisierung \\
\hline FITC & Fluoreszeinisothiocyanat \\
\hline g & Gramm, Erdbeschleunigungskonstante \\
\hline ggf. & gegebenenfalls \\
\hline GFP & green fluorescent protein \\
\hline
\end{tabular}




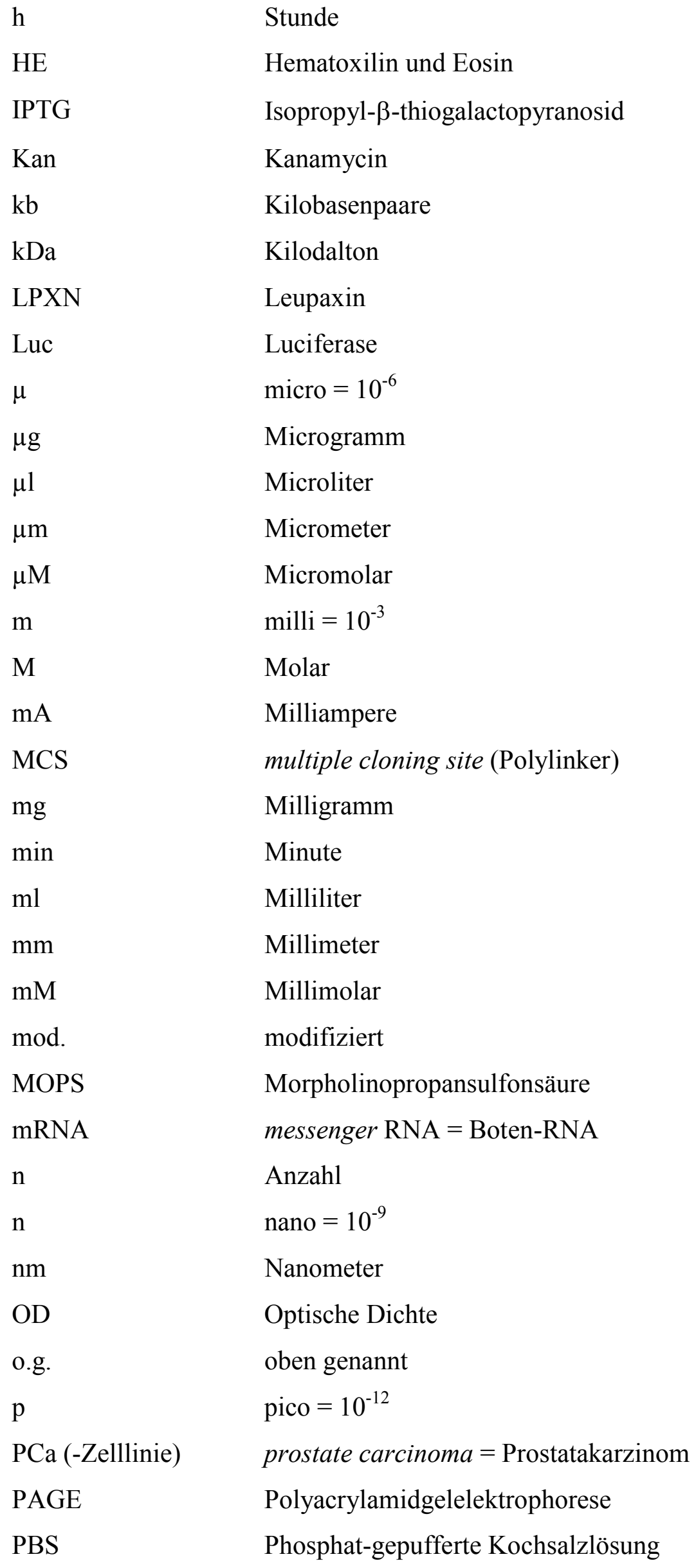

o.g.

$\mathrm{p}$

PCa (-Zelllinie)

PAGE

PBS

Kilodalton

Leupaxin

Luciferase

micro $=10^{-6}$

Microgramm

Microliter

Micrometer

Micromolar

milli $=10^{-3}$

Molar

Milliampere

multiple cloning site (Polylinker)

Milligramm

Minute

Milliliter

Millimeter

Millimolar

modifiziert

Morpholinopropansulfonsäure

messenger RNA = Boten-RNA

Anzahl

nano $=10^{-9}$

Nanometer

Optische Dichte

oben genannt

pico $=10^{-12}$

prostate carcinoma $=$ Prostatakarzinom

Polyacrylamidgelelektrophorese

Phosphat-gepufferte Kochsalzlösung 


\begin{tabular}{ll}
\hline PCR & Polymerase-Kettenreaktion \\
pg & Picogramm \\
pH & Negativer dekadischer Logarithmus der Protonenkonzentration \\
RNA & Ribonukleinsäure \\
RNAi & RNA interference \\
RNase & Ribonuklease \\
rpm & Rounds per minute \\
RT & Raumtemperatur; reverse Transkription \\
SDS & Natriumdodecylsulfat \\
sec & Sekunde \\
siRNA & small interfering RNA \\
sog. & sogenannt \\
ss & einzelsträngig \\
Tab. & Tabelle \\
Taq & Thermus aquaticus \\
U & Unit= definierte Enzymeinheit \\
UV & ultraviolettes Licht \\
u.a. & unter anderem \\
V & Volt \\
Vgl. & vergleiche \\
Vol & Volumen \\
X-GAL & zum. Teil \\
z.B. & Rom-Chlor-3-Indolyl- $\beta$-D-Galactopyranosid \\
\hline
\end{tabular}




\section{Fachwortverzeichnis}

Englische Fachbegriffe der Molekularbiologie werden, soweit sinnvoll, auch als solche verwendet und nicht ins Deutsche übersetzt, da deutsche Ersatzwörter oftmals unwissenschaftlich klingen und nur eine Umschreibung dessen sind, was im Englischen mit einem Wort ausgedrückt werden kann. Die Bedeutung dieser Fachbegriffe wird hier nochmals aufgeführt, sofern dies nicht im Text geschieht.

Annealing

Array

Assay

Blebbing

Downstream

Elongation

Focal adhesion site(s)

Full length
Wörtlich übersetzt: ausglühen, härten

Primer-Anlagerung während der PCR

Wörtlich übersetzt: Datenreihe

Wörtlich übersetzt: untersuchen, Untersuchung

Test, Versuchsreihe

Wörtlich übersetzt: Blasenbildung, Abschnürung von

Membranvesikeln

Wörtlich übersetzt: stromabwärts

In einer Kaskade: unterhalb, als nachgeschalteter Faktor

Bei einem Gen: weiter 3' gelegen

Wörtlich übersetzt: Verlängerung

Hier: DNA-Strang-Verlängerung während der PCR

Wörtlich übersetzt: fokale Adhäsionsstelle(n)

Dies sind Bereiche der Zellmembran, die über Integrin-

cluster mit der ECM interagieren.

Wörtlich übersetzt: Volle Länge

Hier: das gesamte Protein oder kompletten kodierenden

Bereich einer cDNA betreffend 
Gleason Score

Housekeeping

In frame

In vitro

In vivo

Primer

Proofreading

Real time

Sandwich
Klassifizierungssystem für die verschiedenen Stadien des

Prostatakarzinoms

Wörtlich übersetzt: Haushalt

Ein housekeeping-Gen ist ein konstitutiv exprimiertes Gen, das in allen Zellen essentiell ist.

Wörtlich übersetzt: im Rahmen

Bei der Herstellung eines Fusionsproteins muss darauf geachtet werden, dass bei der Klonierung der nachgeschalteten cDNA der Leserahmen der vorgeschalteten cDNA eingehalten wird.

Wörtlich übersetzt: im Glas, organische Vorgänge, die außerhalb eines lebenden Organismus stattfinden

Wörtlich übersetzt: im Lebendigen, Prozesse, die im lebenden Organismus stattfinden

Oligonukleotid von 20-35 Basenpaaren, welches von Polymerasen als Starthilfe zum Ansynthetisieren weiterer Nukleotide genutzt wird.

Wörtlich übersetzt: Korrekturlesen

Polymerasen mit einer Proofreading-Aktivität sind in der Lage, falsch eingebaute Nukleotide über ihre $3^{\prime}-5^{\prime}$ Exonuklease-Aktivität zu entfernen.

Wörtlich übersetzt: Echtzeit

Während der PCR kann die Zunahme der Amplifikate auf einem Monitor in Echtzeit verfolgt werden

Wörtlich übersetzt: belegtes Brot

Hier: Art des Aufbaus beim Western und Northern BlotTransfer. Die Membran wird zwischen Whatman-Papier + Gel und Whatman-Papier gelegt. 
Screening

Tag

Template

Upstream

Yeast-2-Hybrid-System
Wörtlich übersetzt: (durch)sieben, untersuchen

Hier: Durchsuchen einer Bibliothek nach bestimmten

Proteinen und Genen

Wörtlich übersetzt: Anhänger, Kennzeichen

Wörtlich übersetzt: Schablone, Vorlage, Matrize

Hier: RNA oder DNA, die während einer PCR amplifiziert werden soll

Wörtlich übersetzt: stromaufwärts

In einer Kaskade: oberhalb, als vorgeschalteter Faktor

Bei einem Gen: weiter 5'-gelegen

Hefesystem, um Proteine nachzuweisen, die an ein

bestimmtes Protein, das untersucht werden soll, binden 


\section{Einleitung}

\subsection{Leupaxin - Ein Mitglied der Paxillin-Proteinfamilie}

Leupaxin (LPXN) wurde erstmals 1998 von Lipsky et al. beschrieben und auf Grund seiner ausgeprägten Homologie zu dem focal adhesion-Protein Paxillin der Paxillin-Proteinfamilie zugeordnet. Dieser Proteinfamilie gehört auch das androgen receptor-associated protein 55 (ARA55) an. Die wichtigsten gemeinsamen Merkmale aller Mitglieder der PaxillinProteinfamilie sind die einheitliche Struktur ihrer LD-Motive und LIM-Domänen sowie die subzelluläre Lokalisation an den focal adhesion sites. Die vier (ARA55 und Leupaxin) bzw. fünf (Paxillin) LD-Motive in der N-terminalen Hälfte der Proteine bestehen aus kurzen konservierten Leucin-reichen Aminosäuresequenzen, welche ein invariantes Leucin $(\underline{L})$ Aspartat(ㅁ)-Paar enthalten. Die vier LIM-(Lin-11; Isl-1 und Mec-3)-Domänen am Carboxyterminalen Ende der Proteine bestehen aus jeweils ca. 50 Aminosäuren und enthalten konservierte Cycteine, Histidine und Aspartate, welche zusammen Zink-bindende Module bilden [Kosa et al., 1994; Michelsen et al., 1994; Perez-Alvarado et al., 1994] (Abb. 1.1).

\section{Paxillin-Proteinfamilie}
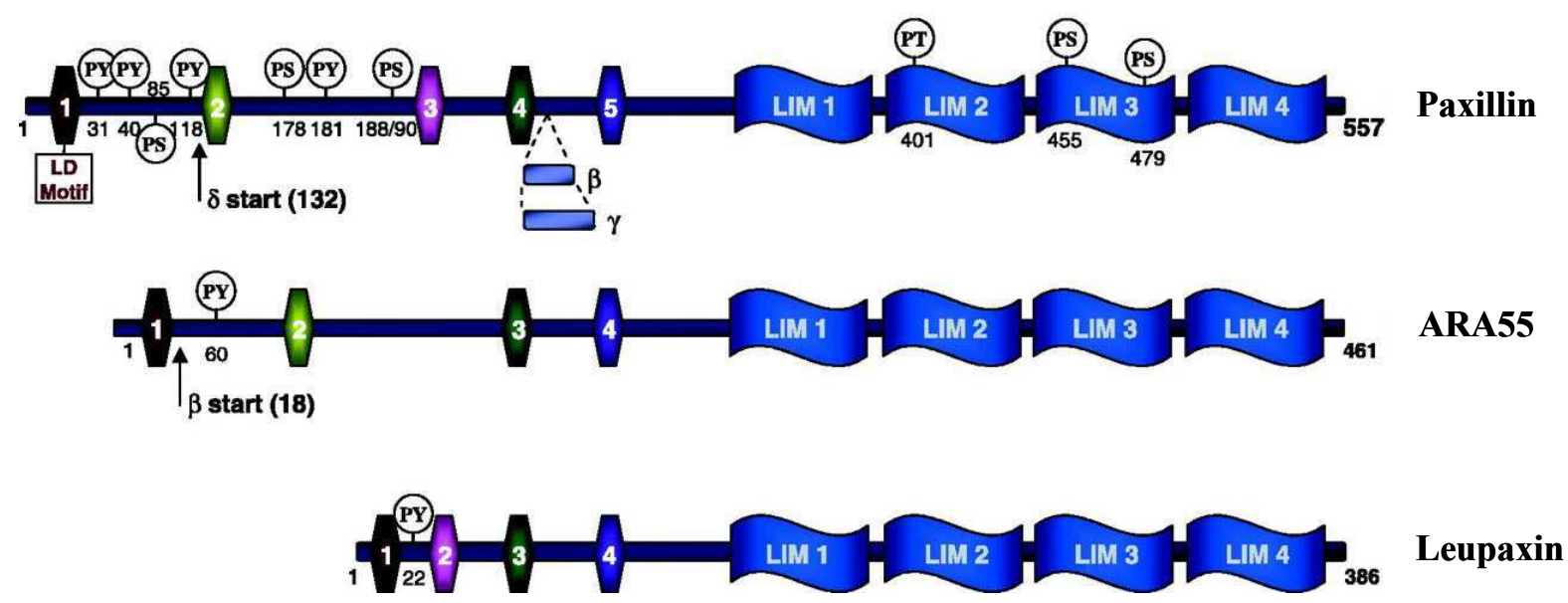

Abb. 1.1: Darstellung der Domänenstruktur der Mitglieder der Paxillin-Proteinfamilie Paxillin, ARA55 und Leupaxin (modifiziert nach Brown et al. [2004]). Paxillin, ARA55 und Leupaxin bestehen aus jeweils vier LIM-Domänen und vier (ARA55 und Leupaxin) bzw. fünf (Paxillin) LD-Motiven. Sowohl die LIM- 
Domänen als auch die LD-Motive vermitteln die Interaktion mit verschiedenen Proteinen. Die LIM-Domänen sind zusätzlich für die Lokalisation der Proteine an den focal adhesion sites verantwortlich. Die Größe der Proteine variiert zwischen 386 (Leupaxin) und 557 (Paxillin) Aminosäuren. Einige Aminosäuren (PY = Thyrosinrest, $\mathrm{PS}=$ Serinrest, $\mathrm{PT}=$ Threoninrest) der Mitglieder der Paxillin-Proteinfamilie können phosphoryliert werden. Die Zahlen beschreiben die Aminosäureposition der phosphorylierten Aminosäuren.

Für Paxillin konnte gezeigt werden, dass sowohl die LD-Motive als auch die LIM-Domänen für die Interaktion mit Proteinen von Bedeutung sind [Brown et al., 1998; Dawid et al., 1998], und dass die LIM-Domänen zusätzlich für die Lokalisation von Paxillin an den focal adhesion sites verantwortlich sind [Brown et al., 1996]. Aufgrund dieser Eigenschaften stellen die Mitglieder der Paxillin-Proteinfamilie wichtige Plattformen zur Koordination von Signalwegen an den focal adhesion sites dar. Die focal adhesion sites sind dynamische Proteinkomplexe, die das Zytoskelett der Zelle mechanisch mit der extrazellulären Matrix (ECM) verankern und so im ständigen Informationsaustausch mit der Umgebung stehen. Es konnte z.B. gezeigt werden, dass Paxillin mit der focal adhesion kinase FAK interagiert und diese Interaktion von der Adhäsion der Zellen an die ECM abhängig ist [Hildebrand et al., 1995]. Weiterhin wurde die Assoziation von Paxillin und FAK im direkten Zusammenhang mit der Karzinogenese beschrieben, wobei ein Einfluss auf die Progression und Invasion von Prostatakarzinomen (PCa) nachgewiesen werden konnte [Tremblay et al., 1996].

\subsection{Zur Expression und Lokalisation von LPXN}

LPXN wurde zunächst als zytoplasmatisches Protein beschrieben, welches hauptsächlich in hämatopoetischen Zellen exprimiert wird [Lipsky et al., 1998]. Erst 2007 konnten Sahu et al. erste Hinweise auf die Expression von LPXN in der PCa-Zelllinie PC-3 erhalten. In unserer Arbeitsgruppe wurde LPXN zum gleichen Zeitpunkt im Rahmen der biologischen Dissertation von Frau Dr. Kaulfuß auf dessen Expression im humanen PCa untersucht. Dabei konnte durch immunhistochemische Analysen an humanen PCa-Präparaten in 22\% der Fälle eine zumeist fokale Expression von LPXN ausschließlich im Epithel des Karzinoms detektiert werden. Die Expression von LPXN korrelierte dabei direkt mit dem Gleason-Muster der LPXN-positiven Tumorbereiche sowie mit dem Gleason-Score des gesamten PCa [Kaulfuß et al., 2008]. Diese Korrelation deutet darauf hin, dass LPXN an der Progression von PCa beteiligt ist. Diese Hypothese wurde durch die Ergebnisse der Expressionsanalyse 
von LPXN in den etablierten PCa-Zelllinien LNCaP, PC-3 und DU 145 unterstützt. Mittels Western Blot-Analyse konnte gezeigt werden, dass LPXN in den invasiven und androgen-unabhängigen PC-3- und DU 145-Zellen sechs- bzw. zweifach stärker exprimiert wird als in den nicht invasiven und androgen-abhängigen LNCaP-Zellen [Kaulfuß et al., 2008].

Die subzelluläre Lokalisation von LPXN in Leukozyten wurde von Lipsky et al. als eine diffuse Verteilung im Zytoplasma beschrieben [1998]. In Osteoklasten hingegen konnte eine Lokalisation von LPXN an den Podosomen beobachtet werden [Gupta et al., 2003, Sahu et al., 2007]. Im Rahmen der biologischen Dissertation von Frau Dr. Kaulfuß wurde die subzelluläre Lokalisation von LPXN in den PC-3-Zellen untersucht. Es konnte festgestellt werden, dass LPXN an den für die Mitglieder der Paxillin-Proteinfamilie typischen focal adhesion sites lokalisiert, wobei zusätzlich in 1-3\% der Zellen eine Kernlokalisation beobachtet werden konnte (Abb. 1.2). Es konnte gezeigt werden, dass der Transport von LPXN aus dem Kern durch ein Kernexportsignal vermittelt wird, welches im Bereich des LD3- bzw. LD4-Motivs liegt [2008]. Die Lokalisation von LPXN sowohl an den focal adhesion sites als auch im Kern konnte ebenfalls von Sundberg-Smith et al. in glatten Muskelzellen beobachtet werden [2008].

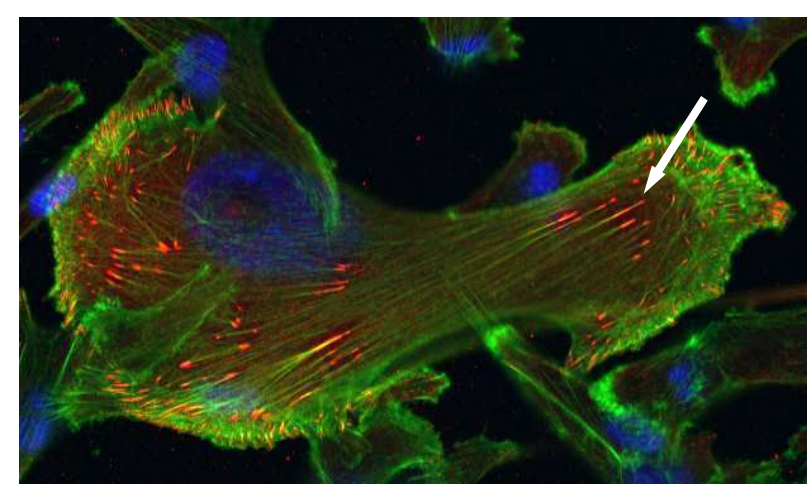

Abb. 1.2: Subzelluläre Lokalisation von LPXN in der PCa-Zelllinie LNCaP (aus vorliegender Arbeit). LNCaP-Zellen wurden auf Fibronektin-beschichteten Glasobjektträgern ausplattiert und für mind. $24 \mathrm{~h}$ inkubiert. Anschließend wurden die Zellen fixiert und mit einem LPXN-spezifischen Antikörper angefärbt. Zur Visualisierung des Zytoskeletts wurde FITC-Phalloidin verwendet. Die Kernfärbung erfolgte mit DAPI. Die Überlagerung zeigt eine deutliche Lokalisation von LPXN an den focal adhesion sites (Pfeil). Die Aufnahme erfolgte mit einem Laserscanning-Mikroskop bei 600facher Vergrößerung. 


\subsection{Zur Funktion von LPXN}

Über die Funktion von LPXN gibt es bisher nur wenige und z.T. kontroverse Ergebnisse. Es ist bekannt, dass LPXN in Lymphozyten mit dem FAK-Familienmitglied PYK2 einen Komplex formt, wodurch Zellfunktionen wie Motilität, Ausbreitung und Apoptose vermittelt werden können [Lipsky et al., 1998]. Weiterhin konnte in Osteoklasten eine Assoziation von LPXN mit der Tyrosinkinase SRC nachgewiesen werden. In diesen Zellen beeinflusst LPXN die Migrations- und Resorptionsfähigkeit und stellt ein wichtiges Adapterprotein bei der Bildung von Adhäsionszonen dar [Gupta et al., 2003]. In B-Zellen interagiert LPXN nach Induktion des B-Zell-Antigenrezeptors (BCR) mit der SRC-Tyrosinkinase LYN, was zur Phosphorylierung von LPXN und anschließend zur Inhibierung des BCR-vermittelten Signalweges führt [Chew et al., 2007]. In neueren Studien wurde von Sundberg-Smith et al. [2008] gezeigt, dass LPXN in glatten Muskelzellen mit FAK einen Komplex bildet, und dass eine erhöhte FAK-Expression eine Akkumulation von LPXN im Kern bewirkt. Im Kern fungiert LPXN als Kofaktor von SRF (serum response factor). Da die Bindung von SRF an konservierte Promotor-Elemente für die Expression von vielen Differenzierungs-Markergenen in glatten Muskelzellen verantwortlich ist, wird LPXN als Aktivator der Muskelzelldifferenzierung beschrieben. 2009 wurde LPXN in einem AML (Akute Myeloische Leukämie) -Patienten mit der Translokation t(11;21)(q12q22) als RUNX1-Fusionsprotein beschrieben. Das Fusionsprotein RUNX1/LPXN sowie das Wildtyp RUNX1-Protein sind im Kern der hämatopoetischen Zellen lokalisiert. Dort konkurrieren beide Proteine um die Bindungsstelle am CSF1R (colony stimulating factor 1 receptor)Promotor. Bindet das Fusionsprotein an dem CSF1R-Promotor, kommt es zu einer Hemmung der Transkription und somit zu einer gestörten Proliferation und Differenzierung der Zellen [Dai et al., 2009]. Weiterhin konnte dieselbe Arbeitsgruppe zeigen, dass sich aus NIH3T3Zellen, die stabil mit pEGFP-N1-RUNX1/LPXN bzw. pEGFP-N1-LPXN transfiziert wurden und anschließend subkutan in BALB/c-Nacktmäuse injiziert wurden, nach 28 Tagen ein Karzinom entwickelte [Dai et al., 2009]. 


\subsection{Zur Funktion von LPXN im Prostatakarzinom}

Sahu et al. konnten 2007 eine Interaktion von LPXN mit den Tyrosin-Kinasen PYK2 und c-SRC sowie der Phosphatase PTP-PEST in PC-3-Zellen demonstrieren. Die Autoren stellten die Hypothese auf, dass als funktionelle Konsequenz aus dieser Komplexbildung eine erhöhte Zellmigration resultiert.

Gleichzeitig wurde im Rahmen der biologischen Dissertation von Frau Dr. Kaulfuß der Einfluss von LPXN auf das Proliferations-, Migrations- und Invasionsverhalten von PCaZellen untersucht. Es konnte gezeigt werden, dass die androgen-abhängigen LNCaP-Zellen nach Herunterregulierung der LPXN-Expression eine veränderte Morphologie aufweisen, sich vom Kulturboden ablösen und apoptotisch werden. In den androgen-unabhängigen PC-3- und DU 145-Zellen konnten eine um 78\% verringerte Invasivität sowie eine deutlich reduzierte Migrationsfähigkeit festgestellt werden. Während meiner Diplomarbeit konnte nach Überexpression von LPXN eine erhöhte Migrations- sowie Invasionsfähigkeit der PC-3Zellen demonstriert werden [Beckemeyer, 2007]. Die Proliferation von PC-3- und DU 145Zellen wird durch die Expressionsstärke von LPXN nicht beeinflusst. Dabei bleibt die Frage offen, welche Auswirkungen eine erhöhte LPXN-Expression auf das Wachstum von PCa in vivo ausübt.

Um zu verstehen, welche Signalwege beim Verlust der adhäsiven und invasiven Eigenschaften nach Herunterregulierung der Leupaxin-Expression eine Rolle spielen, wurde in unserer Arbeitsgruppe von Frau Dr. Kaulfuß ein Zelladhäsions-Array durchgeführt. Auf dem Array waren 96 cDNAs von bekannten Genen aufgespottet, die in Invasion, Adhäsion und Apoptose involviert sind. Es konnte dabei für das Zelladhäsionsmolekül p120Catenin (p120CTN) gezeigt werden, dass es bei verminderter LPXN-Expression in PCa-Zellen stärker exprimiert wird als in den entsprechenden Kontrollzellen. Weiterhin konnte in unserer Arbeitsgruppe gezeigt werden, dass die Zunahme der LPXN-Expression direkt mit der Herunterregulierung der p120CTN-Expression korreliert [Kaulfuß et al., 2009]. p120CTN gehört zur Familie der p120-Catenine, die in Zell-Zell- und Zellmatrix-Interaktionen involviert sind. Kallakury et al. [2001a, b] konnten zeigen, dass beim PCa in fast $50 \%$ der untersuchten Fälle ein Expressionsverlust von p120CTN eintritt. Der Expressionsverlust korreliert dabei signifikant mit dem Gleason Score und dem Tumorstadium. Es stellte sich daher die Frage, ob p120CTN als Vermittler der LPXN-induzierten Eigenschaften fungieren kann. 
In unserer Arbeitsgruppe konnten verschiedene Interaktionspartner von LPXN identifiziert werden, die zusätzliche Hinweise auf die Rolle von LPXN in der Karzinogenese geben. Es konnte gezeigt werden, dass LPXN über seine LIM-Domänen mit dem Androgenrezeptor (AR) interagiert und zudem in Anwesenheit des Liganden DHT (Dihydrotestosteron) seine transkriptionelle Aktivität erhöht. Der AR spielt bei der Progression von PCa eine wichtige Rolle, da er ein unkontrolliertes Wachstum der PCa-Zellen auslösen kann [Stanbrough et al., 2001, Han et al., 2005]. Dabei wird er vor allem im Zusammenhang mit der Entwicklung des androgen-abhängigen zum androgen-unabhängigen PCa beschrieben [Chen et al., 2004; Edwards und Bartlett, 2005]. Darüber hinaus konnte eine liganden-unabhängige Interaktion mit dem Glukokortikoidrezeptor, dem Progesteronrezeptor sowie den Östrogenrezeptoren $\alpha$ und $\beta$ nachgewiesen werden [Herr, 2005; Kaulfuß, 2006].

Durch ein Screening einer Prostata-cDNA-Bibliothek mittels eines Yeast-2-Hybrid-Systems konnten die Aktin-bindenden Proteine Transgelin und Caldesmon als Interaktionspartner von LPXN identifiziert werden [Beckemeyer, 2007]. Shields et al. [2002] konnten zeigen, dass die Expression von Transgelin, auch bekannt als SM22 $\alpha$, im Mammakarzinom herunterreguliert ist, und dass dieser Expressionsverlust in Brust- und Darmkrebs mit der Progression des Tumors korreliert. Für Caldesmon wurde nachgewiesen, dass es die Invasionsfähigkeit von Brust- und Darmkrebszellen durch die Regulation der Podosomen- und Invadopodien-Bildung verringert [Yoshio et al., 2007]. Außerdem reguliert Caldesmon die Proliferation und Migration von vaskulären, glatten Muskelzellen [Yokouchi et al., 2006]. Diese Eigenschaften führten zu der Frage, ob die Veränderungen der PCa-Zellen nach einer deregulierten LPXNExpression durch die Interaktion zwischen LPXN und Caldesmon vermittelt werden können.

Die einzigen in vivo-Experimente zur Aufklärung der Funktionsweise von LPXN wurden bisher in einem Mausmodell durchgeführt, welches Prostata-spezifisch LPXN überexprimiert [Kaulfuß, 2006]. Durch histologische Analysen der Prostatae von diesen transgenen Mäusen, die bis zu zwei Jahre alt waren, wurde demonstriert, dass die Überexpression von LPXN keine morphologische Veränderung des Prostataepithels bewirkt. Dieses Ergebnis konnte an einer weiteren unabhängigen transgenen LPXN-Mauslinie bestätigt werden [Kaulfuß et al., 2009]. Die Analysen unterstützen die Annahme, dass LPXN kein Initiator der Tumorbildung in der Prostata ist, sondern vielmehr die Progression von bestehenden Tumoren beschleunigen könnte. 


\subsection{Ziele der Arbeit}

In der vorliegenden Dissertation sollte aufbauend auf vorangegangene Arbeiten der Einfluss von LPXN auf das Progressionsverhalten von PCa-Zellen analysiert werden. Weiterhin sollten verschiedene Hypothesen, auf welche Weise LPXN die Progression des PCa vermitteln könnte, überprüft werden. Die einzelnen Ziele waren:

- Analyse zum Einfluss von LPXN auf die Progression von bestehenden TRAMPTumoren

- Histopathologische Analysen der Prostatae sowie verschiedener Organe doppelt transgener LPXN/TRAMP- und Kontrollmäuse im Alter zwischen 6 und 30 Wochen

- Analyse der Tumorentwicklung einschließlich der Metastasenbildung in kastrierten, doppelt transgenen LPXN/TRAMP-Mäusen verschiedenen Alters mit Hilfe histopathologischer Verfahren

○ Etablierung und Charakterisierung einer Primärzellkultur aus Prostatatumoren doppelt transgener LPXN/TRAMP- und einfach transgener TRAMP-Mäuse

- Untersuchung des Einflusses von LPXN auf das Migrations- und Invasionsverhalten der etablierten murinen Primärzellen

- Analyse des Einflusses von LPXN auf die Regulation verschiedener Gene

- Untersuchung der Expression von p120CTN in LPXN/TRAMP-Tumoren und in den isolierten murinen Primärzellen

- Herunterregulierung der Expression von p120CTN in den PCa-Zelllinien PC-3 und DU 145

○ Untersuchung des Migrations- und Invasionsverhaltens von PC-3-Zellen nach Herunterregulierung der p120CTN-Expression sowie der simultanen Herunterregulierung der p120CTN- und LPXN-Expression

- Analyse der Lokalisation von $\beta$-Catenin sowie der Expression von $\beta$-CateninZielgenen nach Herunterregulierung der LPXN-Expression

○ Identifizierung von Kandidatengenen, die durch LPXN während der Tumorprogression reguliert werden mit Hilfe von whole genome microarrays an Tumormaterial 
- Untersuchung der Expression, Lokalisation und Funktion des LPXNInteraktionspartners Caldesmon

- Analyse des Einflusses von Caldesmon auf die Migration und Proliferation von PCa-Zellen

- Analysen zur Expression und Phosphorylierung von Caldesmon in Abhängigkeit zur LPXN-Expression

- Untersuchung des Einflusses von LPXN auf die Adhäsion von PCa-Zellen

- Analyse der Bildung von focal adhesion sites in Abhängigkeit von der LPXNExpression

○ Untersuchung der Morphologie der Zellen nach Herunterregulierung der LPXN-Expression

- Identifizierung von Signalwegen, in die LPXN involviert ist

- GST-Pulldown zur Analyse der Aktivität der RhoGTPasen RhoA und Rac in PCa-Zellen mit herunterregulierter LPXN-Expression

○ Durchführung eines Antikörper-Arrays zur Analyse des Einflusses von LPXN auf die Phosphorylierung und Expression weiterer Gene 


\section{Material und Methoden}

\subsection{Chemikalien und Reagenzien}

Alle Substanzen, die nicht aufgeführt sind, wurden von den Firmen Roth (Karlsruhe) oder Sigma-Aldrich (Taufkirchen) bezogen.

\begin{tabular}{ll}
\hline Chemikalien & Hersteller \\
\hline & \\
Acrylamid/Bisacrylamid 40\% (29:1) & Carl Roth GmbH, Karlsruhe \\
Adeninsulfat & AppliChem GmbH, Darmstadt \\
Agar & Carl Roth GmbH, Karlsruhe \\
Agarose & Invitrogen, Karlsruhe \\
Aminosäuren & Biomol, Hamburg \\
Ammoniumsulfat & Carl Roth GmbH, Karlsruhe \\
Ampicillin & Sigma-Aldrich, Taufkirchen \\
Ampuwa & Fresenius AG, Bad Homburg \\
Adenosintriphosphat (ATP) & Biomol GmbH, Hamburg \\
Bacto-Trypton & Carl Roth GmbH, Karlsruhe \\
Chloroform & Baker, Deventer, NL \\
Dexamethason & Sigma-Aldrich, , Taufkirchen \\
Dimethyldicarbonat (DMPC) & Sigma-Aldrich, Taufkirchen \\
Dimethylsulfoxid (DMSO) & Carl Roth GmbH, Karlsruhe \\
Diethylpyrocarbonat (DEPC) & Sigma-Aldrich, Taufkirchen \\
Dithiothreitol (DTT) & Biomol, Hamburg \\
dNTPs (100 mM) & Invitrogen, Karlsruhe \\
Entwickler & Kodak, Darmstadt \\
Ethidiumbromid & Sigma-Aldrich, Taufkirchen \\
Ethylendiamin-tetraacetat (EDTA) & ICN, Aurora, USA \\
Ethylenglycol-bis( $($-aminoethyl)-N,N,N',N'-tetraacetat (EGTA) & Carl Roth GmbH, Karlsruhe \\
Fixierer & Kodak, Darmstadt \\
FuGene HD & Roche Mannheim \\
G418 & Merck, Darmstadt \\
Glukose & Carl Roth GmbH, Karlsruhe \\
Glycerol & Carl Roth GmbH, Karlsruhe
\end{tabular}


Chemikalien

Glycin

Hefeextrakt

HEPES buffered saline (HBS)

Hygromycin

Isopropyl- $\beta$-D-thiogalactopyranosid (IPTG)

Kanamycin

Kollagenase

(N-Morpholino )-Propansulfonsäure (MOPS)

$\beta$-Mercaptoethanol

Natriumdodecylsulfat (SDS)

NuPAGE TM MES Running buffer (20x)

NuPAGE TM LDS Sample buffer (4x)

Orange-G

Penicillin/Streptomycin

Phenol

PMSF

p-Nitrophenyl- $\alpha$-D-Galactopyranosid (PNP- $\alpha-G a l)$

RNase-Inhibitor

RNA-Längenstandard

Roti ${ }^{\circledR}$ Fect

Roti ${ }^{\circledR}-$ Nanoquant

S.O.C. Medium

Simply Blue Safe Stain

$\mathrm{N}, \mathrm{N}, \mathrm{N}^{\prime}, \mathrm{N}^{\prime}-\mathrm{Tetramethylethylenediamine} \mathrm{(TEMED)}$

Tris

Triton X-100

Tween 20

VectaShield mit DAPI

5-Bromo-4-Chloro-3-indolyl a-D-galactopyranosid (X- $\alpha-G a l)$

Zellkulturmedien

\section{Hersteller}

Carl Roth GmbH, Karlsruhe

Carl Roth GmbH, Karlsruhe

Sigma-Aldrich, Taufkirchen

Merck, Darmstadt

Biomol, Hamburg

Sigma-Aldrich, Taufkirchen

Sigma-Aldrich, Taufkirchen

Carl Roth GmbH, Karlsruhe

Serva, Heidelberg

Serva, Heidelberg

Invitrogen, Karlsruhe

Invitrogen, Karlsruhe

Sigma-Aldrich, Taufkirchen

PAN, Aidenbach

Invitrogen, Karlsruhe

Sigma-Aldrich, Taufkirchen

MP Biomedicals, Eschwege

MBI, St. Leon-Rot

Invitrogen, Karlsruhe

Carl Roth GmbH, Karlsruhe

Carl Roth GmbH, Karlsruhe

Invitrogen, Karlsruhe

Invitrogen, Karlsruhe

Carl Roth GmbH, Karlsruhe

Carl Roth GmbH, Karlsruhe

Fluka, Deisenhofen

Merck, Darmstadt

VectorLab, Burlingame, USA

Biomol, Hamburg

PAN, Aidenbach 


\subsection{Biochemikalien und Enzyme}

\begin{tabular}{|c|c|}
\hline Biochemikalien & Hersteller \\
\hline Albumin Fraktion V & Biomol, Hamburg \\
\hline Aprotinin & Sigma-Aldrich, Taufkirchen \\
\hline Biocoll Lösung & Biochrom AG, Berlin, Germany \\
\hline Complete Mini & Roche, Mannheim \\
\hline Direct PCR Lyse Reagenz & Peqlab, Erlangen \\
\hline DNAse & Sigma-Aldrich, Taufkirchen \\
\hline Fetales Kälberserum (SeraPlus) & PAN, Aidenbach \\
\hline MangoTaq-DNA-Polymerase & Bioline, Luckenwalde \\
\hline Lachsspermien-DNA & Sigma-Aldrich, Taufkirchen \\
\hline Leupeptin & Sigma-Aldrich, Taufkirchen \\
\hline Medium 199 & Invitrogen, Karlsruhe, Germany \\
\hline NuSerum $^{\mathrm{TM}}$ & BD Bioscience, San Jose, USA \\
\hline Pepstatin A & Sigma-Aldrich, Taufkirchen \\
\hline PfuUltra-HF-DNA Polymerase & Stratagene, La Jolla, USA \\
\hline PhosSTOP & Roche, Invitrogen \\
\hline Platinum-Taq-DNA Polymerase & Invitrogen, Karlsruhe \\
\hline Proteinase K & Carl Roth GmbH, Karlsruhe \\
\hline Restriktionsenzyme & Invitrogen, Karlsruhe \\
\hline Reverse Transkriptase SuperScript II & Invitrogen, Karlsruhe \\
\hline RNase A & Invitrogen, Karlsruhe \\
\hline Phusion High-Fidelity DNA Polymerase & Biozym, Hess. Oldendorf \\
\hline T4-DNA-Ligase & Promega, Mannheim \\
\hline
\end{tabular}




\subsection{Gebrauchswaren}

Nicht aufgeführte Gebrauchswaren wurden von den Firmen Schütt und Omnilab-Krannich

(Göttingen), sowie Sarstedt (Nümbrecht) bezogen.

\begin{tabular}{|c|c|}
\hline Gebrauchswaren & Hersteller \\
\hline $6-, 12-$ oder 24well-Zellkultur-Platten & Corning Inc., New York, (USA) \\
\hline 384well-Platten, weiß & ABgene, Hamburg \\
\hline flachbödige 96well-Mikrotiterplatten & Greiner, Nürtingen \\
\hline Blottingpapier GB 002, 003, 004 & Schleicher \& Schüll, Dassel \\
\hline CentriSart I & Sartorius, Göttingen \\
\hline FALCON culture slides & Becton Dickinson GmbH, Heidelberg \\
\hline PVDF-Transfer Membran & GE Healthcare, München \\
\hline Einmalfilter Minisart & Sartorius, Göttingen \\
\hline NML (Porengröße 0,20 und 0,45 $\mu \mathrm{m}$ ) Filterpapier 0858 & Schleicher \& Schüll, Dassel \\
\hline NuPage $^{\mathrm{TM}} 4-12 \%$ Bis-Tris Gele & Invitrogen, Karlsruhe \\
\hline Hybond $^{\mathrm{TM}} \mathrm{C}$ Membran extra & GE Healthcare, München \\
\hline Membranfilter & Millipore, Morlsheim \\
\hline Petrischalen & Greiner Nunc., Nürtingen \\
\hline Pipettenspitzen & Sarstedt, Nürnbrecht \\
\hline Reaktionsgefäße & Sarstedt, Nürnbrecht \\
\hline Quarz-Küvetten & Hellma, Mühlheim \\
\hline $\begin{array}{l}\text { Röntgenfilme (CL-XPosure }{ }^{\mathrm{TM}} \text { Film, Clear Blue X-Ray } \\
\text { Film) }\end{array}$ & Thermo Scientific, Rockford, USA \\
\hline Sterilfilter & Sartorius, Göttingen \\
\hline Objektträger Superfrost ${ }^{\circ}$ Plus & Schütt, Göttingen \\
\hline Wundklammern $(7,5 \times 1,75 \mathrm{~mm})$ & Braun, Tuttlingen \\
\hline 4-Well-Slides & Becton Dickinson GmbH, Heidelberg \\
\hline $100 \mathrm{ml}$ Plastikflaschen & Sarstedt, Nürnbrecht \\
\hline Zellkulturflaschen & Greiner Nunc., Nürtingen \\
\hline
\end{tabular}




\subsection{Sterilisationsverfahren}

Gebrauchswaren, Lösungen und Kulturmedien wurden über Nacht bei $220^{\circ} \mathrm{C}$ hitzesterilisiert oder bei $121^{\circ} \mathrm{C}$ und 1,5 Bar autoklaviert. Hitzeempfindliche Lösungen wurden steril filtriert $(0,2 \mu \mathrm{m})$. Wässrige Lösungen für RNA-Präparationen und RNA-Analysen wurden mit 1\% (v/v) Dimethyldicarbonat versetzt, für $12-24 \mathrm{~h}$ bei RT inkubiert und anschließend autoklaviert.

\subsection{Gebrauchsfertige Reaktionssysteme}

\begin{tabular}{|c|c|}
\hline Reaktionssystem & Hersteller \\
\hline DirectPCR tail reagent & Peqlab, Erlangen \\
\hline ECL Plus & GE Healthcare, München \\
\hline $\begin{array}{l}\text { Proliferationsassay (Cell Titer 96®AQ } \mathrm{Q}_{\text {ueous }} \text { Non- } \\
\text { Radioactive Cell Proliferation Assay) }\end{array}$ & Promega, Mannheim \\
\hline Matrigel Invasionsassay & Becton Dickinson, Bedford, MA \\
\hline Matrigel Migrationsassay & Millipore, Morlsheim \\
\hline Micro Spin TM-S200 HR Säulen & GE Healthcare, München \\
\hline Montage ${ }^{\mathrm{TM}}$ PCR Centrifugal Filter Devices & Millipore, Schwalbach \\
\hline OneStep RT-PCR-Kit & Qiagen, Hilden \\
\hline Plasmid Midi Kit Nucleobond AX100 & Macherey \& Nagel, Düren \\
\hline Plasmid Midi Kit & Invitrogen, Karlsruhe \\
\hline Platinum $^{(\mathrm{R})} \mathrm{SYBR}^{(\mathrm{R})}$-Green qPCR SuperMix-UDG & Invitrogen, Karlsruhe \\
\hline NucleoSpin ${ }^{(\mathrm{R})}$ Extract II & Macherey \& Nagel, Düren \\
\hline peqGOLD Total RNA Kit & Peqlab, Erlangen \\
\hline Tri-Reagent ${ }^{\mathrm{TM}}$ & Sigma-Aldrich, Taufkirchen \\
\hline
\end{tabular}




\subsection{Lösungen}

Für den routinemäßigen Gebrauch vorgesehene Lösungen wurden nach Sambrook et al., [1989] angesetzt. Die dazu benötigten Chemikalien wurden in bidestilliertem oder DEPCbehandeltem Wasser gelöst und nach Bedarf autoklaviert oder steril filtriert $(0,2 \mu \mathrm{m})$.

\begin{tabular}{|c|c|}
\hline Lösung/ Puffer & Zusammensetzung \\
\hline \multirow[t]{3}{*}{ Alkalische-Phosphatase-Färbelösung } & $45 \mu 1 \mathrm{NBT}(75 \mathrm{mg} / \mathrm{ml}$ in DMF $)$ \\
\hline & $35 \mu 1 \mathrm{BCIP}(50 \mathrm{mg} / \mathrm{ml}$ in DMF $)$ \\
\hline & in $10 \mathrm{ml} \mathrm{AP-Puffer}$ \\
\hline \multirow[t]{3}{*}{ AP-Puffer } & $100 \mathrm{mM} \mathrm{NaCl}$ \\
\hline & $50 \mathrm{mM} \mathrm{MgCl}_{2}$ \\
\hline & $100 \mathrm{mM}$ Tris/ $\mathrm{HCl}$ pH 9.5 \\
\hline \multirow[t]{2}{*}{ Blockpuffer I (Western Blot) } & $1 \mathrm{x}$ PBS \\
\hline & 2-5\% Magermilchpulver \\
\hline \multirow[t]{2}{*}{ Blockpuffer II (Western Blot) } & 1x TBS/0,1\% Tween 20 \\
\hline & 5\% Magermilchpulver \\
\hline \multirow[t]{2}{*}{ Blockpuffer III (Immunhistochemie) } & $1 \mathrm{x}$ PBS \\
\hline & $3 \%$ BSA \\
\hline \multirow[t]{3}{*}{ Coomassie-Lösung } & $30 \%(\mathrm{v} / \mathrm{v})$ Methanol \\
\hline & $10 \%(\mathrm{v} / \mathrm{v})$ Essigsäure \\
\hline & $0,05 \%(\mathrm{w} / \mathrm{v})$ Coomassie-Brilliant Blau R250 \\
\hline \multirow[t]{3}{*}{ Formalin für Mausorgane } & $12 \mathrm{mM} \mathrm{H}_{2} \mathrm{NaO}_{4} \mathrm{P}$ \\
\hline & $55 \mathrm{mM} \mathrm{HNa}_{2} \mathrm{O}_{4} \mathrm{P}$ \\
\hline & $10 \%$ Formaldehyd (37\%ig) \\
\hline \multirow[t]{2}{*}{ Kaliumphosphat (1M) } & $0,17 \mathrm{M} \mathrm{KH}_{2} \mathrm{PO}_{4}$ \\
\hline & $0,72 \mathrm{M} \mathrm{K}_{2} \mathrm{HPO}_{4}$ \\
\hline \multirow[t]{7}{*}{ Lysispuffer I (für Proteine (Zellkultur)) } & $150 \mathrm{mM} \mathrm{NaCl}$ \\
\hline & $1 \mathrm{mM}$ EDTA \\
\hline & 50 mM Tris- $\mathrm{HCl}, \mathrm{pH} 7.4$ \\
\hline & $1 \% \mathrm{NP}-40$ \\
\hline & $0,25 \%$ Natriumdeoxycholat \\
\hline & $1 \mathrm{Tab} / 10 \mathrm{ml}$ Complete Mini \\
\hline & $1 \mathrm{Tab} / 10 \mathrm{ml}$ PhosSTOP \\
\hline
\end{tabular}




\begin{tabular}{|c|c|}
\hline Lösung/ Puffer & Zusammensetzung \\
\hline Lysispuffer II (Glycerol-Lysis-Puffer) & $\begin{array}{l}25 \mathrm{mM} \text { Tris/HCL } \mathrm{pH} 7.5 \\
100 \mathrm{mM} \mathrm{NaCl} \\
1 \% \mathrm{NP}-40 \\
5 \mathrm{mM} \mathrm{MgCl}_{2} \\
1 \mathrm{mM} \mathrm{EDTA} \\
0,1 \mathrm{mM} \mathrm{EGTA} \\
5 \% \text { Glycerol } \\
1 \mathrm{mM} \mathrm{DTT} \\
1 \mathrm{Tab} / 10 \mathrm{ml} \text { Complete Mini } \\
1 \mathrm{Tab} / 10 \mathrm{ml} \text { PhosSTOP }\end{array}$ \\
\hline Lysispuffer III (Pierce) & $\begin{array}{l}25 \mathrm{mM} \text { Tris/HCL pH } 7.5 \\
150 \mathrm{mM} \mathrm{NaCl} \\
5 \mathrm{mM} \mathrm{MgCl}_{2} \\
1 \% \mathrm{NP}-40 \\
5 \% \text { Glycerol }\end{array}$ \\
\hline Lysispuffer für Bakterienpellets & $\begin{array}{l}100 \mathrm{mM} \text { Tris/HCL } \\
1 \mathrm{mM} \mathrm{NaCl} \\
0,5 \mathrm{mM} \text { EDTA } \\
0,2 \% \text { Triton X-100 } \\
0,1 \% \text { Tween } 20 \\
8 \% \text { Glycerol } \\
250 \mathrm{mM} \mathrm{Urea} \\
0,1 \mathrm{mM} \text { DTT } \\
\text { Pepstatin A }(1 \mu \mathrm{g} / \mathrm{ml}) \\
\text { Leupeptin }(1 \mu \mathrm{g} / \mathrm{ml}) \\
\text { Aprotinin }(1 \mu \mathrm{g} / \mathrm{ml}) \\
1 \mathrm{mM} \mathrm{Na} \mathrm{VO}_{4} \\
1 \mathrm{mM} \mathrm{NaF} \\
1 \mathrm{mM} \mathrm{PMSF}\end{array}$ \\
\hline Lysispuffer für Organe & $\begin{array}{l}1 \% \text { TritonX-100 } \\
150 \mathrm{mM} \text { HEPES } \\
1 \mathrm{mM} \text { EDTA } \\
1 \mathrm{Tab} / 10 \mathrm{ml} \mathrm{Complete} \mathrm{Mini}\end{array}$ \\
\hline Lysispuffer für Kinexus Antikörper-Array & $\begin{array}{l}20 \mathrm{mM} \text { MOPS pH } 7.0 \\
2 \mathrm{mM} \text { EGTA } \\
5 \mathrm{mM} \text { EDTA } \\
30 \mathrm{mM} \mathrm{NaF} \\
60 \mathrm{mM} \text {-Glycerolphosphat } \\
20 \mathrm{mM} \text { Natrium-Pyrophosphat }\end{array}$ \\
\hline
\end{tabular}




\begin{tabular}{|c|c|}
\hline Lösung/ Puffer & Zusammensetzung \\
\hline & $1 \mathrm{mM}$ Natrium-Orthovanadat \\
\hline & $1 \mathrm{Tab} / 10 \mathrm{ml}$ Complete Mini \\
\hline & $1 \%$ TritonX-100 \\
\hline & $1 \mathrm{mM}$ DTT \\
\hline \multirow[t]{3}{*}{ MOPS-Puffer (10x) } & $50 \mathrm{mM}$ Natriumacetat \\
\hline & $10 \mathrm{mM}$ EDTA \\
\hline & 200 mM MOPS (pH 7.0) \\
\hline \multirow[t]{2}{*}{ Narkosemittel für Mäuse } & 65 mg/kg Körpergewicht Ketamin \\
\hline & 13 mg/kg Körpergewicht Xylazin \\
\hline \multirow[t]{3}{*}{ P1 Puffer (Plasmid-Minipräparation) } & $50 \mathrm{mM}$ Tris/HCl, $\mathrm{pH} 8.0$ \\
\hline & $10 \mathrm{mM}$ EDTA \\
\hline & $100 \mu \mathrm{g} / \mathrm{ml}$ RNase A \\
\hline \multirow[t]{2}{*}{ P2 Puffer (Plasmid-Minipräparation) } & $200 \mathrm{mM} \mathrm{NaOH}$ \\
\hline & $1 \% \mathrm{SDS}$ \\
\hline P3 Puffer (Plasmid-Minipräparation) & 3 M Natriumacetat (pH 5.5) \\
\hline \multirow[t]{3}{*}{ Probenpuffer für RNA } & $75 \mu \mathrm{l}$ Formaldehyd (37\%ig) \\
\hline & $45 \mu 110 x$ MPOS \\
\hline & $180 \mu \mathrm{l}$ Formamid (99\%ig) \\
\hline \multirow[t]{4}{*}{ 10x PBS } & $1,37 \mathrm{M} \mathrm{NaCl}$ \\
\hline & $81 \mathrm{mM} \mathrm{Na}_{2} \mathrm{HPO}_{4}$ \\
\hline & $27 \mathrm{mM} \mathrm{KCl}$ \\
\hline & $14,7 \mathrm{mM} \mathrm{KH}_{2} \mathrm{PO}_{4}$ \\
\hline \multirow[t]{2}{*}{ Sammelgelpuffer } & $0,5 \mathrm{M}$ Tris/HCl pH 6.8 \\
\hline & $0,4 \%$ SDS \\
\hline \multirow[t]{2}{*}{ SSC (20x) } & $3 \mathrm{M} \mathrm{NaCl}$ \\
\hline & $0,3 \mathrm{M}$ Natriumcitrat, $\mathrm{pH} 7.0 \mathrm{mit} \mathrm{NaOH}$ \\
\hline \multirow[t]{4}{*}{ Stop-Mix I } & 95\% Formamid \\
\hline & $20 \mathrm{mM}$ EDTA \\
\hline & $0,05 \%$ Bromphenolblau \\
\hline & 0,05\% Xylencyanol \\
\hline \multirow[t]{3}{*}{ Stop-Mix II } & 15\% Ficoll 400 \\
\hline & $200 \mathrm{mM}$ EDTA \\
\hline & $0,1 \%$ Orange $\mathrm{G}$ \\
\hline \multirow[t]{2}{*}{ 50x TAE-Puffer } & 2 M Tris-Acetat, $\mathrm{pH} 8.3$ \\
\hline & 0,05 M EDTA \\
\hline \multirow[t]{3}{*}{ TBE-Puffer $(5 x)$} & $445 \mathrm{mM}$ Tris/HCl, $\mathrm{pH} 8.0$ \\
\hline & 445 mM Borsäure \\
\hline & $10 \mathrm{mM}$ EDTA \\
\hline
\end{tabular}




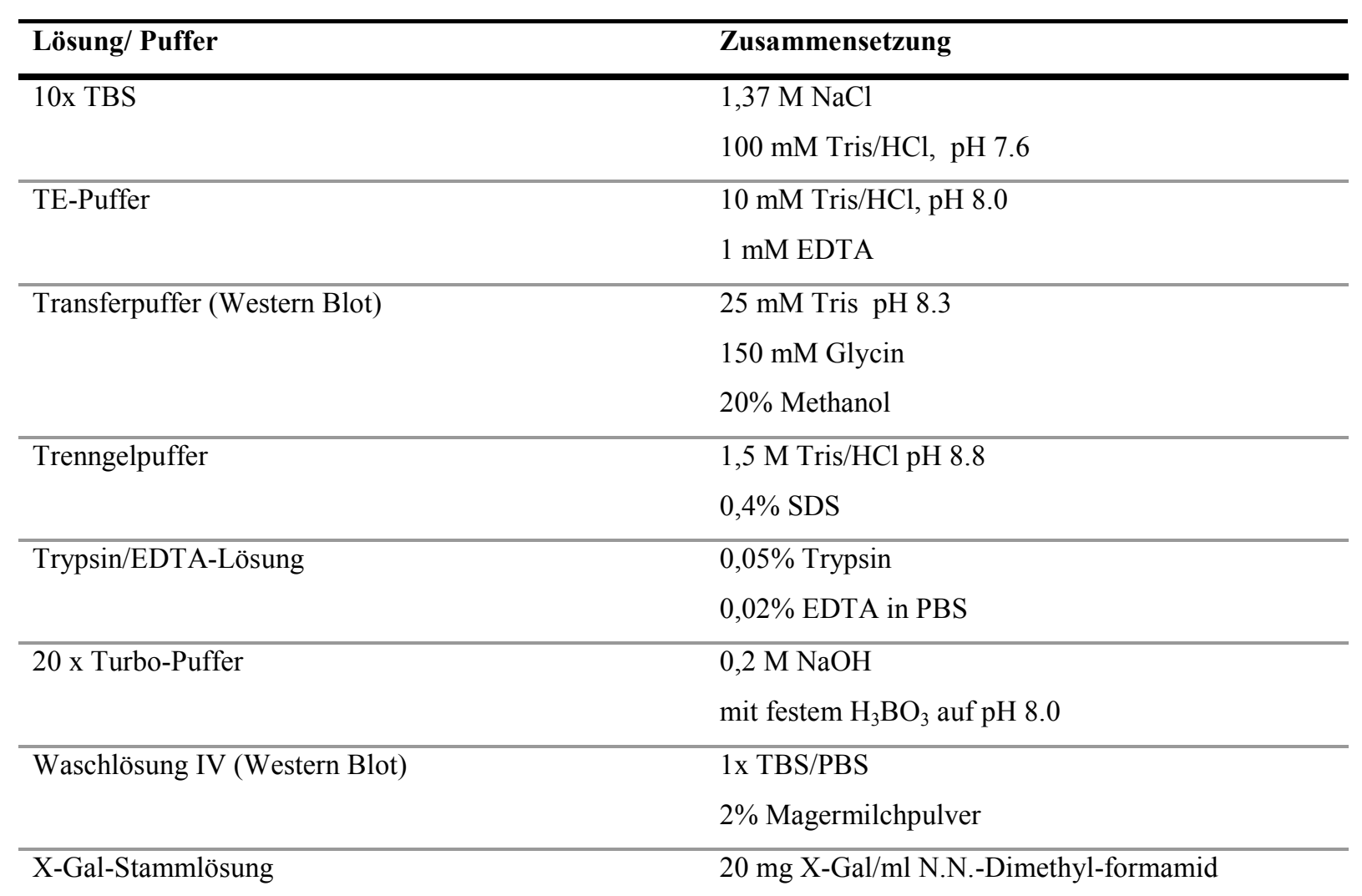

\subsection{Medien, Antibiotika, Agarplatten}

\subsubsection{Medien für Bakterien}

LB (Luria-Bertani)-Medium:

10 g/l Trypton

$5 \mathrm{~g} / 1 \quad$ Hefeextrakt

$10 \mathrm{~g} / 1 \mathrm{NaCl}$

pH 7.0

2x YT-Medium :

16 g/l Trypton

$10 \mathrm{~g} / 1$ Hefeextrakt

$5 \mathrm{~g} / \mathrm{l} \quad \mathrm{NaCl}$

pH 7.0 
Die Medien wurden mit bidestilliertem Wasser angesetzt, autoklaviert und bei $4^{\circ} \mathrm{C}$ gelagert. Für die selektive Anreicherung der ausplattierten Bakterien wurden der jeweiligen Resistenz entsprechend Ampicillin (Endkonzentration 50-200 $\mu \mathrm{g} / \mathrm{ml}$ ) bzw. Kanamycin (Endkonzentration $25 \mu \mathrm{g} / \mathrm{ml}$ ) zugegeben.

\subsubsection{Agarplatten}

Zur Herstellung von Agarplatten wurde dem flüssigen LB-Medium vor dem Autoklavieren $1,5 \%(w / v)$ Agar-Agar zugefügt. Nach dem Autoklavieren wurde das Medium auf $55^{\circ} \mathrm{C}$ abgekühlt und unter Rühren ggf. mit den unten angegebenen Reagenzien versetzt. Anschließend wurde das Medium in Petrischalen gegossen. Nach dem Aushärten wurden die Agarplatten in einer sterilen Plastiktüte bei $4^{\circ} \mathrm{C}$ aufbewahrt.

Ampicillin : Endkonzentration $50 \mu \mathrm{g} / \mathrm{ml}$

Kanamycin: Endkonzentration $25 \mu \mathrm{g} / \mathrm{ml}$

\subsubsection{Medien für eukaryontische Zellkulturen}

Die für die Kultur eukaryontischer Zellen verwendeten Medien wurden käuflich erworben (PAN, Aidenbach). Vor Gebrauch wurden diese mit fetalem Kälberserum (FKS) und Antibiotika (Penicillin/Streptomycin) versetzt und anschließend sterilfiltriert. Für die Zellkulturen wurden folgende Medien verwendet:

Medium für PC-3-, LNCaP- und

DU 145-Zellen:

RPMI 1640 (PAN)

$100 \mu \mathrm{g} / \mathrm{ml}$ Streptomycin

$100 \mathrm{U} / \mathrm{ml}$ Penicillin

$10 \%$ FKS 
Medium für Primärzell-Klone 19-83A, 19-72A,

T-27F, T-45F:

\author{
Advanced DMEM (Invitrogen, Karlsruhe) \\ 2 mM Glutamin \\ $20 \%$ FKS \\ $8 \%$ NuSerum (Invitrogen) \\ $0,2 \mu \mathrm{g} / \mathrm{ml}$ Gentamycin \\ $100 \mathrm{nM}$ DHT
}

Die Langzeitlagerung der Zellen erfolgte in flüssigem Stickstoff, wobei das entsprechende Medium dafür zuvor mit 10\% DMSO versetzt wurde.

\title{
2.8 Biologisches Material
}

\subsubsection{Bakterienstämme}

Der Bakterienstamm Escherichia coli DH5 $\alpha$ [Hanahan, 1983] von Invitrogen (Karlsruhe) wurde für die Transformation von Plasmiden in kompetente Bakterienstämme verwendet. Der Bakterienstamm Escherichia coli BL21(DE3) pLys S (Invitrogen, Karlsruhe) wurde für die Transformation der GST-Expressionsplasmide sowie der TAT-Plasmide in kompetente Bakterienstämme verwendet.

\subsubsection{Eukaryontische Zelllinien}

PC-3 Humane Prostataadenokarzinom-Zelllinie (Knochen-Metastase), ATCC, Rockville, USA, Androgen-unabhängige Zellen [Kaighn et al., 1979; Ohnuki et al., 1980]

DU 145 Humane Prostataadenokarzinom-Zelllinie (Gehirn-Metastase), ATCC, Rockville, USA, Androgen-unabhängige Zellen [Mickey et al., 1977; Stone et al., 1978]

LNCaP Humane Prostataadenokarzinom-Zelllinie (Lymphknoten-Metastase) ATCC, Rockville, USA, Androgen-abhängige Zellen [Horoszewicz et al., 1983] 
19-83A Murine Prostataadenokarzinom-Primärzelllinie aus dem Prostatatumor der doppelt transgenen LPXN/TRAMP-Maus 19-83A

19-72A Murine Prostataadenokarzinom-Primärzelllinie aus dem Prostatatumor der doppelt transgenen LPXN/TRAMP-Maus 19-72A

T-27F Murine Prostataadenokarzinom-Primärzelllinie aus dem Prostatatumor der einfach transgenen TRAMP-Maus 27F

T-45F Murine Prostataadenokarzinom-Primärzelllinie aus dem Prostatatumor der einfach transgenen TRAMP-Maus 45F

\subsubsection{Mausstämme}

Die verwendeten Mäuse des FVB-Stammes stammten aus institutseigenen Beständen oder dem Max-Planck Institut für experimentelle Medizin (Göttingen). Die verwendeten TRAMPMäuse wurden von der Firma Jackson Lab (Bar Harbor, Maine, USA) erworben und die verwendeten transgenen LPXN-Mäuse auf FVB-Hintergrund wurden in unserem Labor generiert [Herr, 2005; Kaulfuß, 2006). Die Haltungsbedingungen bestanden aus einem zwölfstündigen Hell-Dunkel-Rhythmus in pathogenfreier Umgebung bei $22^{\circ} \mathrm{C}$ und $55 \pm 5 \%$ relativer Luftfeuchtigkeit. Tierfutter wurde von der Firma ssniff-Spezialdiäten (Soest) bezogen.

\subsubsection{Synthetische Oligonukleotide}

\subsubsection{Synthetische DNA-Oligonukleotide}

Für die Generierung von cDNA-Produkten bzw. die Sequenzierung von Konstrukten wurden synthetische Oligonukleotide von der Firma Eurofins MWG Operon (Ebersberg) erworben. 
Vektor-spezifische Primer:

$\begin{array}{ll}\text { pGADT7Fw } & \text { 5'-TCG ATG ATG AAG ATA CCC CAC CAA ACC-3' } \\ \text { pGADT7Rev } & \text { 5'-AGA TGG TGC ACG ATG CAC AGT TGAA GTG-3' } \\ \text { pGBKT7Fw } & \text { 5'-TCA TCG GAA GAG AGT AGT AAC AAA GG-3' } \\ \text { pGBKT7Rev } & \text { 5'-CTA AGA GTC ACT TTA AAA TTT GTA TAC AC-3' } \\ \text { SP6new } & \text { 5'-TTA GGT GAC ACT ATA GAA TAC TCA AGC-3' } \\ \text { T7new } & \text { 5'-AAT ACG ACT CAC TAT AGG GCG AAT TGG-3' } \\ \text { GFPC1-Top+ } & \text { 5'-GAT CAC ATG GTC CTG CTG GAG TTC GT-3' } \\ \text { GFP-C1-R+ } & \text { 5'-GTA AAA CCT CTA CAA ATG TGG TAT GG-3' } \\ \text { pCMVseqFw } & \text { 5'-CTC AGT GGA TGT TGC CTT TAC TTC T-3' } \\ \text { pCMVseqRev } & \text { 5'-AAG CAA TAG CAT CAC AAA TTT CAC A-3' } \\ \text { pGEXSeqfor } & \text { 5'-GGG CTG GCA AGC CAC GTT TGG TG-3' }\end{array}$

LPXN-spezifische Primer:

$\begin{array}{ll}\text { LPXN-663Fw } & \text { 5'-CTT TGA GCG GAG TGG CTT GGC CTA CTG-3' } \\ \text { LPXN-689Rev } & \text { 5'-CAG TAG GCC AAG CCA CTC CGC TCA AAG-3' } \\ \text { LPXN(LD)-Fw pEGFP } & \text { 5'-CTT GGG AAT TCG ACA ATG GAA GAG TTA GAT GCC-3' } \\ \text { LPXN(LIM)-Rev pEGFP } & \text { 5'-CAG TTG CTC GAG CAG TGG GAA GAG CTT ATT GAA GC-3' } \\ \text { LPXN-Fw-Eco Myc-His } & \text { 5'-GA ATT CCA ATG GAAGAGTTAGATGCCTTATTGGAGGAAC-3' } \\ \text { LPXN-Rev-Xho Myc-His } & \text { 5'-CTCGAGTTACAGTGGGAAGAGCTTATTGAAGCAAGG-3' } \\ \text { LPXN-TAT-Fw } & \text { 5'-AGGCGGCCGCAAGGTGGTGAAGAGTTAGATGCCTTATTGGA-3' } \\ \text { LPXN-TAT-Rev } & \text { 5'-TTGCGGCCGCCTACCACCCAGTGGGAAGAGCTTATTGAAGC-3' } \\ \text { Human LPXN-Q-Fw 1 } & \text { 5'-TGATGAGACTTCGGAGATCCTTTC-3' } \\ \text { Human LPXN-Q-Rev 1 } & \text { 5'-CGTTTTAGAAGGTGGTGGTGATTC-3' } \\ \text { Human LPXN-Q-Fw 3 } & \text { 5'-TCTTAGCCATGTTCTCACCCAAGT-3' } \\ \text { Human LPXN-Q-Rev 3 } & \text { 5'-CCAGTTCAAAGAAGGAGCCAGTAG-3' } \\ \text { Human LPXN-Q4-Fw } & \text { 5'-AGTTCCTTTGCGGTCCTCTTCTTC-3' } \\ \text { Human LPXN-Q4-Rev } & \text { 5'-TTCCAGTTCCTCCAATAAGGCATC-3' } \\ \text { Human LPXN-Q4b-Rev } & \text { 5'-GTCTCCTTTCTGGAATGCTGATCC-3' }\end{array}$


p120CTN-spezifische Primer:

$\begin{array}{ll}\text { Human CTNND1-Q-Fw } & \text { 5'-TGG ACG TGA CCA GGA TAA CAA GAT-3' } \\ \text { Human CTNND1-Q-Rev } & \text { 5'-GGC GTG GCT TAC AGT CTT CAT TAG-3' } \\ \text { Human CTNND1-Q1A-Fw } & \text { 5'-CCA AGA AGG GCA AAG GGA AAA AAC C-3' } \\ \text { Human CTNND1-Q1A-Rev } & \text { 5'-GCT AAA TCT TCT GCA TCA AGG GTG TTG-3' } \\ \text { Maus CTNND1-Q1-Fw } & \text { 5'-GGAAGAAATCAGACTTCCAGGTGA-3' } \\ \text { Maus CTNND1-Q1-Rev } & \text { 5'-TGGTCTCCTCTCTCATTCAGTGTG-3' }\end{array}$

Caldesmon-spezifische Primer:

$\begin{array}{ll}\text { Cald1mouse-Fw } & \text { 5'-GTT TCC AGC CGC ATT AAC GAA TGG C-3' } \\ \text { Cald1mouse-Rev } & \text { 5'-GAG TTT ACT TCA CAG CAT GGT TTC TTT-3' } \\ \text { Cald pGADT7 EcoRI Fw } & \text { 5'-GAA TTC ATG GAT GAT TTT GAG CGT-3' } \\ \text { Cald pGADT7XhoI Rev } & \text { 5'-C TCG AGG TCA AAC CTT AGT GGG-3' } \\ \text { Cald pGFP EcoRI Fw } & \text { 5'-CT CGA GTC ATG GAT GAT TTT GAG-3' } \\ \text { Cald pGFP XhoI Rev } & \text { 5'-GA ATT CGA TCA AAC CTT AGT GGG-3' } \\ \text { Cald pGFP XhoI Fw T1-3 } & \text { 5'-CT CGA GTC ATG GAT GAT TTT GAG CGT CGC AG A-3' } \\ \text { Cald pGFP EcoRI Rev } & \text { 5'-GA ATT CGA TCA AAC CTT AGT GGG GGA AGT GAC-3' } \\ \text { Cald pGAD Xho fw T1-3 } & \text { 5'-TTC ATG GAT GAT TTT GAG CGT CGC AGA-3' } \\ \text { Cald pGAD EcoRI rev } & \text { 5'-C TCG AGG TCA AAC CTT AGT GGG GGA AGT GAC-3' } \\ \text { Cald pCMV HA, Myc Sfil fw } & \text { 5'-GCA ATG GAG GCC ATG GAT GAT TTT GAG CGT CGC AG A-3' } \\ \text { Cald pCMV HA, Myc Xho1 rev } & \text { 5'-CTC GAG GTC AAC CTT AGT GGG GGA AGT GAC-3' } \\ \text { Caldesmon intern1 } & \text { 5'-CTA CCG AGA AGG AAG AAA AAA GTG AA-3' } \\ \text { Caldesmon intern2 } & \text { 5'-CCT GGA GGG AGG GCC AGC GTG-3' } \\ \text { Human Cald1-Q3-Fw } & \text { 5'-AACCTTCTGACTTGAGACCAGGAGA-3' } \\ \text { Human Cald1-Q3-Rev } & \text { 5'-AGCTTGGGTTCTTTCTGGAACTGTC-3' } \\ \text { Human Cald1-Q4-Fw } & \text { 5'-CAAGCTCAAGACGCAGGACGAG-3' } \\ \text { Human Cald1-Q4-Rev } & \text { 5'-AAGTCTCTATTTCACAGCATGGGTTTC-3' }\end{array}$

Genotypisierungs-spezifische Primer:
LPXN-LD1-rev
5'-GAA GGT GGT GGT GAT TCC TTT GGC TC-3'
$\mathrm{rPb}-423-\mathrm{fw}$
5'-CTC TGC ACC TTG TCA GTG AGG TCC AG-3'
TRAMP-SV40Tag Rev
5'-CTCCTTTCAAGACCTAGAAGGTCCA-3' 
Primer für Housekeeping-Gene:

$\begin{array}{ll}\text { Maus-HPRT-Q-Fw } & \text { 5'-CGTCGTGATTAGCGATGATG-3' } \\ \text { Maus-HPRT-Q-Rev } & \text { 5'-TATGTCCCCCGTTGACTGAT-3' } \\ \text { Maus/Human-GAPDH-Q-Fw } & \text { 5'-CATCACCATCTTCCAGGAGC-3' } \\ \text { Maus/Human-GAPDH-Q-Rev } & \text { 5'-ATGACCTTGCCCACAGCCTT-3' } \\ \text { Maus-TBP-Q-Fw } & \text { 5'-CACCAATGACTCCTATGACCCCTA-3' } \\ \text { Maus-TBP-Q-Rev } & \text { 5'-CAGTTGTCCGTGGCTCTCTTATTC-3' } \\ \text { Maus-TBP-Q2-Fw } & \text { 5'-CCCACAACTCTTCCATTCTCAAAC-3' } \\ \text { Maus-TBP-Q2/3-Rev } & \text { 5'-TCAAGTTTACAGCCAAGATTCACG-3' } \\ \text { Human-PBGD-Q-Fw } & \text { 5'-GCAATGCGGCTGCAACGGCGGAAG-3' } \\ \text { Human-PBGD-Q-Rev } & \text { 5'-CCTGTGGTGGACATAGCAATGATT-3' } \\ \text { Human-TBP-Q-Fw } & \text { 5'-AGCCTGCCACCTTACGCTCAG-3' } \\ \text { Human-TBP-Q-Rev } & \text { 5'-TGCTGCCTTTGTTGCTCTTCCA-3' }\end{array}$

Sonstige Human-spezifische Primer für quantitative real time PCR-Analysen:

\begin{tabular}{|c|c|}
\hline Human-MM & 5'-CCGCGTCATAGAAATAATGCAC \\
\hline Human-MMP-7-Q2-Rev & 5'-GATGTCAGCAGTTCCCCATACAAC-3' \\
\hline Human-MMP-7-Q3-Fw & 5'-TGAGTGAGCTACAGTGGGAACAGG-3' \\
\hline Human-MMP-7-Q3-Rev & 5'-GCATTATTTCTATGACGCGGGAGT-3' \\
\hline Human-IL6-Q1-Fw & 5'-TGAACCTTCCAAAGATGGCTGAAA-3' \\
\hline Human-IL6-Q1-Rev & 5'-TTTCTGCAGGAACTGGATCAGGAC-3' \\
\hline Human-IL6-Q2-Rw & 5'-CACAGACAGCCACTCACCTCTTCA-3' \\
\hline Human-IL6-Q2-Rev & 5'-TTTCAGCCATCTTTGGAAGGTTCA-3' \\
\hline Human- TAK1- & $5^{\prime}-\mathrm{T}$ \\
\hline Human- TAK1- Q1-Rev & 5'-TTTGCTGGTCCTTTTCATCC-3' \\
\hline Human- TAK1- Q2-Fw & 5'-ACAGTGTTCCCAAGGAGTGG-3' \\
\hline Human- TAK1- Q2-Rev & 5'-AACTTCAGGTGCCATCCAAG-3' \\
\hline Human-Yes-Q1-Fw & 5'-TATGGCTGCTCAGATTGCTG-3' \\
\hline Human-Yes-Q1/Q2-Rev & 5'-TTTTGCACCTTGTCTTGCTG-3' \\
\hline Human-Yes-Q2-Fw & 5'-AGCTGGTTGATATGGCTGCT-3' \\
\hline Human-GSK3a-Q3-Fw & 5'-ACTCCAGTGGCGAGAAGAAA-3' \\
\hline Human-GSK3a-Q3/Q4-Rev & 5'-TTGAGGACAGCAGTGTCAGG-3' \\
\hline Human-GSK3a-Q4-Fw & 5'-CCAGTGGCGAGAAGAAAGAC-3' \\
\hline Human-KDELR-Q-Fw & 5'-TCGCCATCATCTTGCTACTG-3' \\
\hline Human- KDELR- Q-Rev & 5'-TCTGAACGTGTCATGGTTCC-3' \\
\hline Human-CDC2-Q1-Fw & 5'-GACACAAAACTACAGGTCAAGTGG-3' \\
\hline Human-CDC2-Q1-Rev & 5'-AGATCCATGGAAAGAAACTCAAAG-3' \\
\hline
\end{tabular}




$\begin{array}{ll}\text { Human-PSEN1-Q1-Fw } & \text { 5'-CATTTTCTACAGTGTTCTGGTTGG-3' } \\ \text { Human-PSEN1-Q1-Rev } & \text { 5'-GAATGCTAATTGGTCCATAAAAGG-3' } \\ \text { Human-PSEN1-Q2-Fw } & \text { 5'-TATAATGCAGAAAGCACAGAAAGG-3' } \\ \text { Human-PSEN1-Q2-Rev } & \text { 5'-CCAACCAGAACACTGTAGAAAATG-3' } \\ \text { Human-Maspin-Q1-Fw } & \text { 5'-CTCTTCTCTCCAATCTGTCTCTCC-3' } \\ \text { Human-Maspin-Q1-Rev } & \text { 5'-CCGCTTGATTAGTTTCAGTGAGTA-3' } \\ \text { Human-Maspin-Q2-Fw } & \text { 5'-AAGGAATTGGAAACTGTTGACTTC-3' } \\ \text { Human-Maspin-Q2-Rev } & \text { 5'-GTTTGGTGTCTGTCTTGTTGACTC-3' }\end{array}$

Sonstige Maus-spezifische Primer für quantitative real time PCR-Analysen:

$\begin{array}{ll}\text { Maus-IL-6 Q1-Fw } & \text { 5'-CAAGTCCGGAGAGGAGACTTCACA-3' } \\ \text { Maus-IL-6- Q1-Rev } & \text { 5'-CAGATTGTTTTCTGCAAGTGCATCATCGT-3' } \\ \text { Maus-PSEN-Q1-Fw } & \text { 5'-GTG GCA CTG CCG CGA ACA GAG G-3' } \\ \text { Maus-PSEN-Q1-Rev } & \text { 5'-CTC CGG ATG GCG CTG CTG GAG T-3' } \\ \text { Maus-PSEN-Q2-Fw } & \text { 5'-ACA GCC ACT CCA GCA GCG CCA T-3' } \\ \text { Maus-PSEN-Q2-Rev } & \text { 5'-GTG GCC ACG ACG ACG ACC ATG C-3' } \\ \text { Maus-PSEN-Q3-Fw } & \text { 5'-ACCTTTGTCCTACTTCCAGAATGC -3' } \\ \text { Maus-PSEN-Q3-Rev } & \text { 5'-CTTGGCTCCATATTTCAATGTCAG -3' } \\ \text { Maus-PSEN-Q4-Fw } & \text { 5'-TGACAACCCTGAGCCAATATCTAA -3' } \\ \text { Maus-PSEN-Q4-Rev } & \text { 5'-GGTGTAGATTAGCTGACCGTCCTT -3' } \\ \text { Maus-Maspin-Q1-Fw } & \text { 5'-ACT GCC TCT GAG CTC CTT CGG C-3' } \\ \text { Maus-Maspin-Q1-Rev } & \text { 5'-TGC TGT GTC GCC TTT GGT GCC C-3' } \\ \text { Maus-Maspin-Q2-Fw } & \text { 5'-TTG TGC TCC CCA AGG ACG TGG A-3' } \\ \text { Maus-Maspin-Q2-Rev } & \text { 5'-TGG CAT TGG CCA TGG TAC TGG GGT-3' } \\ \text { Maus-Yes-Q1-Fw } & \text { 5'-CGG CCC CTT CTC GTC CTA GCG G-3' } \\ \text { Maus-Yes-Q1-Rev } & \text { 5'-CCC TTT GTG GAA GAG GTC GGG GCA-3' } \\ \text { Maus-Yes-Q2-Fw } & \text { 5'-GCT GGA GGT CTG TGT CGC CGG A-3' } \\ & \end{array}$




\subsubsection{Synthetische RNA-Oligonukleotide}

Die synthetischen siRNA-Oligonukleotide wurden von der Firma Eurogentec (Seraing, Belgien) und Invitrogen (Karlsruhe) käuflich erworben.

Humanes LPXN „D-LPXN“

$\begin{array}{ll}\text { Zielsequenz } & \text { 5'-UAUUCCAACCCAGCUCCUC-3' } \\ \text { Erster Strang } & \text { 5'-UAUUCCAACCCAGCUCCUCdTdT-3' }^{\prime} \\ \text { Zweiter Strang } & \text { 5'-GAGGAGUGGGUUGGAAUAdTdT-3' }^{\prime}\end{array}$

Humanes LPXN „D-LPXNst““

$\begin{array}{ll}\text { Zielsequenz } & \text { 5'-GGCGCAGCUCGUGUAUACUACCAAU -3' } \\ \text { Erster Strang } & \text { 5'-GGCGCAGCUGGUGUAUACUACCAAUdTdT-3' } \\ \text { Zweiter Strang } & \text { 5'-AUUGGUAGUAUACACGAGCUGCGCCdTdT-3' }\end{array}$

Luciferase (Photinus pyralis) „D-Luc““

$\begin{array}{ll}\text { Zielsequenz } & \text { 5'-CGUACGCGGAAUACUUCGA -3' } \\ \text { Erster Strang } & \text { 5'-CGUACGCGGAAUACUUCGAdTdT-3' } \\ \text { Zweiter Strang } & \text { 5'-UCGAAGUAUUCCGCGUACGdTdT-3' }\end{array}$

Humanes p120Catenin ,p120CTN-1“

$\begin{array}{ll}\text { Zielsequenz } & \text { 5'-GGCUAGAGGAUGACCAGCGUAGUAU -3' } \\ \text { Erster Strang } & \text { 5'-GGCUAGAGGAUGACCAGCGUAGUAUdTdT -3' } \\ \text { Zweiter Strang } & \text { 5'-AUACUACGCUGGUCAUCCUCUAGCCdTdT -3' }\end{array}$

Humanes p120Catenin ,p120CTN-2“

$\begin{array}{ll}\text { Zielsequenz } & \text { 5' - GCAGCUCCCAAUGUUGCCAACAAUA-3' }^{\prime} \\ \text { Erster Strang } & 5^{\prime} \text { - GCAGCUCCCAAUGUUGCCAACAAUAdTdT -3' } \\ \text { Zweiter Strang } & 5^{\prime} \text { '- UAUUGUUGGCAACAUUGGGAGCUGCdTdT-3' }\end{array}$


Humanes p120Catenin ,p120CTN-3“

Zielsequenz

Erster Strang

Zweiter Strang
5'-CCCAGGAUCACAGUCACCUUCUAUA -3'

5' - CCCAGGAUCACAGUCACCUUCUAUAdTdT -3'

5'-UAUAGAAGGUGACUGUGAUCCUGGGdTdT -3'

Humanes Caldesmon „Cald-A“

Zielsequenz

Erster Strang

Zweiter Strang
5'-ACAUAUUGAUACCUAUCUGCCAUGU -3'

5' - ACAUAUUGAUACCUAUCUGCCAUGUdTdT -3'

5'-ACAUGGCAGAUAGGUAUCAAUAUGUdTdT -3'

Humanes Caldesmon „Cald-B“
Zielsequenz
5'-CAGAAGGAGUUCGACCCAACAAUAA -3'
Erster Strang
5' - CAGAAGGAGUUCGACCCAACAAUAAdTdT -3'
Zweiter Strang
5'-UUAUUGUUGGGUCGAACUCCUUCUGdTdT -3'

Humanes Caldesmon „Cald-1“

$\begin{array}{ll}\text { Zielsequenz } & 5^{\prime} \text {-CCUGCUGAAGGUGUACGCAACAUCA -3' } \\ \text { Erster Strang } & 5^{\prime} \text {-CCUGCUGAAGGUGUACGCAACAUCAdTdT -3' } \\ \text { Zweiter Strang } & 5^{\prime} \text { '-UGAUGUUGCGUACACCUUCAGCAGGdTdT -3' }\end{array}$

Humanes Caldesmon „Cald-2““

$\begin{array}{ll}\text { Zielsequenz } & \text { 5'-ACCAAAUAAGGAAACUGCUGGCUUG -3' } \\ \text { Erster Strang } & \text { 5'-ACCAAAUAAGGAAACUGCUGGCUUGdTdT -3' } \\ \text { Zweiter Strang } & \text { 5'-CAAGCCAGCAGUUUCCUUAUUUGGUdTdT -3' }\end{array}$

Humanes Caldesmon „Cald-3“
Zielsequenz
5'-CCGCAUCAAUGAAUGGCUAACUAAA -3'
Erster Strang
5' - CCGCAUCAAUGAAUGGCUAACUAAAdTdT -3'
Zweiter Strang
5' - UUUAGUUAGCCAUUCAUUGAUGCGGdTdT-3' 


\subsubsection{Antikörper}

\section{Primärantikörper \\ Hersteller}

Anti-Caldesmon, (Cald-8) monoklonaler

Antikörper, Maus (\#C6292)

Anti-Caldesmon (8-L-Caldesmon) monoklonaler

Antikörper, Maus (\#610660)

Anti-phospho-Caldesmon Ser-789: sc-12931, polyklonaler Antikörper, Kaninchen

Anti- $\beta$-Catenin monoklonaler Antikörper,

Kaninchen

Anti-cmyc Tag (clone 4A6), monoklonaler Antikörper IgG1, Maus

Anti-GST, monoklonaler Antikörper, Maus (\#G1160)

Anti-HSC70 (B-6) sc:7298 monoklonaler Antikörper, Maus

Anti-phospho-JNK (Thr183/Tyr185) (\#9251), polyklonaler Antikörper, Kaninchen

anti-LPXN (283 G), monoklonaler Antikörper, Maus

Anti-Phospho-MKK3/6 (Ser 189/207) 22A8 monoklonaler Antikörper, Kaninchen anti-p120CTN, monoklonaler Antikörper, Maus

Anti-Phospho-p38 (Tyr-182)-R sc:7975-R polyklonaler Antikörper, Kaninchen

Anti-Rac1/2/3 (L129) monoklonaler Antikörper, Kaninchen

Anti-RhoA (67B9) monoklonaler Antikörper, Kaninchen Anti-Src (32G6) \#2123 monoklonaler Antikörper, Kaninchen
Sigma-Aldrich, Deisenhof

BD Transduction Laboratories, Heidelberg

Santa Cruz Biotechnology, Heidelberg

BD Transduction Laboratories, Heidelberg

Upstate-Chemicon, Hampshire, UK

Sigma-Aldrich, Deisenhof

Santa Cruz Biotechnology, Heidelberg

Cell signaling, Danvers, MA, USA

ICOS Corp., Bothell, USA

Cell signaling, Danvers, MA, USA

BD Transduction Laboratories, Heidelberg

Santa Cruz Biotechnology, Heidelberg

Cell signaling, Danvers, MA, USA

Cell signaling, Danvers, MA, USA

Cell signaling, Danvers, MA, USA 


\section{Hersteller}

Anti-phospho-SRC-Familie 416 polyklonaler

Cell signaling, Danvers, MA, USA

Antikörper, Kaninchen

Anti-SV40, monoklonaler Antikörper, Maus

BD Transduction Laboratories, Heidelberg

Anti-TAK1 \#4505 polyklonaler Antikörper,

Cell signaling, Danvers, MA, USA

Kaninchen

anti- $\alpha$-Tubulin (clone B-5-1-2), monoklonaler

Sigma-Aldrich, Taufkirchen

Antikörper, Maus

Anti-phospho-Tyrosin (P-Tyr-100) monoklonaler

Cell signaling, Danvers, MA, USA

Antikörper, Kaninchen

\section{Sekundärantikörper}

anti-Kaninchen IgG, Alkalische Phosphatase

konjugiert (A-3687), Ziege

anti-Kaninchen IgG $(\mathrm{H}+\mathrm{L})$, HRP (horse radish

peroxidase) konjugiert, Ziege

anti-Kaninchen IgG, Cy3 konjugiert (C2306)

anti-Maus IgG, Alkalische Phosphatase konjugiert

(A-3688)

anti-Maus $\operatorname{IgG}(\mathrm{H}+\mathrm{L}), \quad$ HRP konjugiert,

Kaninchen

anti-Maus IgG, Cy3 konjugiert (C2181)

\section{Hersteller}

Sigma-Aldrich, Taufkirchen

Dianova, Hamburg, Jackson ImmunoResearch

Sigma-Aldrich, Taufkirchen

Sigma-Aldrich, Taufkirchen

Dianova, Hamburg, Jackson ImmunoResearch 


\subsubsection{Plasmide und Vektoren}

\begin{tabular}{ll}
\hline Plasmid/Vektor & Herkunft \\
& \\
pEGFP-C1 & Clontech-Takara, Saint-Germain-en-Laye, Frankreich \\
pGEM-Teasy & Promega, Wisconsin, USA \\
pCMV-His & Clontech-Takara, Saint-Germain-en-Laye, Frankreich \\
pCMV-Myc & Clontech-Takara, Saint-Germain-en-Laye, Frankreich \\
pGEX-4T3 & GE Healthcare, München \\
pSport-Caldesmon & ImaGenes, Berlin, Deutschland \\
pET-28-TAT-GFP-Strep-Tag & Dr. Franco Laccone, Wien \\
pBAC-CTNND1 & ImaGenes, Berlin, Deutschland \\
pGEX-4T1-PAK-RBD & Dr. S. Kliche, Institut für molekulare und klinische \\
pGEX-4T1-TRBD & Immunologie, Magdeburg \\
& Dr. S. Kliche, Institut für molekulare und klinische \\
& Immunologie, Magdeburg \\
& Dr. S. Kaulfuß, 2006 \\
\hline
\end{tabular}

\subsubsection{Verwendete Konstrukte und Plasmide}

\begin{tabular}{|c|c|c|c|}
\hline & $\begin{array}{l}\text { Plasmid/Ve } \\
\text { ktor }\end{array}$ & Herkunft & Primer/ Schnittstelle \\
\hline $\begin{array}{l}\text { pCMV- LPXN - } \\
\text { cMyc }\end{array}$ & pCMV-Myc & LPXN full length (NM_004811) & $\begin{array}{l}\text { LPXN-Fw-Eco Myc-HA und } \\
\text { LPXN-Rev-Xho Myc-HA / } \\
\text { EcoRI, XhoI }\end{array}$ \\
\hline pCMV-LPXN-HA & pCMV-HA & LPXN full length (NM_004811) & $\begin{array}{l}\text { LPXN-Fw-Eco Myc-HA und } \\
\text { LPXN-Rev-Xho Myc-HA / } \\
\text { EcoRI, XhoI }\end{array}$ \\
\hline $\begin{array}{l}\text { pCMV-Myc- } \\
\text { Caldesmon }\end{array}$ & pCMV-Myc & $\begin{array}{l}\text { Caldesmon full length Transkript- } \\
\text { variante } 2 \\
\text { (NM_004342) }\end{array}$ & $\begin{array}{l}\text { Cald pCMV HA, Myc SfiI fw } \\
\text { und Cald pCMV HA, Myc } \\
\text { Xho1 rev / SfiI, XhoI }\end{array}$ \\
\hline $\begin{array}{l}\text { pCMV-HA- } \\
\text { Caldesmon }\end{array}$ & pCMV-HA & $\begin{array}{l}\text { Caldesmon full length Transkript- } \\
\text { variante } 2 \\
\text { (NM_004342) }\end{array}$ & $\begin{array}{l}\text { Cald pCMV HA, Myc SfiI fw } \\
\text { und Cald pCMV HA, Myc } \\
\text { Xho1 rev / SfiI, XhoI }\end{array}$ \\
\hline pEGFP-Caldesmon & pEGFP-C1 & $\begin{array}{l}\text { Caldesmon full length Transkript- } \\
\text { variante } 2 \\
\text { (NM_004342) }\end{array}$ & $\begin{array}{l}\text { Cald pGFP XhoI Fw T1-3 und } \\
\text { Cald pGFP EcoRI Rev / XhoI, } \\
\text { EcoRI }\end{array}$ \\
\hline pGEX-LPXN & pGEX-4T3 & LPXN full length (NM_004811) & LPXN-Fw-Eco / EcoRI, XhoI \\
\hline
\end{tabular}




\begin{tabular}{llll}
\hline & $\begin{array}{l}\text { Plasmid/Ve } \\
\text { ktor }\end{array}$ & Herkunft & Primer/ Schnittstelle \\
\hline pGEX-LPXN-LIM & pGEX-4T3 & $\begin{array}{l}\text { LPXN-LIM-Domäne } \\
\text { (NM_004811) }\end{array}$ & LPXN(LIM) Fw/ EcoRI, XhoI \\
pGEX-LPXN-LD & pGEX-4T3 & LPXN LD-Domäne (NM_004811) & LPXN(LD)Fw / EcoRI, XhoI
\end{tabular}

\subsubsection{Datenbanken}

\begin{tabular}{ll}
\hline Verwendung & Programm \\
\hline Analyse von DNA- und Protein- & BLAST-Programm [Altschul et al., 1990] (http://www.ncbi.nlm.nih.gov) \\
Sequenzen & \\
\hline Bioinformatik & BCM Search Launcher (http://searchlauncher.bcm.tmc.edu/) \\
& Ensembl v32 (http://www.ensembl.org/) \\
& National Center for Biotechnology Information (http://ncbi.nlm.nih.gov/) \\
& DCODE.org Comparative Genomics Center (http://www.dcode.org) \\
& XLStat2010 Exel \\
\hline Restriktionsschnittstellen & WEB Cutter 2.0 (http://rna.lundberg.gu.se/cutter2) \\
\hline Auswahl von Oligonukleotiden & Primer3 (http://frofo.wi.mit.edu/chi-bin/primer3/primer3_www.cgi) \\
\hline
\end{tabular}

\subsection{Isolierung und Aufreinigung von Nukleinsäuren}

\subsubsection{Minipräparation von Plasmid-DNA}

Zur Isolierung und Überprüfung rekombinanter Plasmide wurde zunächst eine geringe Menge an Plasmid-DNA präpariert. Hierzu wurde $1 \mathrm{ml}$ einer angeimpften Übernachtkultur bei $13000 \mathrm{x}$ g abzentrifugiert und das Pellet in $250 \mu \mathrm{P}$ 1-Lösung resuspendiert. Anschließend wurde das Zellpellet in einer modifizierten alkalischen Lyse mit $250 \mu 1$ P2 aufgeschlossen. Nach der Zugabe von $250 \mu$ P3 (Neutralisierung) wurde die Probe nach 5 minütiger Inkubationszeit bei 16000 x g für 10 min zentrifugiert. Der die Plasmid-DNA enthaltene Überstand wurde in ein neues Eppendorf-Cup überführt, mit 0,7 Vol Isopropanol versetzt, 
und bei 16000 x g für 30 min gefällt. Anschließend wurde das DNA-Pellet mit $500 \mu l$ $70 \%$ igem Ethanol gewaschen und nach dem Trocknen in 20-50 $\mu 1 \mathrm{H}_{2} \mathrm{O}$ aufgenommen.

\subsubsection{Herstellung von Bakterien-Glycerin-Stocks}

$1 \mathrm{ml}$ einer Bakteriensuspension wurden mit 10\% sterilem Glycerin versetzt, gut gemischt und bei $-80^{\circ} \mathrm{C}$ aufbewahrt.

\subsubsection{Midipräparation von Plasmid-DNA}

Für die Präparation größerer Mengen hochreiner Plasmid-DNA wurden $50 \mathrm{ml}$ einer Übernachtkultur mit dem Plasmid-Midi Kit der Firma Macherey \& Nagel, (Düren) oder Invitrogen (Karlsruhe) isoliert. Die DNA wurde dabei über Säulen affinitätschromatographisch aufgereinigt. Die Aufarbeitung erfolgte nach dem Protokoll der Hersteller. Diese hochaufgereinigte Plasmid-DNA kann u.a. für die Transfektion von Zelllinien, für Restriktionsanalysen und zur Subklonierung oder Sequenzierung eingesetzt werden. Wurde nicht hochreine Plasmid-DNA benötigt, wurde die Übernachtkultur im größeren Maßstab nach der Methode der Minipräparation aufgereinigt und ggf. über Säulen (Invitek, Berlin oder Millipore, Schwalbach) weiter aufgereinigt.

\subsubsection{Ethanolfällung von DNA aus wässrigen Lösungen}

[Sambrook et al., 1989]

[ aus Beckemeyer, 2007]

Die Ethanolfällung wurde eingesetzt, um DNA zu konzentrieren und sie von Salzverunreinigungen $\mathrm{zu}$ befreien. Zur Fällung von Plasmid-DNA oder PCR-Produkten wurde der Ansatz mit 1/10 Vol 3 M Kaliumacetat-Essigsäure, pH 5.2, und 3 Vol 96\% Ethanol versetzt. Die Präzipitation erfolgte durch Inkubation für $10 \mathrm{~min}$ bei RT oder für mehrere Stunden bei $-20^{\circ} \mathrm{C}$. Der Ansatz wurde für $30 \mathrm{~min}$ bei $16000 \mathrm{x}$ g zentrifugiert und das Pellet mit 70\%igem Ethanol gewaschen. Anschließend wurde das Pellet getrocknet und in einem entsprechenden Volumen $\mathrm{H}_{2} \mathrm{O}$ aufgenommen 


\subsubsection{Phenol/Chloroform- Aufreinigung von Nukleinsäuren}

[ aus Beckemeyer, 2007]

Die Phenol/Chloroform-Extraktion dient der Reinigung der DNA von Proteinen und Membranbestandteilen. Die zu extrahierenden DNA-Proben wurden mit gleichen Volumina Phenol versetzt und intensiv gemischt. Die Phasentrennung erfolgte durch Zentrifugation bei 16000 x g für 2-5 min. Die wässrige Phase wurde in ein neues Eppendorf-Gefäß überführt und die Extraktion nun mit 1 Vol Phenol/Chloroform/ Isoamylalkohol (25:24:1) wiederholt. Die sich in der wässrigen Phase befindende DNA wurde anschließend einer Ethanolfällung (2.9.4) unterzogen

\subsubsection{Isolierung von Gesamt-RNA aus Zellkulturen}

Zur Isolierung von Gesamt-RNA aus Zellkulturen wurde das RNeasy Mini Kit der Firma Qiagen (Hilden) nach den Angaben des Herstellers eingesetzt. Die Ausbeute an RNA betrug dabei zwischen 0,5 und $1,0 \mu \mathrm{g} / \mu \mathrm{l}$.

\subsubsection{Isolierung von Gesamt-RNA aus Organen der Maus}

Die Isolierung von Gesamt-RNA aus Organen der Maus erfolgte über Säulen der Firma Peqlab (Erlangen). Die Gewebestücke wurden unmittelbar nach dem Abtöten der Maus in flüssigem Stickstoff eingefroren. Ohne dass die Gewebestücke auftauten wurden diese in einem eisgekühlten Mörser zerstoßen und anschließend in ein 1,5 ml Eppendorf-Gefäß gegeben, welches mit $400 \mu$ Lysispuffer gefüllt war und gevortext. Die weitere Isolierung erfolgte nach dem Protokoll des Herstellers (pegGOLD Total RNA Kit).

\subsubsection{Konzentrationsbestimmung von Nukleinsäuren}

Zur Bestimmung der Konzentration von Nukleinsäuren wurde ein Spektralphotometer (BioPhotometer, Eppendorf, Hamburg) eingesetzt. Nachdem die Nullwerte abgeglichen wurden, konnte das Absorptionsmaximum der gemessenen Nukleinsäuren (bei $260 \mathrm{~nm}$ ) 
bestimmt werden und gleichzeitig Verunreinigungen durch Proteine (bei $280 \mathrm{~nm}$ ) bzw. Salze (bei $320 \mathrm{~nm}$ ) ermittelt werden. Die Berechnung der Nukleinsäurekonzentration erfolgte dabei über das Lambert'sche Gesetz.

Um niedrige Konzentrationen zu ermitteln, wurde eine bestimmte Menge der DNA auf ein Agarosegel, welches mit EtBr versetzt worden war, neben einem DNA-Standard (MassRuler, MBI) aufgetragen, für den bei jeder Bande die entsprechende Menge an DNA bekannt ist. Nach dem Lauf wurde die DNA unter UV-Licht sichtbar gemacht und fotografiert und die Konzentration der Probe bestimmt, indem die zu bestimmenden Banden mit Banden des Standards ähnlicher Größe verglichen wurden.

\subsection{Klonierungstechniken}

\subsubsection{Spaltung von DNA mit Restriktionsendonukleasen}

Zur enzymatischen Spaltung von DNA durch Restriktionsendonukleasen wurde ein Restriktionsansatz mit einem Volumen von mindestens $10 \mu \mathrm{l}$ vorbereitet. Pro $\mu \mathrm{g}$ DNA wurden 2-3 U des jeweiligen Restriktionsenzyms eingesetzt und zusammen mit einem passenden Puffer bei der für das Enzym optimalen Temperatur für 1-2 h oder über Nacht inkubiert. Wurden für die Spaltung der DNA zwei Restriktionsendonukleasen benötigt, wurde ein Puffer eingesetzt, der beiden Enzymen eine ausreichende Aktivität erlaubte.

\subsubsection{Isolierung von DNA-Fragmenten aus Agarosegelen}

Die Isolierung von DNA-Fragmenten aus Agarosegelen erfolgte unter Zuhilfenahme der NucleoSpin $^{(\mathrm{R})}$ Extract II-Säulen (Macherey und Nagel, Düren). Nachdem die über ein Agarosegel aufgetrennten DNA-Fragmente mit einem sterilen Skalpell aus dem Gel geschnitten wurden, wurden diese in einem ersten Schritt bei $50^{\circ} \mathrm{C}$ aus der Agarose gelöst. Anschließend wurde die Lösung auf die Säulen gegeben und nach den Angaben des Herstellers weiter aufgereinigt. Danach wurde die DNA mit Wasser eluiert. 


\subsubsection{Dephosphorylierung von Plasmid-DNA}

Um zu verhindern, dass es zu einer Religation linearisierter Plasmid-DNA kommt, wurde eine Dephosphorylierung durchgeführt. Hierbei wurden endständige 5'-Phosphatgruppen des Vektors mit Hilfe des Enzyms Alkalische Phosphatase entfernt. Die DNA wurde dazu mit 2 U Alkalischer Phosphatase für $1 \mathrm{~h}$ bei $37^{\circ} \mathrm{C}$ inkubiert. Anschließend wurde die DNA mit Hilfe von Phenol/Chloroform aufgereinigt, mit 2,5 Vol Ethanol und 1/10 Vol $3 \mathrm{M}$ Natriumacetat ( $\mathrm{pH} 4.8$ ) gefällt und in $\mathrm{H}_{2} \mathrm{O}$ resuspendiert.

\subsubsection{Ligation von DNA-Fragmenten}

Durch die Ligation konnte lineare Plasmid-DNA mit DNA-Fragmenten enzymkatalytisch verknüpft werden. Dabei wurden die 3'-Hydroxyl- und 5'-Phosphatenden der linearisierten DNA mit Hilfe des Enzyms T4-DNA-Ligase unter Bildung von Phosphodiesterbindungen verbunden. So entstehen rekombinante DNA-Moleküle. Es wurde folgender Ligationsansatz verwendet:

$\begin{array}{ll}25-50 \mathrm{ng} & \text { Vektor-DNA } \\ 30-120 \mathrm{ng} & \text { Insert-DNA } \\ 1 \mu \mathrm{l} & \text { T4-DNA-Ligase }(5 \mathrm{U} / \mu \mathrm{l}) \\ 1 \mu \mathrm{l} & 10 \times \text { Ligationspuffer } \\ \text { ad } 10 \mu \mathrm{H}_{2} \mathrm{O} & \end{array}$

Der Ansatz wurde für $2 \mathrm{~h}$ bei RT oder über Nacht bei $4^{\circ} \mathrm{C}$ inkubiert.

\subsubsection{Subklonierung von PCR- und RT-PCR-Produkten}

Blunt-End PCR- und RT-PCR-Produkte können in den pGEM-Teasy Vektor, welcher 5' T-Überhänge besitzt, ligiert werden, wenn diesem zuvor ein dA an das 3'-Ende angehängt wird. Taq- und andere Polymerasen besitzen eine terminale Transferase-Aktivität, welche 
Grundlage dieser TA-Klonierungsstrategie ist. Wurden die PCR-Produkte mit einer Polymerase amplifiziert, welche eine Transferase-Aktivität besitzt, konnten die PCR-Produkte direkt in den pGEM-Teasy Vektor ligiert werden. Dafür wurden folgende Komponenten gemischt und über Nacht bei $4^{\circ} \mathrm{C}$ inkubiert.

$50 \mathrm{ng}$ pGEM-T Easy Vektor

PCR-Produkt (3:1, Insert: Vektor-Verhältnis)

$1 \mu 1$ T4-DNA-Ligase 10x Puffer

$1 \mu 1$ T4-DNA-Ligase

in einem Gesamtvolumen von $10 \mu 1$

Wurde zur Amplifizierung der PCR-Produkte eine Polymerase verwendet, welche keine Transferase-Aktivität besitzt, wurde ein A-tailing durchgeführt, bevor das PCR-Produkt in den pGEM-Teasy Vektor kloniert werden konnte. Dafür wurde das PCR-Produkt für 30 min bei $70^{\circ} \mathrm{C}$ mit einer Taq-Polymerase inkubiert, die nachträglich ein dATP an das PCR-Produkt anhängt. Dazu wurden folgende Komponenten gemischt:

$7 \mu \mathrm{l} \quad$ PCR-Produkt

0,7 $\mu 1$ MangoTaq-DNA-Polymerase (1 U/ $\mu 1)$

$0,3 \mu \mathrm{l} \quad \mathrm{MgCl}_{2}(50 \mathrm{mM})$

$1 \mu 1 \quad \mathrm{dATP}(2 \mathrm{mM})$

$1 \mu 1 \quad 10 x$ Polymerase-Puffer

Anschließend wurden 1-2 $\mu 1$ des Ansatzes direkt für die Ligation in pGEM-Teasy eingesetzt.

\subsection{Gelelektrophorese}

\subsubsection{Gelelektrophorese von DNA}

Agarose-Gelelektrophoresen wurden zur Auftrennung von DNA-Fragmenten verwendet. Die Konzentration der Agarose betrug zwischen 0,5-2,0 \% (w/v) und wurde je nach Größe der aufzutrennenden DNA-Fragmente bestimmt. Die Agarose wurde in $100 \mathrm{ml}$ 0,5x Turbo-Puffer durch Kochen gelöst, mit EtBr (Endkonzentration 0,5 $\mu \mathrm{l} / \mathrm{ml}$ ) versetzt und anschließend in einen Gelträger überführt. Nach vollständiger Verfestigung des Gels wurde die 
Elektrophorese in einer mit 0,5x Turbo-Puffer gefüllten Gelkammer bei konstanter Spannung von 200-220 V durchgeführt. Bei der Verwendung der TBE-Agarosegele wurde die Agarose in 1x TBE-Puffer gelöst und wie oben beschrieben weiterbehandelt. Die Elektrophorese wurde dann bei einer konstanten Spannung mit 150 V durchgeführt.

\subsubsection{Gelelektrophorese von RNA}

[Maniatis et al., 1980]

Die Ausbildung von Sekundärstrukturen der RNA wurde während der Gelelektrophorese verhindert, indem eine Formaldehyd-Lösung in 1x MOPS/Agarose-Lösung zugesetzt wurde (Endkonzentration 6,6\%). Die RNA-Proben wurden vor der Auftrennung folgendermaßen behandelt:

$\begin{array}{ll}\mathrm{x} \mu \mathrm{l} & \text { RNA (5-6 } \mu \mathrm{g} \text { Gesamt-RNA) } \\ 2 \mu \mathrm{l} & \text { 10x MOPS } \\ 8 \mu \mathrm{l} & \text { deionisiertes Formamid } \\ 3 \mu \mathrm{l} & \text { Formaldehyd (37\%ige Lösung) } \\ 20 \mu \mathrm{l} & \text { Gesamtansatz }\end{array}$

Der Ansatz wurde bei $65^{\circ} \mathrm{C}$ für $10 \mathrm{~min}$ denaturiert und anschließend für 5 min auf Eis abgekühlt. Anschließend wurden die RNA-Proben mit 0,2 Vol Stop-Mix II mit Ethidiumbromid versetzt und bei $60 \mathrm{~V}$ über Nacht gelelektrophoretisch aufgetrennt.

\subsubsection{Längenstandards}

Während der DNA- und RNA- Gelelektrophorese wurde zur Bestimmung der Größe parallel immer ein Längenstandard mitgeführt.

$1 \mathrm{~kb}$ DNA Ladder

100 bp DNA Ladder

0,5-10 kb RNA Ladder

MassRuler
Invitrogen, Darmstadt

Invitrogen, Darmstadt

Invitrogen, Darmstadt

MBI Fermentas, St. Leon-Rot 


\subsection{Transfertechniken von Nukleinsäuren}

\subsubsection{Northern Blot-Analysen}

Die RNA-Fragmente wurden im denaturierenden Agarosegel aufgetrennt und anschließend mit Hilfe des Northern-Blot-Verfahrens auf Nitrocellulosefilter (Hybond-C-Membran) übertragen. Der Transfer der RNA auf die mit 2x SSC aktivierte Membran erfolgte über Nacht mit einem Turbo-Blotter (Schleicher \& Schüll, Dassel) nach den Angaben des Herstellers. Nach 12 - 18 h wurde der Blot abgebaut und die Positionen der Geltaschen auf der Membran markiert. Der Filter wurde zur Fixierung der RNA für $2 \mathrm{~h}$ bei $80^{\circ} \mathrm{C}$ inkubiert.

\subsubsection{Radioaktive Markierung von DNA und Hybridisierung membrangebundener RNA}

\subsubsection{Random Prime-Markierung}

(Feinberg und Vogelstein, 1983)

Für die Markierung von DNA-Fragmenten mit [ $\alpha-32 \mathrm{P}]$ Isotopen wurde das Ready Prime Kit II (GE Healthcare, Freiburg) verwendet. Die Methode basiert auf dem von Feinberg and Vogelstein (1989) entwickelten Prinzips des random priming. Der Reaktionsmix enthält dATP, dGTP, dTTP, Klenow Fragment (4-8 U) und zufällige Oligodeoxyribonukleotide.

20-50 ng der Sonden-DNA wurden in einem Gesamtvolumen von $45 \mu \mathrm{l}$ in einem Wasserbad für 3-5 min denaturiert und anschließend auf Eis abgekühlt. Die Probe wurde in das Ready Prime Reaktionsgefäß überführt, gut gemischt, und zum Schluss wurden $5 \mu$ von $[\alpha-32 \mathrm{P}]$ dCTP $(40 \mu \mathrm{Ci})$ zum Reaktionsmix zugegeben. Die Markierungsreaktion wurde bei $37^{\circ} \mathrm{C}$ für 30 min durchgeführt. Die markierte DNA wurde danach mit Hilfe von MicroSpin S 200HR Säulen (GE Healthcare) über Zentrifugationsschritte aufgereinigt. Die spezifische Aktivität der DNA-Sonde wurde mit einem Szintillationsmessgerät (Tri-Carb 4530, Packard Instruments, Warrenville, USA) gemessen. Sie lag idealerweise zwischen $4 \times 10^{8}$ und $5 \times 10^{9}$ $\mathrm{cpm} / \mu \mathrm{g}$ DNA. 


\subsubsection{Hybridisierung membrangebundener RNA mit radioaktiv markierten DNA-Sonden}

Der fixierte Nitrocellulosefilter mit darauf gebundener RNA wurde zunächst in 2x SSC-Puffer getränkt und luftblasenfrei in ein Hybridisierungs-Glasröhrchen überführt. Anschließend wurde überschüssiges $2 \mathrm{xSC}$ entfernt und $8 \mathrm{ml}$ des auf $65^{\circ} \mathrm{C}$ vorgewärmten Rapid-HybPuffer (GE Healthcare) zu der Membran dazugegeben. Die Prähybridisierung erfolgte für $1 \mathrm{~h}$ bei $65^{\circ} \mathrm{C}$ im Rollofen (Bachofer, Reutlingen). Anschließend wurden die denaturierte Sonde sowie $300 \mu \mathrm{l}$ Lachsspermien-DNA $(10 \mathrm{mg} / \mathrm{ml})$ für $10 \mathrm{~min}$ bei $95^{\circ} \mathrm{C}$ denaturiert und abgekühlt zur Hybridisierungslösung gegeben. Die Hybridisierung erfolgte über Nacht unter denselben Bedingungen wie die Prähybridisierung. Die Filter wurden danach zunächst 15-30 min mit vorgewärmten 2x SSC-Puffer und anschließend für 2-5 min mit 0,2x SSC + 0,1\% SDS bei $65^{\circ} \mathrm{C}$ im Rollofen gewaschen. Lag der Hintergrund bei $0,5-1 \mathrm{~Bq} / \mathrm{cm}^{2}$ wurde die noch feuchte Membran in eine Folie eingeschweißt und zur Auswertung in eine Autoradiographie-Kassette eingeklebt. Zur Exposition mit einem Röntgenfilm wurde die Kassette bei $-70^{\circ} \mathrm{C}$ eingefroren und der Film nach 12-72 h entwickelt.

\subsection{Polymerase-Kettenreaktion (PCR)}

[Saiki et al., 1985]

Unter Verwendung von spezifischen Oligonukleotid-Primern, ausgehend von einer DNAMatrize, wurde ein Fragment enzymatisch mittels einer PCR in vitro amplifiziert. Dazu wurde zunächst die doppel-strängige DNA bei $95^{\circ} \mathrm{C}$ denaturiert. Die anschließende Erniedrigung der Temperatur ermöglicht die Anlagerung der Primer an die einzel-strängige DNA. Die Aktivierung einer zugesetzten DNA-Polymerase zur Synthese des DNA-Fragements wird durch eine erneute Temperaturerhöhung bewirkt. Durch mehrfache Wiederholung dieses Zyklus lassen sich aufgrund der exponentiellen Vervielfältigung große Mengen eines Fragments amplifizieren. Mittels Agarose-Gelelektrophorese (2.11.1) wurde der Erfolg der PCR anschließend überprüft.

Die in dieser Arbeit eingesetzten Oligonukleotide sind in Kapitel 2.8.4 aufgeführt. 


\subsubsection{PCR an Plasmid-DNA}

Die PCR wurde mit folgendem Reaktionsansatz durchgeführt:

$\begin{array}{rl}\mathrm{x} \mu \mathrm{l} & \text { template-DNA }(10-50 \mathrm{ng}) \\ 1 \mu \mathrm{l} & \text { Primer } 1(10 \mathrm{pmol} / \mu \mathrm{l}, \text { sequenzspezifisch }) \\ 1 \mu \mathrm{l} & \text { Primer } 2(10 \mathrm{pmol} / \mu \mathrm{l} \text {, sequenzspezifisch }) \\ 5 \mu \mathrm{l} & \mathrm{dNTPs}(2 \mathrm{mM}) \\ 5 \mu \mathrm{l} & \text { Taq-Polymerase Puffer }(10 \mathrm{x}) \\ 0,7 \mu \mathrm{l} & \text { MangoTaq-Polymerase }(1 \mathrm{U} / \mu \mathrm{l}) \\ \text { ad } 50 \mu \mathrm{l} & \mathrm{dH}_{2} \mathrm{O}\end{array}$

Die DNA-Amplifikation erfolgte in 30 - 40 Zyklen in einem Primus 25 Thermocycler der Firma MWG Biotech (High Point, NC, USA). Die einzelnen Temperaturschritte und die jeweilige Anzahl/Dauer der Zyklen wurden für jedes DNA-Fragment und die dafür eingesetzten Primer neu gewählt. Ein Zyklus bestand aus folgenden Einzelschritten:

$\begin{array}{lll}95^{\circ} \mathrm{C} & 30-60 \mathrm{sec} & \text { Denaturierung } \\ 50-65^{\circ} \mathrm{C} & 30-90 \mathrm{sec} & \text { Annealing } \\ 72^{\circ} \mathrm{C} & 30-90 \mathrm{sec} & \text { Elongation }\end{array}$

Vor dem ersten Zyklus wurde der Ansatz 1 - 3 min bei $95^{\circ} \mathrm{C}$ denaturiert. Nach Beendigung der gewünschten Zyklen wurde ein letzter Elongationsschritt von 7 min bei $72^{\circ} \mathrm{C}$ angeschlossen. Ca. 1/10 Vol des Reaktionsansatzes wurde mit Stop-Mix II gemischt, je nach Größe des PCR-Produkts auf ein 1-1,5\%iges Agarosegel aufgetragen und anschließend elektrophoretisch aufgetrennt.

\subsubsection{Reverse Transkription}

Um cDNA aus Gesamt-RNA zu synthetisieren, wurde eine Reverse Transkription durchgeführt. Dazu wurden die SuperScript II (Invitrogen, Karlsruhe) und oligo(dT)-Primer, die mit den poly $(\mathrm{A})^{+}$-Sequenzen der mRNA paaren, verwendet. 
Es entsteht ein sog. cDNA-Strang (für complementary DNA), der zur mRNA komplementär ist und später DNA-abhängigen DNA-Polymerasen zugänglich gemacht werden kann.

Für die Reverse Transkription wurden $2-5 \mu \mathrm{g}$ RNA mit $1 \mu$ l oligo(dT)-Primer $(0,5 \mu \mathrm{g} / \mu \mathrm{l})$ und $1 \mu \mathrm{ldNTP}(10 \mathrm{mM})$ in $12 \mu \mathrm{l} \mathrm{Gesamtvolumen} \mathrm{gemischt} \mathrm{und} 10 \mathrm{~min}$ bei $70^{\circ} \mathrm{C}$ inkubiert. Nach Zugabe von:

\author{
$4 \mu 15 x$ First Strand buffer \\ $2 \mu 1 \operatorname{DTT}(0,1 \mathrm{M})$ \\ $1 \mu 1$ RNase-Inhibitor
}

wurde die Probe 2 min bei $42^{\circ} \mathrm{C}$ inkubiert und $1 \mu$ l SuperScript II hinzugefügt. Die Reverse Transkription wurde 50 min bei $42^{\circ} \mathrm{C}$ durchgeführt. Anschließend wurde die Reverse Transkriptase bei $70^{\circ} \mathrm{C}$ für 15 min inaktiviert.

\title{
2.13.3 Quantitative real time PCR-Analysen
}

[mod. aus Beckemeyer, 2007]

Real time PCR bezeichnet ein PCR-Verfahren, bei dem während der PCR die Menge der entstandenen Produkte in Echtzeit gemessen wird. Die Messung der Produktzunahme geschieht anhand von Fluoreszenzlicht, welches in Abhängigkeit von der Produktmenge emittiert wird. Eine Möglichkeit zur Generierung produktabhängiger Fluoreszenz bieten dsDNA bindende Fluoreszenzfarbstoffe. Hier wurde der Cyaninfarbstoff SYBR ${ }^{\circledR}-$ Green I, welcher als Platinum ${ }^{\circledR}$ SYBR $^{\circledR}$ Green qPCR SuperMix-UDG der Firma Invitrogen (Karlsruhe) vertrieben wird, verwendet. Der Farbstoff bindet weitgehend sequenzunspezifisch in der kleinen Furche doppelsträngiger DNA, mit einer etwa 100 fach höheren Affinität als Ethidiumbromid. Das derart gebundene SYBR $®-G r e e n$ fluoresziert nach Anregung etwa 1000 x stärker als der freie Farbstoff, weshalb SYBR®-Green sehr gut geeignet ist, die Akkumulation doppelsträngiger PCR-Produkte sichtbar zu machen [Morrison et al., 1998]. SYBR ${ }^{\circledR}-$ Green lässt sich in Gegenwart von doppelsträngiger DNA mit Blaulicht (480 nm) anregen und zeigt ein Emissionsspektrum mit einem Maximum bei $520 \mathrm{~nm}$.

Die Analyse wurde im 384well-Maßstab mit dem „ABI Prism 7900T Sequence Detection System" durchgeführt. Dieses System arbeitet mit einem Temperatur-Cycler und einem Laser, 
der zu jedem der 384 Reaktionsansätze gelenkt wird und diese anregt. Über ein ladungsempfindliches Detektionssystem erfolgte die Messung der Fluoreszenz jeder Probe, die durch an dsDNA gebundenes SYBR ${ }^{\circledR}-$ Green emittiert wird. Die Daten wurden mit Hilfe der Sequenz-Detektionssystem-Software (SDS Version 2.1, PE Applied Biosystems) quantifiziert, exportiert und in Excel (Microsoft) ausgewertet. Die Reaktions-Ansätze enthielten je 0,25 $\mu \mathrm{M}$ der Oligonukleotide und $5 \mu \mathrm{S}$ SYBR ${ }^{\circledR}-$ Green. Letzterer enthält die HotStarTaq ${ }^{\mathrm{TM}}$ DNA-Polymerase in einem optimierten Puffer, dNTP-Mix (mit dUTP-

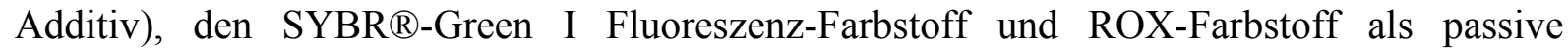
Referenz. Der ROX-Farbstoff soll die Korrektur minimaler Abweichungen erlauben, die durch Pipettier-Ungenauigkeiten oder Fluoreszenz-Schwankungen entstehen können.

Jedem Ansatz wurden entweder 25 ng genomische DNA (bei Kopienzahlbestimmung des Transgens; Endkonzentration 2,5 ng/ $\mu \mathrm{l}$ ) oder 2,5 $\mu 1$ 1:100 verdünnter cDNA (bei Bestimmung differentieller Genexpression) zugefügt. Für die Erstellung einer Standardkurve wurden Ansätze mitgeführt, die genomische DNA einer transgenen Maus der F1-Generation in den Endkonzentrationen $20 \mathrm{ng} / \mu \mathrm{l}, 10 \mathrm{ng} / \mu \mathrm{l}, 5 \mathrm{ng} / \mu \mathrm{l}, 2,5 \mathrm{ng} / \mu \mathrm{l}, 1,25 \mathrm{ng} / \mu \mathrm{l}$ und $0,625 \mathrm{ng} / \mu \mathrm{l}$ enthielten. Um das Auftreten von unspezifischen Produkten auszuschließen, wurde nach Abschluss der Amplifikation eine Schmelzkurvenanalyse durchgeführt. Dabei wurde kontinuierlich die Fluoreszenz (F) bei steigender Temperatur (T) gemessen und die Steigung $\mathrm{dF} / \mathrm{dT}$ (1. Ableitung) errechnet. Diese wurde gegen die Temperatur aufgetragen und damit die Maxima bei den primerspezifischen Schmelztemperaturen aufgezeigt. Zusätzliche Maxima verrieten unspezifische Produkte, z.B. Primer-Dimere. Folgendes Programm wurde für alle Primer verwendet:

\begin{tabular}{|c|c|c|c|}
\hline $50^{\circ} \mathrm{C}$ & $2 \min$ & & \\
\hline $95^{\circ} \mathrm{C}$ & $15 \mathrm{~min}$ & & Aktivierung $T a q$ \\
\hline $94^{\circ} \mathrm{C}$ & $15 \mathrm{~s}$ & & Denaturierung \\
\hline $58^{\circ} \mathrm{C}$ & $30 \mathrm{~s}$ & 40 Zyklen & Annealing \\
\hline $72^{\circ} \mathrm{C}$ & $1 \min 30 \mathrm{sec}$ & & Elongation \\
\hline $95^{\circ} \mathrm{C}$ & $15 \mathrm{~s}$ & & \\
\hline $60^{\circ} \mathrm{C}$ & $15 \mathrm{~s}$ & & \\
\hline $60^{\circ} \mathrm{C}-95^{\circ} \mathrm{C}$ & $2^{\circ} \mathrm{C} / \mathrm{min}$ & & Schmelzkurve \\
\hline
\end{tabular}


Die relative Quantifizierung der initialen Kopienzahl erfolgt bei der real time PCR anhand des Verhältnisses der Kopienzahl des zu untersuchenden Testamplikons und eines Referenzamplikons, das unter identischen Bedingungen amplifiziert wird. Für die Genotypisierung wurde ein HPRT (Hypoxanthin-Guanin-Phosphoribosyltransferase)spezifisches Primerpaar verwendet, da das HPRT-Gen genau eine Kopie im Mausgenom hat. Für die quantitativen Genexpressionsanalysen wurden als Referenz die housekeeping-Gene PBGD (Porphobilinogen-Deaminase) und TBP (TATA-binding protein) verwendet. Bei der Auswertung wird ein Signal-Schwellenwert definiert, bei welchem sich jede Einzelreaktion in der exponentiellen Phase befinden sollte. Der Zeitpunkt (in Zyklen), zu dem das Signal diesen Schwellenwert erreicht, wird als Schwellenwertzyklus oder $\mathrm{C}_{\mathrm{T}}$-Wert (threshold cycle) bezeichnet. Dieser $\mathrm{C}_{\mathrm{T}}$-Wert korreliert mit der Anzahl der Kopien, die für die Reaktion eingesetzt wurden. Wie in Abbildung 2.1 gezeigt, resultiert eine höhere oder niedrigere StartKopienzahl in einem signifikant früheren oder späteren Anstieg der Fluoreszenz-Emission.

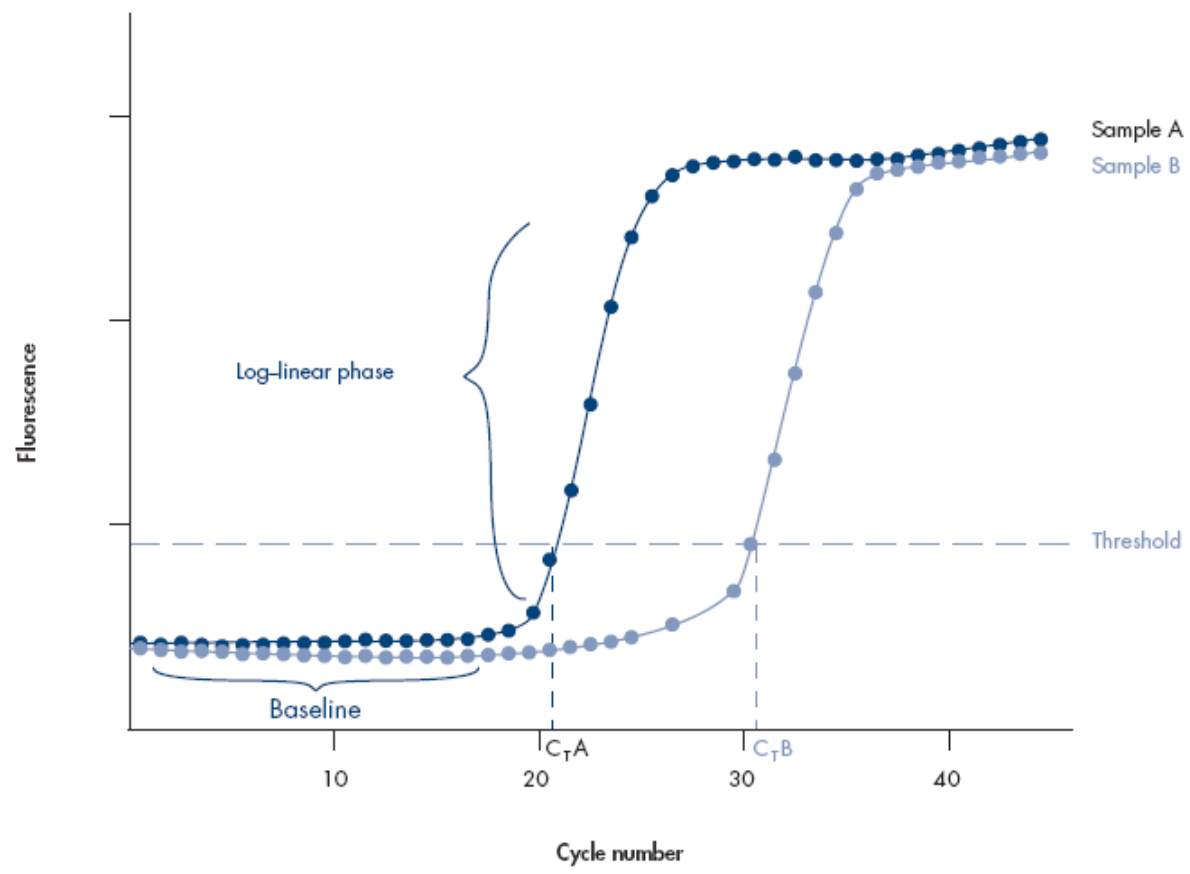

Abb. 2.1: Zunahme der Fluoreszenz zweier Proben (A und B) in Abhängigkeit von der PCR-ZyklusAnzahl. Probe A enthält eine größere Menge an Start-Kopien als Probe B und überschreitet den Schwellenwert daher bei einem früheren Zyklus als Probe A. $\mathrm{C}_{\mathrm{T}}$ : Schwellenwertzyklus. Quelle: QuantiTect SYBR®-Green PCR Handbook, Qiagen (2003). 
Aus den Daten der Standardkurven für jedes Amplikon interpoliert das Programm SDS 2.1 die theoretisch eingesetzte DNA-Menge für Referenzamplikon und Testamplikon jeder Probe (cDNA oder Maus-DNA). Da für das Testamplikon und das Referenzamplikon einer Probe exakt gleiche DNA-Mengen für die Taqman-Analyse einsetzt werden, sollte das Verhältnis der durch das Programm interpolierten DNA-Menge von Testamplikon zu Referenzamplikon den Wert 1 ergeben. Im Falle einer homozygot transgenen LPXN-Maus, befindet sich doppelt soviel template-DNA für das Testamplikon wie für das Referenzamplikon in den TaqmanAnsätzen. Bei der Berechnung des Verhältnisses Testamplikon zu Referenzamplikon wird in diesem Fall ein Wert von ca. 2 erhalten.

\subsection{Sequenzanalyse}

Die Sequenzierung von DNA-Fragmenten basiert auf dem Prinzip des KettenabbruchVerfahrens nach Sanger. Vier Didesoxynukleotide (A, G, T, C) werden jeweils mit verschiedenen Fluoreszenzfarbstoffen markiert, welche wiederum während der gelelektrophoretischen Analyse über Laserabtastung automatisch detektiert werden. Wird ein solches Nukleotid anstelle eines normalen Nukleotids in die wachsende DNA-Kette eingebaut, führt dies zu einem Abbruch der Polymerasereaktion. Die endständige Base sämtlicher DNA-Fragmente ist somit bekannt. Für die Sequenzreaktion wurden 100 ng/1000 bp Plasmid-DNA, 10 pmol sequenzspezifischem Primer und 2,5 $\mu$ l ET-Mix (DYEnamic ET terminator Cycle sequencing Kit der Firma GE Healthcare, München) eingesetzt. Der Gesamtansatz betrug $10 \mu 1$ und wurde nach folgendem Programm analysiert:

$\left.\begin{array}{ll}95^{\circ} \mathrm{C} & 1 \mathrm{~min} \\ 95^{\circ} \mathrm{C} & 30 \mathrm{sec} \\ 60^{\circ} \mathrm{C} & 30 \mathrm{sec} \\ 60^{\circ} \mathrm{C} & 2 \mathrm{~min} \\ 60^{\circ} \mathrm{C} & 5 \mathrm{~min}\end{array}\right\} \begin{aligned} & \text { Denaturierung } \\ & \text { Denaturierung } \\ & 25 \text { Zyklen } \\ & \text { Annealing } \\ & \text { Elongation } \\ & \text { Elongation }\end{aligned}$

Nach der Sequenzreaktion wurde der Gesamtansatz mit $10 \mu \mathrm{l}_{2} \mathrm{O}$ aufgefüllt und anschließend über SephadexG50-Säulen aufgereinigt. Die gelelektrophoretische Analyse wurde mit der automatischen Sequenzanlage MegaBACE ${ }^{\text {TM}} 1000$ der Firma Molecular Dynamics (GE Healthcare) durchgeführt. 


\subsection{Proteinchemische Techniken}

\subsubsection{Isolierung von Gesamtprotein aus Zellkulturen}

Die Isolierung von Gesamtprotein aus Zellkulturen erfolgte aus $25 \mathrm{~cm}^{2}$ großen Zellkulturflachen (Konfluenz $>80 \%$ ). Nach dem Entfernen des Mediums und dem Waschen der Zellen mit kaltem PBS wurden die Zellen in $300 \mu 1$ Lysis-Puffer I lysiert. Die adhärenten Zellen wurden mit einem Zellschaber oder einer Pipette vom Boden der Zellkulturflasche gelöst und in ein 1,5 ml Eppendorf-Gefäß überführt. Suspensionszellen wurden bei $100 \mathrm{x} g$ für 5 min zentrifugiert, mit PBS gewaschen und anschließend in $300 \mu$ l Lysis-Puffer aufgenommen. Nach einer Inkubation für 10 min bei RT wurden unlösliche Zellbestandteile durch Zentrifugation bei 16000 x g für $10 \mathrm{~min}$ entfernt. Der Überstand, in dem die Zellproteine enthalten sind, wurde in ein sauberes Eppendorf-Gefäß überführt. Anschließend wurde die Proteinkonzentration bestimmt (2.15.3) und das Lysat in geeigneten Aliquots bei $-80^{\circ} \mathrm{C}$ aufbewahrt.

\subsubsection{Isolierung von Gesamt-Protein aus Organen der Maus}

Die nach dem Abtöten der Maus entnommenen Organe wurden unmittelbar danach in flüssigem Stickstoff eingefroren. Zur Isolierung der Proteine wurden die Organe, ohne dass sie auftauten, in einem eisgekühlten Mörser zerstoßen und anschließend in ein 1,5 ml Eppendorf-Gefäß gegeben, welches mit $1 \mathrm{ml}$ Lysispuffer gefüllt war und gevortext. Dem Lysispuffer wurden zuvor Proteaseinhibitoren (Complete Mini, Roche, Karlsruhe) sowie ggf. Phosphataseinhibitoren (PhosSTOP, Roche, Karlsruhe) zugegeben. Nach einer Inkubationszeit von 10 min wurden die nicht löslichen Bestandteile für 10 min bei $4^{\circ} \mathrm{C}$ und 16000 x g abzentrifugiert. Der die Proteine enthaltene Überstand wurde in ein vorgekühltes, sauberes Eppendorf-Gefäß überführt, die Konzentration wie unter 2.15 .3 beschrieben bestimmt und bis zur weiteren Verwendung in Aliquots bei $-80^{\circ} \mathrm{C}$ eingefroren. 


\subsubsection{Konzentrationsbestimmung von Proteinen}

[Bradford, 1976]

Die Konzentration von Proteinen wurde nach der Methode von Bradford mit Hilfe von Roti ${ }^{\circledR}-$ Nanoquant (Roth) bestimmt. Diese Methode hat den Vorteil, dass Konzentrationen von 200 ng bis $25 \mu \mathrm{g}$ gemessen werden können. Der Coomassie-Farbstoff Brilliant-Blau bindet in saurer Lösung an Proteine, wodurch eine Verschiebung des Absorptionsmaximums von $495 \mathrm{~nm}$ auf $595 \mathrm{~nm}$ auftritt. Eine zuvor erstellte BSA-Eichreihe (0-6.7 $\mu \mathrm{g}$ BSA/ml) dient als interner Standard und ermöglicht, dass die Proteinkonzentration direkt anhand der ermittelten Optischen Dichte bei 495 und $595 \mathrm{~nm}$ abgelesen werden kann.

$20 \mathrm{ml} \mathrm{des}$ Roti $^{\circledR}$-Nanoquant-Farbstoffs (5x-Konz.) wurden mit $80 \mathrm{ml} \mathrm{H} \mathrm{H}_{2} \mathrm{O}_{\mathrm{dd}}$ gemischt und gekühlt gelagert. Jeweils $200 \mu \mathrm{l}$ dieser Arbeitslösung wurden zu $50 \mu$ l einer 1:100 Verdünnung der zu messenden Proteine gegeben. Die Messung der Extinktion erfolgte in flachbödigen, durchsichtigen 96well-Mikrotiterplatten in einem SynergyMx Microplate Reader (Bio-Tek Instruments Inc., Winooski, Vt.) bei 490/595 nm. Die Messungen erfolgten jeweils in Dreifachbestimmungen und wurden anschließend gemittelt.

\subsubsection{SDS-Polyacrylamidgelelektrophorese (SDS-PAGE)}

Zur Auftrennung von Proteinen wurden Gradientengele $\left(\mathrm{NuPAGE}^{\mathrm{TM}}\right.$ 4-12\% Bis-Tris Gel, Invitrogen, Karlsruhe) verwendet. Dieses Polyacrylamid-Gelsystem beruht auf dem SDSPAGE-Prinzip [Laemmli, 1970], wodurch Proteine nach ihrem Molekulargewicht aufgetrennt werden. Durch einen konstanten pH-Wert der Gele und der Puffer von 7.0 wird die Stabilität der Proteine erhöht, was zu einem besseren Ergebnis der Elektrophorese führt.

Die gekühlten Proteinproben wurden mit 0,25 Vol Probenpuffer (LDS Sample Buffer (4x), $\mathrm{NuPAGE}^{\mathrm{TM}}$, Invitrogen, Karlsruhe) gemischt, $10 \mathrm{~min}$ bei $70^{\circ} \mathrm{C}$ erhitzt, abzentrifugiert und nach Abkühlen auf Eis auf das Gel aufgetragen. Die Elektrophorese erfolgte mit 1x MESPuffer (Invitrogen) bei 150-180 V für ca. 1-2 h. Zur Bestimmung der Größe der aufgetragenen Proteine wurde parallel zu den Proteinproben ein Proteinstandard (NuPAGETM See Blue Plus2, Invitrogen) mit aufgetragen. 


\subsubsection{Western Blot-Analysen von Proteinen auf PVDF-Membranen}

[Gershoni et al., 1982, 1983]

Eine PVDF-Membran (Macherey \& Nagel), die auf die Größe des zu blottenden Polyacrylamidgels zugeschnitten wurde, wurde für $10 \mathrm{sec}$ in $100 \%$ Methanol aktiviert und anschließend in Transferpuffer für 10 min unter Schütteln äquilibriert. Anschließend wurde die PVDF-Membran auf fünf Whatman GB003 Filter (Schleicher \& Schüll, Dassel) derselben Größe, die zuvor ebenfalls in Transferpuffer getränkt wurden, gelegt. Dabei wurde besonders darauf geachtet, dass die Membran zu keinem Zeitpunkt trocken fiel. Auf die Membran wurde das nach der elektrophoretischen Auftrennung der Proteine mit Wasser abgespülte Polyacrylamidgel gelegt. Fünf weitere mit Transferpuffer getränkte Filter komplettierten das sandwich-Model. Nach dem Beseitigen der Luftblasen erfolgte der Proteintransfer vom Gel auf die Membran in einem Elektroblotter (Biometra, Göttingen) bei $220 \mathrm{~mA}$ für 1,5 h.

\subsubsection{Färbung von Polyacrylamidgelen}

Zur Kontrolle des Western Blot-Transfers wurden die SDS-Polyacrylamidgele nach dem Blotten mit Coomassie-Brillant Blue-Lösung für 2-4 h angefärbt und anschließend bis zur gewünschten Farbintensität mit $\mathrm{H}_{2} \mathrm{O}$ entfärbt.

\subsubsection{Inkubation von membrangebundenen Proteinen mit Antikörpern}

Nach dem Transfer der Proteine auf die PVDF-Membran, wurde diese zum Abblocken von unspezifischen Bindungsstellen in 5\% Magermilchpulver in 1x TBS-Tween für $1 \mathrm{~h}$ bei RT inkubiert. Nach anschließendem Waschen in TBS-Tween erfolgte die Inkubation der Membran mit dem Primärantikörper in der für den Antikörper spezifischen Verdünnung in 1x TBS-Tween oder 5\% Magermilchpulver in 1x TBS-Tween bei $4^{\circ} \mathrm{C}$ über Nacht. Anschließend wurde die Membran für 2x 10 min in 2,5\% Milchpulver in TBS-Tween gewaschen und mit dem Sekundärantikörper in deiner Verdünnung von 1:1000 bis 1:10000 in 5\% Milchpulver in TBS-Tween für $2 \mathrm{~h}$ bei RT inkubiert.

Für den Nachweis der Proteine über Chemilumineszenz wurde die Membran zunächst für 3x 15 min mit 2,5\% Milchpulver in 1x TBS-Tween gewaschen, um Milchpulverrückstände zu 
entfernen. Gleichzeitig wurde etwa $1 \mathrm{ml}$ der ECL Plus-Arbeitslösung hergestellt, indem Luminol/Enhancer-Lösung und die stabile Peroxid-Lösung der Firma GE Healthcare 1:40 gemischt wurden. Die Peroxidase-Lösung setzt das Substrat der Arbeitslösung um. Anschließend wurde die Lösung für 5 min unter Lichtabschluss auf die gewaschene Membran gegeben. Nach der Inkubationszeit wurde die abgetropfte Membran in Plastik eingeschweißt und in eine Filmkammer eingeklebt. In der Dunkelkammer wurde ein Film aufgelegt und zunächst nach 1 min entwickelt. Je nach Intensität der Banden wurde die Entwicklungszeit verlängert oder verkürzt.

Für den Nachweis der Proteine über die Alkalische Phosphatase wurde bereits ein Sekundärantikörper verwendet, der AP gekoppelt war. Nach Inkubation der Membran für 3x 15 min in 2,5\% Milchpulver in 1x TBS-Tween wurde die Membran für 5 min bei RT in APPuffer gewaschen. Nachfolgend wurde die Membran unter Lichtabschluss in $10 \mathrm{ml}$ Färbelösung (Alkalische Phosphatase-Färbelösung) inkubiert, wodurch die Proteine sichtbar gemacht wurden. Durch das Waschen mit 1x TBS-Tween wurde die Reaktion abgestoppt und danach die Membran getrocknet.

Tab. 2.1: Übersicht über die in der Western Blot-Analyse verwendeten Antikörper-Verdünnungen sowie das Puffersystem

\begin{tabular}{|c|c|c|c|}
\hline Antikörper & $\begin{array}{c}\text { Verdünnung } \\
\text { Primärantikörper }\end{array}$ & $\begin{array}{c}\text { Verdünnung } \\
\text { Sekundärantikörper }\end{array}$ & $\begin{array}{l}\text { Puffer- } \\
\text { System }\end{array}$ \\
\hline anti-phospho-Caldesmon (Ser789) & $1: 2000$ & $1: 4000$ & $1 \times$ TBS- $0,2 \%$ Tween \\
\hline anti-phospho JNK (Thr183/Tyr185) & $1: 2000$ & $1: 2000$ & $1 \times$ TBS- $0,2 \%$ Tween \\
\hline anti-phospho MKK3/6 (Ser 189/207) & $1: 1500$ & $1: 2000$ & $1 \times$ TBS- $0,2 \%$ Tween \\
\hline anti-phospho p38 (Tyr182) & $1: 2000$ & $1: 3000$ & $1 \times$ TBS- $0,2 \%$ Tween \\
\hline anti-phospho SRC-Familie (Ser416) & $1: 2000$ & $1: 3000$ & $1 \times$ TBS- $0,2 \%$ Tween \\
\hline anti-SV40 T-Ag & $1: 4000$ & $1: 4000$ & $1 \times$ TBS- $0,2 \%$ Tween \\
\hline ánti-HSC-70 & $1: 7500$ & $1: 10000$ & $1 \times$ TBS- $0,2 \%$ Tween \\
\hline anti-Caldesmon & $1: 3000$ & $1: 4000$ & $1 \times$ TBS- $0,2 \%$ Tween \\
\hline anti-p120CTN & $1: 4000$ & $1: 4000$ & $1 \times$ TBS- $0,2 \%$ Tween \\
\hline anti-Rho A & $1: 2000$ & $1: 2000$ & $1 \times$ TBS- $0,2 \%$ Tween \\
\hline anti-Rac & $1: 2000$ & $1: 2000$ & $1 \times$ TBS- $0,2 \%$ Tween \\
\hline anti-TAK1 & $1: 3000$ & $1: 4000$ & $1 \times$ TBS- $0,2 \%$ Tween \\
\hline anti-SRC & $1: 4000$ & $1: 4000$ & $1 \mathrm{x}$ TBS- $0,2 \%$ Tween \\
\hline anti- $\alpha$-Tubulin & $1: 7500$ & $1: 10000$ & $1 \times$ TBS- $0,2 \%$ Tween \\
\hline anti-LPXN & $1: 1600$ & $1: 2000$ & $1 \times$ TBS- $0,2 \%$ Tween \\
\hline & & & $5 \%$ Magermilch \\
\hline
\end{tabular}




\subsubsection{Densitometrische Auswertung}

Zur genauen Analyse der Western Blots wurden die Bandenintensitäten quantifiziert. Dazu wurden die Filme zunächst eingescannt. Die Quantifizierung erfolgte mit Hilfe der Quantitiy One ${ }^{\circledR}$ Quantification Software Version 4.1 der Firma BIORAD.

\subsection{Aufreinigung eines TAT-Transduktionsproteins}

[mod. aus Beckemeyer, 2007]

Zur Überexpression des humanen LPXN in Karzinomzellen wurde ein TAT-LPXNFusionsprotein verwendet. TAT besitzt die Eigenschaft, gefaltete Proteine über die Zellmembran zu transportieren, ohne dabei die Integrität der Membran zu stören.

\subsubsection{Expression des TAT-LPXN-Fusionsproteins}

Die als Glycerolstock gelagerten E.coli BL21 pLys-Bakterien, in die das Konstrukt pET-28TAT-LPXN-EGFP-Strep-Tag [Beckemeyer, 2007] transformiert wurde, wurden zunächst in $50 \mathrm{ml} 2 \times$ YT-Medium über Nacht bei $37^{\circ} \mathrm{C}$ angezogen. Anschließend wurden die Bakterien 1:25 verdünnt und bis zu einer $\mathrm{OD}_{600}=0,6$ bei $37^{\circ} \mathrm{C}$ unter Schütteln weiter inkubiert. Die Induktion der Proteinexpression erfolgte anschließend mit $1 \mathrm{mM}$ IPTG für $4 \mathrm{~h}$ bei RT, um schwerlösliche Expressionsprodukte in Form von inclusion bodies zu vermeiden.

Die Expressionskontrolle durch IPTG (Isopropyl-ß-D-thiogalactosid) [Studier und Moffat, 1986] wird durch die lac-Repressor-Bindungsstelle vermittelt, durch die eine effiziente Repression des T7-Promotors garantiert ist. Durch die Bindung der lac-Repressor-Proteine an die Operatorregion wird der T7-Promotor blockiert. Wird der Bakterienkultur jedoch IPTG zugesetzt, kann sich dieses an die lac-Repressor-Proteine binden, sodass die T7-Promotorregion freiliegt. Die RNA-Polymerasen sind dann in der Lage, beginnend am Promotor, die Sequenz zu translatieren. 


\subsubsection{Herstellung von Proteinlysaten aus Bakterien und Aufreinigung des Fusionsproteins}

Nach der Induktion der transformierten E.coli BL21 pLys wurden die Bakterien bei $4500 \mathrm{x} g$ für $10 \mathrm{~min}$ abzentrifugiert und der Mediumüberstand verworfen. Pro $50 \mathrm{ml}$ Pellet wurde $1 \mathrm{ml}$ Lysispuffer (siehe 2.6) zum Auflösen der Pellets verwendet. Das Lysieren der Pellets geschah durch 10 minütiges Vortexen sowie vorsichtiges Auf- und Abpipettieren. Nach einer Inkubationszeit von $10 \mathrm{~min}$ auf Eis wurde das Bakterienlysat $3 \times 1 \mathrm{~min}$ sonifiziert und anschließend 15 min bei 13000 x g in einer Kühlzentrifuge abzentrifugiert. Der das Protein enthaltende lösliche Überstand wurde abgenommen und das Protein nach den Vorgaben des Herstellers (IBA, Göttingen) über Strep-Tactin Säulen aufgereinigt. Proteine, die einen Streptavidin-Tag enthalten, binden an die Strep-Tactin Sepharose-Matrix der Säulen, während die restlichen bakteriellen Proteine durch Waschen entfernt werden. Anschließend kann das Fusionsprotein durch Zugabe von Desthiobiotin von der Matrix eluiert und isoliert werden (Abb. 2.2). Nach der Elution des Fusionsproteins wurde das Desthiobiotin aus dem Eluat entfernt. Dazu wurde die Proteinlösung in Centrisart-Röhrchen (c.off $=20 \mathrm{kDa}$ ) bei $4500 \mathrm{x} \mathrm{g}$ zentrifugiert und durch wiederholte Zugabe von PBS gewaschen. Zur Kontrolle des aufgereinigten Fusionsproteins wurde dieses über SDS-PAGE aufgetrennt und mittels Coomassie-Färbung analysiert.

A

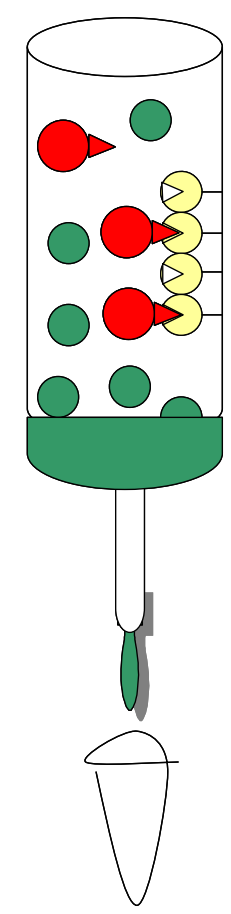

B

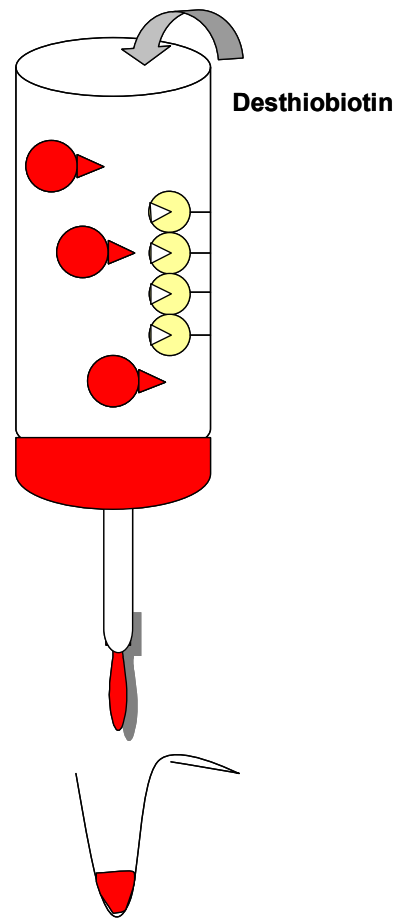


Abb. 2.2: Aufreinigung des Fusionsproteins über Strep-Tactin-Säulen von IBA. Proteine, die einen Streptavidin-Tag enthalten, können an die Strep-Tactin Sepharose-Matrix der Aufreinigungs-Säulen binden. Das generierte TAT-LPXN-EGFP-Strep-Tag-Fusionsprotein kann so durch das Binden an die Säulenmatrix von den übrigen Proteinen getrennt werden (A). Nach Durchlauf des gesamten Proteinlysats kann das gebundene Fusionsprotein durch die Zugabe von Desthiobiotin von der Matrix gelöst werden (B).

\subsubsection{Transduktion des TAT-Fusionsproteins}

Zur Transduktion des TAT-LPXN-EGFP-Strep-Tag-Fusionsproteins in humane Prostatakarzinomzellen wurden von diesen Zellen zunächst 50000 in 12-Well-Platten ausplattiert. Nach $12 \mathrm{~h}$ wurde das LPXN-Fusionsprotein in einer Konzentration von $500 \mathrm{nM}$ auf die Zellen gegeben und für $24 \mathrm{~h}$ inkubiert. Anschließend wurde das Protein abgenommen, die Zellen zweimal vorsichtig mit PBS gewaschen und für nachstehende Versuche vorbereitet.

\subsection{Zellbiologische Methoden}

\subsubsection{Zellkultur eukaryontischer Zellen}

Die adhärent wachsenden PC-3-, LNCaP- und DU 145-Zellen wurden in RPMI 1640-Medium mit Zusatz von 1,2\% Penicillin/Streptomycin und 10\% FKS in oberflächenbehandelten Gewebekulturflaschen kultiviert. Die Inkubation der Zellen erfolgte im Brutschrank mit 5\% $\mathrm{CO}_{2}$ bei $37^{\circ} \mathrm{C}$. In Abhängigkeit von der Wachstumsrate wurden die Zellen ein- bis zweimal pro Woche geteilt. Die Zellen wurden dabei zunächst mit 1x DPBS (PAN) gewaschen und anschließend mit Trypsin-EDTA (PAA, Pasching, Östereich) so lange inkubiert, bis sich die Zellen vom Boden der Kulturflasche gelöst haben. Nach dem Lösen der Zellen wurden diese 1:2 bis 1:5 geteilt und die verbliebenen Zellen in frischem Medium weiter kultiviert. 


\subsubsection{Isolierung von Primärzellen aus murinen Prostatakarzinomen}

Zur Etablierung der murinen Primärzellkultur wurden die LPXN/TRAMP- und TRAMPMäuse unmittelbar zuvor abgetötet und der entnommene Prostatatumor unter sterilen Bedingungen zunächst mit einer Rasierklinge mechanisch zerkleinert. Anschließend erfolgte die weitere Zerkleinerung mit einem Tissue Chopper (H. Saur Laborbedarf, Reutingen). Das zerkleinerte Gewebe wurde in HBS gewaschen und in ein steriles Falkon mit $5 \mathrm{ml}$ Kollagenase $(1 \mathrm{mg} / \mathrm{ml})$ und $5 \mathrm{ml}$ Medium 199 überführt. Die Suspension wurde für zwei Stunden unter Schütteln bei $37^{\circ} \mathrm{C}$ inkubiert. Anschließend wurde die Suspension abzentrifugiert und in Medium 199 mit 0,04\% DNAse I resuspendiert. Danach erfolgte die Trennung der verschiedenen Zelltypen mittels Biocoll-Gradienten durch die Zentrifugation bei 2000 x g für 20 min. Die mittlere Fraktion wurde in $50 \mathrm{ml}$ Medium 199 verdünnt und erneut zentrifugiert. Anschließend wurde das Pellet in Advanced DMEM (Invitrogen) mit Zusätzen und Antibiotika gelöst und in kleinen Kulturschalen, die zuvor mit RattenschwanzKollagen beschichtet wurden, ausplattiert. Zur Überprüfung der erfolgreichen Isolierung der epithelialen Tumorzellen wurde eine Immunzytochemie, wie unter 2.23.1 beschrieben, mit einem SV40-Antikörper durchgeführt.

\subsubsection{Zellkultur eukaryontischer muriner Primärzellen}

Die Primärzelllinien T-27F, T-45F, L-T-19-83A und L-T-72A wurden in advanced DMEM mit FKS, NuSerum, Gentamycin und DHT kultiviert (siehe 2.7.3). Zum Abtöten der Fibroblasten wurden die Zellen zusätzlich mit $1 \mu \mathrm{M}$ Dexamethason behandelt. Die Inkubation der Zellen erfolgte im Brutschrank mit $5 \% \mathrm{CO}_{2}$ bei $37^{\circ} \mathrm{C}$. Je nach Fibroblastenkonzentration wurden die Zellen drei- bis siebenmal pro Woche differentiell trypsiniert. Die Zellen wurden dazu zunächst mit 1x DPBS (PAN) gewaschen und anschließend mit Trypsin-EDTA (PAA, Pasching, Östereich) für ca. 3 min bei $37^{\circ} \mathrm{C}$ inkubiert. Nach der Inkubationszeit wurden die gelösten Zellen entfernt und die adhärenten Zellen in frischem Medium weiter kultiviert. Waren die Zellenkulturen frei von Fibroblasten, wurden sie je nach Proliferationsrate ein- bis zweimal pro Woche geteilt. 


\subsubsection{Kryokonservierung und Revitalisierung von eukaryontischen Zellen}

Zur Konservierung der eukaryontischen Zellen wurden diese zuvor bis zu einer Konfluenz von $>80 \%$ wachsen gelassen und anschließend mit DPBS gewaschen. Nach dem Trypsinieren der Zellen wurden sie einer entsprechenden Menge Kulturmedium mit 10\% DMSO resuspendiert und für ca. 7 Tage bei $-70^{\circ} \mathrm{C}$ aufbewahrt. Danach wurden sie in flüssigem Stickstoff konserviert. Zur Revitalisierung wurden die Zellen bei $37^{\circ} \mathrm{C}$ aufgetaut, in vorgewärmtes Kulturmedium überführt und über Nacht inkubiert. Nach 12 - 24 h wurde das Medium zur vollständigen Entfernung des DMSO gewechselt.

\subsubsection{Transfektion eukaryontischer Zellen}

Die Transfektion von eukaryontischen Zellen erfolgte zur Überexpression von Fusionsproteinen, zum Nachweis der subzellulären Lokalisation von Fusionsproteinen und zum Nachweis der Kolokalisation ausgewählter Proteine mit Hilfe von immunzytochemischen Experimenten. Das verwendete Transfektionsreagenz FuGENE HD (Roche, Mannheim) stellt ein nicht-kationisches Lipid dar und hat daher eine besonders geringe Toxizität. Das Produkt wurde speziell dazu entwickelt, besonders schwer zu transfizierende Zelllinien zu transfizieren, da es auch in serumhaltigen Medien und bei geringer Zelldichte eingesetzt werden kann. Für die Transfektion wurden nur Zellen verwendet, die sich in einer permanenten Wachstumsphase befanden. Ca. $18 \mathrm{~h}$ vor der Transfektion wurden die Zellen in 6-Well-Platten oder kleinen Kulturflaschen so ausplattiert, dass am folgenden Tag eine Zelldichte von $80 \%$ erreicht wurde. Das Kulturmedium ohne Zusätze wurde mit der DNA und dem Transfektionsreagenz nach dem Protokoll des Herstellers gemischt, für 20-30 min bei RT inkubiert und vorsichtig auf die Zellen getropft. Zuvor wurden die Zellen mit PBS gewaschen und mit Kulturmedium ohne Antibiotika beschichtet. Nach 12-18 h wurden das Transfektionsmedium komplett gegen normales Medium mit allen Zusätzen ausgetauscht und die Zellen zur Proteinexpression 24-72 h unter Kulturbedingungen inkubiert. 


\subsubsection{Anfertigung von Zytospin-Präparaten}

Zur Fixierung von Zellen auf Objektträgern wurde neben der Kultivierung der Zellen auf Objektträgern auch die Methode der Zytospin-Präparation angewendet. Dazu wurden ca. $7 \times 10^{5}$ Zellen in einem speziellen Rotor (Sigma, Rotor 11234) bei 90 x g für 7 min auf einen Objektträger zentrifugiert. Nach dem Trocknen wurden die Präparate für immunzytochemische Experimente verwendet oder in Aluminiumfolie eingewickelt und bei $-20^{\circ} \mathrm{C}$ aufbewahrt.

\subsubsection{Collagen-Aufreinigung aus Rattenschwänzen}

Zur Beschichtung von Zellkulturschalen wurde Kollagen aus Rattenschwänzen verwendet. Dazu wurden diese zunächst mit 70\% igem EtOH gereinigt. Anschließend wurde die Haut der Schwänze entfernt und beginnend von der Schwanzspitze die Wirbel einzeln herausgebrochen und die Kollagenfasern aus dem Bindegewebe gezogen. Die einzelnen Kollagenfasern wurden getrocknet und in ca. $2 \mathrm{~cm}$ lange, blutfreie Stränge zerkleinert. Danach wurden die Fasern über Nacht in einer flachen Schale unter UV-Licht sterilisiert und anschließend in sterile

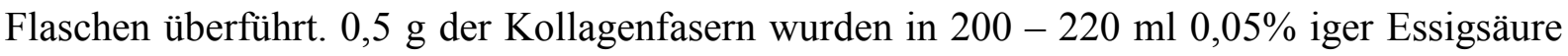
für mind. $24 \mathrm{~h}$ bei $4{ }^{\circ} \mathrm{C}$ unter sterilen Bedingungen gerührt, bevor die Lösung bei $6000 \mathrm{rpm}$ für $1-2 \mathrm{~h}$ zentrifugiert wurde. Der zähflüssige Überstand war für ca. $1 \mathrm{Jahr}$ bei $4{ }^{\circ} \mathrm{C}$ lagerbar.

\subsection{Invasionsassay}

Zur Bestimmung der invasiven Eigenschaften der Zellen wurden BioCoat Matrigel Invasion Chambers (Becton Dickinson, Bedford, MA) nach dem Protokoll des Herstellers verwendet. Diese stellen die Basalmembran in vitro dar und bieten den Zellen die Bedingungen, die sie benötigen, um ihre invasive Eigenschaft in vitro zu zeigen. Die Invasions-Kammern bestehen aus einer BD Falcon ${ }^{\mathrm{TM}}$ TC Companion Platte mit Falcon ${ }^{\mathrm{TM}}$ Cell Culture Inserts, die eine PETMembran ( $8 \mu \mathrm{m}$ Porengröße) mit einer dünnen Schicht Matrigel Basement Membrane Matrix enthalten. Die Matrigel-Schicht schließt die Poren der Membran, so dass nur invasive Zellen durch die Matrigel-Matrix und die Poren der Membran wandern können. Dagegen können nicht invasive Zellen nicht durch die Membran wandern, sondern verbleiben auf der Matrigel 
Matrix. Die Membran kann nach dem Färben der Zellen leicht aus den Inserts heraus geschnitten werden und für Licht- und Elektronenmikroskopie verwendet werden.

LPXN-siRNA, p120CTN-siRNA bzw. LPXN- und p120CTN-siRNA transfizierte PC-3- und DU 145-Zellen sowie die murinen Primärzellen wurden im entsprechenden Kulturmedium jeweils in einer Konzentration von $7 \times 10^{5}$ Zellen/ml resuspendiert. $500 \mu 1$ dieser Zellsuspension wurden in den oberen Teil eines Inserts gegeben und für $18-24 \mathrm{~h}$ bei $37^{\circ} \mathrm{C}$ und 5\% $\mathrm{CO}_{2}$ inkubiert. Anschließend wurden die nicht invasiven Zellen vorsichtig mit einem Wattestäbchen von der oberen Oberfläche der Membran entfernt. Anschließend wurde die Membran mit einem Skalpell aus dem Chamber geschnitten und die Zellen auf der unteren Seite der Membran mit dem Diff-Quik Staining Set (Dade Behring GmbH, Marburg) gefärbt. So konnten die invasiven Zellen unter einem Mikroskop (BX60, Olympus Optical Co., Japan) bei 100 facher Vergrößerung gezählt werden. Die Daten entsprechen der Anzahl invasiver Zellen aus fünf zufällig gewählten Sichtfeldern. Alle Experimente wurden in 3facher Wiederholung durchgeführt.

\subsection{Proliferationsassay}

Zur Bestimmung der Proliferationsfähigkeit von Zellen wurde ein Proliferationsassay der Firma Promega, Mannheim gewählt (Cell Titer $96{ }^{\circledR} \mathrm{AQ}_{\text {ueous }}$ Non-Radioactive Cell Proliferation Assay). Dieser macht sich die Eigenschaft von lebenden Zellen zunutze, welche schwach gefärbte Tetrazoliumsalze (MTS) in intensiv gefärbte Formazanderivate umwandeln können. Da diese Reduktion intakte Mitochondrien erfordert, kann sie nur in lebenden Zellen stattfinden und bietet daher eine Möglichkeit zwischen lebenden und abgestorbenen Zellen zu unterscheiden. $\mathrm{Zu}$ Beginn des Tests wurden pro Well der 96-Well-Platten 3x $10^{3}$ Zellen ausplattiert. Nach einer Adhäsionsphase von 2 h wurde ein Nullwert, welcher von allen übrigen Messungen abgezogen wurde, zur Minimierung der Fehlerrate nach dem Protokoll des Herstellers gemessen. Die Intensität des Farbumschlages des Chromophors in jedem Well wurde mit einem Mikrotiterplatten-Lesegerät (SynergyMx Universal Microplate Reader, BIOTEK Instr. Inc.) verifiziert. Die Absorption wurde im Abstand von $24 \mathrm{~h}$ analysiert, wobei darauf geachtet wurde dass die Konfluenz der Zellen nicht auf über 95\% anstieg. Die Messung erfolgte bei $450 \mathrm{~nm}$ gegen eine Referenzwellenlänge von $620 \mathrm{~nm}$ (zum Abzug des Hintergrundes). 


\subsection{Assay zur Bestimmung der Adhäsion von Zellen}

Zur Bestimmung der adhäsiven Eigenschaften der PC-3- und DU 145-Zellen mit herunterregulierter LPXN-Expression wurden sog. Adhäsionsassays durchgeführt. Dazu wurden die Zellen zunächst über Nacht mit siRNA gegen LPXNst bzw. als Kontrolle mit siRNA gegen Luciferase transfiziert. Anschließend wurden die Zellen gründlich mit DPBS gewaschen und in neuem Medium für weitere $48 \mathrm{~h}$ kultiviert. Mit 0,3 mM EDTA in DPBS wurden die Zellen nach der Kultivierung vom Boden der Kulturschale gelöst und in einem $50 \mathrm{ml}$ Falcon in Kulturmedium ohne Serum verdünnt bevor die genaue Zellzahl durch zweifaches Auszählen bestimmt wurde. Die murinen Primärzellen wurden ohne vorherige Transfektion vom Boden der Kulturschale gelöst, verdünnt und ausgezählt. Anschließend wurden die Zellen für weitere $15 \mathrm{~min}$ in dem Falcon unter der Sterilbank stehen gelassen. Auf 4-Well-Slides, die zuvor mind. $1 \mathrm{~h}$ bei $37^{\circ} \mathrm{C}$ mit $10 \mu \mathrm{g} / \mu \mathrm{l}$ Fibronektin, RattenschwanzCollagen, 1\%iger Gelatine oder $20 \mu \mathrm{g} / \mu \mathrm{l}$ BSA beschichtet worden sind, wurden jeweils $1 \mathrm{x} 10^{4}$ Zellen in $500 \mu 1$ Gesamtvolumen zugegeben. Nach Inkubation für 1, 2 oder $24 \mathrm{~h}$ bei $37^{\circ} \mathrm{C}$ wurde das Medium vorsichtig entfernt und die adhärenten Zellen mit 4\% Formaldehyd in PBS für 20 min fixiert. Anschließend erfolgte eine immunzytochemische Färbung mit einem anti-phospho-Tyrosin-Antikörper oder mit FITC-Phalloidin über Nacht. Nach Beendigung der immunzytochemischen Färbung wurden die adhärenten Zellen unter einem Floureszenzmikroskop ausgezählt und deren Fläche bestimmt.

\subsection{Bestimmung der Migrationsfähigkeit von Zellen}

Zur Bestimmung der Migrationsfähigkeit von PC-3- und DU 145-Zellen nach Herunterregulierung der LPXN- und p120CTN-Expression bzw. von murinen Primärzellen wurde der sog. scratch-Assay oder auch Wundheilungsassay angewendet.

Zunächst wurden die PC-3- und DU 145-Zellen mit siRNA gegen LPXN, p120CTN bzw. LPXN und p120CTN und als Kontrolle gegen Luciferase transfiziert. $24 \mathrm{~h}$ nach der Transfektion wurden die Zellen vom Boden der Kulturflasche gelöst und 1x $10^{4}$ Zellen wurden pro Well eines 4-Well-Slides ausplattiert. Die Primärzellen wurden direkt vom Boden der Kulturflasche gelöst und in einem 4-Well-Slide ausplattiert. Nach $24 \mathrm{~h}$ hatten die Zellen eine geschlossene Ein-Zellschicht am Boden gebildet. In diese Ein-Zellschicht wurde mit Hilfe einer sterilen, gelben Pipettenspitze eine vertikale Wunde zugefügt, anschließend das 
Kulturmedium zur Beseitigung der abgekratzten Zellen gewechselt und die Wunde mit Hilfe eines inversen Mikroskops dokumentiert. Nach einer Inkubationszeit von 8 - 24 h wurden die Zellen erneut fotografiert und der Wundheilungsprozess dokumentiert.

Zur Bestimmung der Migrationsfähigkeit der PC-3- und DU 145-Zellen mit herunterregulierter Caldesmon Expression wurde ein Transwell-Migrationsassay (24-Well Millicell, Millipore, Morlsheim) durchgeführt. $8 \mu \mathrm{m}$ großen Poren in der PET-Membran am Boden der Migrations-Kammern erlauben es migrierenden Zellen auf die andere Seite der Membran zu gelangen. Die PCa-Zellen wurden zunächst wie unter 2.22.2 beschrieben mit Caldesmon-spezifischer siRNA und als Kontrolle mit Luciferase-spezifischer siRNA transfiziert. $8 \times 10^{4}$ Zellen in einem Gesamtvolumen von $500 \mu 1$ wurden anschließend in die mit Medium aktivierte Kammer gegeben und für 18 - $24 \mathrm{~h}$ inkubiert. Anschließend wurden die Zellen, welche nicht auf die Unterseite der Membran migriert waren, vorsichtig mit einem Wattestäbchen entfernt und danach die Zellen auf der Unterseite der Membran mit dem DiffQuik Staining Set (Dade Behring GmbH, Marburg) gefärbt. Nach der Färbung wurde die PET-Membran mit einer Rasierklinge vorsichtig aus der Migrations-Kammer geschnitten und auf einem Objektträger mit einem Tropfen Öl eingedeckelt. Unter einem Mikroskop (BX60, Olympus Optical Co., Japan) wurden die Zellen bei 100 facher Vergrößerung gezählt. Die Daten entsprechen der Anzahl migrierter Zellen aus fünf zufällig gewählten Sichtfeldern. Alle Experimente wurden in 3 facher Wiederholung durchgeführt.

\subsection{Herunterregulierung der Genexpression mittels RNA-Interferenz}

[mod. aus Kaulfuß, 2006]

Der Terminus RNA-Interferenz (RNAi) beschreibt die Verwendung von doppelsträngiger RNA, um spezifische mRNAs für die Degradierung zu markieren, wodurch die Expression der entsprechenden Gene verringert wird. RNAi ist eines aus einer breiten Klasse von RNAsilencing- Phänomenen, die in Pflanzen, Tieren und Pilzen gefunden worden sind [Cogoni et al., 2000; Elbashir et al., 2001a; Elbashir et al., 2001b; Tuschl, 2001]. 


\subsection{1 Überblick über den Mechanismus von RNAi}

Im ersten Schritt wird doppelsträngige RNA in 21-23 Nukleotide small interfering RNAs(siRNA) geteilt, welche auch als guide RNAs bezeichnet werden [Hammond et al., 2001; Sharp, 2001]. Das Enzym Dicer, ein Mitglied der RNase III-Familie der dsRNAspezifischen Ribonukleasen, schneidet prozessiv die dsRNA (direkt oder über ein Transgen oder Virus eingeführt) in ATP-abhängiger Weise. Das sukzessive Schneiden degradiert die RNA in 19- 21 bp-Duplexe (siRNAs), die jedes einen 2-Nukleotid-Überhang am 3'-Ende besitzen [Hutvagner et al., 2002]. Im Effektor-Schritt binden die siRNA-Duplexe an einen Nuklease- Komplex, um den sog. RISC (RNA-induced silencing complex) zu bilden. Das ATPabhängige Entwinden der siRNA-Duplexe ist für die Aktivierung von RISC notwendig. Der aktive RISC geht gezielt gegen homologe Transkripte durch Basenpaarung vor und schneidet die mRNA $\sim 12$ Nukleotide vom 3'-Terminus der siRNA [Hammond et al., 2001; Sharp, 2001]. In Säugerzellen führt das Einbringen langer doppelsträngiger RNA (>30 Nukleotide) zur Initiation einer antiviralen Antwort, die z.B. eine unspezifische Inhibierung der Proteinsynthese oder RNA-Degradation auslöst. Diese antivirale Antwort in Säugerzellen kann umgangen werden, indem synthetische siRNAs eingebracht oder siRNAs von Vektoren exprimiert werden (Abb. 2.3).

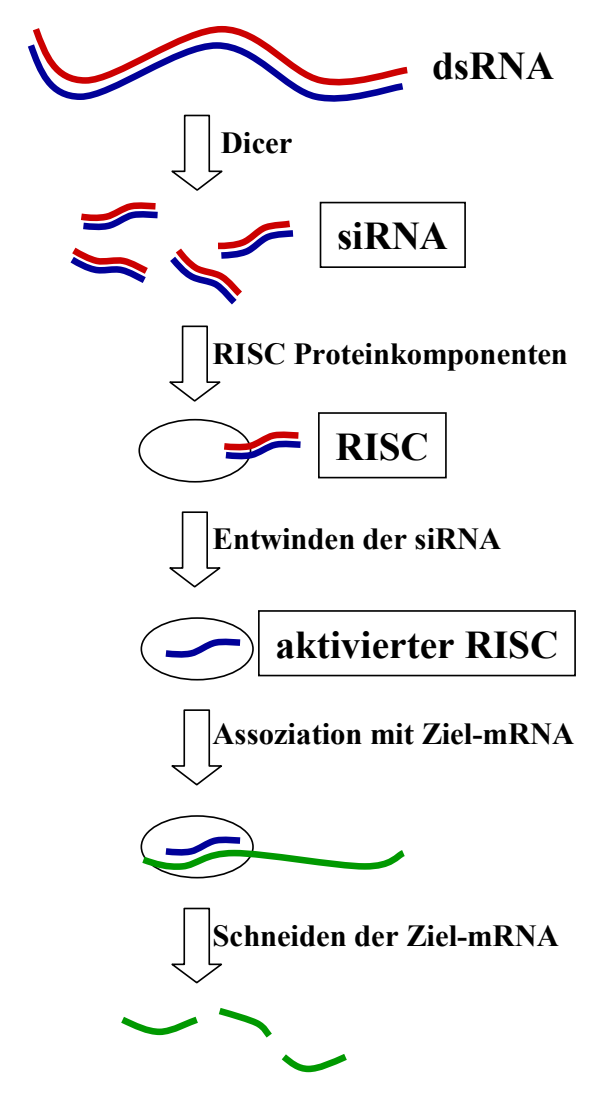


Abb. 2.3: Übersicht über den Mechanismus von RNAi [mod. nach www.ambion.com]. RNAi wird durch das Enzym Dicer initiiert, welches doppelsträngige RNA in 22-Nukleotide kleine small interfering RNAs (siRNAs) prozessiert. Die siRNAs werden dann in eine Multikomponenten-Nuklease (RISC) inkorporiert. RISC wird anschließend von einer latenten Form, die doppelsträngige siRNA enthält, in eine aktive Form durch Entwindung der siRNAs überführt. Der aktivierte RISC verwendet dann die entwundenen siRNAs als eine Schablone für die Substratselektion und die Ziel-mRNA wird geschnitten.

\subsubsection{Transfektion eukaryontischer Zellen mit siRNAs}

Die auf RNAi basierende Methode kann verwendet werden, um eine spezifische mRNA zur Degradierung zu markieren, wodurch es zur Verminderung der entsprechenden Genexpression (gene silencing) kommt. Es wurde ebenfalls gezeigt, dass sequenz-spezifische einzelsträngige RNA-Oligonukleotide sowohl in sense- als auch in antisense-Orientierung als Negativkontrolle für dieses spezifische gene silencing eingesetzt werden können, da sie keinen Effekt auf die spezifische mRNA-Degradierung haben [Tuschl et al., 1999]. Transfektionen von PC-3-, LNCaP- und DU 145-Zellen wurden mit dem Transfektionsreagenz OligoFectamine ${ }^{\mathrm{TM}}$ (Invitrogen, Karlsruhe) durchgeführt, welches stabile Komplexe zwischen Lipiden und Oligonukleotiden bildet. So können die RNA-Moleküle effizient in die Säugetier-Zellen aufgenommen werden. Die Transfektion wurde nach dem Protokoll des Herstellers mit genspezifischen siRNA-Duplex-Oligonukleotiden in einer Endkonzentration von $80 \mathrm{nM}$ im Transfektionsmedium durchgeführt. Als eine weitere Kontrolle wurden die PCa-Zellen mit siRNA-Duplex-Oligonukleotiden gegen das LuciferaseGen des Leuchtkäfers (Photinus pyralis; nicht-verwandte Sequenz) transfiziert (Sequenzen der Oligonukleotide siehe 2.8.4.2).

Für die Transfektion wurden die PCa-Zellen entweder in kleinen Kulturflaschen $\left(22 \mathrm{~cm}^{2}\right)$, in 6-Well-Platten oder 12-Well-Platten bis zu einer Konfluenz von 50\% kultiviert. Alle Angaben der nachfolgend beschriebenen Transfektion beziehen sich auf ein Well einer 12-well-Platte; für kleine Kulturflaschen wurden die 3fachen Mengen verwendet. $3 \mu$ Duplex-siRNA $(20 \mu \mathrm{M})$ wurden mit $100 \mu \mathrm{l}$ OptiMEM I (Invitrogen) in einem 1,5 ml-Gefäß vermischt. $3 \mu \mathrm{l}$ OligoFectamine ${ }^{\mathrm{TM}}$ wurden zu $20 \mu \mathrm{l}$ OptiMEM I in einem weiteren 1,5 ml-Gefäß gegeben und für 10 min bei RT inkubiert. Anschließend wurde die OligoFectamine-Lösung zu der RNAProbe hinzugefügt und für 25 min bei RT inkubiert. Während dieser Inkubationszeit wurden die Zellen mit PBS gewaschen und $1 \mathrm{ml}$ OptiMEM I wurde in jedes Well gegeben. Anschließend wurde das Transfektionsgemisch (RNA/OligoFectamine ${ }^{\mathrm{TM}}$ in OptiMEM I) vorsichtig auf die Zellen gegeben und die Zellen bei $37^{\circ} \mathrm{C}$ und $5 \% \mathrm{CO}_{2}$ in einem Inkubator 
8 - 12 h kultiviert. Nach Entnahme des Transfektionsmediums wurde normales Kulturmedium $\mathrm{zu}$ den Zellen gegeben und die Zellen unter den gleichen Bedingungen weiterkultiviert. $\mathrm{Zu}$ verschiedenen Zeitpunkten nach der Transfektion wurden die Zellen zur Isolierung von Proteinen, RNA und für immunhistochemische Experimente zur Verifizierung des gene silencing und zur Untersuchung der Effekte der jeweiligen Gen-Herunterregulierung verwendet.

\subsection{Methoden zur subzellulären Lokalisierung eines Proteins}

\subsubsection{Immunzytochemische Färbung eukaryontischer Zellen}

Die etablierten PCa-Zellen und die Primärzellen wurden bis zu einer Konfluenz von 80 \% auf speziellen Objektträgern mit angehefteter Kulturflasche (FALCON culture slides, Becton Dickinson $\mathrm{GmbH}$, Heidelberg) in entsprechendem Kulturmedium kultiviert. Die adhärenten Zellen wurden einmal vorsichtig mit PBS gewaschen und in 3,7\% Formaldehyd in PBS für 20 min fixiert. Zur Permeabilisierung der Zellmembran wurden die Zellen für 15 min in 0,1\% Triton X-100 in PBS inkubiert. Nach kurzem Waschen der Zellen in PBS wurden diese für 30 min bei RT mit 3\% BSA in PBS zur Blockierung unspezifischer Bindungsstellen inkubiert. Anschließend erfolgten das Ablösen der angehefteten Kulturflasche von den Objektträgen und die Inkubation mit dem Primärantikörper in entsprechender Konzentration in 3\% BSA in PBS bei $4^{\circ} \mathrm{C}$ in einer feuchten Kammer für mindestens $12 \mathrm{~h}$. Nach der Inkubationszeit wurden die Zellen für $5 \mathrm{~min}$ in PBS gewaschen und mit dem jeweiligen Fluoreszenz-markierten Sekundärantikörper in entsprechender Verdünnung, sowie einem Antikörper zur Visualisierung des Zytoskeletts, mindestens $2 \mathrm{~h}$ bei RT inkubiert. Nach intensivem Waschen für mindestens 3 x 10 min in 1x PBS wurden die Präparate in Vectashield/DAPI eingedeckelt. Unter dem Floureszenzmikroskop (BX60, Olympus) wurden die immunzytochemischen Präparate mit dem analySIS-Programm CellF (soft imaging $\mathrm{GmbH}$ ) analysiert, fotografiert und bearbeitet. 
Tab. 2.2: Übersicht über die in der immunzytochemischen Analyse verwendeten AntikörperVerdünnungen

\begin{tabular}{lcc}
\hline \multicolumn{1}{c}{ Antikörper } & $\begin{array}{c}\text { Verdünnung } \\
\text { Primärantikörper }\end{array}$ & $\begin{array}{c}\text { Verdünn } \\
\text { Sekundärantik }\end{array}$ \\
\hline anti-B-Catenin & $1: 300$ & $1: 400$ \\
anti-Caldesmon & $1: 200$ & $1: 400$ \\
anti-cmyc & $1: 200$ & $1: 400$ \\
anti-Phospho-Tyrosin & $1: 500$ & $1: 500$ \\
anti-SV40 T-Ag & $1: 500$ & $1: 500$ \\
anti-p120CTN & $1: 300$ & $1: 400$ \\
FITC-Phalloidin & $1: 2000$ & -
\end{tabular}

\subsubsection{Subzelluläre Lokalisation von Fusionsproteinen}

Für die subzelluläre Lokalisation von LPXN und Caldesmon wurde jeweils der komplette offene Leserahmen in frame in den pEGFP-C1-Vektor kloniert (Clontech, Heidelberg). Dadurch entstand ein Fusionskonstrukt, bei dem LPXN [Kaulfuß, 2006] bzw. Caldesmon an den C-Terminus der EGFP-kodierenden Sequenz gekoppelt ist. PCa-Zellen wurden in 6-WellPlatten ausplattiert und gemäß 2.17.5 mit den Fusionskonstrukten transfiziert. Nach einer 24 stündigen Inkubation wurden die Zellen vom Boden des Wells abgelöst und 1x $10^{6}$ Zellen auf speziellen Objektträgern mit aufgesetzter Kulturflasche (FALCON culture slide) ausplattiert. Nach erneuter Kultivierung für $24 \mathrm{~h}$ wurden die Zellen vorsichtig mit PBS gewaschen und für 20 min in 3,7 \% Formaldehyd in PBS fixiert. Nach erneutem Waschen wurden die Zellen mit Vectashield/DAPI eingedeckelt und nach dem Trocknen unter einem Fluoreszenz-Mikroskop (BX60, Olympus) ausgewertet. Für die Kolokalisation von LPXN und Caldesmon wurde LPXN zunächst in einen Vektor kloniert, der einen cmyc Tag enthielt (pCMV-cmyc). Anschließend wurden die Zellen mit dem LPXN-cmyc- und dem Caldesmon-pEGFPFusionsprotein gemäß 2.17.5 transfiziert. Die Visualisierung des LPXN-cmycFusionsproteins erfolgte dann mittels Immunzytochemie mit einem cmyc-spezifischen Antikörper. 


\subsection{Histologische Techniken}

[mod. aus Beckemeyer, 2007]

Die folgenden histologischen Methoden erfolgten in Zusammenarbeit mit PD Dr. Stefan Schweyer (Abteilung Pathologie, Universitätsmedizin Göttingen).

\subsubsection{Fixierung des Gewebes}

Das frisch präparierte Material wurde direkt in Bouin'sches Fixativ gegeben und je nach Größe des Präparates für eine Stunde bis zu 2 Tagen bei RT fixiert. Mit Hilfe einer aufsteigenden Alkoholreihe (50\%, 70\%, 90\% und 96\%) wurde das Gewebe entwässert. Um das Ethanol vor der Einbettung in das Paraffin vollständig zu entfernen, wurde das Gewebe über Nacht in Methylbenzoat inkubiert. Für die Einbettung wurde das Paraffin im Wasserbad bei $58^{\circ} \mathrm{C}$ geschmolzen. Die Einbettung bestand aus mehreren Schritten, die sämtlich bei $58^{\circ} \mathrm{C}$ durchgeführt wurden. Für die Entfernung des Methylbenzoats wurde das Gewebe zweimal mit Benzol und zweimal in einem 1:1 Benzol/Paraffin-Gemisch jeweils für $1 \mathrm{~h}$ inkubiert. Zur vollständigen Durchdringung des Gewebes mit dem Paraffin wurde das Präparat anschließend zweimal für $1 \mathrm{~h}$ in Paraffin inkubiert. Im Anschluss daran wurde die auf $58^{\circ} \mathrm{C}$ temperierte Einbettungsform etwa zur Hälfte mit geschmolzenem Paraffin gefüllt, das Gewebe in die Form überführt und mit Paraffin aufgefüllt. Nach der Aushärtung über Nacht wurde der Paraffinblock aus der Form entnommen und bei $4{ }^{\circ} \mathrm{C}$ gelagert.

\subsubsection{Vorbehandlung der Objektträger}

Die Objektträger wurden $20 \mathrm{~min}$ in $0,1 \mathrm{M} \mathrm{HCl}$ gekocht und danach $2 \mathrm{x} 5 \mathrm{~min}$ in $\mathrm{H}_{2} \mathrm{O}$ gewaschen. Anschließend wurden die Objektträger für $30 \mathrm{~min}$ in $96 \%$ Ethanol gelegt, getrocknet und über Nacht in 1x Denhardt's Lösung inkubiert. Nach 20minütiger Fixierung in Ethanol/Eisessig (3:1) wurden die Objektträger in einer absteigenden Alkoholreihe (96\%, $70 \%, 50 \%, 30 \%$ Ethanol, je $5 \mathrm{~min}$ ) rehydriert und über Nacht bei $70^{\circ} \mathrm{C}$ in $1 \%$ Organosilan (pH 3.4) inkubiert. Schließlich wurden sie $5 x 5$ min in $\mathrm{H}_{2} \mathrm{O}$ gewaschen und über Nacht bei $100^{\circ} \mathrm{C}$ gebacken. In diesem Zustand können die beschichteten Objektträger bis zu sechs Monate aufbewahrt werden. Die Aktivierung der Objektträger erfolgte in 10\% Glutaraldehyd 
in PBS, pH 7.0, für 30 min. Anschließend wurden sie 5 min in $\mathrm{H}_{2} \mathrm{O}$ gewaschen, bevor die Aktivierung in 0,1 M Natrium-Perjodat 15 min unter dem Abzug stabilisiert wurde. Schließlich wurden die Objektträger $3 \mathrm{x}$ in PBS gewaschen und über Nacht bei $42^{\circ} \mathrm{C}$ getrocknet. Im aktivierten Zustand können die Objektträger mindestens 8 Wochen verwendet werden.

\subsubsection{Herstellung der Paraffinschnitte}

Die Paraffinblöcke mit dem fixierten Gewebe wurden zu Quadern geeigneter Größe zurechtgeschnitten und in das Mikrotom (JUNG RM 2035, Leica) eingespannt. Die Schnittdicke betrug 5-7 $\mu \mathrm{m}$. Mit Hilfe eines feinen Pinsels wurden die Schnitte auf $58^{\circ} \mathrm{C}$ warmes Wasser gelegt, mit einem Objektträger aufgenommen und getrocknet. Bis zur weiteren Verwendung wurden die Schnitte bei $4^{\circ} \mathrm{C}$ gelagert.

\subsubsection{Immunlokalisierung von Proteinen in Paraffingewebeschnitten}

Zunächst wurden die Schnitte 2x $10 \mathrm{~min}$ in Xylol deparaffiniert, in einer absteigenden Alkoholreihe (100\% Ethanol für 1x 5 min und 1x 2 min, 96\%, 70\% Ethanol für je 5 min) rehydriert und in $\mathrm{H}_{2} \mathrm{O}(5 \mathrm{~min})$ gespült. Die Gewebeschnitte wurden $45 \mathrm{~min}$ in einem Dampfgarer gekocht. Nach 20 min Abkühlzeit wurden sie für 5 min mit $\mathrm{H}_{2} \mathrm{O}$ gespült und kurz in $\mathrm{H}_{2} \mathrm{O}_{\text {dd }}$ getaucht. Die überschüssige Flüssigkeit wurde abgesaugt und unspezifische Bindungsstellen wurden 20 min mit 3\% $\mathrm{H}_{2} \mathrm{O}_{2}$ abgesättigt. Danach wurde erneut 5 min mit $\mathrm{H}_{2} \mathrm{O}$ gespült und die Gewebeschnitte kurz in $\mathrm{H}_{2} \mathrm{O}_{\text {dd }}$ und TBS getaucht. Anschließend wurde 20 min mit BSA geblockt. Auf das Präparat wurde der Primärantikörper (LPXN, Klon G, 1:500; SV40-Tag 1:400) gegeben und $2 \mathrm{~h}$ bei RT inkubiert. Unspezifische AntikörperBindungen wurden in TBS 3x 2 min abgewaschen. Der Zweitantikörper (HRP) wurde entsprechend den Firmenempfehlungen (DAKO EnVision) in TBS verdünnt. Nach 30 min Inkubation in einer feuchten Kammer wurden nicht gebundene Antikörper 3x 2 min in TBS ausgewaschen. Die DAB-Chromogen-Färbung erfolgte während einer Inkubationszeit von 15 min bei RT. Die Reaktion wurde mit TBS abgestoppt und die Gewebeschnitte anschließend 5 min in $\mathrm{H}_{2} \mathrm{O}$ gewaschen. Danach wurde 8 min mit Hämalaun gegengefärbt. Die Gewebeschnitte wurden für 10 min unter fließendem Leitungswasser gebläut und anschließend eingedeckelt. 


\subsection{Whole Genome Microarray}

Für eine genomweite Transkriptomanalyse an Prostatatumormaterial von doppelt transgenen LPXN/TRAMP-Mäusen und einfach transgenen TRAMP-Kontrollmäusen wurde eine whole genome Microarray-Analyse durchgeführt. Dafür wurde der GeneChip ${ }^{\circledR}$ ST Array (Maus) und der GeneChip ${ }^{\circledR}$ Whole Transcript (WT) Sense Target Labeling Assay der Firma Affymetrix (Santa Clara, USA) verwendet.

\subsubsection{Vorbereitung der Gewebeproben}

Die Transkriptom-Analyse erfolgte an Prostatatumoren, die eine definierte Größe (ca. $10 \mathrm{~mm}^{2}$ ) erreicht hatten. Das Wachstum der Prostatatumore der transgenen TRAMP/LPXN- und TRAMP-Mäuse wurde dazu durch regelmäßiges Abtasten der unteren Bauchregion eruiert. Bei Erreichen der definierten Größe wurden die Mäuse abgetötet, der Prostatatumor herauspräpariert und sofort in flüssigem Stickstoff eingefroren.

\subsubsection{Isolierung der RNA}

Für die RNA-Isolierung aus dem Prostatatumorgewebe wurde TRIzol der Firma Invitrogen (Karlsruhe) verwendet. TRIzol ist eine einphasige Lösung aus Phenol und GuanidinIsothiocyanat und hält während der Homogenisierung der Gewebeproben die RNA intakt, während es die Zellen zerstört und die Zellkomponenten löst. Um RNase-Kontaminationen zu verhindern, wurden vor Arbeitsbeginn alle Arbeitsutensilien sowie der Arbeitsplatz mit RNaseZAP $^{\circledR}$ (Sigma-Aldrich, Taufkirchen) gereinigt.

Jedes Gewebestückchen wurde mit $1 \mathrm{ml}$ TRIzol versetzt und mit einem Handhomogenisator homogenisiert. Nach einer Inkubationszeit von 5 min bei RT wurde die Suspension mit $200 \mu 1$ Chloroform versetzt und nach sorgfältigem Mischen für weitere $5 \mathrm{~min}$ inkubiert. Danach wurden die Proben zunächst bei $12000 \mathrm{x}$ g für $15 \mathrm{~min}$ bei $4^{\circ} \mathrm{C}$ zentrifugiert und anschließend die obere wässrige Phase in ein neues Eppendorf-Gefäß überführt. Für die Präzipitation der RNA wurden $500 \mu$ I Isopropanol und $1 \mu$ l GlycoBlue zur besseren Visualisierung der RNAPellets pro ml TRIzol zu den Proben gegeben. Nach sorgfältigem Mischen wurden die Proben bei $20^{\circ} \mathrm{C}$ für 30 min oder über Nacht inkubiert. Anschließend folgte ein Zentrifugationsschritt der Proben bei $12000 \mathrm{x}$ g für $30 \mathrm{~min}$ bei $4^{\circ} \mathrm{C}$. Das RNA-Pellet wurde dann einmal mit 
$75 \%$ igem Ethanol gewaschen und erneut bei 12000 x g für 5 min bei $4^{\circ} \mathrm{C}$ zentrifugiert. Nach einer Behandlung der Proben mit DNase I (nach Angaben des Herstellers) und anschließender Zentrifugation bei $12000 \mathrm{x}$ g für $30 \mathrm{~min}$ bei $4^{\circ} \mathrm{C}$ wurde der Überstand entfernt und das Pellet bei $37^{\circ} \mathrm{C}$ getrocknet. Danach wurde das Pellet in 50-100 $\mu$ RNAse-freiem $\mathrm{H}_{2} 0$ gelöst.

Zur Überprüfung der Quantität der isolierten RNA wurden $2 \mu 1$ jeder Probe mit Hilfe des Eukaryote Total RNA Nano Assays im Bioanalyser 2100 (Agilent, Waldbronn) analysiert. Die Überprüfung der Qualität der RNA erfolgte mit Hilfe eines Photometers (Nanodrop, Thermo Scientific, Wilmington, USA). Die Lagerung der RNA erfolgte bei $-80^{\circ} \mathrm{C}$.

\subsubsection{Labeling und Hybridisierung der Proben}

Alle Arbeitsschritte erfolgten nach Angaben des Herstellers. Abbildung 2.4 gibt einen schematischen Überblick über die durchgeführten Arbeitsschritte.

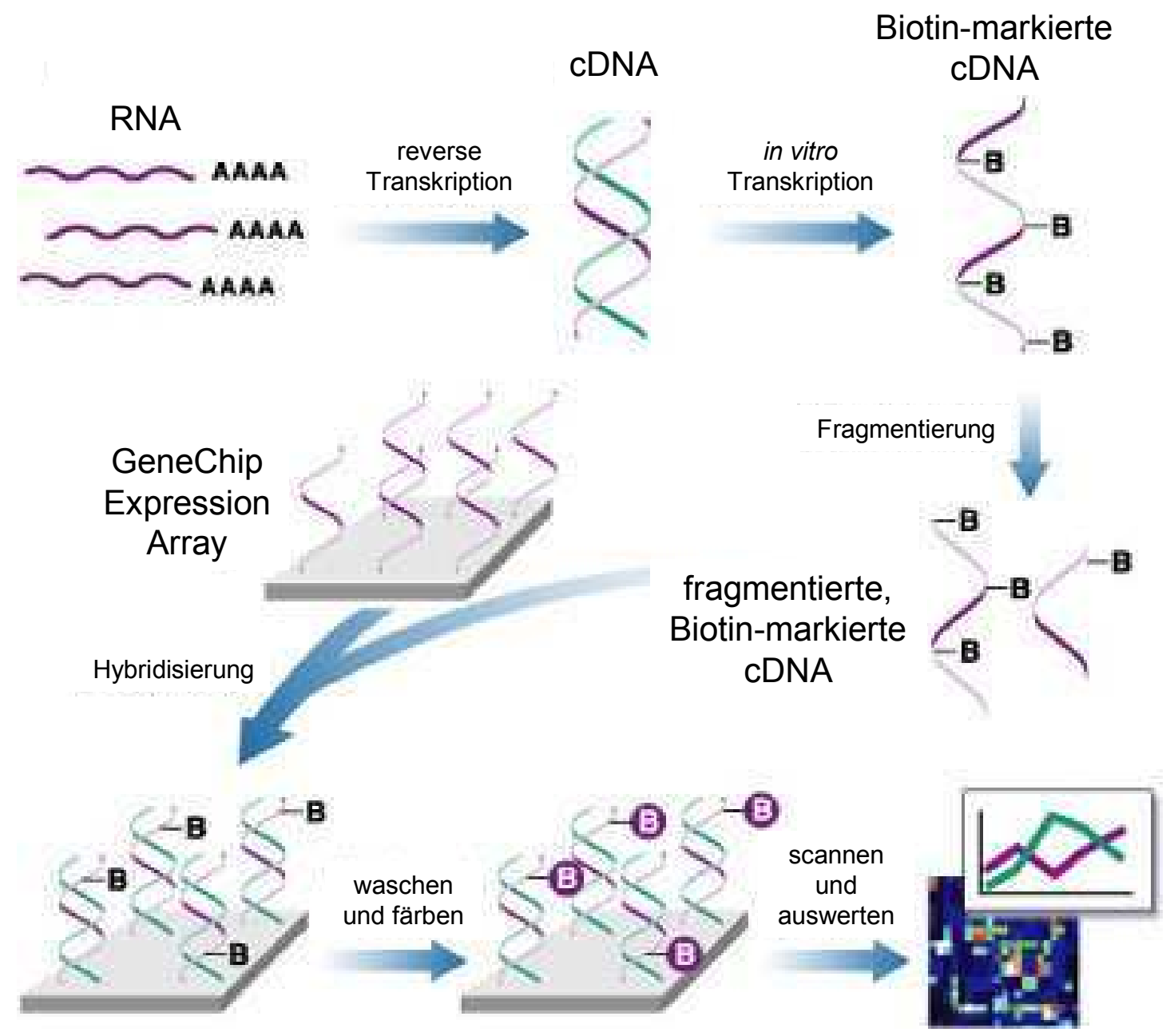


Abb. 2.4: Schematischer Überblick über die Durchführung des Microarray-Experiments. (mod. nach www. Dkfz.de) Durch die reverse Transkription wurde die RNA in cDNA umgeschrieben. Nach der Synthese der cRNA (hier nicht abgebildet) wurde die cDNA unter der Verwendung Biotin-markierter Basen (CTP und UTP) durch in vitro-Transkription synthetisiert. Anschließend folgte die Fragmentierung der cDNA und die Hybridisierung mit dem Gene Chip Expression Array. Nach dem Waschen des hybridisierten Arrays wurde dieser mit R-Phycoerythrin-markiertem Streptavidin gefärbt.

Nach der Synthese der Erststrang-cDNA wurde die Zweitstrang-cDNA synthetisiert. Anschließend folgte die Synthese und Aufreinigung der cRNA bevor eine weitere ErststrangcDNA-Synthese erfolgte. Die restliche cRNA wurde hydrolisiert und die einsträngige cDNA aufgereinigt. Danach wurde die einsträngige cDNA fragmentiert und mit Biotin markiert. Die Hybridisierung der Microarrays mit den jeweiligen gelabelten Proben erfolgte im Hybridisierungsofen (GeneChip ${ }^{\circledR}$ Hybridization Oven 640, Affymetrix, Santa Clara, USA) für $16 \mathrm{~h}$ bei $60 \mathrm{rpm}$ und $45^{\circ} \mathrm{C}$. Anschließend wurden die Microarrays in der GeneChip ${ }^{\circledR}$ Fluidics Station 450 (Affymetrix) gewaschen und mit Streptavidin R-Phycoerythrin (SAPE, Invitrogen, USA) gefärbt. Um das Signal zu amplifizieren wurde die SAPE-Lösung zweimal hinzugefügt. Zwischen den Färbeschritten wurde ein biotinylierter anti-Streptavidin Antikörper (Vector Laboratories, CA) hinzugegeben.

\subsubsection{Auswertung des Microarrays}

Die Auswertung des Microarrays erfolgte mit Hilfe des GeneChip ${ }^{\circledR}$ Scanner 3000 (Affymetrix). Die erhaltenen Daten wurden in Zusammenarbeit mit Herrn Lennart Opitz (Transkriptomanalyse-labor, Universitätsmedizin Göttingen) statistisch ausgewertet. Diese statistische Auswertung enthielt unter anderem den $\log \mathrm{FC}$-Wert (Logarithmus fold change), die FDR (false positive rate) und den $\rho$-Wert aller aufgespotteten fast 21000 Gene. Der FC wird berechnet aus dem Verhältnis des Mittelwerts der Genexpression der drei Tumore der LPXN/TRAMP-Mäuse zu dem Mittelwert der Genexpression der drei Tumore der TRAMPMäuse. Die FDR gibt an, mit welcher Wahrscheinlichkeit der $\log F C$ falsch positiv ist. Geordnet wurden die Gene nach der niedrigsten FDR. 


\subsection{Kinex $^{\mathrm{TM}}$ Antikörper-Array}

Die Untersuchung von PC-3-Zellen mit herunterregulierter LPXN-Expression auf deregulierte Proteine erfolgte in Zusammenarbeit mit der Firma Kinexus (Vancouver, Kanada). Dafür wurden PC-3-Zellen zunächst gemäß 2.22.2 mit siRNA gegen LPXN und als Kontrolle gegen Luciferase transfiziert. Anschließend erfolgte die Kultivierung der Zellen für $48 \mathrm{~h}$. Nach der Kultivierung wurden die Zellen 2x mit eiskaltem PBS gewaschen, in dem entsprechenden eiskalten Lysispuffer (siehe 2.6) lysiert und 4x für 10 sek sonifiziert. Anschließend wurde das Lysat für 30 min bei $4^{\circ} \mathrm{C}$ zentrifugiert und der Überstand in ein neues Eppendorf-Gefäß überführt. Mittels Western Blot-Analyse wurde das Protein auf die Herunterregulierung der LPXN-Expression überprüft. Die Transfektion und die anschließende Proteinisolierung wurden $3 \mathrm{x}$ wiederholt, überprüft und anschließend gepoolt. Der Versand erfolgte auf Trockeneis, das weitere Verfahren wurde vom Hersteller durchgeführt.

\subsection{GST-Pulldown}

Ein Experiment, um die Protein-Protein-Wechselwirkungen zwischen Proteinen nachzuweisen, stellt der GST (Gluthation-S-Transferase)-Pulldown dar. GST tritt natürlich mit einem Molekulargewicht von $26 \mathrm{kDa}$ auf und kann in E. coli exprimiert werden.

\subsubsection{Aufreinigung der Glutathionsepharose 4-Beads}

Da die GST-Sepharose in 20\% Ethanol geliefert wird, wurden jeweils $200 \mu 1$ der Sepharose zunächst mit $500 \mu 1$ PBS gewaschen und anschließend bei 500x g für 5 min zentrifugiert. Dieser Schritt wurde $3 \mathrm{x}$ wiederholt, bevor die Sepharose in DPBS aufgenommen wurde, so dass eine $50 \%$ ige Lösung entstand. 


\subsubsection{GST-Pulldown-Experiment zum Interaktionsnachweis von Caldesmon und LPXN}

Zum Nachweis der Interaktion von Caldesmon und LPXN wurden PC-3-Zellen zunächst wie unter 2.17.5 beschrieben mit pEGFP-Caldesmon transfiziert und das Gesamtprotein nach $48 \mathrm{~h}$ wie unter 2.15.1 beschrieben isoliert. Der pGEX-LPXN-, pGEX-LPXN-LIM-, pGEX-LPXNLD-, und als Kontrolle der pGEX-4T3-Leervektor wurden in E.coli BL21 pLys transformiert und anschließend überexprimiert. Dazu wurden die Bakterien zunächst in $50 \mathrm{ml} 2 \mathrm{x}$ YTMedium über Nacht bei $37^{\circ} \mathrm{C}$ angezogen. Anschließend wurden die Bakterien 1:25 verdünnt und bis zu einer $\mathrm{OD}_{600}=0,6$ bei $37^{\circ} \mathrm{C}$ unter Schütteln weiter inkubiert. Die Induktion der Proteinexpression erfolgte anschließend mit $1 \mathrm{mM}$ IPTG für $4 \mathrm{~h}$ bei RT. Anschließend wurden die Zellen abzentrifugiert und das Pellet in $1 \mathrm{ml}$ DPBS pro $50 \mathrm{ml}$ Bakterienpellet lysiert. Von nun an wurden alle Arbeitsschritte, sofern nicht anders angegeben, auf Eis durchgeführt. Nach dem Lysieren der Pellets wurde das Bakterienlysat 3 x 1 min sonifiziert und anschließend TritonX-100 bis zu einer Endkonzentration von 1\% hinzu gegeben. Nach 30 minütigem Schütteln wurde das Bakterienlysat bei 12000 x g für 10 min und $4^{\circ} \mathrm{C}$ abzentrifugiert. Der Überstand wurde anschließend in ein neues Eppendorf-Cup überführt. $200 \mu \mathrm{l}$ des Bakterienüberstandes, $40 \mu \mathrm{l}$ der aufgereinigten GST-Sepharose und $500 \mu \mathrm{g}$ des pEGFP-Caldesmon-Proteins wurden gemischt und für 45 min bei $4^{\circ} \mathrm{C}$ unter Schütteln inkubiert. Danach folgte ein Zentrifugationsschritt bei 13000 x g für $5 \mathrm{~min}$. Der Überstand wurde verworfen und die Sepharose-Beads 3 x mit $500 \mu$ Lysispuffer II (GlycerolLysispuffer) gewaschen. Nachfolgend wurden $40 \mu \mathrm{l}$ des LDS-Sample Puffers + 1 mM DTT $\mathrm{zu}$ den Beads gegeben und für $5 \mathrm{~min}$ bei $70^{\circ} \mathrm{C}$ erhitzt. Anschließend erfolgte eine erneute Abzentrifugation der Beads. Der Überstand wurde in ein neues Eppendorf-Cup überführt und auf Eis gelagert. Die Beads wurden aufbewahrt und wie unter 2.28 .3 beschrieben aufgereinigt. Für den anschließenden SDS-Gellauf wurden $20 \mu 1$ des Lysats eingesetzt. Die Western BlotAnalyse erfolgte mit einem anti-Caldesmon spezifischen Antikörper. 


\subsubsection{GST-Pulldown-Experiment zum Nachweis der LPXN-abhängigen Aktivierung von RhoA und Rac}

Zum Nachweis der LPXN-abhängigen Aktivierung von RhoA und Rac wurden für den GSTPulldown die Effektoren TRBD (Rhotekin-binding domain) und RBD (Rac-binding-domain) verwendet. Diese können nur von RhoA bzw. Rac gebunden werden, wenn sie aktiviert sind. PC-3-Zellen wurden zunächst wie unter 2.22.2 beschrieben mit siRNA gegen LPXN und als Kontrolle gegen Luciferase transfiziert und nach 48 h Gesamtprotein wie unter 2.15.1 beschrieben isoliert. Die E.coli BL21 pLys Bakterien, welche mit pGEX-4T1-PAK-RBD, pGEX-4T1-TRBD (2.8.6) bzw. dem pGEX-4T1-Leervektor (2.8.5) transformiert wurden, wurden zunächst in $50 \mathrm{ml} 2 \times$ YT-Medium über Nacht bei $37^{\circ} \mathrm{C}$ angezogen. Anschließend wurden die Bakterien 1:25 verdünnt und bis zu einer $\mathrm{OD}_{600}=0,6$ bei $37^{\circ} \mathrm{C}$ unter Schütteln weiter inkubiert. Die Induktion der Proteinexpression erfolgte anschließend mit $1 \mathrm{mM}$ IPTG für $4 \mathrm{~h}$ bei $37^{\circ} \mathrm{C}$. Anschließend wurden die Zellen abzentrifugiert und das Pellet in $1 \mathrm{ml}$ DPBS pro $50 \mathrm{ml}$ Bakterienpellet lysiert. Von nun an wurden alle Arbeitsschritte, sofern nicht anders angegeben, auf Eis durchgeführt. Nach dem Lysieren der Pellets wurde das Bakterienlysat 3 x 1 min sonifiziert und anschließend TritonX-100 bis zu einer Endkonzentration von 1\% hinzu gegeben. Nach 30minütigem Schütteln wurde das Bakterienlysat bei $12000 \mathrm{x}$ g für $10 \mathrm{~min}$ und $4^{\circ} \mathrm{C}$ abzentrifugiert. Der Überstand wurde anschließend in ein neues Eppendorf-Cup überführt. $200 \mu 1$ des Bakterienüberstandes, $40 \mu 1$ der aufgereinigten GST-Sepharose und $500 \mu \mathrm{g}$ des pEGFP-Caldesmon-Proteins wurden gemischt und für $45 \mathrm{~min}$ bei $4^{\circ} \mathrm{C}$ unter Schütteln inkubiert. Danach folgte ein Zentrifugationsschritt bei 13000 x g für 5 min. Der Überstand wurde verworfen und die Sepharose-Beads 3 x mit $500 \mu$ l Lysispuffer III (2.6). Nachfolgend wurden $40 \mu 1$ des LDSSample Puffers $+1 \mathrm{mM}$ DTT zu den Beads gegeben und für 5 min bei $70^{\circ} \mathrm{C}$ erhitzt. Anschließend erfolgte eine erneute Abzentrifugation der Beads. Der Überstand wurde in ein neues Eppendorf-Cup überführt und auf Eis gelagert. Die Beads wurden aufbewahrt und wie unter 2.27.5 beschrieben aufgereinigt. Für den anschließenden SDS-Gellauf wurden $20 \mu \mathrm{l}$ des Lysats eingesetzt. Die Western Blot-Analyse erfolgte mit einem anti-Caldesmon spezifischen Antikörper. 


\subsubsection{In vitro Aktivierung von RhoA und Rac durch GTP $\gamma \mathrm{S}$}

Als Positivkontrolle für das unter 2.27.3 beschriebene GST-Pulldown-Experiment wurde das PC-3-Zelllysat vor der Inkubation mit dem Bakterienüberstand und der GST-Sepharose einer Behandlung mit GTP $\gamma \mathrm{S}$ unterzogen. Dafür wurden $500 \mu \mathrm{l}$ des Zelllysats mit $10 \mu 10,5 \mathrm{M}$ EDTA, pH 8.0, (Endkonzentration $10 \mathrm{mM}$ ) gut gemischt. Anschließend wurden $5 \mu 110 \mathrm{mM}$ GTP $\gamma$ S (Endkonzentration $0.1 \mathrm{mM}$ ) zu dem Lysat gegeben, gevortext und für $15 \mathrm{~min}$ bei $30^{\circ} \mathrm{C}$ unter leichtem Schütteln inkubiert. Zum Abstoppen der Reaktion wurde das Lysat $32 \mu 1 \mathrm{M} \mathrm{MgCl} 2$ (Endkonzentration $60 \mathrm{mM}$ ) versetzt, gevortext und auf Eis gestellt.

\subsubsection{Regenerierung der Glutathionsepharose 4 Beads}

Zur Wiederverwendung der Glutathionsepharose 4 Beads wurden diese abwechselnd in einem basischen und einem sauren Puffer gewaschen. Zunächst erfolgte die Resuspension der Beads in 2 Vol des basischen Puffers ( $\mathrm{pH}$ 8.5: 0,1 M Tris HCL, 0,5 M NaCl). Nach Zentrifugation wurde der Überstand abgenommen und die Beads in 2 Vol. des sauren Puffers resuspendiert. ( $\mathrm{pH}$ 4.5: 0,1 M NaAc, 0,5 M NaCl). Nach erneuter Zentrifugation wurden die Schritte $4-5 \mathrm{x}$ wiederholt und die Beads anschließend in 3 - 5 Vol PBS aufgenommen. Die regenerierte Glutathionsepharose konnte bis zu 4 Wochen bei $4^{\circ} \mathrm{C}$ gelagert und verwendet werden.

\subsection{Kastration transgener Mäuse}

Eine Anzahl männlicher transgener LPXN/TRAMP-, TRAMP- und LPXN-Mäuse wurde im Alter von 8 Wochen unter sterilen Bedingungen kastriert. Dafür wurde den Mäusen zur Narkotisierung zunächst $65 \mathrm{mg} / \mathrm{kg}$ Ketamin und $13 \mathrm{mg} / \mathrm{kg}$ Xylazin (siehe 2.6) subkutan gespritzt. Anschließend wurde der Leistenkanal der Mäuse beidseits durch einen Längsschnitt geöffnet und der Samenstrang aufgesucht. Dieser wurde mit einem selbstauflösenden Faden abgeschnürt und anschließend mit einer feinen Schere durchtrennt. Der abgetrennte Hoden wurde entfernt. Nach Entfernung beider Hoden und Kontrolle auf Bluttrockenheit wurde der Leistenkanal mittels zweischichtiger Klammerung verschlossen. Die Wunde wurde anschließend mit einem Wundpuder versehen und die Mäuse zum Aufwachen auf einen $37^{\circ} \mathrm{C}$ warmen Wärmeblock gelegt. 


\section{Ergebnisse}

Während meiner Diplomarbeit konnten zur Analyse der Leupaxin (LPXN)-Funktion zwei verschiedene Linien doppelt transgener LPXN/TRAMP-Mäuse generiert werden (LPXN/TRAMP \#19, LPXN/TRAMP \#20). Diese sollten Erkenntnisse darüber geben, ob LPXN an der Progression von TRAMP-Prostatatumoren beteiligt ist. Als Kontrolle wurden einfach transgene TRAMP-Mäuse mit dem gleichen Hintergrund generiert. Während der Diplomarbeit konnten jedoch nur insgesamt neun Tiere der doppelt transgenen LPXN/TRAMP-Linie 19, acht Tiere der doppelt transgenen LPXN/TRAMP-Linie 20 und 21 Tiere der einfach transgenen TRAMP-Linie analysiert werden. Histopathologische Auswertungen deuteten bereits darauf hin, dass durch die Überexpression von LPXN die Progression der TRAMP-Tumore verstärkt ist [Beckemeyer, 2007].

Um eine signifikante Aussage über den Einfluss von LPXN auf die Progression von TRAMPProstatatumoren treffen zu können, war u.a. die weitere Analyse und Charakterisierung der doppelt transgenen LPXN/TRAMP-Mäuse Gegenstand der vorliegenden Arbeit.

\subsection{Einfluss von LPXN auf die Progression von Prostatakarzinomen in einem Mausmodel}

Um den Einfluss von LPXN auf das Progressionsverhalten von Prostatakarzinomen (PCa) in vivo signifikant zu bestimmen, wurden von jeder der drei Versuchstiergruppen (doppelt transgene LPXN/TRAMP-Mäuse Linie \#19, doppelt transgene LPXN/TRAMP-Mäuse Linie \#20, einfach transgene TRAMP-Kontrollmäuse) zu jedem Zeitpunkt (6, 10, 14, 18, 22, 26, 30 Wochen) mindestens acht Tiere präpariert. Von jedem Tier wurden zum Zeitpunkt der Präparation das Gewicht des Urogenitaltraktes sowie das Körpergewicht gemessen. Um die Morphologie der Prostatae zu analysieren, wurden diese direkt nach der Präparation in Formalin fixiert. Nach der Einbettung in Paraffin wurden Gewebeschnitte angefertigt und mit Hämatoxilin und Eosin (HE, siehe Material und Methoden 2.24) angefärbt. Zusätzlich zum Urogenitaltrakt wurden den Tieren Leber, Lunge, Niere, Milz und gegebenenfalls Lymphknoten entnommen und diese auf Metastasen hin untersucht. Diese Analysen wurden in Zusammenarbeit mit PD Dr. Stefan Schweyer (Abteilung Pathologie, Universitätsmedizin Göttingen) durchgeführt. 


\subsubsection{Analyse von doppelt transgenen LPXN/TRAMP-Mäusen}

\subsubsection{Endogenes LPXN spielt keine Rolle bei der Entwicklung des TRAMP-Tumors}

Immunhistochemische Analysen der Prostatae konnten bestätigen, dass die Expression des transgenen LPXN-cmyc ausschließlich in den Prostatae (normale Prostata und Prostatatumor) doppelt transgener LPXN/TRAMP-Mäuse zu detektieren ist. In den Prostatae einfach transgener TRAMP-Kontrollmäuse konnte keine LPXN-Expression detektiert werden. Dadurch kann ausgeschlossen werden, dass durch die Überexpression des SV40 large T- und small t-Antigens (T/t-Ag), die zur Entwicklung des TRAMP-Tumors führen, die Expression des endogenen LPXN beeinflusst wird (Abb. 3.1).

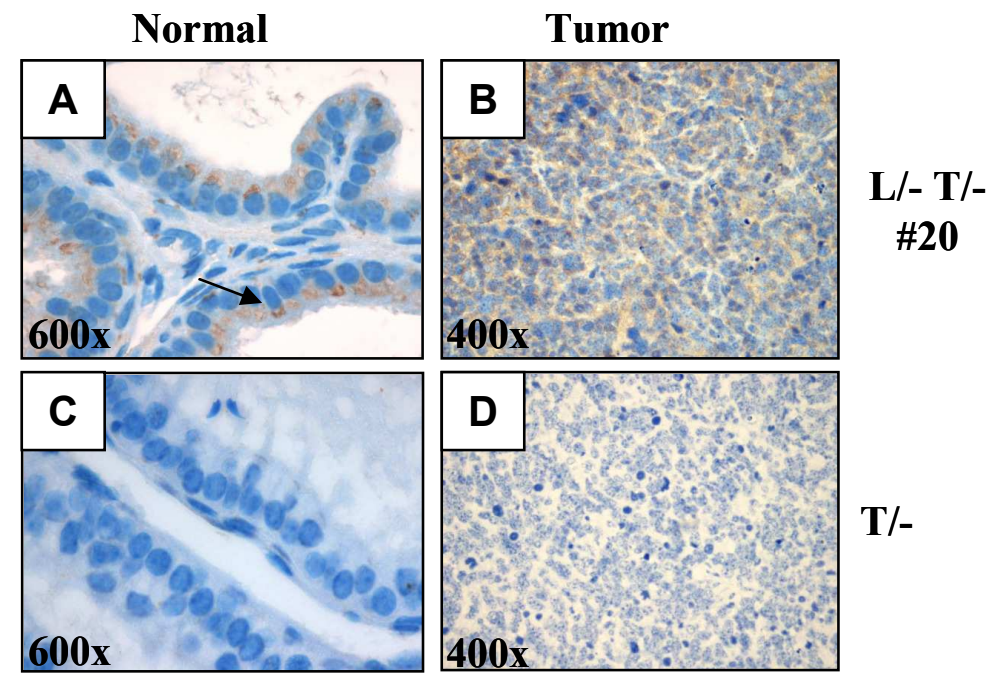

Abb. 3.1: Immunhistochemische Analyse zur Detektion von LPXN in den Gewebeschnitten der Prostata doppelt und einfach transgener Mäuse [mod. aus Kaulfuß et al., 2009]. Zur Detektion von LPXN in den Gewebeschnitten der Prostata von doppelt transgenen LPXN/TRAMP- (L/-T/-) und einfach transgenen TRAMP (T-)-Mäusen wurde eine immunhistochemische Analyse mit einem LPXN-Antikörper (283G) durchgeführt. Im Prostataepithel (A, 600fache Vergrößerung) und im Prostatatumor (B, 400fache Vergrößerung) doppelt transgener Mäuse (hier L/-T/- \#20) ist eine deutliche Anfärbung des LPXN-cmyc zu erkennen (A, Pfeil). Im Prostatagewebe einfach transgener TRAMP- (T/-) Mäuse ist sowohl im normalen Prostataepithel als auch im Prostatatumor keine LPXN-Expression zu detektieren (C, 600fache Vergrößerung und D, 400fache Vergrößerung). 


\subsubsection{Analyse der Tumormasse doppelt transgener LPXN/TRAMP- und einfach transgener TRAMP-Mäuse}

Zur Ermittlung der relativen Tumormasse der Versuchsmäuse wurde jeweils das Gewicht des Urogenitaltraktes (GU) zum Zeitpunkt der Präparation gegen das Körpergewicht aufgetragen. Die logarithmische Trendlinie der doppelt transgenen LPXN/TRAMP-Mäuse (L/-T/- \#19- und L/-T/- \#20) verläuft zu jedem Zeitpunkt oberhalb der Trendlinie der einfach transgenen TRAMP-Kontrollmäuse (T/-). Dies weist auf eine erhöhte Tumormasse und somit auf einen aggressiveren Verlauf des PCa durch die Überexpression von LPXN hin (Abb. 3.2).

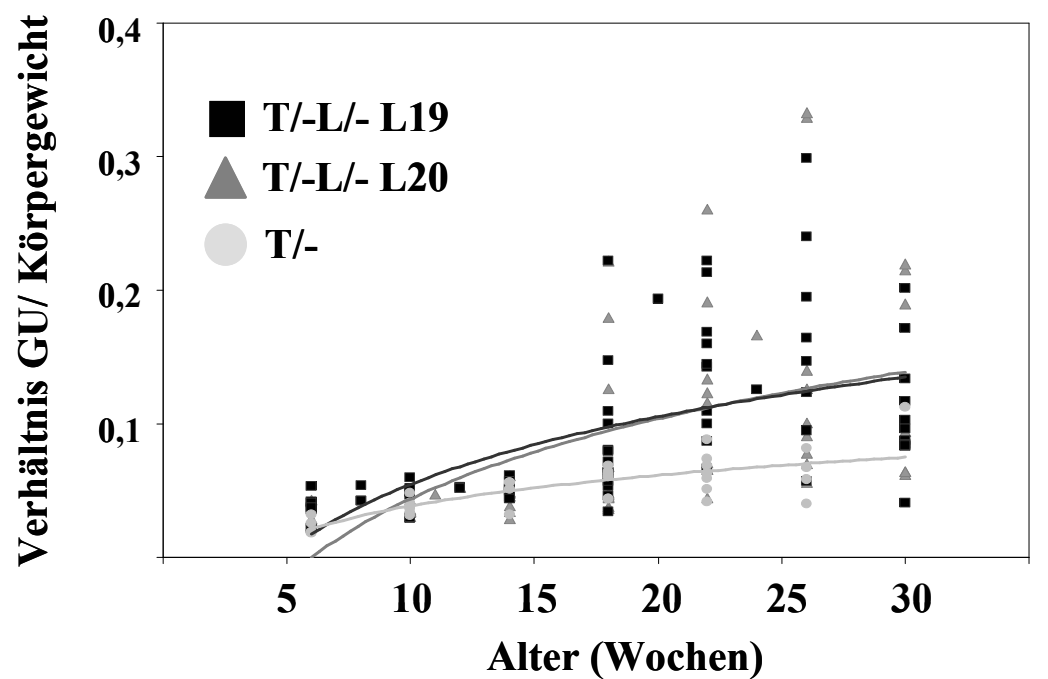

Abb. 3.2: Vergleich der relativen Tumormassen der doppelt transgenen LPXN/TRAMP- und einfach transgenen TRAMP-Mäuse [mod. aus Kaulfuß et al., 2009]. Von der sechsten Woche an, im Abstand von vier Wochen, wurden mindestens acht Mäuse jeder Versuchstiergruppe (L/-T/- \#19, L/-T/- \#20, T/-) abgetötet, der Urogenitaltrakt entnommen und gewogen. Die logarithmische Trendlinie aus dem Verhältnis von Urogenitaltraktgewicht (GU) zum Körpergewicht demonstriert zu allen Zeitpunkten eine signifikant höhere relative Tumormasse in beiden doppelt transgenen LPXN/TRAMP-Mauslinien im Vergleich zu den einfach transgenen TRAMP-Mäusen. 


\subsubsection{Analyse der Morphologie der Prostatae doppelt transgener LPXN/TRAMP- und einfach transgener TRAMP-Mäuse}

Zusätzlich zu der Tumormasse der Versuchsmäuse wurden weiterhin die Gewebeschnitte der Prostatae der doppelt (L/-T/-) und einfach (T/-) transgenen Mäuse histopathologisch analysiert. Die Morphologie der Prostatae wurde anschließend einem Stadium des progressiven PCa zugeordnet. Dabei wurden die Prostata intraepitheliale Neoplasie (PIN), das gut differenzierte Karzinom (WDC) und das schlecht differenzierte Karzinom (PDC) als verschiedene Stadien des PCa gewählt.

Im Alter zwischen 18 und 26 Wochen entwickelte die Mehrheit der doppelt transgenen LPXN/TRAMP-Mäuse beider Linien (L/-T/- \#19 und L/-T/- \#20) bereits ein PDC, während der am häufigsten auftretende Phänotyp bei den Kontrollmäusen (T/-) die PIN ist. Daher wurde in Abbildung 3.3 stellvertretend für die am häufigsten vorkommende morphologische Veränderung der Prostata in jeder Versuchtiergruppe und zu jedem der drei Zeitpunkte der Gewebeschnitt eines Tieres abgebildet. Die PIN bezeichnet ein Stadium, bei dem die Zellen des Prostataepithels beginnen zu entarten. Langgezogene, größere Zellkerne verwischen die sonst gleichmäßige Struktur nebeneinander angeordneter Zellen des Epithels. Weiterhin entsteht eine siebartige Form der Prostatadrüsen, wobei verstärkt Mitosen und Apoptosen zu erkennen sind (vergl. Abb. 3.3 G-I). Ein PDC zeichnet sich durch das Vorkommen von pleomorphen Zellen mit unregelmäßigen, großen Zellkernen und wenig Zytoplasma aus. Außerdem sind große nekrotische Areale und eine hohe Vaskularisation des Tumorgewebes bezeichnend für ein PDC. Die verbliebenen Drüsen sind meistens vollkommen vom Tumorgewebe eingeschlossen (vergl. Abb. 3.3 A-F). Als zusätzliche Kontrolle wurden, wie in Abbildung $3.3 \mathrm{zu}$ erkennen, Gewebeschnitte der Prostatae von einfach transgenen LPXNMäusen angefertigt. Diese zeigen keine morphologische Veränderung des Prostatagewebes (Abb. 3.3 J-L). Dadurch kann wiederum ausgeschlossen werden, dass LPXN an der Initiation des Prostatatumors beteiligt ist, sondern ausschließlich an der Progression. 


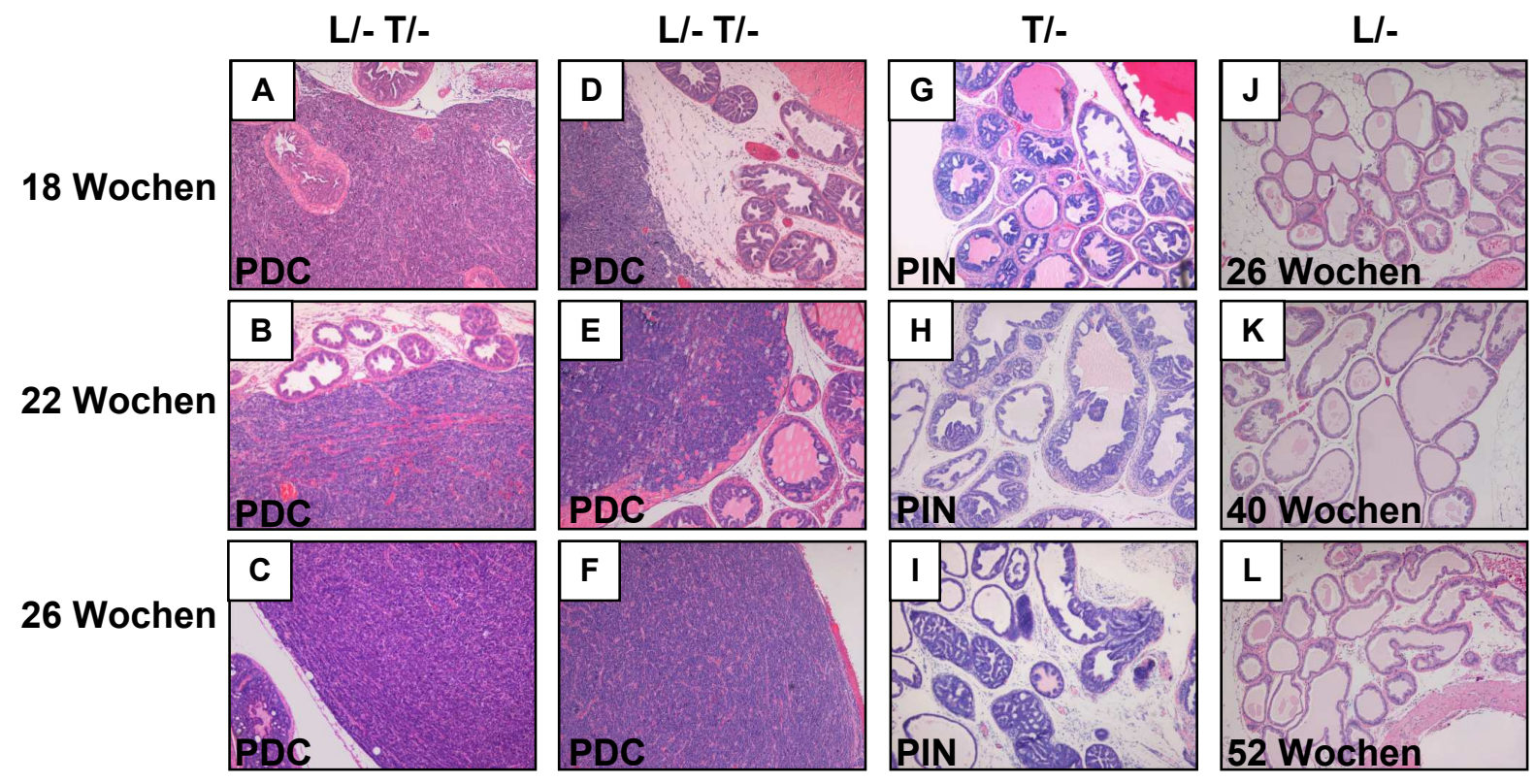

Abb. 3.3: Die Überexpression von LPXN resultiert in einer verstärkten Progression des TRAMP-Tumors [mod. aus Kaulfuß et al., 2009]. Histopathologische Analysen von mindestens acht Mäusen jeder Versuchstiergruppe (L/-T/- \#19, L/-T/- \#20, T/-) zu jedem angegebenen Zeitpunkt ergaben einen signifikanten Unterschied in der Tumorprogression von doppelt transgenen LPXN/TRAMP-Mäusen (L/-T/-) im Vergleich zu einfach transgenen TRAMP-Mäusen (T/-). Während bei den L/-T/- Mäusen im Alter von 18 bis 26 Wochen die am häufigsten auftretende morphologische Veränderung der Prostata das schlecht differenzierte Karzinom (PDC) war (A-F), konnte in den (T/-)-Kontrollmäusen am zahlreichsten das Anfangsstadium der Tumorentwicklung, die Prostata intraepitheliale Neoplasie (PIN), beobachtet werden (G-I). Transgene LPXN-Mäuse (L/-) entwickelten bis $\mathrm{zu}$ einem Alter von 52 Wochen keinen Prostatatumor (J-L). Alle Aufnahmen wurden mit einem Fluoreszenzmikroskop mit einer 40fachen Vergrößerung angefertigt.

In Abbildung 3.4 werden alle analysierten Mäuse mit Angabe des jeweiligen histologischen Befundes zusammengefasst. 56\% ( $\mathrm{n}=9$ ) der doppelt transgenen Mäuse der Linie \#19 bildeten im Alter von 18 Wochen ein PDC aus, während im Alter von 22 Wochen bereits 93\% aller untersuchten Mäuse dieser Versuchstiergruppe das Stadium des PDC aufwiesen. Zum Zeitpunkt von 26 Wochen konnte bei allen untersuchten doppelt transgenen Mäusen der Linie \#19 durch die verstärkte Expression von LPXN ausschließlich ein PDC festgestellt werden. Bei der Kontrollgruppe der einfach transgenen TRAMP-Mäuse war ein deutlich milderer Verlauf des PCa zu erkennen. Im Alter von 18 Wochen war nur bei 12,5\% der untersuchten Mäuse (n=1) ein PDC zu erkennen, während im Alter von 26 Wochen der Prozentsatz nur unwesentlich angestiegen war $(16 \%(n=2))$. Der am häufigsten beobachtete histologische Befund der Prostata in der (T/-)-Kontrollgruppe war zu jedem Zeitpunkt das Anfangsstadium der Tumorentwicklung, die PIN (Abb. 3.4). 
A

\begin{tabular}{|c|c|c|c|c|c|}
\hline 18 Wochen & Mäuse [n] & PIN [n (\%)] & WDC [n (\%)] & PDC [n (\%)] & Metastasen [n (\%)] \\
\hline $\mathrm{T} /-$ & 8 & $6(75 \%)$ & $1(12.5 \%)$ & $1(12.5 \%)$ & $\mathbf{0}$ \\
\hline L/- T/- \#19 & 16 & $6(38 \%)$ & $1(6 \%)$ & $9 \quad(56 \%)$ & $1(7 \%)$ \\
\hline L/- T/- \#20 & 12 & $4(33.5 \%)$ & $1(8 \%)$ & $7 \quad(58.5 \%)$ & $1(8 \%)$ \\
\hline \multicolumn{6}{|l|}{22 Wochen } \\
\hline $\mathrm{T} /-$ & 9 & $7(78 \%)$ & $1(11 \%)$ & $1(11 \%)$ & $\mathbf{0}$ \\
\hline L/- T/-\#19 & 14 & 0 & $1(7 \%)$ & $13(93 \%)$ & $6(43 \%)$ \\
\hline L/- T/- \#20 & 10 & $3(30 \%)$ & $\mathbf{0}$ & $7 \quad(70 \%)$ & $1(10 \%)$ \\
\hline \multicolumn{6}{|l|}{26 Wochen } \\
\hline T/- & 12 & $6(50 \%)$ & $3(25 \%)$ & $2(16 \%)$ & $1(8 \%)$ \\
\hline L/- T/- \#19 & 12 & 0 & $\mathbf{0}$ & $12(100 \%)$ & $6(50 \%)$ \\
\hline L/- T/- \#20 & 9 & $2(22 \%)$ & $1(11 \%)$ & $6(67 \%)$ & $5(55 \%)$ \\
\hline
\end{tabular}

B

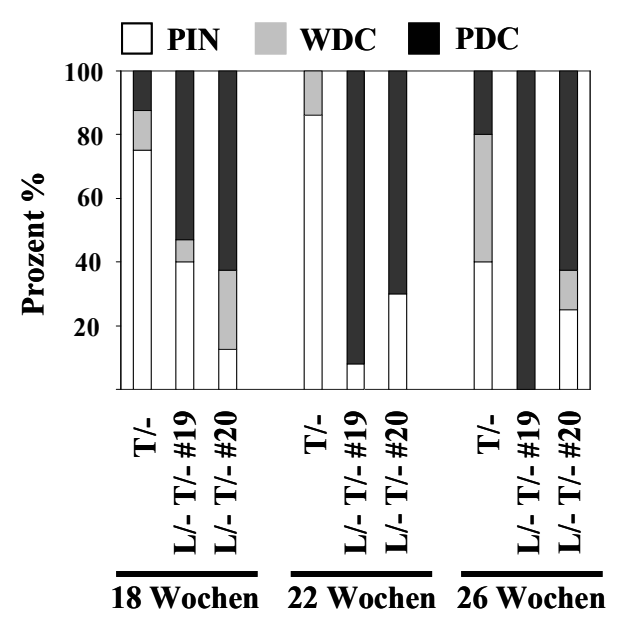

Abb. 3.4: LPXN verstärkt die Progression von TRAMP-Tumoren [mod. aus Kaulfuß et al., 2009]. A. Die morphologische Analyse der Prostatae doppelt transgener LPXN/TRAMP-Mäuse zweier Linien (L/-T/- \#19, L/-T/- \#20) im Vergleich zu den Prostatae einfach transgener TRAMP-Mäuse (T/-) an Hand von Gewebeschnitten zeigt einen deutlich aggressiveren Verlauf des Prostatatumors in den Mäusen mit erhöhter LPXN-Expression. Die Einteilung der Progressionsstadien des Tumors erfolgte in Prostata intraepitheliale Neoplasie (PIN), gut differenziertes Karzinom (WDC) und schlecht differenziertes Karzinom (PDC). B. Der grafische Überblick betont den erhöhten Anteil schlecht differenzierter Karzinome in den doppelt transgenen LPXN/TRAMP-Mäusen im Vergleich zu den einfach transgenen TRAMP-Mäusen durch die Überexpression von LPXN. 


\subsubsection{Analyse zur Bildung von Fernmetastasen in doppelt transgenen LPXN/TRAMP- und einfach transgenen TRAMP-Mäusen}

Um den Einfluss von LPXN auf die Entwicklung von Metastasen im TRAMP-Prostatatumor $\mathrm{zu}$ untersuchen, wurden Gewebeschnitte von verschiedenen Organen doppelt transgener LPXN/TRAMP- und einfach transgener TRAMP-Mäuse angefertigt, mit HE gefärbt und analysiert (Material und Methoden, 2.24). Es konnte festgestellt werden, dass zu allen untersuchten Zeitpunkten die Bildung von Metastasen in Leber, Lunge oder Lymphknoten in den doppelt transgenen LPXN/TRAMP-Mäusen im Vergleich zu den Kontrollmäusen stark erhöht war. Im Alter von 26 Wochen entwickelten 40\% der LPXN/TRAMP-Mäuse der Linie 19 (L-T- \#19) und 55\% der LPXN/TRAMP-Mäuse der Linie 20 (L-T- \#20) Fernmetastasen, während in den TRAMP-Mäusen (T-) zum gleichen Zeitpunkt nur bei 10\% der untersuchten Tiere Metastasen detektiert werden konnten (vergl. Abb. 3.4 und Abb. 3.5).

L/- T/-

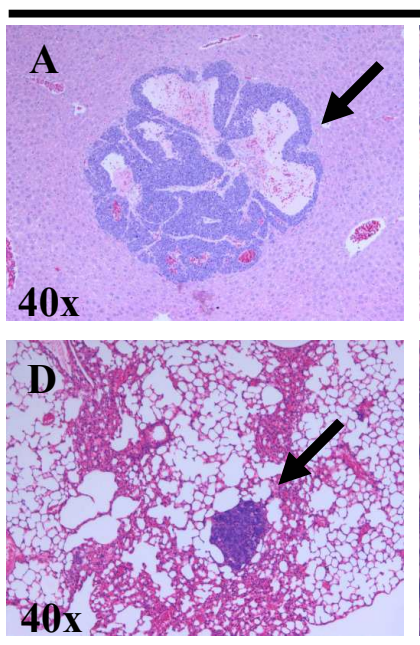

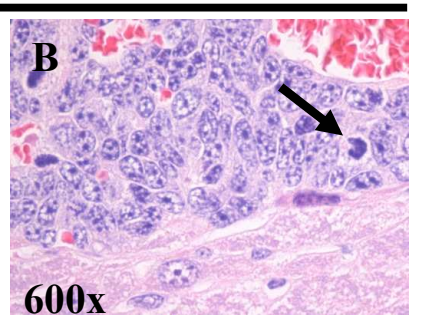

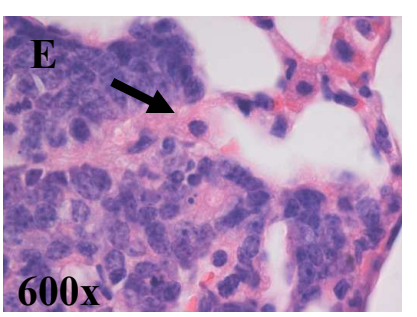

T-

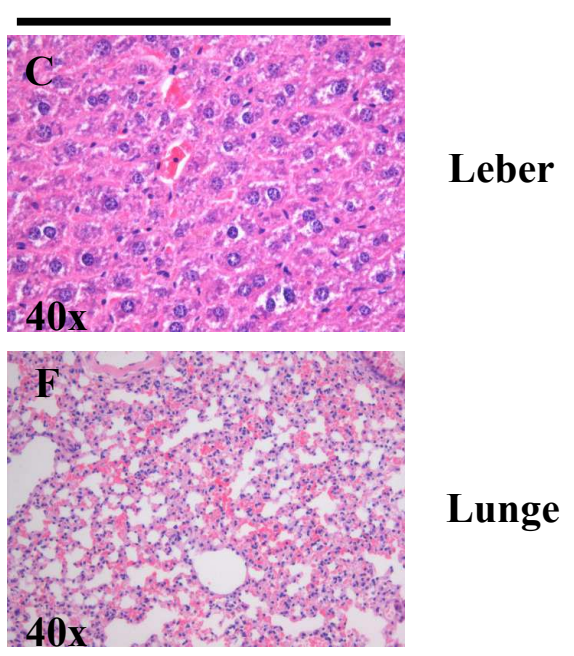

Abb. 3.5: LPXN verstärkt die Bildung von Fernmetastasen beim TRAMP-Prostatatumor [mod. aus Kaulfuß et al., 2009]. Zur Analyse der Bildung von Metastasen wurden Gewebeschnitte von Lymphknoten, Leber, Lunge, Niere und Milz doppelt (L/-T/-) und einfach transgener (T/-) Mäuse angefertigt, mit HE gefärbt und analysiert. Mehr als 50\% der 26 Wochen alten doppelt transgenen L/-T/- Mäuse entwickelten Fernmetastasen in Lymphknoten, Leber oder Lunge $(\mathrm{A}+\mathrm{B}, \mathrm{D}+\mathrm{E})$, während bei den einfach transgenen T/- Mäusen bei weniger als 10\% Metastasen detektiert werden konnten $(\mathrm{C}+\mathrm{F})$. Bei 600facher Vergrößerung der Leber- und Lungenmetastase sind deutlich die typischen Mitosen im Tumorgewebe zu erkennen (B + E, Pfeile). 
Weiterhin wurden zur Überprüfung der Metastasen immunhistochemische Analysen mit einem SV40 T-Ag spezifischen Antikörper durchgeführt (Material und Methoden, 2.24). Stammen die Metastasen vom Prostata-Primärtumor ab, muss das SV40T/t Ag, welches transgen in der Prostata von TRAMP-Tumoren überexprimiert wird, auch in den Metastasen detektiert werden können. Dafür wurden Gewebeschnitte der präparierten Organe angefertigt und diese mit einem SV40 T-Ag-Antikörper behandelt. Wie in Abbildung $3.6 \mathrm{zu}$ erkennen, exprimieren auch die Metastasen (hier Lymphknoten) das SV40 T/t-Ag (A + B). Als Positivkontrolle wurde ein Gewebeschnitt eines Prostatatumors dargestellt, als Negativkontrolle ein Gewebeschnitt des Nebenhodens. Dieses Gewebe zeigt keine spezifische SV40 T-Ag Kernfärbung (E + F).
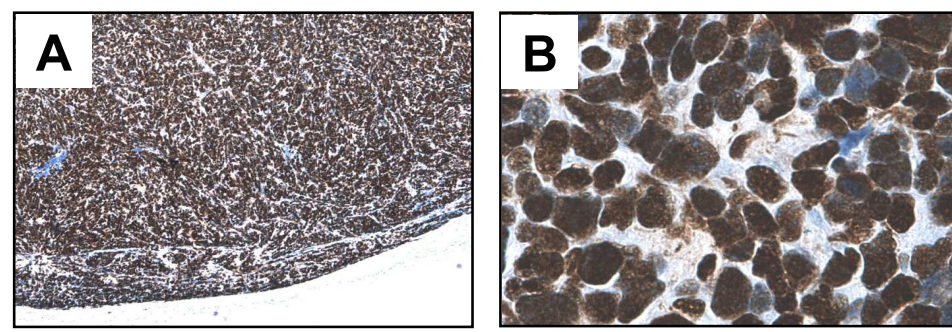

\section{Lymphknoten}
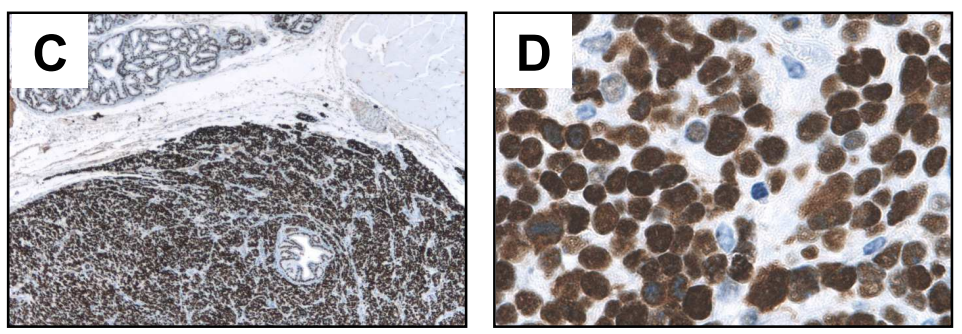

Prostata
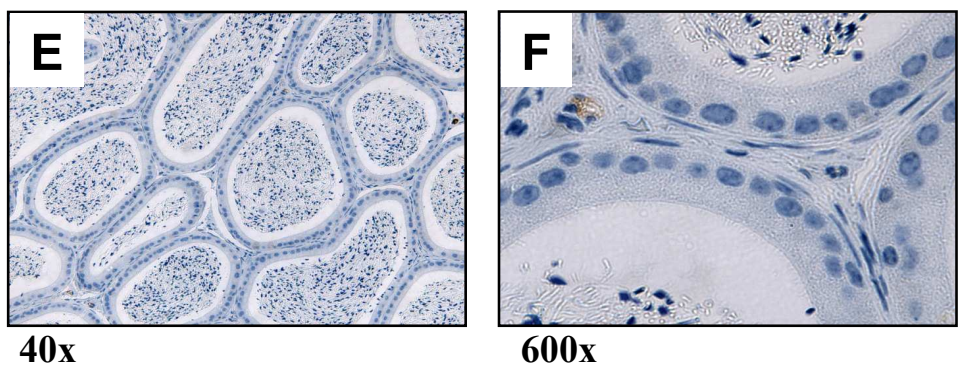

\section{Nebenhoden}

Abb. 3.6: Immunhistochemische Analyse zur Expression des transgenen SV40 T-Ag in Metastasen von doppelt transgenen LPXN/TRAMP-Mäusen. Zur Überprüfung, ob die gebildeten Metastasen in den Organen der doppelt und einfach transgenen TRAMP-Mäuse vom transgenen Prostata-Primärtumor abstammen, wurde eine immunhistochemische Analyse mit einem SV40 T-Ag-spezifischen Antikörper durchgeführt. Dazu wurden die Organe sowie der Urogenitaltrakt der Mäuse präpariert, in Formalin fixiert und in Paraffin eingebettet. Die Gewebeschnitte wurden dann mit einem SV40 T-Ag-Antikörper behandelt. In den Lymphknotenmetastasen der LPXN/TRAMP-Mäuse können starke Signale für SV40 T-Ag in den Zellkernen detektiert werden (A. 40fache Vergrößerung, B. Ausschnitt aus A, 600 fache Vergrößerung). Als Positivkontrolle, und um nachzuweisen, dass das SV40 T-Ag-Transgen in dem Prostatatumor stabil ist, wurde eine SV40 T-Ag-Färbung an Prostatagewebe durchgeführt. In den Ausschnitten C (40fache Vergrößerung) und D (600fache Vergrößerung) ist deutlich zu 
erkennen, dass die Expression von SV40 T-Ag im Prostatatumor vorhanden ist. Ausschnitt E (40fache Vergrößerung) und Ausschnitt F (600fache Vergrößerung) zeigen in der Negativkontrolle, dass die Expression von SV40 T-Ag nicht im Nebenhoden zu detektieren ist und somit ausschließlich auf die Prostata und die aus dem Tumor stammenden metastasierenden Zellen beschränkt ist.

\subsubsection{LPXN erhöht die Progression von Prostatakarzinomen in kastrierten TRAMP-Mäusen}

Bei der Progression des Prostatakarzinoms nimmt der Androgenrezeptor (AR) eine bedeutende Stellung ein [Heinlein und Chang, 2004]. Dabei wird beschrieben, dass vor allem eine erhöhte AR-Aktivität die Entwicklung vom androgen-abhängigen zum androgen-unabhängigen Rezidiv fördert. Dieses androgen-unabhängige Stadium ist ebenfalls Ergebnis und Problem der humanen Antiandrogen-Therapie.

Kaulfuss et al. konnten 2008 zeigen, dass LPXN in vitro mit dem Androgenrezeptor sowohl interagiert als auch dessen transkriptionelle Aktivität erhöht. Deswegen wurde im Rahmen dieser Arbeit untersucht, ob LPXN auch in die Progression androgen-unabhängiger Prostatatumore involviert ist, z.B. durch die Koaktivierung des AR.

Um das Tumorwachstum nach Androgen-Unterdrückung in vivo zu imitieren, wurden die Versuchsmäuse einer Kastration unterzogen (Material und Methoden, 2.28). Das operative Entfernen der Testes resultierte in einem vollkommenen Androgenentzug (siehe 3.1.2.1). Jeweils 20 Tiere doppelt transgener LPXN/TRAMP-Mäuse der Linie \#19, einfach transgener TRAMPKontrollmäuse sowie einfach transgener LPXN-Mäuse wurden im Alter von acht Wochen kastriert. In der Folgezeit wurden die Größe der Prostatatumore durch wöchentliches Abtasten der unteren Bauchregion und der Gesundheitszustand der Tiere beobachtet. Kachektische Tiere oder Tiere mit einer Tumorgröße von ca. $1500-2000 \mathrm{~mm}^{3}$ wurden abgetötet und die Prostata, Leber, Lunge, Niere, Milz und gegebenenfalls die Lymphknoten herauspräpariert und in Formalin fixiert (Abb. 3.7). Nach der Einbettung in Paraffin wurden die Gewebeschnitte histopathologisch in Zusammenarbeit mit PD Dr. Stefan Schweyer (Universitätsmedizin Göttingen, Abteilung Pathologie) analysiert. 

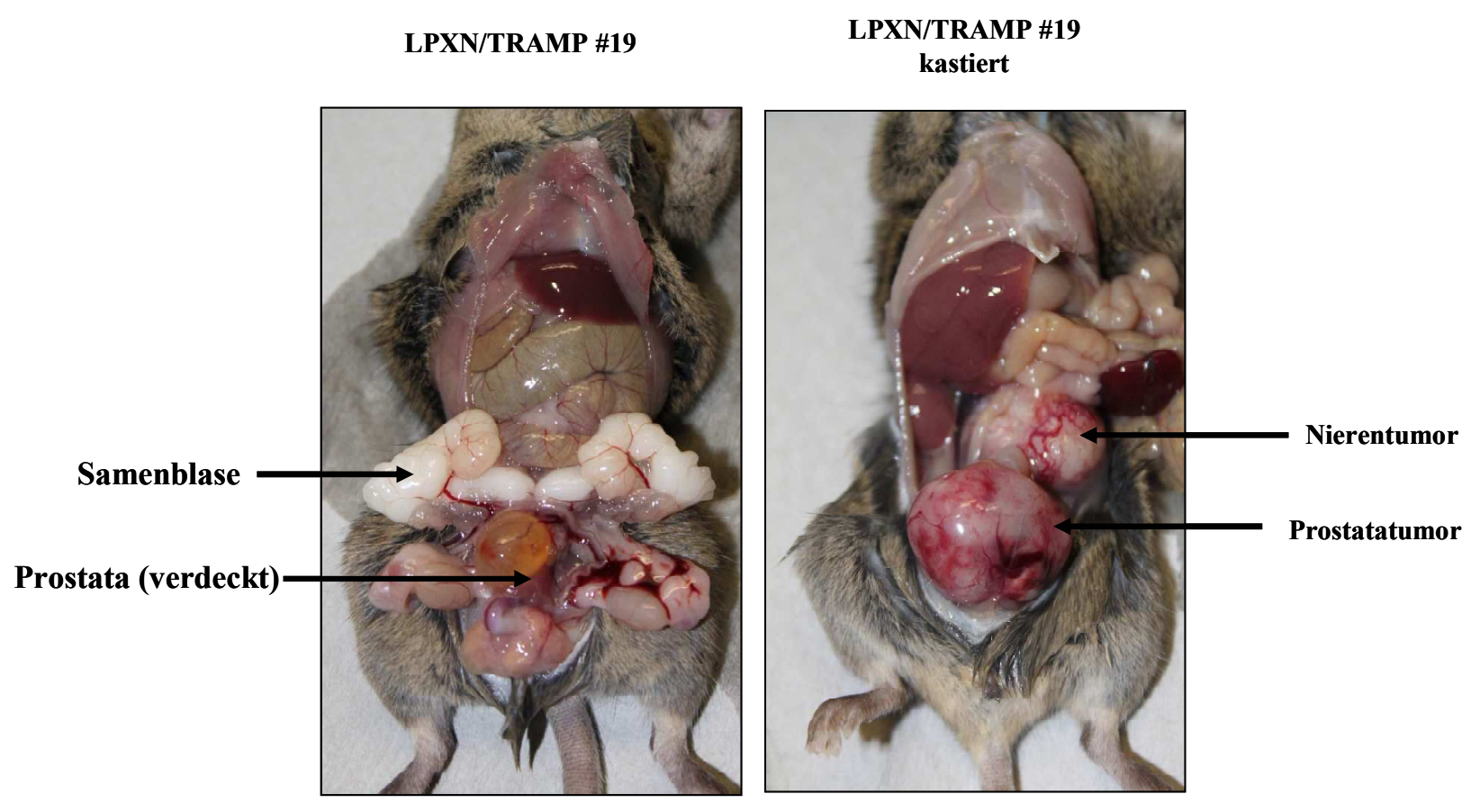

Abb. 3.7: Präparation von kastrierten doppelt transgenen LPXN/TRAMP-Mäusen. Bei der Kastration der Tiere werden die Testes operativ entfernt. Der dadurch entstehende Androgenentzug resultiert in einer Verkümmerung der Samenblasen (vergl. LPXN/TRAMP \#19 und LPXN/TRAMP \#19 kastriert). Tiere mit einem Tumorvolumen von ca. $1500-200 \mathrm{~mm}^{3}$ wurden unabhängig vom Alter abgetötet (LPXN/TRAMP \#19 kastriert). Prostata, Leber, Lunge, Niere, Milz und gegebenenfalls Lymphknoten wurden herauspräpariert und in Formalin fixiert. Anschließend wurden zur Analyse der Morphologie von allen Organen Gewebeschnitte angefertigt.

\subsubsection{1 Überprüfung der Expression des transgenen SV40 T-Ag in den kastrierten Mäusen als Indiz für den Erfolg der Kastration}

Bei der Präparation der Mäuse wurde von allen Organen Gewebestücke für RNA- und Proteinisolierungen konserviert. Nach der Isolierung des Gesamt-Proteins wurde eine Western Blot-Analyse mit einem SV40 T-Ag-spezifischen Antikörper durchgeführt. SV40 T-Ag und LPXN stehen unter der Kontrolle des AR-abhängigen Probasin-Promotors der Ratte. Eine erfolgreiche Kastration und damit ein Entzug der Androgene sollte in einem Verlust der Expression des SV40 T-Ag (und LPXN) resultieren. Die Western Blot-Analyse zeigt, dass, wie erwartet, vier Tage nach der Kastration die Expressionsstärke des SV40 T-Ag zurückging. Vier Wochen nach der Kastration konnte jedoch wieder eine SV40 T-Ag-Expression detektiert 
werden. Im Prostatatumor, vier Monate nach der Kastration, konnte ebenfalls SV40 T-Ag nachgewiesen werden. Als Kontrolle der aufgetragenen Proteinmenge wurde ein Antikörper gegen HSC70 verwendet (Abb. 3.8).

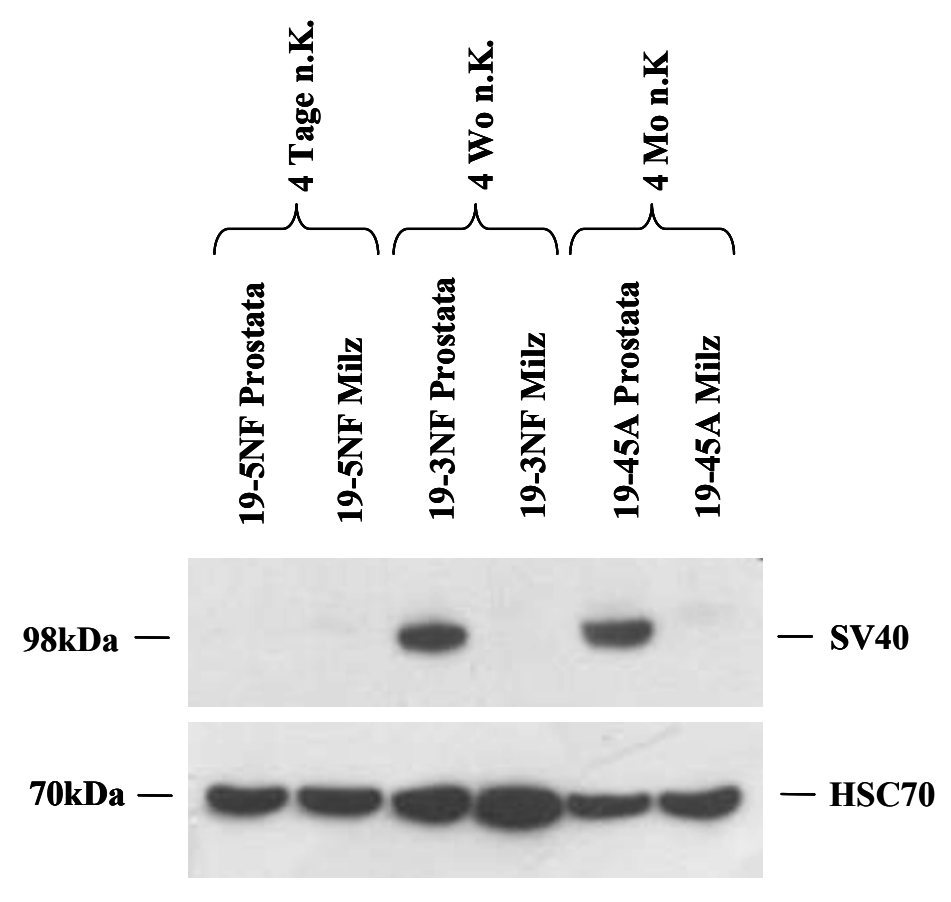

Abb. 3.8: Western Blot-Analyse zur Expression des SV40 T-Ag in den Prostatae kastrierter LPXN/TRAMPMäuse. Doppelt transgene LPXN/TRAMP-Mäuse wurden vier Tage (19-5NF), vier Wochen (19-3NF) und vier Monate (19-45A) nach der Kastration abgetötet und die Prostatae herauspräpariert. Anschließend wurde aus den Prostatageweben Gesamt-Protein isoliert und $50 \mu \mathrm{g}$ für eine Western Blot-Analyse eingesetzt. Die Detektion des SV40 T-Ag erfolgte mit einem SV40 T-Ag-Antikörper, der bei der für SV40 T-Ag erwarteten Größe von 98 kDa eine spezifische Bande darstellt. Zur Kontrolle der aufgetragenen Proteinmenge wurde ein Antikörper gegen HSC70 verwendet. Vier Wochen sowie vier Monate nach der Kastration konnte die Expression von SV40 T-Ag in den Prostatae der doppelt transgenen LPXN/TRAMP-Mäuse 19-3NF und 19-45A nachgewiesen werden. Wie erwartet, geht die Expression des SV40 T-Ag direkt nach der Kastration zunächst zurück (19-5NF).

\subsubsection{Analyse der Tumorentwicklung in kastrierten doppelt transgenen LPXN/TRAMP-Mäusen}

Die kastrierten doppelt (L/-T/-) und einfach (T/-) transgenen Versuchstiere wurden erst präpariert, wenn sich ihr Gesundheitszustand verschlechterte oder wenn der Prostatatumor eine definierte Größe erreicht hatte. Das Alter der Tiere zum Zeitpunkt der Präparation wurde notiert und daraus eine Kaplan-Meier-Überlebenskurve erstellt. Es kann festgestellt werden, dass in den 
doppelt transgenen LPXN/TRAMP-Mäusen mit einer durchschnittlichen Überlebensdauer von 18,7 Wochen ein noch aggressiverer Verlauf der Tumorprogression stattfindet. Die einfach transgenen TRAMP-Mäuse erreichten ein durchschnittliches Lebensalter von 20,6 Wochen (Abb. 3.9). Durch die Untersuchung der Gewebeschnitte wurde die Bildung von Metastasen in den entnommenen Organen beobachtet. In 64\% der untersuchten doppelt transgenen LPXN/TRAMP- und einfach transgenen TRAMP-Mäuse konnten Metastasen in Lunge, Leber, Niere oder Lymphknoten detektiert werden (Abb. 3.9 und Abb. 3.10). Da es durch Infektionen der doppelt transgenen LPXN/TRAMP-Mäuse \#20 zu einer Verminderung der kastrationsfähigen Tiere kam, konnte bis zum jetzigen Zeitpunkt diese Linie nicht mit in die Statistik einfließen. Als Kontrolltiere wurden die Mäuse der einfach transgenen LPXN-Linie kastriert und im Alter von 56 Wochen abgetötet. Bis dato deuten die Ergebnisse darauf hin, dass durch den Androgenentzug die Tumorprogression, einschließlich der Bildung von Metastasen, sowohl in den doppelt transgenen LPXN/TRAMP- als auch in den einfach transgenen TRAMPMäusen beschleunigt ist. In den doppelt transgenen LPXN/TRAMP-Mäusen verläuft dennoch die Tumorprogression durch die Überexpression von LPXN aggressiver.

\section{Kumulative Überlebensfunktion}

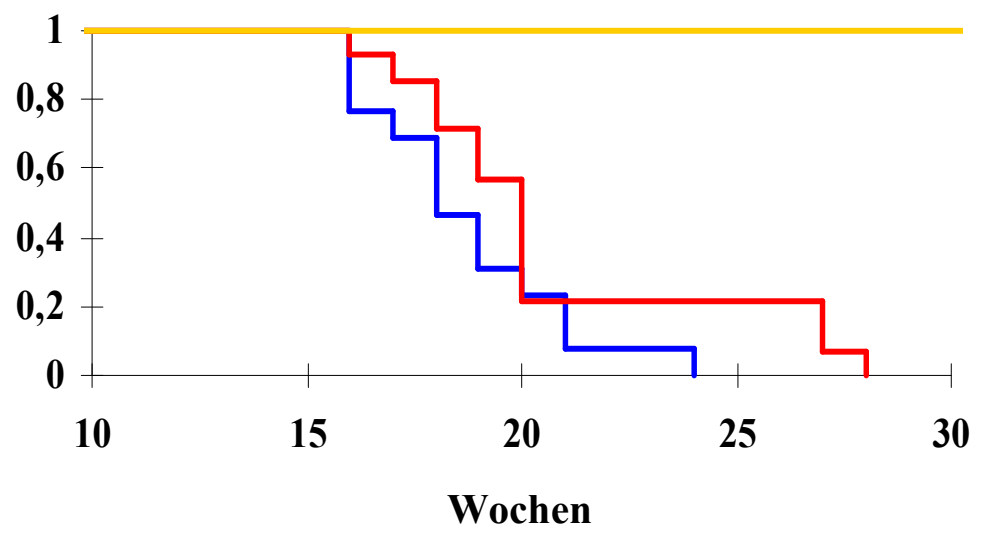

$-\mathbf{L} /-\mathbf{T} /--\mathbf{T} /--\mathbf{L} /-$

\begin{tabular}{|l|c|c|c|c|c|c|}
\hline & $\begin{array}{c}\text { Anzahl } \\
\text { der Tiere }\end{array}$ & $\begin{array}{c}\text { Mittlere } \\
\text { Ubberlebensdauer }\end{array}$ & $\begin{array}{c}\text { Standard- } \\
\text { abweichung }\end{array}$ & $\begin{array}{c}\text { Untergrenze } \\
\mathbf{( 9 5 \% )}\end{array}$ & $\begin{array}{c}\text { Obergrenze } \\
\mathbf{( 9 5 \% )}\end{array}$ & Metastasen \\
\hline L/-T/- & 14 & 18,7 & 0,654 & 17,4 & 20,0 & $64 \%$ \\
\hline T/- & 14 & 20,6 & 1,025 & 18,6 & 22,6 & $64 \%$ \\
\hline L/- & 10 & 56,0 & & & & $0 \%$ \\
\hline
\end{tabular}


Abb. 3.9: Kaplan-Meier-Kurve zur statistischen Analyse der Überlebensrate doppelt transgener LPXN/TRAMP- und einfach transgener TRAMP-Mäuse nach Kastration. Die kumulative Überlebensfunktion der doppelt transgenen LPXN/TRAMP- (L/-T/-), einfach transgenen TRAMP- (T/-) und einfach transgenen LPXN(L/-) Mäuse zeigt, dass die Kurve der L/-T/- Mäuse (blau) zu jedem Zeitpunkt vor der Kurve der T/- Kontrollmäuse liegt. Während die mittlere Überlebensdauer der L/-T/- Mäuse bei 18,7 Wochen liegt, ist das durchschnittlich erreichte Alter der T/- Mäuse 20,6 Wochen. Die L/- Kontrollmäuse, welche keinen Prostatatumor entwickeln, wurden im Alter von 56 Wochen abgetötet. In 64\% der L/-T/- und T/- Mäuse konnten Metastasen in Lunge, Leber oder Lymphknoten detektiert werden.

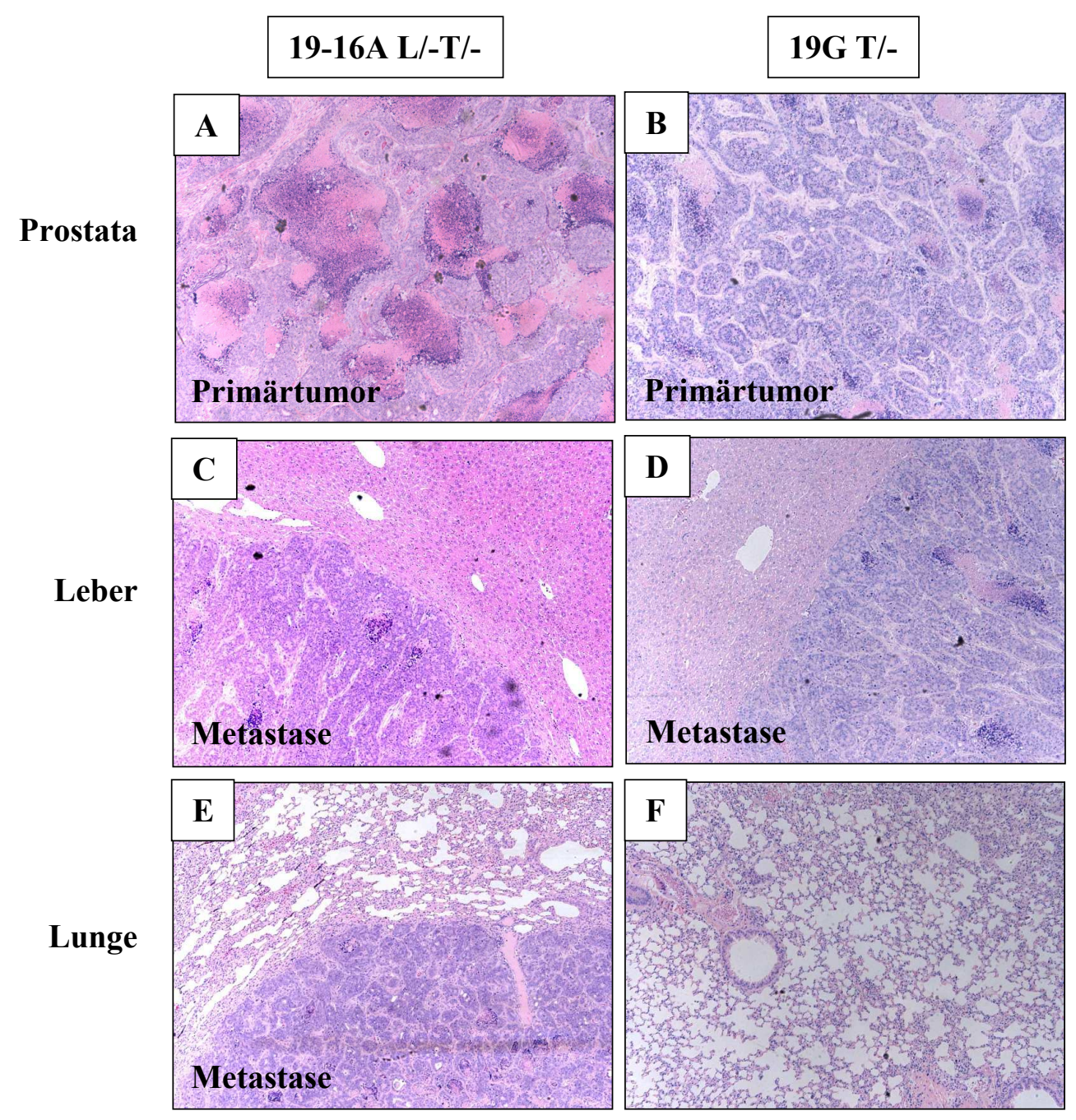




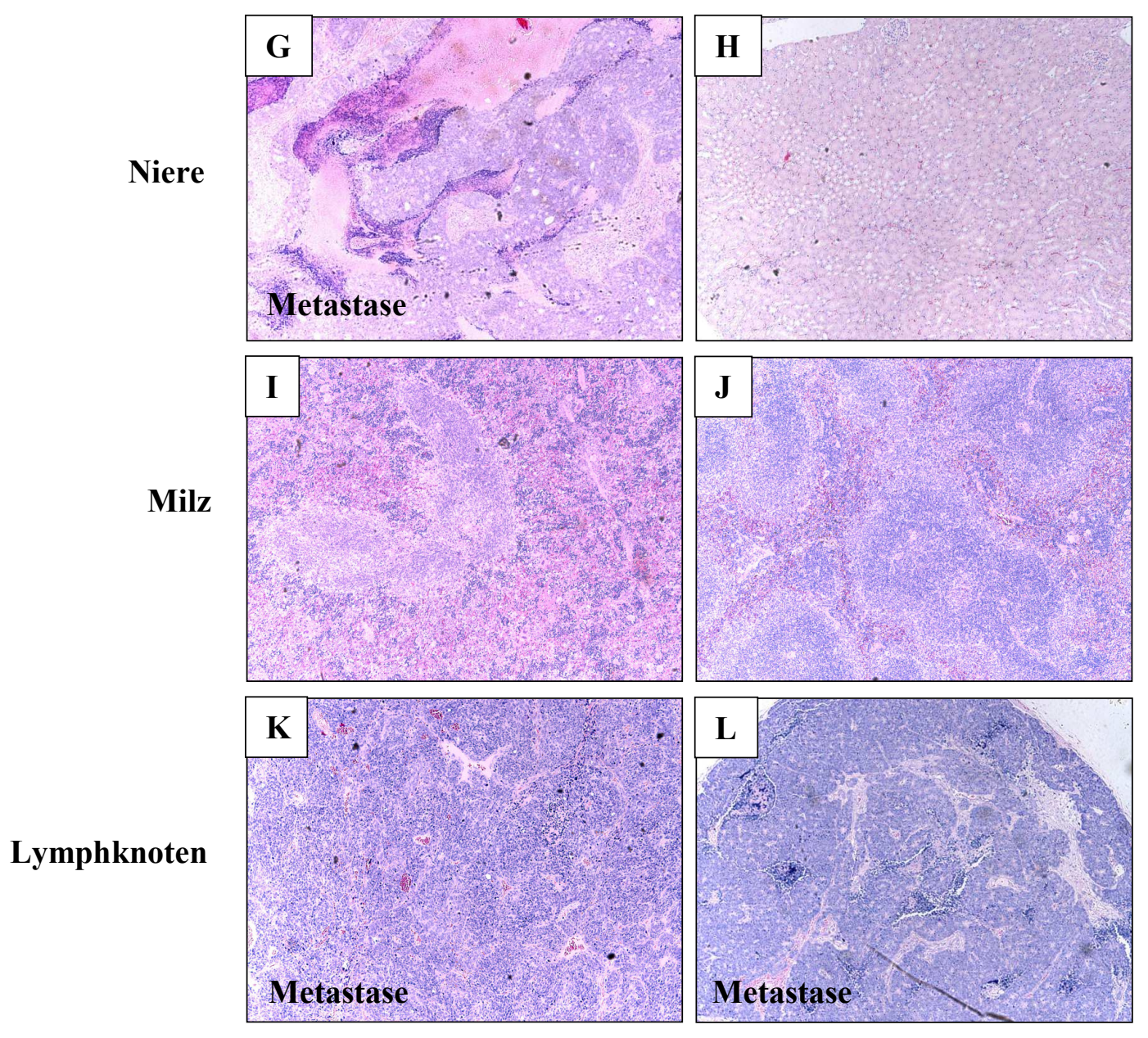

Abb. 3.10: Histopathologische Analyse zur Überprüfung der morphologischen Veränderung der Organe von doppelt (L/-T/-) und einfach (T/-) transgenen kastrierten Mäusen. Allen kastrierten Mäusen wurde nach dem Abtöten ein Teil des Prostatatumors, der Leber, der Lunge, der Niere, der Milz und ggf. die Lymphknoten herausgenommen, in Formalin fixiert und HE-Schnitte angefertigt. In allen bisher untersuchen Mäusen konnte ein schlecht differenzierter Prostatatumor, sowie in 64\% der doppelt transgenen LPXN/TRAMP- und einfach transgenen TRAMP-Mäuse Metastasen in Leber, Lunge, Niere oder Lymphknoten beobachtet werden. Stellvertretend werden hier die HE-Schnitte der Mäuse 19-16A (L/-T/-) und 19G (T/-) dargestellt. In den HESchnitten der L/-T/-Maus 19-16A konnten Metastasen in Leber, Lunge, Niere und Lymphknoten detektiert werden (C, E, G, K). In den HE-Schnitten der T/- Maus 19G konnten Metastasen in Leber und in den Lymphknoten beobachtet werden. Alle Abbildungen wurden mit einem Fluoreszenzmikroskop mit einer 40fachen Vergrößerung aufgenommen. 


\subsection{Einfluss von LPXN auf das Migrations- und Invasionsverhalten von primären Prostatakarzinomzellen}

Die in vivo-Daten, die aus den bisherigen Versuchen gewonnen werden konnten, lassen eindeutig den Schluss zu, dass LPXN die Progression der TRAMP-Tumore beschleunigt. Weiterhin erhöht LPXN die Entwicklung von Metastasen in Lymphknoten, Leber, Lunge und Niere. Um diese Daten auch in vitro zu bestätigen, wurden Primärzellen aus den murinen Prostatakarzinomen etabliert und näher charakterisiert.

\subsubsection{Etablierung einer Primärzellkultur aus Prostatatumoren doppelt transgener LPXN/TRAMP- und einfach transgener TRAMP- Mäuse}

Zur funktionellen Analyse von LPXN in vitro wurde aus den Tumoren der doppelt transgenen LPXN/TRAMP-Mäuse (L/-T-) und der einfach transgenen TRAMP-Kontrollmäuse (T/-) Primärzellen isoliert und in Kultur gebracht (siehe Material und Methoden, 2.17.2). Zur Überprüfung der Ausbeute epithelialer Primärzellen nach der Isolierung wurden die Zellen auf einem Objektträger ausplattiert, fixiert und immunzytochemisch mit einem SV40 T-AgAntikörper analysiert, da nur die Epithelzellen der Prostata das SV40 Transgen überexprimieren (Abb. 3.11). Die Zellklone 72A und 83A aus Tumoren der L/-T/- Mäuse und die Zellklone $27 \mathrm{~F}$ und $45 \mathrm{~F}$ aus Tumoren der $\mathrm{T} /$ - Mäuse wiesen den höchsten Anteil von Epithelzellen (90-100\%) auf und wurden für die folgenden Experimente verwendet. 
FITC-

SV40 T-Ag
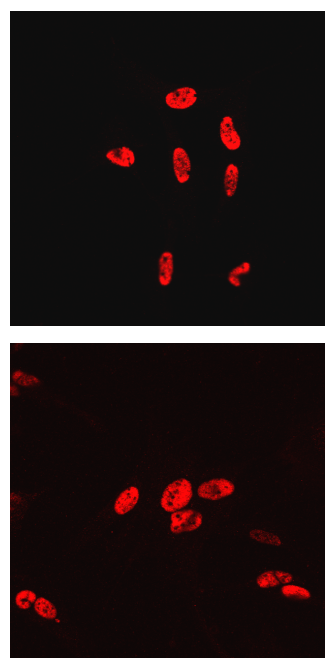

Phalloidin
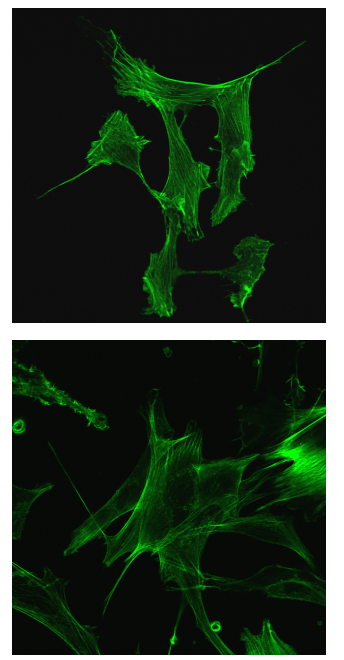

Überlagerung
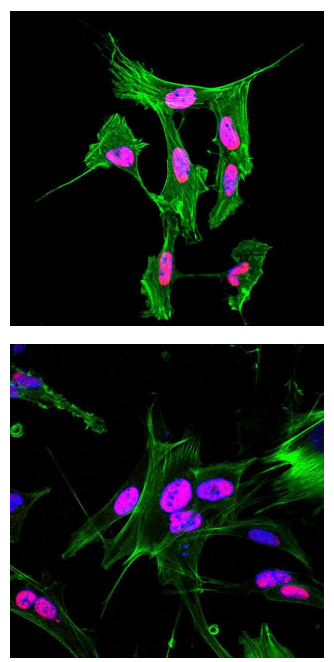

\section{Überblick}
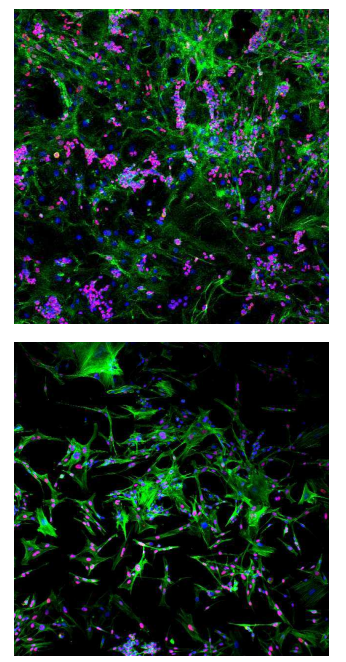

$72 \mathrm{~A} \mathrm{L/-T/-}$

45F $\mathrm{T} /-$

Abb. 3.11: Immunzytochemische Analyse zur Darstellung des Epithelzell-Anteils in den Primärzellkulturen [mod. aus Kaulfuß et al., 2009]. Zur Untersuchung der progressiven Eigenschaften von LPXN in TRAMP-Tumoren wurden primäre Zellkulturen etabliert. Dazu wurden aus den Tumoren doppelt transgener LPXN/TRAMP- (L/-T/-) und einfach transgener TRAMP- (T/-) Mäuse die Prostatatumore herauspräpariert und die Zellen isoliert. Die doppelt transgenen Primärzellklone L/-T/- (83A und 72A, hier 72A L/-T/-) und die einfach transgenen Primärzellklone T/- (27F und 45F, hier 45F T/-) wiesen die höchste Ausbeute an SV40 T-Ag-positiven und damit an Epithelzellen auf. Zur Visualisierung des F-Aktins des Zytoskeletts wurden die Zellen mit FITCPhalloidin (grün) behandelt. Die Kerne wurden mit DAPI sichtbar gemacht (blau). Die Überlagerung zeigt eine deutliche SV40 T-Ag-Färbung in den Kernen. Bis auf die Überblick-Bilder (100fache Vergrößerung) wurden alle Bilder in 600 facher Vergrößerung aufgenommen.

Als weitere Kontrolle und zum Nachweis der bestehenden LPXN-Expression in den Primärzellen aus den doppelt transgenen Prostatatumoren wurde eine Western Blot-Analyse durchgeführt. Während die SV40 T-Ag-Expression in allen isolierten Primärzellen zu erkennen ist, kann die Expression des transgenen LPXN (tLPXN-cmyc, $60 \mathrm{kDa}$ ) ausschließlich in den Zellklonen 83A und 72A (L/-T/-) nachgewiesen werden. Zur Kontrolle der aufgetragenen Proteinmenge wurde ein Antikörper gegen $\alpha$-Tubulin verwendet (Abb. 3.12). 


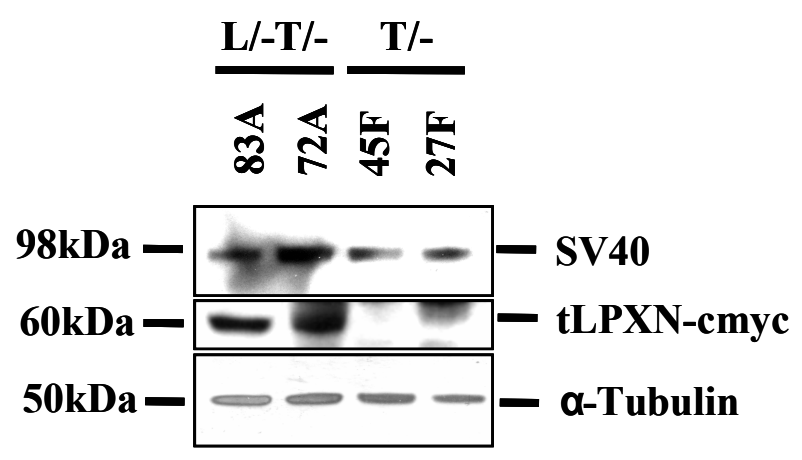

Abb. 3.12: Western Blot-Analyse zur Detektion des transgenen LPXN-cmyc in Primärzellen von doppelt transgenen LPXN/TRAMP-Mäusen [mod. aus Kaulfuß et al., 2009]. Aus den Primärzellklonen 83A und 72A der doppelt transgenen LPXN/TRAMP- (L/-T/-) Mäuse sowie 45F und 27F der einfach transgenen TRAMP (T/-)Mäuse wurde Protein isoliert und jeweils $70 \mu \mathrm{g}$ für eine Western Blot-Analyse eingesetzt. Mit einem spezifischen SV40 T-Ag -Antikörper konnte in allen Zellen das transgene SV40 T-Ag bei einer Größe von 98 kDa nachgewiesen werden. Die Detektion des transgenen LPXN (tLPXN-cmyc) in den Primärzellen (83A L/-T/- und 72A L/-T/-) erfolgte mit einem LPXN-spezifischen Antikörper. Zur Kontrolle der aufgetragenen Proteinmenge wurde die Membran mit einem $\alpha$-Tubulin Antikörper hybridisiert.

\subsubsection{LPXN erhöht das Migrations- und Invasionsverhalten von primären PCa-Zellen}

Die Aggressivität von Tumorzellen, aus der eine beschleunigte Tumorprogression resultiert, ist durch eine verstärkte Migration bzw. Invasion gekennzeichnet [Grossmann et al., 2001; Bogenrieder et al., 2003]. Um zu untersuchen, wie sich das Migrations- und Invasionsverhalten der doppelt transgenen Primärzellen auf Grund der Überexpression von LPXN im Vergleich zu den einfach transgenen Primärzellen ändert, wurden ein Scratch-Assay und ein Matrigel-Invasions-Assay (siehe Material und Methoden, 2.18) durchgeführt. Im Scratch-Assay ist das Zuwachsen der durch eine gelbe Spitze zugefügten Wunde einer geschlossenen Zellschicht ein Indiz für das Migrationsverhalten von Zellen. Wie in Abbildung $3.13 \mathrm{zu}$ erkennen, zeigen die doppelt transgenen Primärzellen durch die Überexpression von LPXN im Vergleich zu den einfach transgenen Primärzellen ein deutlich aggressiveres Migrationsverhalten. $24 \mathrm{~h}$ nach Beginn des Versuchs konnte bei dem 83A L/-T- Zellklon eine fast geschlossene Zellschicht beobachtet werden, während bei dem 45F T/- Zellklon die Verletzung der Zellschicht noch deutlich zu erkennen war (Abb. 3.13 A). Nach dreimaliger 
Wiederholung des Scratch-Assays für alle Zelllinien konnte ein statistisch relevantes, dreifach höheres Migrationsverhalten der doppelt transgenen Primärzellen 83A L/-T/- und 72A L/-T/im Vergleich zu den einfach transgenen Primärzellen 27F T/- und 45F T/- ermittelt werden (Abb. 3.13 B).

A

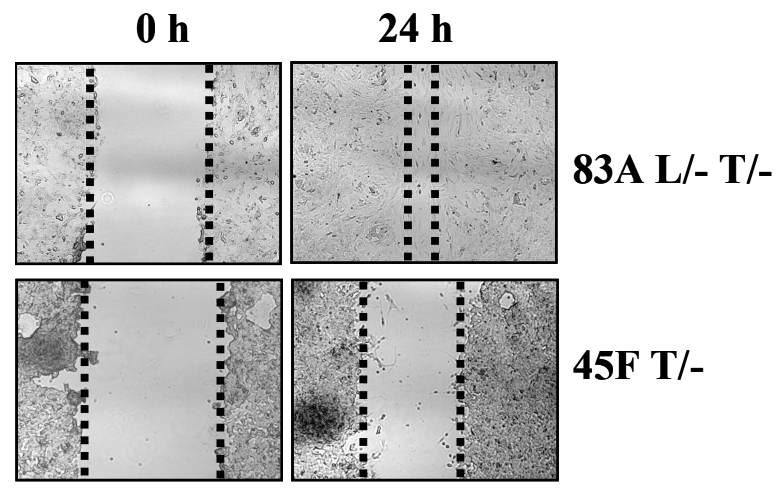

B

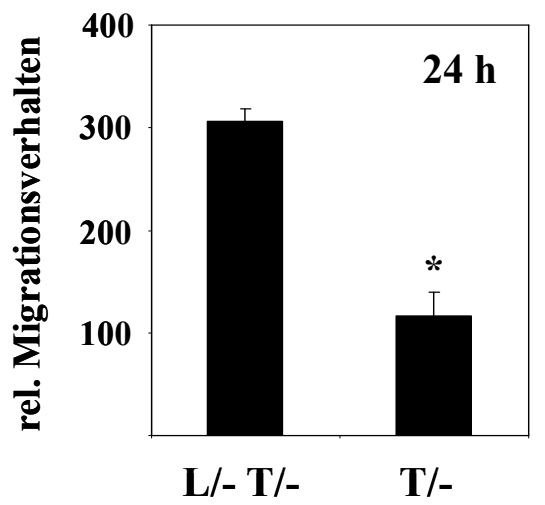

Abb. 3.13: Erhöhte Migrationsfähigkeit durch die Überexpression von LPXN [mod. aus Kaulfuß et al., 2009]. Jeweils zwei verschiedene Primärzellklone von doppelt transgenen LPXN/TRAMP (L/-T/-)- sowie TRAMP (T/-)-Tumoren wurden mittels Scratch-Assay auf ihre Migrationsfähigkeit untersucht (hier 82A L/- T/und 45F T/-). Unmittelbar nachdem der Scratch gezogen wurde sowie nach $24 \mathrm{~h}$, wurden die Zellen unterhalb einer Markierung fotografiert. A. Anschließend wurde die Breite des Scratches zu beiden Zeitpunkten errechnet und durch die Differenz der beiden Werte die Migrationsfähigkeit ermittelt. B. Das Diagramm beschreibt den Mittelwert \pm Standardabweichung von drei unabhängig voneinander durchgeführten Experimenten. Der $\rho$-Wert $\left(^{*}\right)$ wurde durch den paired Student's t-test ermittelt und betrug $\rho \leq 0.04$.

Die invasiven Eigenschaften der Primärzellen wurden mit Hilfe des Matrigel-Invasionsassays analysiert. Der Boden einer Matrigel-Invasions-Kammer ist eine mit Matrigel bedeckte Membran. $8 \mu \mathrm{m}$ große Poren in dieser Membran ermöglichen es invasiven Zellen, auf die Unterseite der Membran zu gelangen. Diese invasiven Zellen wurden fixiert, gefärbt und analysiert. Dafür wurden die gleiche Anzahl einfach (T/-) und doppelt (L/-T/-) transgener Zellen in jeweils einer Matrigel-Invasions-Kammer für $24 \mathrm{~h}$ ausplattiert. Für die Zellklone 83A $\mathrm{L} /-\mathrm{T} /$ - und 72A L/-T/-konnte im Vergleich zu den Zellklonen 27F T/- und 45F T/- ein zweifach höheres Invasionsverhalten beobachtet werden (Abb. 3.14). Diese stärkere Invasionsbereitschaft der doppelt transgenen L/-T/- Primärzellen ist auf die Überexpression von LPXN zurückzuführen und unterstreicht die Beobachtungen der verstärkten Progression des PCa in dem doppelt transgenen LPXN/TRAMP-Mausmodel. 


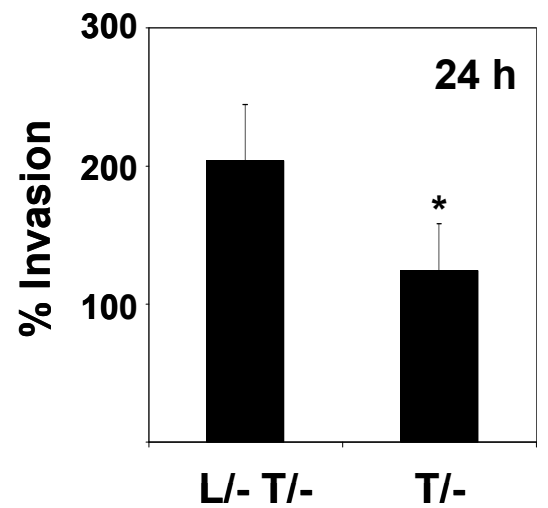

Abb. 3.14: Die erhöhte Tumorprogression resultiert aus den durch LPXN erhöhten invasiven Eigenschaften der murinen PCa-Zellen [mod. aus Kaulfuß et al., 2009]. Mit Hilfe eines MatrigelInvasionsassays wurde die Invasivität der doppelt transgenen Primärzellen L/-T/- (83A und 72A) mit den einfach transgenen Primärzellen T/- (27F und 45F) verglichen. Die Primärzellen der doppelt transgenen Mäuse zeigten dabei eine zweifach höhere Invasivität als die Primärzellen der einfach transgenen Mäuse. Das Diagramm beschreibt den Mittelwert \pm Standardabweichung von drei unabhängigen Experimenten. Der $\rho$-Wert $(*)$ wurde durch den paired Student's t-test ermittelt und betrug $\rho \leq 0.04$.

Die vorangegangenen in vivo- und in vitro- Experimente zeigen deutlich, dass LPXN in die Progression von Prostatakarzinomen involviert ist. Diese Beobachtungen führten zu der Frage, wie LPXN die Progression von Prostatakarzinomen beeinflussen kann. Verschiedene Möglichkeiten sollen hier vorgestellt und im Weiteren durch Ergebnisse bestätigt werden.

1. Hypothese: LPXN hat einen direkten Einfluss auf die Regulation verschiedener Gene

2. Hypothese: LPXN interagiert mit Proteinen, die die Zellmigration/ Invasion fördern

3. Hypothese: LPXN beeinflusst die Zelladhäsion

4. Hypothese: LPXN ist in Signalwege involviert, welche die Zellprogression beeinflussen 


\subsection{LPXN reguliert die Expression von verschiedenen Genen}

\subsubsection{Die Expression des Zelladhäsions-Moleküls p120CTN korreliert negativ mit der LPXN-Expression}

Im Rahmen der biologischen Dissertation von Frau Dr. Kaulfuß [2006] wurde in einem Zelladhäsionsarray die differentielle Expression von 96 Zelladhäsions-relevanten Genen nach Herunterregulierung der LPXN-Expression untersucht. Dabei konnte für p120CTN gezeigt werden, dass es in den PCa-Zelllinien PC-3 und DU 145 mit verminderter LPXN-Expression stärker exprimiert wird als in den jeweiligen Kontrollzellen. Mittels quantitativer real time PCR- und Western Blot-Analyse konnte die erhöhte Expression von p120CTN nach Herunterregulierung der LPXN-Expression durch spezifische siRNA-Oligonukleotide in den PCa-Zellen bestätigt werden [Kaulfuß, 2006].

Weiterhin konnte sowohl auf RNA- als auch auf Proteinebene demonstriert werden, dass nach induzierbarer Überexpression von LPXN durch das Tet-on-System in den PCa-Zellen LNCaP [Kaulfuß, 2006] die Expressionszunahme von LPXN direkt mit der Expressionsabnahme von p120CTN korreliert [Beckemeyer, 2007].

\subsubsection{1 Überexpression von LPXN in PCa-Zelllinien korreliert mit der Expressionsabnahme von p120CTN}

Um durch eine zweite Methode zu bestätigen, dass eine Abnahme der p120CTN-Expression in PCa-Zellen mit der Überexpression von LPXN korreliert, wurde das TAT-TransduktionsSystem [Becker-Hapak et al., 2001, Material und Methoden, 2.16] verwendet. Das TATTransduktions-System wurde bereits zur Untersuchung der morphologischen Veränderungen von PCa-Zellen nach Überexpression von LPXN angewendet [Beckemeyer, 2007]. Das TATLPXN-EGFP-StrepTag- (TAT-LPXN) Fusionsprotein und als Kontrolle das TAT-EGFPStrepTag- (TAT-EGFP) Fusionsprotein wurden für $24 \mathrm{~h}$ in einer Endkonzentration von $1 \mu \mathrm{M}$ 
auf die zu analysierenden PCa-Zellen gegeben. Eine daraus resultierende Repräsentation von TAT-LPXN in den Zellen konnte mittels Western Blot-Analyse bestätigt werden (Abb. 3.15).

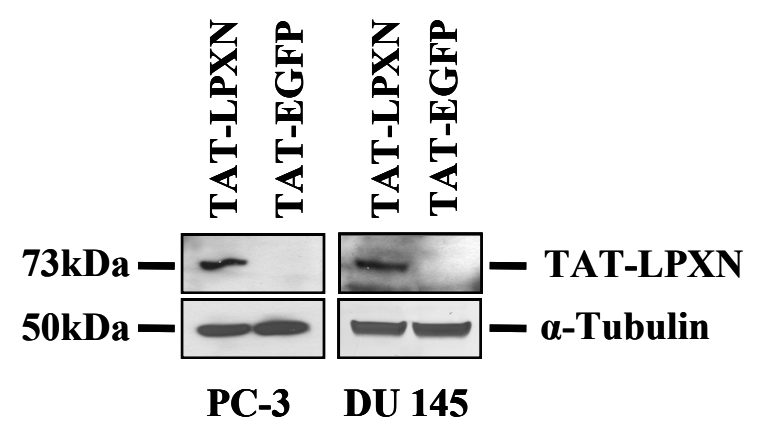

Abb. 3.15: Überexpression von LPXN durch das TAT-Transduktions-System in PCa-Zelllinien [mod. aus Kaulfuß et al., 2009]. Die PCa-Zelllinien PC-3 und DU 145 wurden entweder mit dem TAT-LPXNEGFP-Fusionsprotein (TAT-LPXN) oder als Kontrolle mit dem TAT-EGFP-Fusionsprotein (TAT-EGFP) transduziert. $24 \mathrm{~h}$ nach der Transduktion wurde von den Zellen Gesamt-Protein isoliert und $50 \mu \mathrm{g}$ für die Western Blot-Analyse verwendet. Zur Detektion des TAT-LPXN-EGFP-Fusionsproteins (73 kDa) wurde ein Antikörper gegen LPXN (283G) verwendet. Zur Kontrolle der eingesetzten Proteinmenge wurde ein Antikörper gegen $\alpha$-Tubulin eingesetzt.

Anschließend wurde die Expression von p120CTN in DU 145-Zellen nach Transduktion mit TAT-EGFP bzw. TAT-LPXN analysiert. Wie in Abbildung $3.16 \mathrm{zu}$ erkennen ist, resultiert eine LPXN-Repräsentation (TAT-LPXN) im Vergleich zur Kontrolle in einer deutlich verringerten Expression von p120CTN auf Proteinebene.

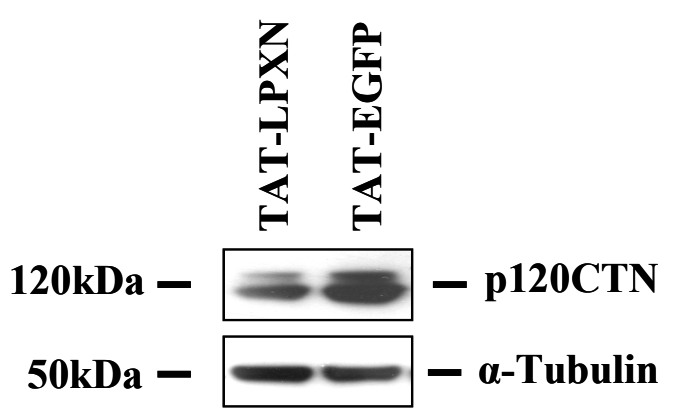

\footnotetext{
Abb. 3.16: Nachweis der p120CTN-Expression nach Transduktion von PCa-Zellen mit TAT-LPXN [mod. aus Kaulfuß et al., 2009]. Die 24stündige Transduktion von DU 145 PCa-Zellen mit dem TAT-LPXNEGFP-Fusionsprotein (TAT-LPXN) resultiert im Western Blot in einer deutlichen Expressionsabnahme von p120CTN. Zellen, die hingegen als Kontrolle unter gleichen Bedingungen mit dem TAT-EGFP-Fusionsprotein transduziert wurden, zeigen auf Grund der nicht erhöhten LPXN-Reepräsentation keine verringerte p120CTNExpression. Die Transduktion mit anschließender Western Blot-Analyse wurde als Triplett durchgeführt. Verwendet wurde ein p120CTN-spezifischer Antikörper, der eine spezifische Bande bei der für p120CTN erwarteten Größe von 120 kDa darstellt. Ein Antikörper gegen $\alpha$-Tubulin diente als Kontrolle der aufgetragenen Proteinmenge.
} 
Um auszuschließen, dass das im TAT-LPXN-Fusionsprotein enthaltene EGFP bzw. der StrepTag Einfluss auf die Funktion von LPXN ausüben, wurden drei Plasmide (pCMV-LPXN-His (LPXN-His), pCMV-LPXN-Myc (Myc-LPXN), pEGFP-LPXN (EGFP-LPXN)) zur Überexpression von verschieden getaggten LPXN-Fusionsproteinen in PC-3-Zellen transfiziert. Als Kontrolle wurden die Leervektoren verwendet. $48 \mathrm{~h}$ nach der Transfektion wurde Gesamt-Protein isoliert und eine Western Blot-Analyse durchgeführt (Abb. 3.17). Es ist deutlich zu erkennen, dass die Überexpression der jeweiligen LPXN-Fusionsproteine in einer verringerten Expression von p120CTN in PCa-Zellen resultiert.

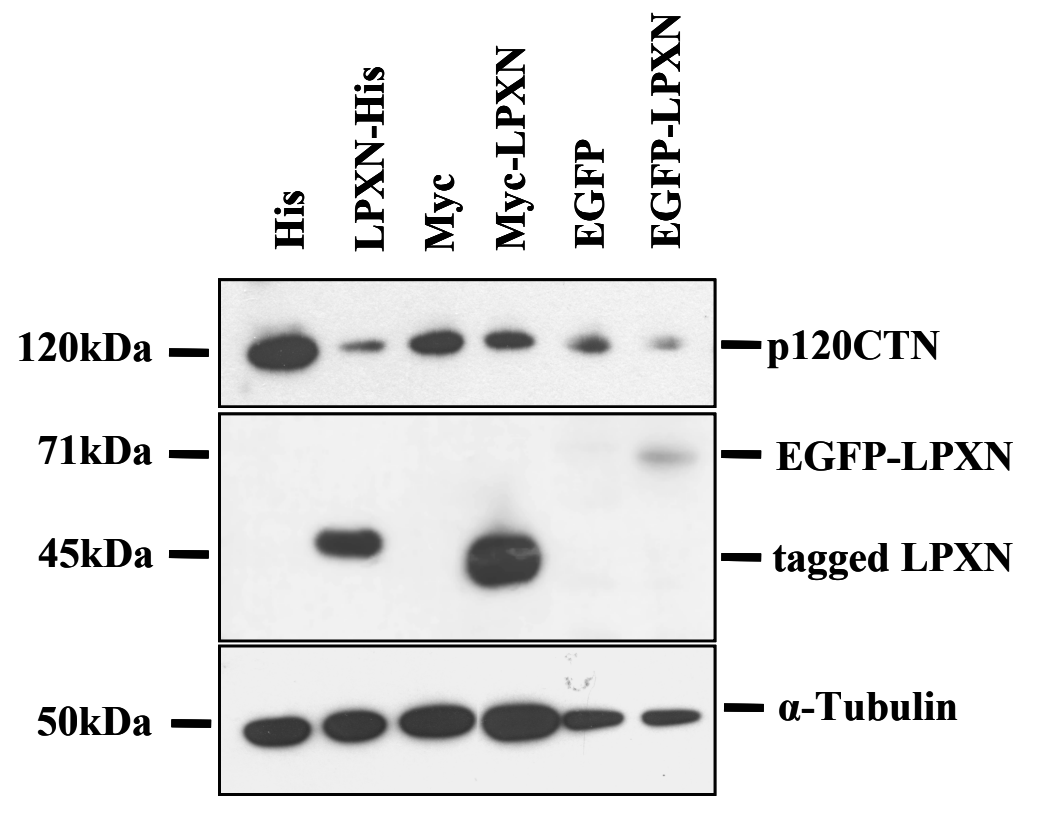

Abb. 3.17: Western Blot zur Expressions-Analyse von p120CTN nach Überexpression von verschieden getaggten LPXN-Fusionsproteinen [mod. aus Kaulfuß et al., 2009]. PC-3-Zellen wurden für $48 \mathrm{~h}$ mit Plasmiden transfiziert, die spezifisch für die Fusionsproteine LPXN-His, Myc-LPXN und EGFP-LPXN kodieren. Zur Kontrolle wurden die entsprechenden Leervektoren verwendet. Anschließend wurde Gesamt-Protein isoliert und $50 \mu \mathrm{g}$ für die Western Blot-Analyse eingesetzt. Zunächst wurde die Membran mit einem Antikörper gegen LPXN (283G) hybridisiert, wodurch die entsprechenden LPXN-Fusionsproteine (ca. $45 \mathrm{kDa}, 71 \mathrm{kDa}$ ) detektiert werden konnten. Zur Darstellung der p120CTN-Expression wurde ein Antikörper gegen p120CTN verwendet (120 kDa). Die Hybridisierung mit einem $\alpha$-Tubulin-spezifischen Antikörper bestätigt die aufgetragene Proteinmenge. 


\subsubsection{Expression von p120CTN im LPXN/TRAMP-Mausmodell}

In den vorangegangenen Experimenten konnte gezeigt werden, dass eine verstärkte Expression von LPXN in den PCa-Zelllinien PC-3 und DU $145 \mathrm{zu}$ einer verminderten Expression des Zell-Zell-Adhäsionsmoleküls p120CTN führt. Um zu untersuchen, ob diese Korrelation auch auf das biologisch relevante in vivo-Modell übertragbar ist, wurde die Expressionsstärke von p120CTN zunächst in den Prostatae von LPXN/TRAMP- und TRAMP-Mäusen (normales Prostatagewebe und Tumorgewebe) untersucht. Dafür wurden je zwei zehn Wochen alte Tiere der doppelt transgenen LPXN/TRAMP-Mauslinie und der TRAMP-Kontrolllinie abgetötet und die Prostata herauspräpariert. Diese Tiere hatten zu diesem Zeitpunkt noch keinen Prostatatumor entwickelt. Anschließend wurde eine Western Blot-Analyse mit einem p120CTN-spezifischen Antikörper durchgeführt. Zusätzlich wurden isolierte Proteine aus zwei Tumoren einfach transgener TRAMP-Mäuse aufgetragen. Im humanen PCa ist die p120CTNExpression im Vergleich zum Normalgewebe bei $50 \%$ der Fälle herunterreguliert [Kallakury et al., 2001a, b]. Aus der Western Blot-Analyse geht hervor, dass die p120CTNExpression auch in den Tumoren des TRAMP-Mausmodells herunterreguliert wird und damit dieses Mausmodell für die Analyse des Einflusses von LPXN auf p120CTN verwendet werden kann. Weiterhin konnte beobachtet werden, dass auch in vivo allein die Überexpression von LPXN (L/-T/-) im Normalgewebe der Prostata (N1, N2) zu einer verminderten Expression von p120CTN führt (Abb. 3.18 A). Die densitometrische Auswertung von drei Western BlotExperimenten bestätigte, dass im Normalgewebe der Prostata von LPXN/TRAMP-Mäusen die p120CTN-Expression um 50\% reduziert ist (Abb. 3.18 B).

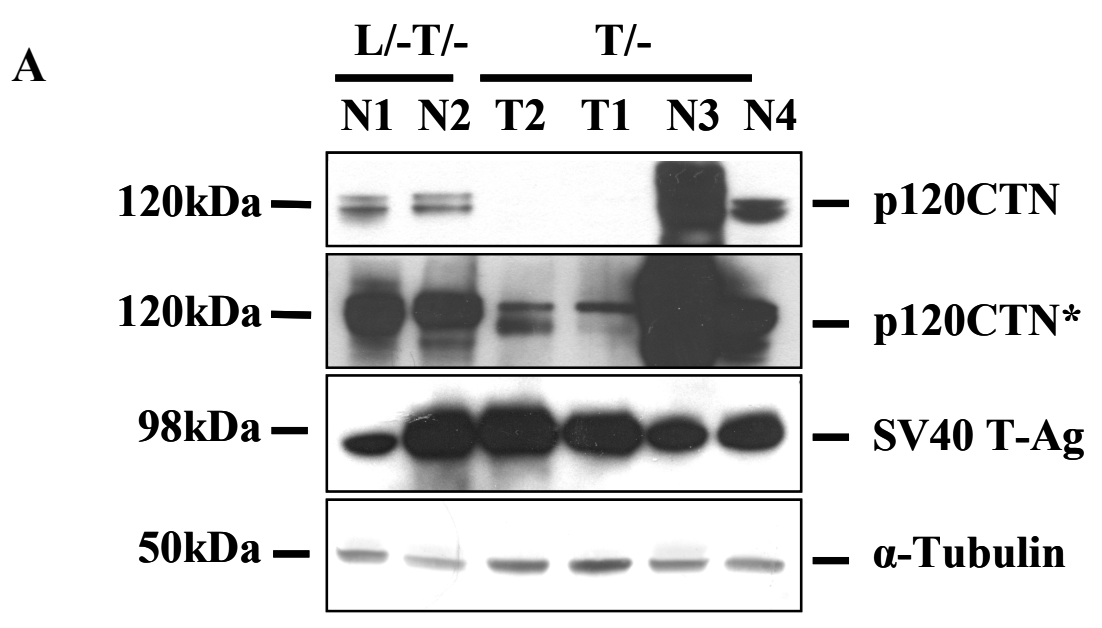


B

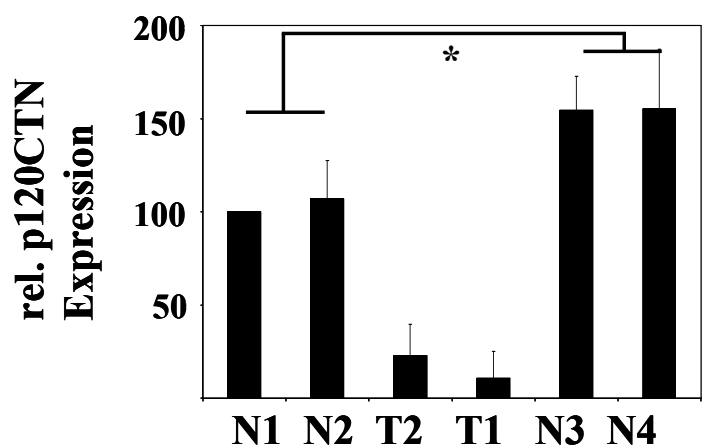

Abb. 3.18: Western Blot zur Expressions-Analyse von p120CTN im Normal- und im Tumorgewebe von doppelt (L/-T/-) und einfach (T-) transgenen TRAMP-Mäusen [mod. aus Kaulfuß et al., 2009]. A. Für die Western Blot-Analyse wurde Gesamt-Protein aus normalem Prostatagewebe von doppelt transgenen LPXN/TRAMP-(L/-T/-) und einfach transgenen TRAMP-Mäusen (T/-) sowie aus Tumorgewebe von T/- Mäusen isoliert. Die Expression von p120CTN ist im Normalgewebe der Prostata (N1, N2) doppelt transgener L/-T/- Mäuse im Vergleich zu einfach transgenen T/- Mäusen durch die Überexpression von LPXN signifikant reduziert. Weiterhin ist eine starke Expressionsabnahme von p120CTN im Prostatatumorgewebe (T1, T2) im Vergleich zum Normalgewebe der Prostata (N3, N4) in T/- Mäusen zu beobachten. Dabei handelt es sich nicht um einen kompletten Verlust der p120CTN-Expression, wie die Darstellung einer längeren Belichtungsdauer zeigt (p120CTN*). Weiterhin wurde SV40 T-Ag zur Kontrolle des verwendeten Prostatamaterials abgebildet. Zur Überprüfung der aufgetragenen Proteinmenge wurde ein Antikörper gegen $\alpha$-Tubulin eingesetzt. B. Die densitometrische Analyse demonstriert eine 50\%ige Reduktion der p120CTN-Expression im Normalgewebe von L/T/- Mäusen im Vergleich zu T/- Mäusen. Der Mittelwert \pm Standardabweichung wurde von drei unabhängigen Western Blots berechnet. Der $\rho$-Wert $(*)$ wurde durch den paired Student's $t$-test ermittelt und betrug $\rho \leq 0.01$.

Der Einfluss von LPXN auf die Expression von p120CTN im Tumorgewebe von doppelt transgenen LPXN/TRAMP-Mäusen wurde im Vergleich zum Tumorgewebe von einfach transgenen TRAMP-Mäusen mittels Western Blot untersucht. Dazu wurden LPXN/TRAMPMäuse der Linien \#19 und \#20, sowie TRAMP-Mäuse im Alter zwischen 20 und 30 Wochen abgetötet, die Prostatatumore herauspräpariert und Gesamt-Protein isoliert. Wie in Abbildung $3.19 \mathrm{zu}$ erkennen ist, liegt eine signifikant reduzierte Expression von p120CTN in den Tumoren der LPXN/TRAMP-Mäuse im Vergleich zu den TRAMP-Mäusen vor. Dieser Expressionsunterschied bestätigt wiederum die negative Korrelation der LPXN- und der p120CTNExpression. 


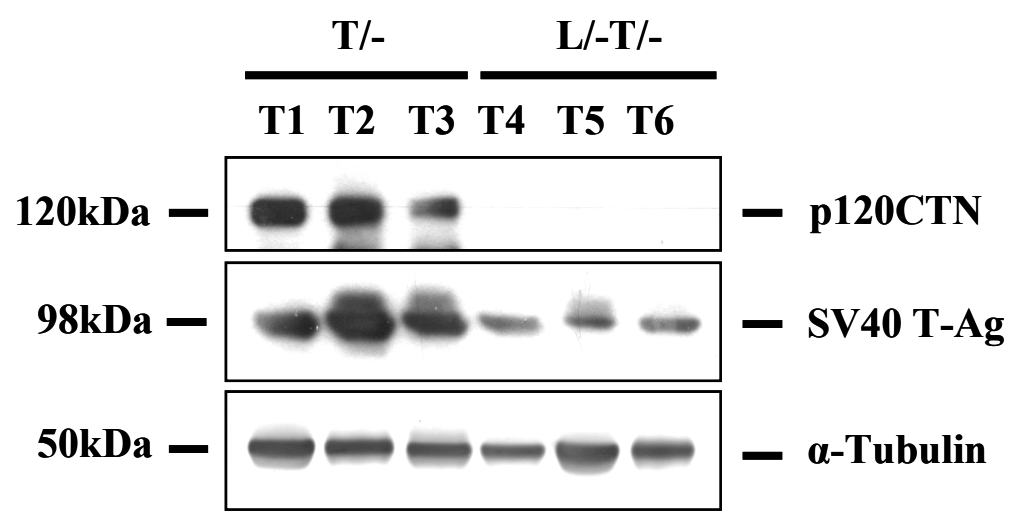

Abb. 3.19: Western Blot zur Expressions-Analyse von p120CTN im Tumorgewebe von doppelt transgenen LPXN/TRAMP- und einfach transgenen TRAMP-Mäusen [mod. aus Kaulfuß et al., 2009]. Jeweils drei L/-T/bzw. T/- Mäuse wurden abgetötet und die Prostatatumore herauspräpariert. Anschließend wurde Gesamt-Protein isoliert und $50 \mu \mathrm{g}$ für die Western Blot-Analyse eingesetzt. Mit einem p120CTN-Antikörper konnte eine spezifische Bande bei $120 \mathrm{kDa}$ detektiert werden. Um nachzuweisen, dass das verwendete Material aus der Prostata stammt, wurde zusätzlich ein Antikörper gegen SV40 T-Ag verwendet. Die aufgetragene Protein-Menge wurde mit einem $\alpha$-Tubulin-spezifischen Antikörper untersucht. Durch die Überexpression von LPXN ist in den Tumoren der L/-T/- Mäuse eine deutliche Herunterregulierung der p120CTN-Expression im Vergleich zu den T/- Mäusen zu erkennen.

\subsubsection{Expression von p120CTN in Primärzellen von LPXN/TRAMP- Tumoren}

Die im Mausmodell erhaltenen Ergebnisse zur differentiellen Expression von p120CTN nach LPXN-Überexpression sollten in murinen Primärzellen ex vivo überprüft werden. Wie bereits in Abbildung $3.10 \mathrm{zu}$ erkennen ist, exprimieren nur die Zellklone 83A L/-T/- und 72A L/-T/-, welche aus den Tumoren doppelt transgener LPXN/TRAMP-Mäuse isoliert wurden, das transgene tLPXN-cmyc. Mit einem spezifischen Antikörper gegen p120CTN konnte in diesen Zellen in einer Western Blot-Analyse eine verminderte Expression von p120CTN festgestellt werden. Die Zellklone, welche das transgene tLPXN-cmyc nicht exprimierten $(27 \mathrm{~F} \mathrm{~T} /-$ und 45F T/-), zeigten hingegen eine stärkere p120CTN-Expression (Abb. 3.20). 


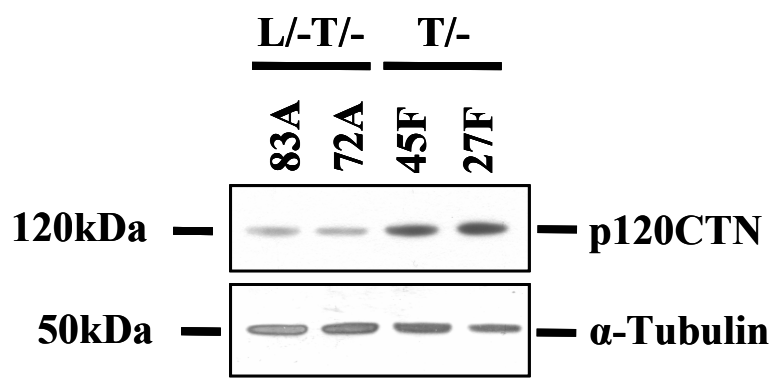

Abb. 3.20: Western Blot zur Analyse der herunterregulierten p120CTN-Expression in den Primärzellen doppelt transgener LPXN/TRAMP-Mäuse im Vergleich zu den Primärzellen einfach transgener TRAMPMäuse [mod. aus Kaulfuß et al., 2009]. Aus den Primärzellklonen 83A und 72A, welche aus den doppelt transgenen L/-T/- Mäusen hervorgegangen sind, sowie aus den Primärzellklonen 45F und 27F, welche aus den einfach transgenen T/- Mäusen hervorgegangen sind, wurde Gesamt-Protein isoliert und $30 \mu g$ für die Westen BlotAnalyse eingesetzt. Ein p120CTN-spezifischer Antikörper wurde zur Detektion des p120CTN bei einer Größe von $120 \mathrm{kDa}$ verwendet. Die Überprüfung der eingesetzten Proteinmenge erfolgte mit einem Antikörper gegen $\alpha$-Tubulin. Durch die Überexpression von LPXN in den doppelt transgenen Primärzellen 83A und 72A ist eine deutlich verminderte Expression des Zell-Zell-Adhäsionsproteins p120CTN zu verzeichnen.

\subsubsection{Analysen zur Funktion von p120CTN}

\subsubsection{Herunterregulierung von p120CTN in den PCa-Zellinien mittels RNA-Interferenz}

Kann p120CTN als Vermittler der LPXN-induzierten verstärkten Progression der PCa-Zellen fungieren? Zur Beantwortung dieser Frage wurden die etablierten PCa-Zelllinien PC-3 und DU 145 zunächst mit drei verschiedenen p120CTN-spezifischen Duplex-siRNAOligonukleotiden transfiziert. Ein siRNA-Oligonukleotid, welches spezifisch für das LuciferaseGen ist, wurde bei jedem Experiment als Kontrolle eingesetzt. Für den knockdown der p120CTN-Expression wurden zwei bzw. drei (si-p120CTN1, si-p120CTN2, si-p120CTN3) verschiedene siRNAs getestet. Die Ergebnisse in Abbildung 3.21 zeigen, dass $72 \mathrm{~h}$ nach der Transfektion mit p120CTN-spezifischer siRNA sowohl auf RNA- als auch auf Proteinebene ein deutlicher knockdown der p120CTN-Expression in PC-3-Zellen zu verzeichnen ist. Zur simultanen Herunterregulierung der p120CTN- und LPXN-Expression wurden die Zellen mit beiden siRNA-Oligonukleotiden transfiziert. Es ist zu erkennen, dass dadurch der Effekt der Hochregulation von p120CTN durch die alleinige Reduktion der LPXN-Expression aufgehoben 
werden kann. Da sich nach mehrfacher Wiederholung der Experimente für die p120CTNspezifische siRNA 3 (si-p120CTN3) die größte Effizienz in der Herunterregulierung der p120CTN-Expression ergab, wurde für alle weiteren Versuche diese siRNA eingesetzt.

A

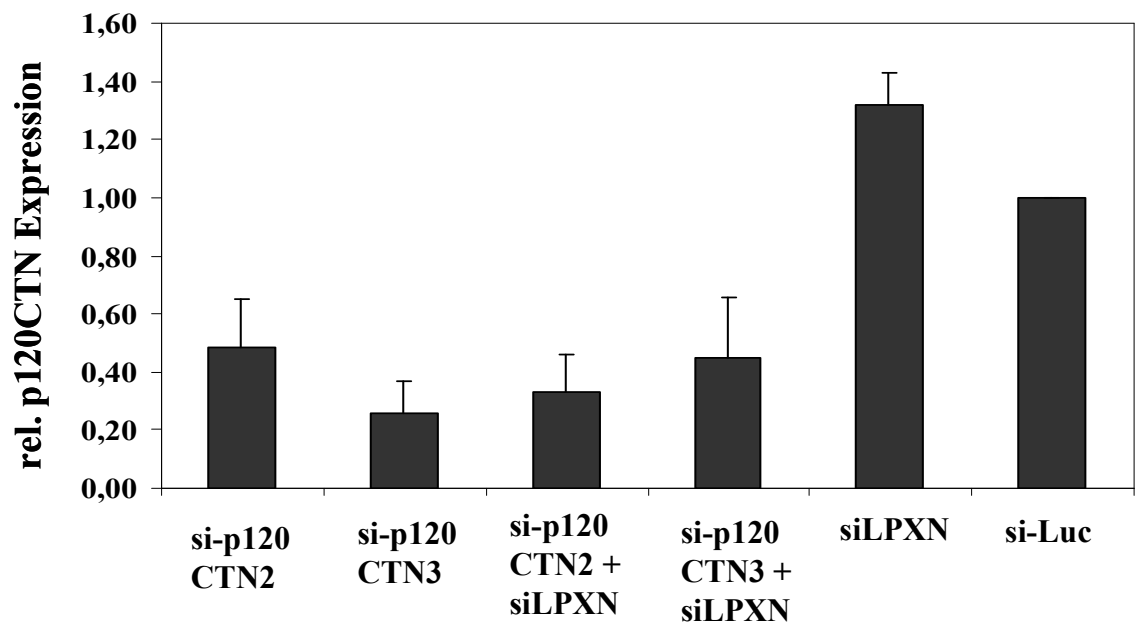

B

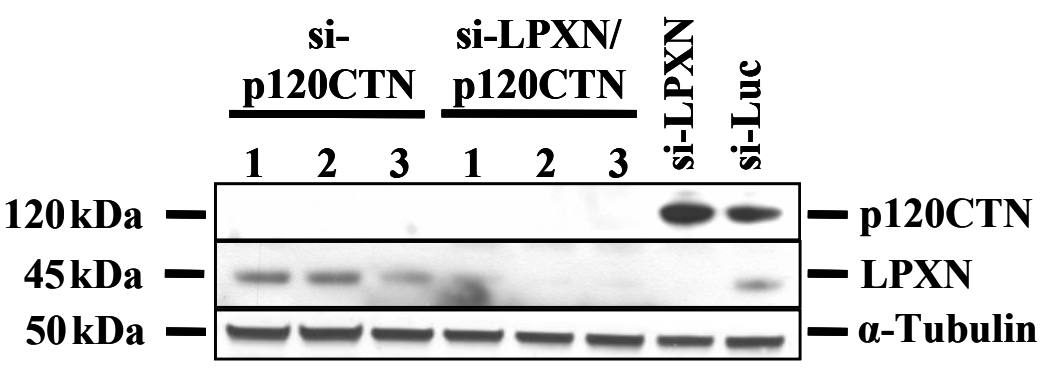

Abb. 3.21: Quantitative real time PCR sowie Western Blot-Analyse zum Nachweis der Herunterregulation von p120CTN und LPXN in PC-3-Zellen [mod. aus Kaulfuß et al., 2009]. A. PC-3-Zellen wurden zur Herunterregulierung der p120CTN- bzw. LPXN-Expression mit spezifischen siRNAs transfiziert. Für die quantitative real time PCR-Analyse wurde nach $72 \mathrm{~h}$ Gesamt-RNA isoliert und mittels reverser Transkriptase in cDNA umgeschrieben. Mit spezifischen p120CTN-Primern konnten die p120CTN-Transkripte in der PCR amplifiziert werden. Abgeglichen gegen zwei Housekeeping-Gene ergab sich für jede cDNA-Probe eine relative p120CTN-Expression. B. Für die Western Blot-Analyse wurde nach den Transfektion der PC-3-Zellen mit den jeweiligen siRNAs Gesamt-Protein isoliert und $30 \mu \mathrm{g}$ eingesetzt. Mittels p120CTN-spezifischem Antikörper konnte in allen Zellen, welche mit p120CTN-spezifischer siRNA (sip120CTN1, sip120CTN2, sip120CTN3) transfiziert wurden, eine Herunterregulierung der p120CTN-Expression detektiert werden. Weiterhin wurde zur Detektion von LPXN ein spezifischer LPXN-Antikörper verwendet. Die Überprüfung der aufgetragenen Proteinmenge erfolgte mit einem $\alpha$-Tubulin-spezifischen Antikörper. 


\subsubsection{Verstärkte Migration und Invasion in PCa-Zellen nach Herunterregulierung der p120CTN-Expression}

Nachdem die Funktionalität der siRNA-Oligonukleotide bestätigt werden konnte, sollten die Migrations-und Invasionseigenschaften der PCa-Zellen nach Herunterregulierung der p120CTNExpression untersucht werden. Zusätzlich sollten diese Eigenschaften analysiert werden, wenn die Expression beider Proteine, LPXN und p120CTN, herunterreguliert sind. Dafür wurden ein scratch-Assay und ein Matrigel-Invasionsassay durchgeführt (Material und Methoden 2.18, 2.21). Für den scratch-Assay wurden $48 \mathrm{~h}$ nach Herunterregulierung der Expression der Zielgene LPXN und p120CTN die Zellen in einer 12-Well-Platte so ausplattiert, dass sich nach $24 \mathrm{~h}$ eine geschlossene Zellschicht gebildet hatte. Anschließend wurde eine Wunde zugefügt und diese oberhalb und unterhalb einer Markierung fotografiert und gemessen. Nach $24 \mathrm{~h}$ wurden die Zellen wiederum oberhalb und unterhalb der Markierung fotografiert.

Wie in Abbildung 3.22 zu erkennen ist, haben PC-3-Zellen, bei denen die p120CTN-Expression herunterreguliert wurde, eine stark erhöhte Migrationsfähigkeit. Die zugefügte Wunde in der Zellschicht war bereits nach $24 \mathrm{~h}$ nicht mehr zu erkennen. Im Gegensatz hierzu stehen die PCaZellen, bei denen die LPXN-Expression herunterreguliert wurde. Im Vergleich zu den mit Luciferase-siRNA transfizierten Kontrollzellen konnte hier eine verminderte Migrationsfähigkeit beobachtet werden. Der gleichzeitige knockdown der Expression von p120CTN und LPXN resultierte in einer Aufhebung der Effekte der einzelnen Herunterregulierungen. Die Breite der bestehenden Wunde unterscheidet sich kaum von derjenigen der Kontrollzellen.

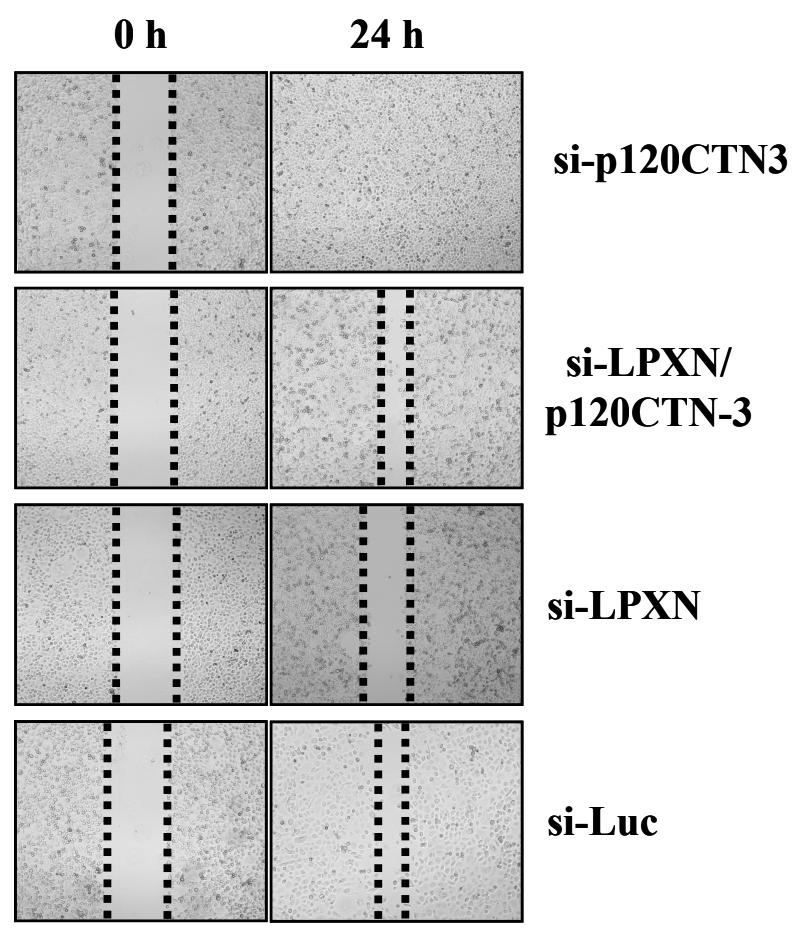


Abb. 3.22: Scratch-Assay zur Bestimmung der Migrationsfähigkeit von PC-3-PCa-Zellen nach Herunterregulierung der p120CTN- und LPXN-Expression [aus Kaulfuß et al., 2009]. In einem scratch-Assay wurde die direkte Migrationsfähigkeit von PC-3-Zellen nach p120CTN knockdown, LPXN knockdown und dem simultanen knockdown der p120CTN- und LPXN-Expression ermittelt. In eine geschlossene Zellschicht von p120CTN-siRNA-, LPXN-siRNA-, p120CTN- und LPXN-siRNA- sowie Luciferase-siRNA (Kontrolle) transfizierten Zellen wurde mit einer gelben Spitze eine Wunde eingefügt. Das Zusammenwachsen der Wunde wurde unter einem inversen Mikroskop in 40facher Vergrößerung beobachtet und fotografiert. Nach 24 h konnte in den p120CTN-siRNA-transfizierten Zellen im Vergleich zu den Kontrollzellen eine stark erhöhte und in den LPXNsiRNA-transfizierten Zellen eine stark verminderte Migrationsfähigkeit der Zellen beobachtet werden. Nach knockdown sowohl der p120CTN als auch der LPXN-Expression erfolgt eine Aufhebung der Effekte, da die Zellen eine ähnliche Migrationsfähigkeit wie die Kontrollzellen zeigen.

Die Invasionsfähigkeit der PCa-Zellen wurde mit einem Matrigel-Invasionsassay analysiert (siehe Material und Methoden, 2.18). PC-3-Zellen wurden dafür mit spezifischer siRNA gegen p120CTN, LPXN bzw. p120CTN und LPXN zusammen und Luciferase transfiziert. Nach 48 h wurden die Zellen in eine Matrigel-Invasions-Kammer gegeben, die eine mit Matrigel bedeckte Membran (8 $\mu \mathrm{m}$ Poren) enthielt. Nach 24 h Inkubation wurden die invasiven Zellen auf der Unterseite der Membran fixiert, angefärbt und gezählt. Nach Herunterregulierung der p120CTNExpression konnte eine um 34\% erhöhte Invasivität der PC-3-Zellen im Vergleich zu den Luciferase-siRNA transfizierten Zellen beobachtet werden. Nach dem knockdown der LPXNExpression hingegen konnte eine verminderte Invasivität der Zellen gezeigt werden [Kaulfuß et al., 2008]. Wurde die Expression beider Gene, p120CTN und LPXN, herunterreguliert, konnte wie auch in der Migrationsfähigkeit eine Aufhebung der jeweiligen Einzeleffekte beobachtet werden (Abb. 3.23).

Diese Ergebnisse deuten darauf hin, dass ein Expressionsverlust von p120CTN die progressiven Eigenschaften des PCa unterstützt und dass p120CTN ein Vermittler der LPXN-induzierten Migrations- und Invasionsfähigkeit darstellt.

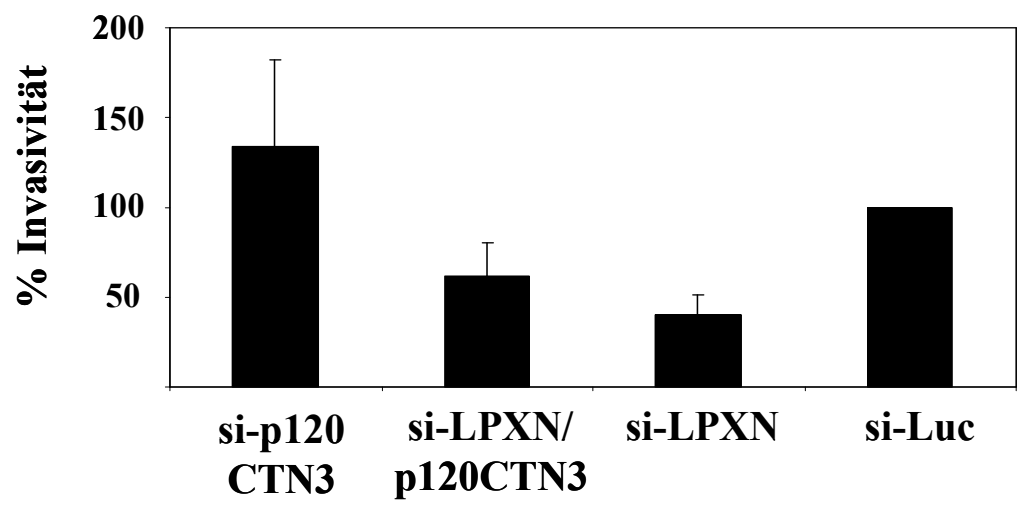


Abb. 3.23: Invasionsassay zur Bestimmung der invasiven Eigenschaften von PC-3-Zellen nach Herunterregulierung der p120CTN- und LPXN-Expression [mod. aus Kaulfuß et al., 2009]. PC-3-Zellen wurden mit spezifischer siRNA gegen p120CTN (si-p120CTN3), LPXN (si-LPXN) und p120CTN und LPXN zusammen (si-LPXN/si-p120CTN3) transfiziert. Kontrollzellen wurden mit siRNA transfiziert, die spezifisch gegen das Luciferase-Gen gerichtet ist. Nach $48 \mathrm{~h}$ wurden die Zellen jeweils in einer Matrigel-Invasions-Kammer ausplattiert und für $24 \mathrm{~h}$ inkubiert. Der Expressionsverlust von p120CTN bewirkt in den Zellen eine erhöhte invasive Eigenschaft im Vergleich zu Kontrollzellen, während der Expressionsverlust von LPXN in den Zellen eine geringere invasive Fähigkeit hervorruft. Zellen, in denen sowohl die Expression von p120CTN als auch LPXN herunterreguliert ist, unterscheiden sich nur unwesentlich in der Invasionsfähigkeit von den Kontrollzellen. Der Mittelwert \pm Standardabweichung wurde von drei unabhängigen Invasions-Assays berechnet.

\subsubsection{3 Änderung der subzellulären Lokalisation von $\beta$-Catenin nach Herunterregulierung der LPXN- und p120CTN-Expression}

$\beta$-Catenin ist wie p120CTN eine Komponente des Zell-Zell-Adhäsionskomplexes. Im Gegensatz zu p120CTN ist $\beta$-Catenin jedoch nicht fest an die Membran gebunden, sondern pendelt zwischen Membran und Kern. An der Membran ist $\beta$-Catenin für die Zellstabilität mitverantwortlich, während es im Kern die Transkription verschiedener Zielgene des WntSignalweges reguliert [Brembeck et al., 2006]. Es konnte bereits gezeigt werden, dass die Änderung der Lokalisation von $\beta$-Catenin mit der Prognose des PCa und dem Expressionslevel von p120CTN assoziiert ist [Jaggi et al., 2005; Perez-Moreno und Fuchs, 2006; Whitaker et al., 2008]. Daher wurde die subzelluläre Lokalisation von $\beta$-Catenin in PC-3-Zellen nach Herunterregulierung der p120CTN- und LPXN-Expression analysiert. Dazu wurden die PC-3-Zellen mit LPXN-spezifischer siRNA, p120CTN-spezifischer siRNA und in Kombination mit siRNA gegen LPXN und p120CTN transfiziert. Als Kontrolle wurde eine Luciferasespezifische siRNA verwendet. $48 \mathrm{~h}$ nach der Transfektion wurden die Zellen auf einem Glasobjektträger ausplattiert. Nach einer weiteren Kultivierung von $24 \mathrm{~h}$ wurden die Zellen mit 4\% Formalin fixiert und eine immunzytochemische Analyse mit einem $\beta$-Catenin-spezifischem Antikörper durchgeführt. Wie in Abbildung 3.24 zu erkennen ist, resultiert ein knockdown der p120CTN-Expression in PC-3-Zellen in einer Akkumulation von $\beta$-Catenin im Kern. Ein knockdown der LPXN-Expression hingegen resultiert fast ausschließlich in der Lokalisation von $\beta$-Catenin an der Zytoplasmamembran. Bei gleichzeitiger Herunterregulierung der p120CTNund LPXN-Expression heben sich die beobachteten Einzeleffekte wieder auf und $\beta$-Catenin 
lokalisiert im Zytoplasma, an der Membran und im Kern. Die gleiche Lokalisation von $\beta$-Catenin ist ebenfalls in den Kontrollzellen zu erkennen.

FITC-

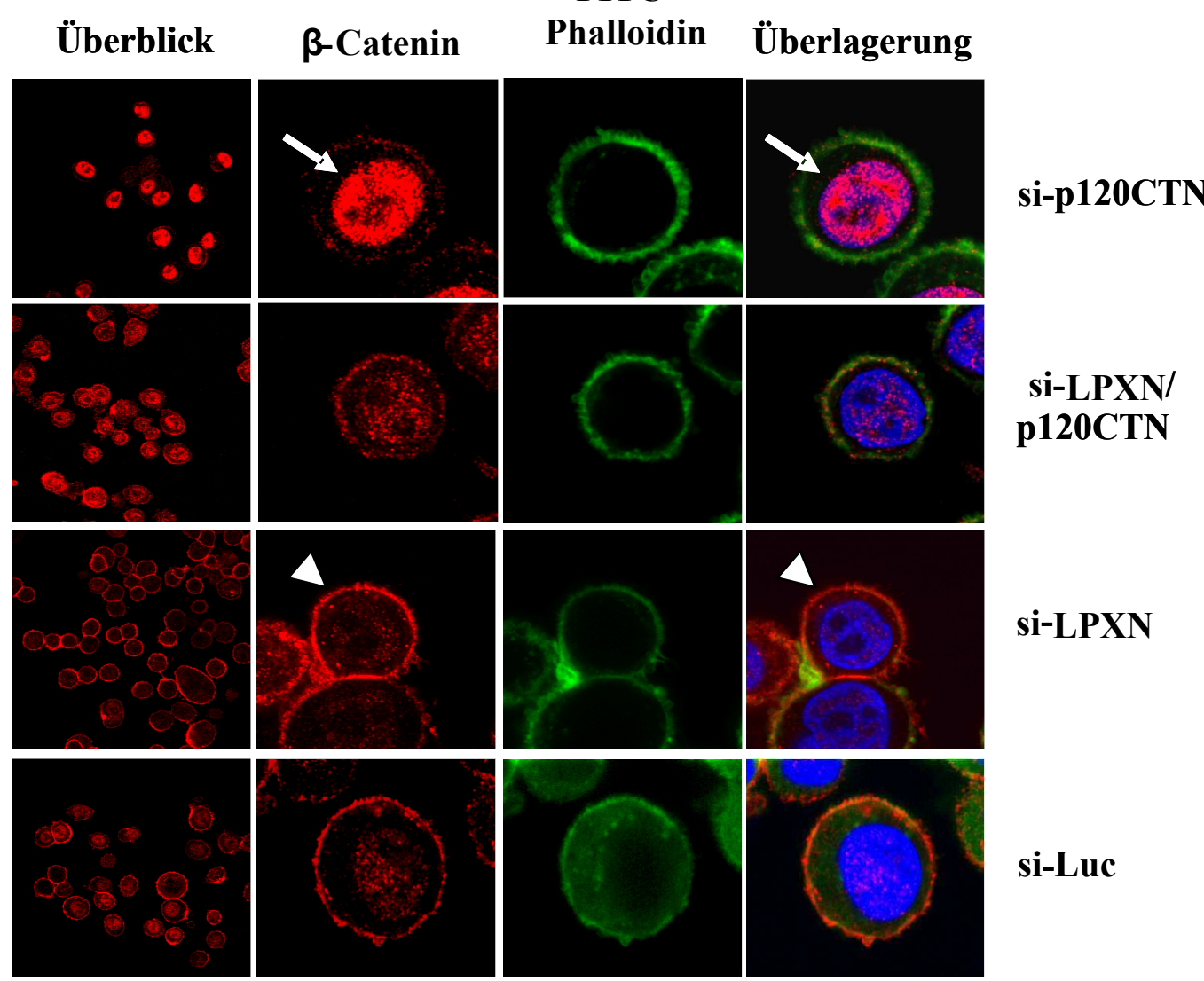

Abb. 3.24: Immunzytochemische Analyse zur Lokalisation von $\beta$-Catenin in PCa-Zellen nach Herunterregulierung der p120CTN- und LPXN-Expression [mod. aus Kaulfuß et al., 2009]. PC-3-Zellen wurden mit den in der Abbildung angegebenen siRNAs transfiziert und nach $48 \mathrm{~h}$ auf Glasobjektträgern ausplattiert. Anschließend wurden die Zellen fixiert und mit einem $\beta$-Catenin-spezifischem Antikörper behandelt. Das Zytoskelett wurde mit FITC-Phalloidin visualisiert, die Kernfärbung erfolgte mit DAPI. In der Überlagerung ist deutlich zu erkennen, dass ein p120CTN knockdown (si-p120CTN3) eine Lokalistion von $\beta$-Catenin im Kern bewirkt, während ein LPXN knockdown (siLPXN) in einer ausschließlichen Lokalisation von $\beta$-Catenin an der Zytoplasmamembran resultiert. Nach Herunterregulierung der LPXN- und p120CTN-Expression (siLPXN/p120CTN3) kann eine Lokalistion von $\beta$-Catenin sowohl an der Membran als auch im Kern detektiert werden. Diese $\beta$-Catenin-Verteilung ist ebenfalls in den Kontrollzellen (siLuc) zu beobachten. Alle Bilder wurden mit 600facher Vergrößerung aufgenommen und anschließend weiter vergrößert (bis auf die Überblickbilder).

Die Akkumulation von $\beta$-Catenin im Kern ist, wie in den vorherigen Versuchen gezeigt werden konnte, abhängig von der Abwesenheit von p120CTN an der Plasmamembran. PC-3-Zellen mit einer Expression von p120CTN an der Membran zeigen eine deutliche Lokalisation von $\beta$-Catenin sowohl an der Membran als auch im Kern. Ist jedoch die Expression von p120CTN herunterreguliert, lokalisiert $\beta$-Catenin ausschließlich im Kern (Abb. 3.25). 


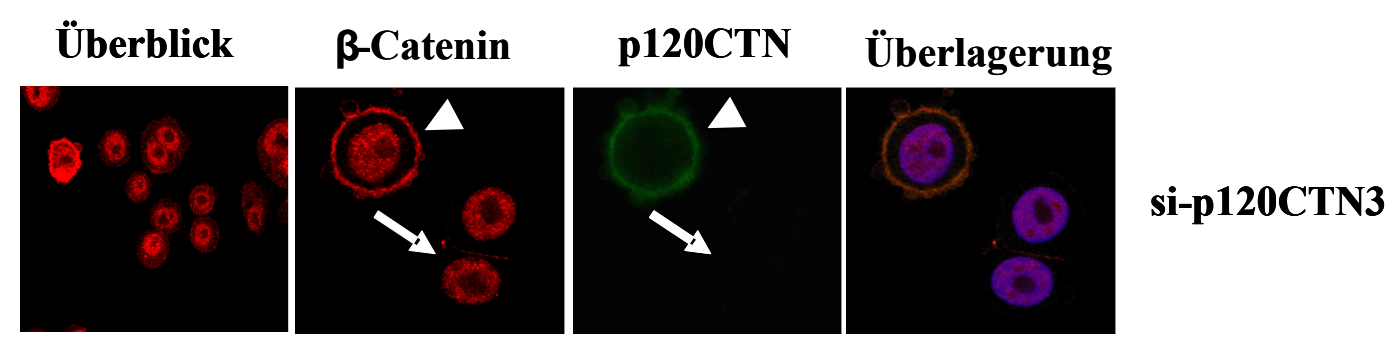

Abb. 3.25: Immunzytochemische Analyse zur Lokalisation von $\beta$-Catenin in PC-3-Zellen bei An- und Abwesenheit von p120CTN [mod. aus Kaulfuß et al., 2009]. Bei Anwesenheit von p120CTN an der Zellmembran (Blockpfeil) konnte eine Verteilung von $\beta$-Catenin sowohl im Kern als auch in der Zytoplasmamembran detektiert werden. Bei Abwesenheit der p120CTN-Expression ist eine ausschließliche Lokalisation von $\beta$-Catenin im Kern zu erkennen. Das Überblicksbild wurde mit 100 facher Vergrößerung, die übrigen Bilder mit 600 facher Vergrößerung aufgenommen.

\subsubsection{Herunterregulierung der LPXN-Expression vermindert die Expression des $\beta$-Catenin Zielgens MMP-7}

Die Akkumulation von $\beta$-Catenin im Kern resultiert in der Transkription verschiedener Zielgene [Ichikawa et al., 2006]. Ein Zielgen von $\beta$-Catenin ist z.B. die Matrix Metalloproteinase-7 (MMP-7). MMP-7 ist ein proteolytisches Enzym und in die Spaltung von Proteinen der extrazellulären Matrix involviert. MMP-7 ist ebenfalls in der Lage, weitere MMPs zu aktivieren und wird daher mit der Tumorinvasion in Verbindung gebracht [Wang et al., 2005; Adachi et al., 1999]. Weiterhin konnte bereits demonstriert werden, dass MMP-7 in mehreren Karzinomen wie Lunge [Bolon et al., 1997], Haut [Karelina et al., 1994], Brust [Heppner et al., 1996] und Prostata [Pajouh et al., 1991] überexprimiert und mit einer schlechten Prognose assoziiert ist.

Die Expression von MMP-7 in PC-3-Zellen nach Herunterregulierung der LPXN- und p120CTN- Expression wurde durch eine quantitative real time PCR-Analyse dargestellt. Dazu wurden die PC-3-Zellen mit LPXN-, p120CTN- und in Kombination mit LPXN- und p120CTNspezifischer siRNA transfiziert und nach $72 \mathrm{~h}$ RNA isoliert. Als Kontrolle wurde RNA von Zellen isoliert, die mit Luciferase-spezifischer siRNA transfiziert wurden. Anschließend wurde die RNA mittels reverser Transkriptase in cDNA umgeschrieben und in der quantitativen real time PCR-Analyse eingesetzt. Wie in Abbildung $3.26 \mathrm{zu}$ erkennen ist, resultiert die Herunterregulierung der LPXN-Expression in einer reduzierten Expression von MMP-7. Die Herunterregulierung der p120CTN-Expression, welche mit einer Akkumulation von $\beta$-Catenin 
im Kern assoziiert ist, resultiert hingegen in einer erhöhten MMP-7-Expression. Der Doppel knockdown der LPXN- und p120CTN-Expression resultiert in keiner signifikanten Veränderung der MMP-7-Expression im Vergleich zu den Luciferase-siRNA transfizierten Kontrollzellen.

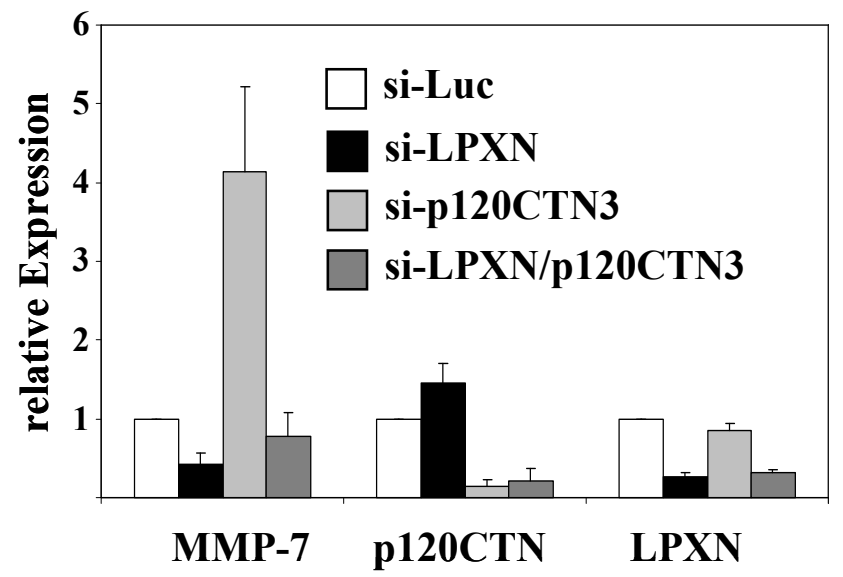

Abb. 3.26: Expressionsverlust von LPXN und p120CTN in PC-3-PCa-Zellen resultiert in einer veränderten Expression des $\beta$-Catenin Zielgens MMP-7 [mod. aus Kaulfuß et al., 2009]. Um die Expression des $\beta$-Catenin Zielgens MMP-7 zu untersuchen, wurden PC-3-Zellen mit siRNA gegen LPXN (si-LPXN), p120CTN (si-p120CTN3), LPXN und p120CTN (si-LPXN/si-p120CTN3) und Luciferase (si-Luc) transfiziert. Anschließend wurde Gesamt-RNA isoliert und in cDNA umgeschrieben. Die quantitative real time PCR-Analyse demonstriert ein Expressionsverlust von MMP-7 nach Herunterregulierung der LPXN-Expression und eine verstärkte Expression von MMP-7 nach Herunterregulierung der p120CTN-Expression. Der Mittelwert \pm Standardabweichung wurde von drei unabhängigen quantitativen real time PCR-Analysen berechnet.

\subsubsection{5 Überexpression von LPXN erhöht die Expression des $\beta$-Catenin Zielgens MMP-7}

Um zu zeigen, dass die Expression von MMP-7 ebenfalls ansteigt, wenn die Expression von LPXN in den PC-3-Zellen hochreguliert wird (gleichzusetzen mit der Herunterregulierung der p120CTN-Expression), wurde eine quantitative real time PCR-Analyse durchgeführt. Dafür wurden die PC-3-Zellen zunächst mit Plasmiden zur Expression von LPXN-Fusionsproteinen transfiziert und nach 48 h Gesamt-RNA isoliert. Nach einer DNAse-Behandlung wurde die RNA mittels reverser Transkriptase in cDNA umgeschrieben und in der quantitativen real time PCRAnalyse eingesetzt. Wie in Abbildung $3.27 \mathrm{zu}$ erkennen ist, konnte eine zwei- bis dreifache Hochregulierung der MMP-7-Expression nach Überexpression von LPXN nachgewiesen werden. 


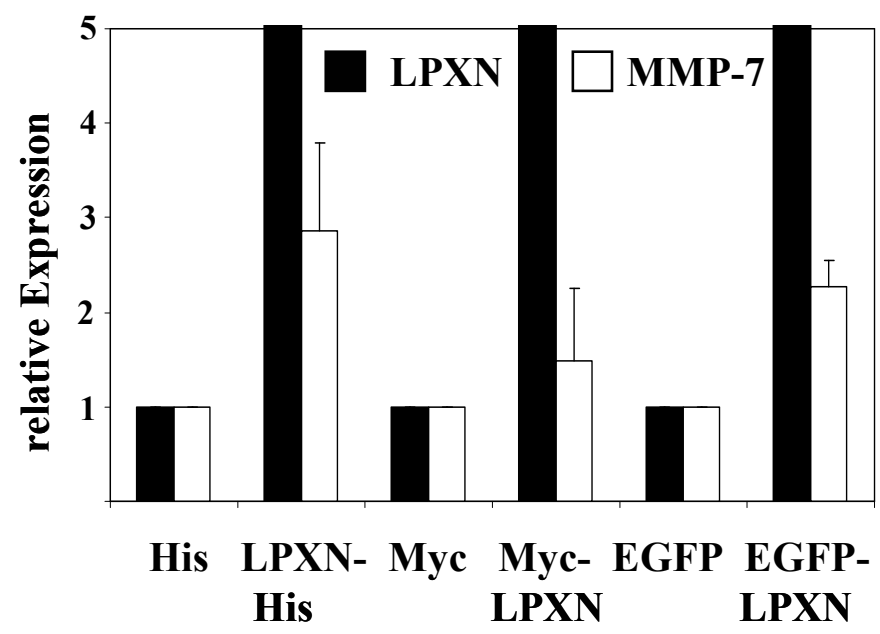

Abb. 3.27: Quantitative real time PCR-Analyse zur Expression des B-Catenin Zielgens MMP-7 nach Überexpression von LPXN [mod. aus Kaulfuß et al., 2009]. PC-3-Zellen wurden mit Plasmiden zur Überexpression von verschiedenen LPXN-Fusionsproteinen (LPXN-His, Myc-LPXN, EGFP-LPXN) und den entsprechenden Kontrollplasmiden (His, Myc, EGFP) transfiziert. Nach 48 h wurde Gesamt-RNA isoliert und in cDNA umgeschrieben. Die anschließende quantitative real time PCR-Analyse verdeutlicht eine erhöhte Expression von MMP-7 nach Überexpression von LPXN durch verschiedene LPXN-Fusionsproteine. Die relative Expression von LPXN und MMP-7 in den Kontroll-transfizierten Zellen wurden jeweils gleich 1 gesetzt. Der Mittelwert \pm Standardabweichung wurde von drei unabhängigen quantitativen real time PCR-Analysen berechnet.

\subsubsection{Whole genome expression microarray zur Ermittlung von Kandidatengenen, welche durch LPXN während der Tumorprogression reguliert werden}

Um gezielt weitere Kandidatengene zu identifizieren, auf dessen Regulation LPXN während der Progression des PCa Einfluss nehmen könnte durch, wurde ein whole genome expression Array in Zusammenarbeit mit dem Transkriptomanalyselabor unter der Leitung von Dr. Gabriela Salinas-Riester (Universitätsmedizin Göttingen) durchgeführt. In diesem Microarray wurde die Expression von Genen in den Tumoren von doppelt transgenen LPXN/TRAMP- und einfach transgenen TRAMP-Mäusen miteinander verglichen. Dafür wurden von jeder Versuchstiergruppe (L/-T/- \#20 und T/-) unabhängig vom Alter drei Mäuse präpariert, die einen erbsengroßen $\left(10 \mathrm{~mm}^{3}\right)$ Tumor entwickelt hatten. Diese definierte Größe des Tumors wurde genau eingehalten, um ein einheitliches Progressionsstadium zu gewährleisten. Ein Teil der präparierten Tumore wurde jeweils für eine histopathologische Analyse zunächst in Formalin fixiert und ein anderer Teil des Tumors wurde für eine RNA- 
Isolierung bei $-80^{\circ} \mathrm{C}$ eingefroren. Wie in Abbildung 3.28 dargestellt, wurden die angefertigten Gewebeschnitte der Prostatatumore mit HE angefärbt und anschließend in Zusammenarbeit mit PD Dr. Stefan Schweyer (Abteilung Pathologie, Universitätsmedizin Göttingen) ausgewertet. Alle für den Array verwendeten Mäuse (L/-T/- \#20 13F, 16F, 20F und T/- 27G, 36G, 44G) hatten zum Zeitpunkt der Präparation einen schlecht differenzierten Tumor (PDC) entwickelt, wobei keine Metastasen in Leber, Lunge, Niere, Milz oder Lymphknoten detektiert werden konnten.

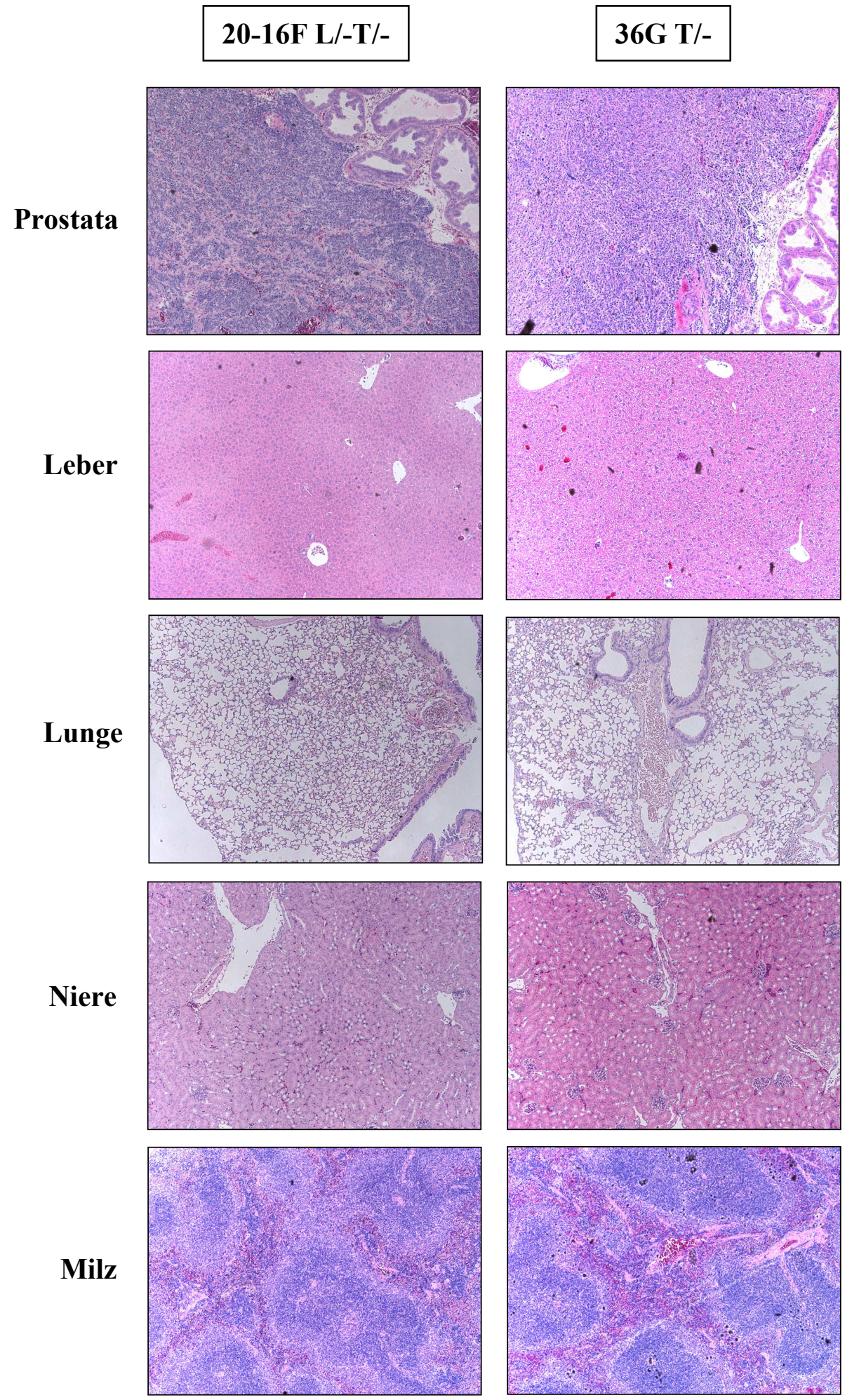


Abb. 3.28 Histopathologische Analyse zur Überprüfung der morphologischen Veränderung der Organe von doppelt (L/-T/-) und einfach (T/-) transgenen Mäusen. Jeweils drei Tiere der doppelt transgenen LPXN/TRAMP- und einfach transgenen TRAMP-Mäuse wurden mit einem PCa-Volumen von ca. $10 \mathrm{~mm}^{3}$ präpariert, ein Teil des Prostatatumors, der Leber, der Lunge, der Niere und der Milz herausgenommen, in Formalin fixiert und HE-Schnitte angefertigt. In allen sechs Mäusen (hier stellvertretend dargestellt 20-16F L/-T/- und 36G T/-) konnten ein schlecht differenziertes Karzinom der Prostata und keine Metastasen festgestellt werden. Alle Abbildungen wurden mit einem Fluoreszenzmikroskop mit einer 40fachen Vergrößerung aufgenommen.

Nach der histopathologischen Auswertung der HE-Schnitte wurde der Microarray durchgeführt. Dafür wurde zunächst aus den isolierten Tumoren RNA aufgereinigt und wie unter 2.25 beschrieben weiter behandelt. Die statistische Auswertung der Array-Daten erfolgte in Zusammenarbeit mit Herrn Lennart Opitz (Transkriptomanalyselabor, Universitätsmedizin Göttingen). Wie in Tabelle 3.1 aufgelistet, konnten von den fast 21000 aufgespotteten Genen auf dem Microarray nur vier Kandidaten ermittelt werden, welche mindestens um den Faktor 0,6 dereguliert ist (L/-T/- vs. T/-) und bei denen die Wahrscheinlichkeit für ein falsch positives Ergebnis unter 99,94\% (FDR = false discovery rate) liegt.

Tab. 3.1 Ergebnisse des cDNA-Microarrays für Tumore mit Überexpression von LPXN L/-T/- im Vergleich zu Kontrolltumoren T/-. Es konnten nur vier potentielle Kandidaten ermittelt werden, bei denen die Wahrscheinlichkeit für ein falsch positives Ergebnis unter 99,94\% liegt.

\begin{tabular}{|c|c|c|c|}
\hline Symbol & Name & $\begin{array}{c}\text { L/-T/- vs. } \\
\text { T/- }\end{array}$ & FDR \\
\hline D430039N05Rik & RIKEN cDNA D430039N05 gene & $-1,05$ & $56,64 \%$ \\
\hline Cbs & cystathionine beta-synthase & $-0,84$ & $56,64 \%$ \\
\hline Ccdc109b & coiled-coil domain containing & 1,19 & $59,19 \%$ \\
\hline Hopx & HOPB homeobox & 1,65 & $71,54 \%$ \\
\hline Is12 & insulin related protein 2 (islet 2) & $-0,62$ & $99,94 \%$ \\
\hline Ephb1 & Eph receptor B1 & $-0,77$ & $99,94 \%$ \\
\hline Rarb & retinoic acid receptor, beta & $-1,10$ & $99,94 \%$ \\
\hline
\end{tabular}


Zur Überprüfung der im Mircroarray ermittelten, in der Tabelle 3.1 gelb hinterlegten, putativen Kandidatengene wurde eine quantitative real time PCR-Analyse durchgeführt. Dafür wurde von der im Array verwendeten RNA cDNA synthetisiert und diese in der quantitativen real time PCR eingesetzt. Für die Gene Isl-2, Ephb1 und Rarb, welche eine „falsch positiv“ Wahrscheinlichkeit von 99,94\% aufwiesen, konnte keine signifikante Herunterregulierung der Genexpression in den Tumoren der doppelt transgenen Mäuse (L/-T/-) nachgewiesen werden. Für die Gene Cbs und Hopx hingegen konnte eine Abnahme bzw. Zunahme der Expression in den Tumoren der doppelt transgenen Mäuse (L/-T/-) bestätigt werden. Die in dem Diagramm aufgezeigten Werte ergeben sich aus dem Mittelwert der Genexpression der Tumore der doppelt transgenen Mäuse (L/-T/- \#20 13F, 16F, 20F) im Vergleich zu den einfach transgenen Mäusen (T/- 27G, 36G, 44G). Die quantitativen real time PCR-Analyse wurde als Duplikat durchgeführt (Abb. 3.29).

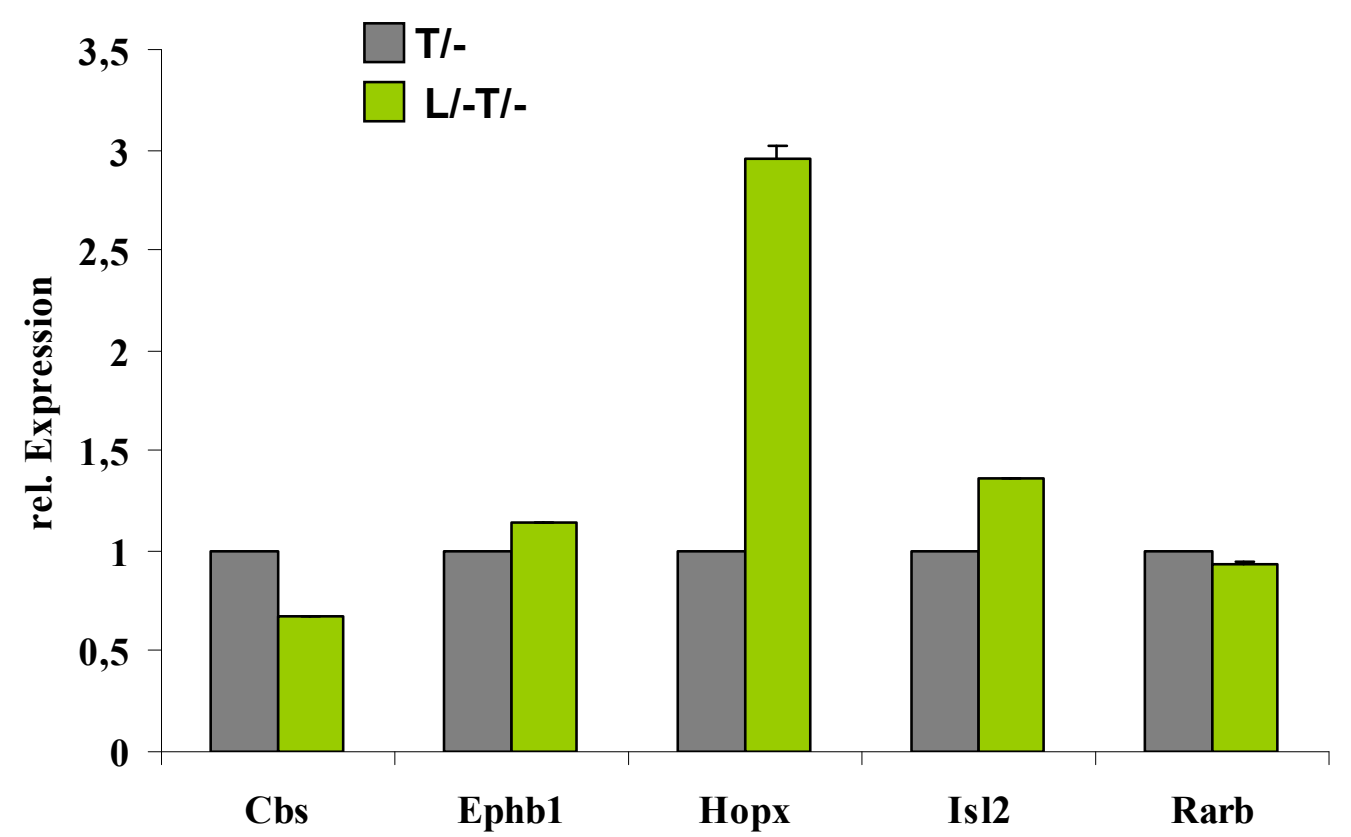

Abb. 3.29: Quantitative real time PCR-Analyse zur Bestätigung der Ergebnisse aus dem cDNAMicroarray. Die in dem Array verwendete RNA aus den Tumoren der doppelt transgenen (L/-T/- \#20 13F, 16F, 20F) und einfach transgenen Mäuse (T/- 27G, 36G, 44G) wurde mittels reverser Transkriptase in cDNA umgeschrieben und für die quantitative real time PCR-Analyse eingesetzt. Für die Gene Ephb1, Isl2 und Rarb konnte der Expressionsverlust in den doppelt transgenen Tumoren (L/-T/-) nicht bestätigt werden. Die Abnahme der Expression von Cbs und die Zunahme der Expression von Hopx in den doppelt transgenen Tumoren (L/-T/-) konnte hingegen gezeigt werden. Die quantitative real time PCR-Analyse wurde doppelt durchgeführt und jeweils der Mittelwert der Versuche angegeben. Die Genexpression in den Tumoren der einfach transgenen Mäuse (T/-) wurde gleich 1 gesetzt und die Genexpression der doppelt transgenen Mäuse (L/-T/-) dazu in Relation gebracht. 


\section{Hypothese: LPXN interagiert mit Proteinen, die die Zellmigration/ Invasion fördern}

\subsection{Caldesmon als Interaktionspartner von LPXN}

Während meiner Diplomarbeit wurde zur Identifizierung von Interaktionspartnern von LPXN ein Yeast-two-Hybrid-Screening durchgeführt. Dafür wurde von der Firma Clontech eine humane Prostata cDNA-Bibliothek erworben, welche gebunden an eine Bindedomäne als „Beuteprotein“ fungierte. LPXN wurde in einen Vektor mit Aktivierungsdomäne kloniert und diente als „Köderprotein“. Das Aktin-bindende Protein Caldesmon konnte dabei als putativer Interaktionspartner von LPXN identifiziert werden [Beckemeyer, 2007].

Durch alternatives splicing von Caldesmon entstehen fünf verschiedene Isoformen [Hayashi et al., 1992]. Während Isoform1 (h-Cald) als in Muskelzellen vorkommende Isoform beschrieben wird $(90-150 \mathrm{kDa})$, treten die Isoformen 2-5 (1-Cald) mit einem geringeren Molekulargewicht $(60-80 \quad \mathrm{kDa})$ in Nichtmuskelzellen auf. In den Nichtmuskelzellen lokalisiert Caldesmon an den Stressfasern, Lamellipodien und Filopodien des Zytoskeletts, wobei es ein bedeutender Faktor in der Organisation und Stabilisation des Mikrofilament-Netzes ist [Sobue et al., 1991]. Es ist bereits bekannt, dass die Phosphorylierung von Caldesmon zu einer Inaktivierung des Proteins führt. Dies wiederum führt zu einer Destabilisierung des gesamten Zytoskeletts [Li et al., 2009].

Da die Interaktion von LPXN und Caldesmon bislang nur mittels gerichteten Yeast-twoHybrid-Experiments bestätigt wurde, war es Gegenstand weiterer Experimente diese Interaktion zu verifizieren.

\subsubsection{Expression von Caldesmon in PCa-Zelllinien}

Die Expression von Caldesmon in den etablierten PCa-Zelllinien PC-3, DU 145 und LNCaP wurde mittels Northern Blot und Western Blot untersucht (Abb. 3.30). Sowohl auf RNA- als auch auf Protein-Ebene kann die stärkste Expression von Caldesmon in der androgenunabhängigen PCa-Zelllinie PC-3 nachgewiesen werden. Im Northern Blot wurde zur Bestätigung der eingesetzten RNA-Menge eine Sonde gegen $\beta$-Aktin, im Western Blot zur Überprüfung der eingesetzten Proteinmenge ein Antikörper gegen $\alpha$-Tubulin verwendet. 
A

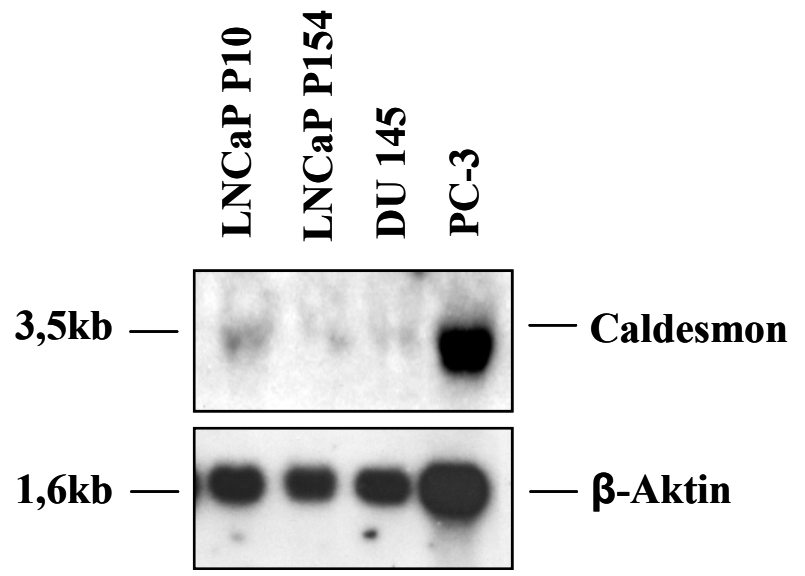

B

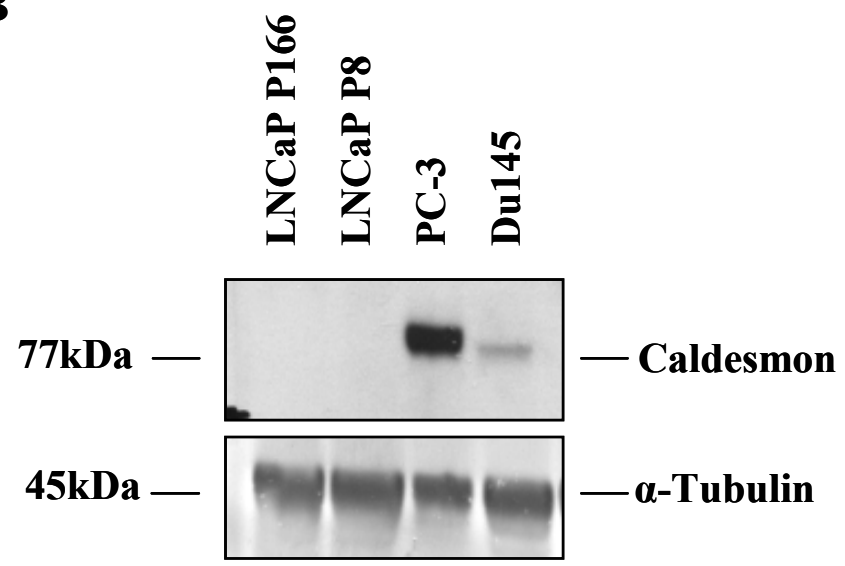

Abb. 3.30: Expression von Caldesmon in verschiedenen PCa-Zelllinien. Zur Untersuchung der Expression von Caldesmon in PCa-Zelllinien wurden eine Northern Blot- und eine Western Blot-Analyse durchgeführt. Zur Detektion von Caldesmon wurde die Northern Blot-Membran mit einer Caldesmon-spezifischen cDNA-Sonde hybridisiert. Die eingesetzte RNA-Konzentration wurde durch eine $\beta$-Aktin-Sonde überprüft. Im Western Blot wurde ein Caldesmon-Antikörper verwendet, der eine spezifische Bande bei der für Caldesmon erwarteten Größe von 77 kDa darstellt. Zur Überprüfung der eingesetzten Proteinmenge wurde ein Antikörper gegen $\alpha$-Tubulin eingesetzt. Sowohl auf RNA- als auch auf Proteinebene konnte die stärkste Expression von Caldesmon in der PCa-Zelllinie PC-3 nachgewiesen werden.

\subsubsection{Untersuchung der subzellulären Lokalisation von Caldesmon in den PCa-Zellen PC-3}

Zur Untersuchung der subzellulären Lokalisation von Caldesmon in den PCa-Zellen PC-3 wurden diese auf Glasobjektträgern ausplattiert und nach $24 \mathrm{~h}$ fixiert. Anschließend wurde zur Detektion von Caldesmon eine Immunzytochemie mit einem Caldesmon-spezifischen 
Antikörper durchgeführt. Wie in Abbildung 3.31 abgebildet, lokalisiert Caldesmon in den untersuchten PC-3-Zellen an den F-Aktin-Filamenten, welche hier zusätzlich durch FITCPhalloidin angefärbt wurden.
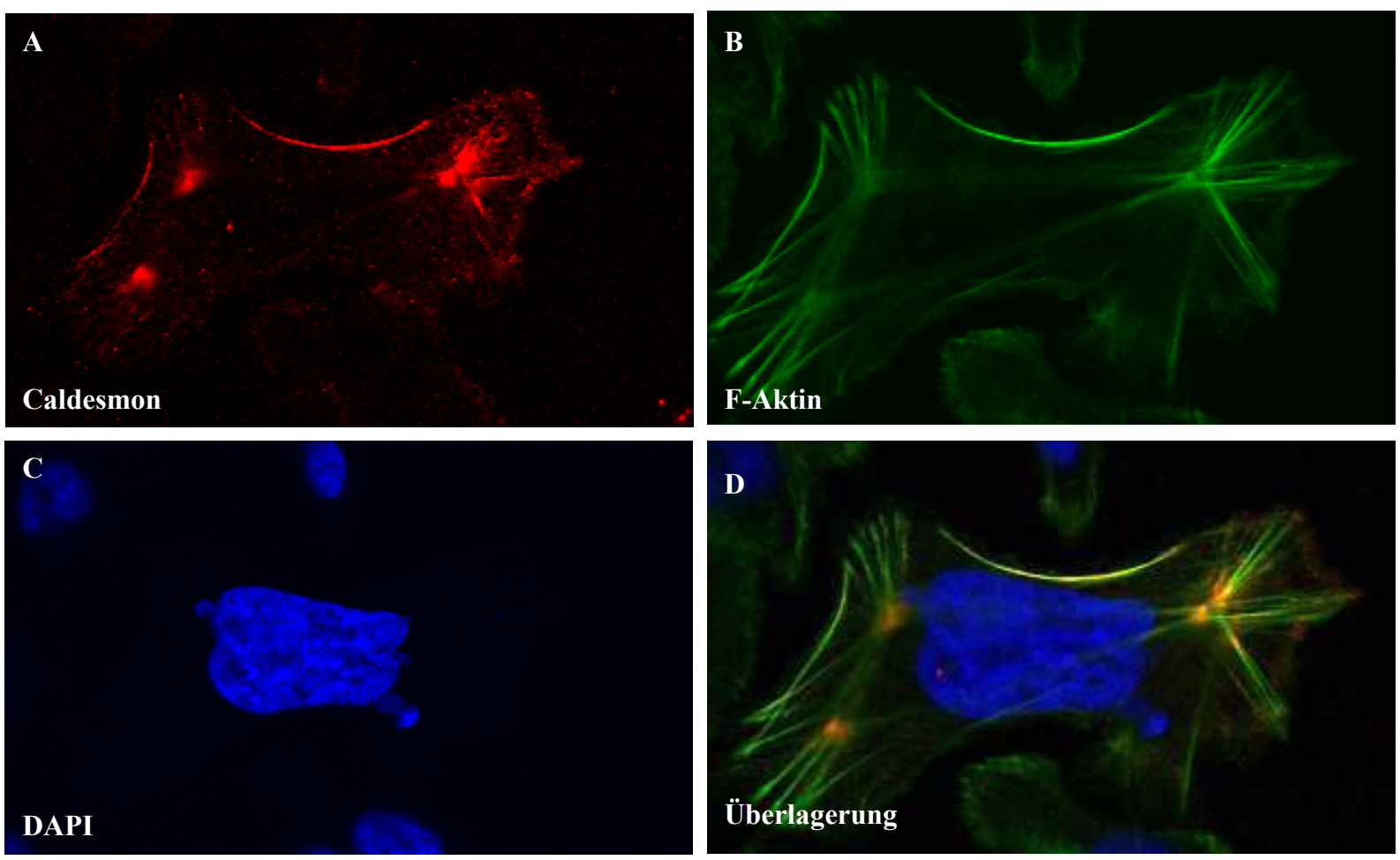

Abb. 3.31: Immunzytochemische Analyse zur subzellulären Lokalisation von Caldesmon in PC-3. A. PC-3-Zellen wurden auf Glasobjektträgern ausplattiert und für $24 \mathrm{~h}$ inkubiert. Anschließend wurden die Zellen fixiert und Caldesmon mit einem spezifischen Antikörper detektiert. B. Die Visualisierung des Zytoskeletts erfolgte mit FITC-Phalloidin (F-Aktin). C. Die Kerne wurden mit DAPI angefärbt. Die OrangeFärbung in der Überlagerung weist auf eine Lokalisation von Caldesmon an den F-Aktin-Filamenten hin. Alle Bilder wurden mit einem konfokale Laserscanning-Mikroskop mit 600facher Vergrößerung aufgenommen.

\subsubsection{Subzelluläre Kolokalisation von LPXN und Caldesmon in den PCa-Zellen PC-3}

Um nachzuweisen, dass die subzelluläre Lokalisation von LPXN mit der Lokalisation von Caldesmon übereinstimmt, wurde eine Immunfärbung durchgeführt. Zuvor wurden die PCaZellen PC-3 mit pEGFP-Caldesmon (Material und Methoden 2.8.7) transfiziert. Gleichzeitig erfolgte eine Transfektion der Zellen mit pCMV-LPXN-cmyc (Material und Methoden 2.8.7). Zur Detektion des Fusionsproteins LPXN-cmyc wurde ein cmyc-spezifischer Antikörper 
verwendet. Die Überlagerung der Grün- und Rotfärbung zeigt deutlich, dass Caldesmon und LPXN am Ende der F-Aktin-Filamente, den focal adhesion sites, kolokalisieren (Abb. 3.32).
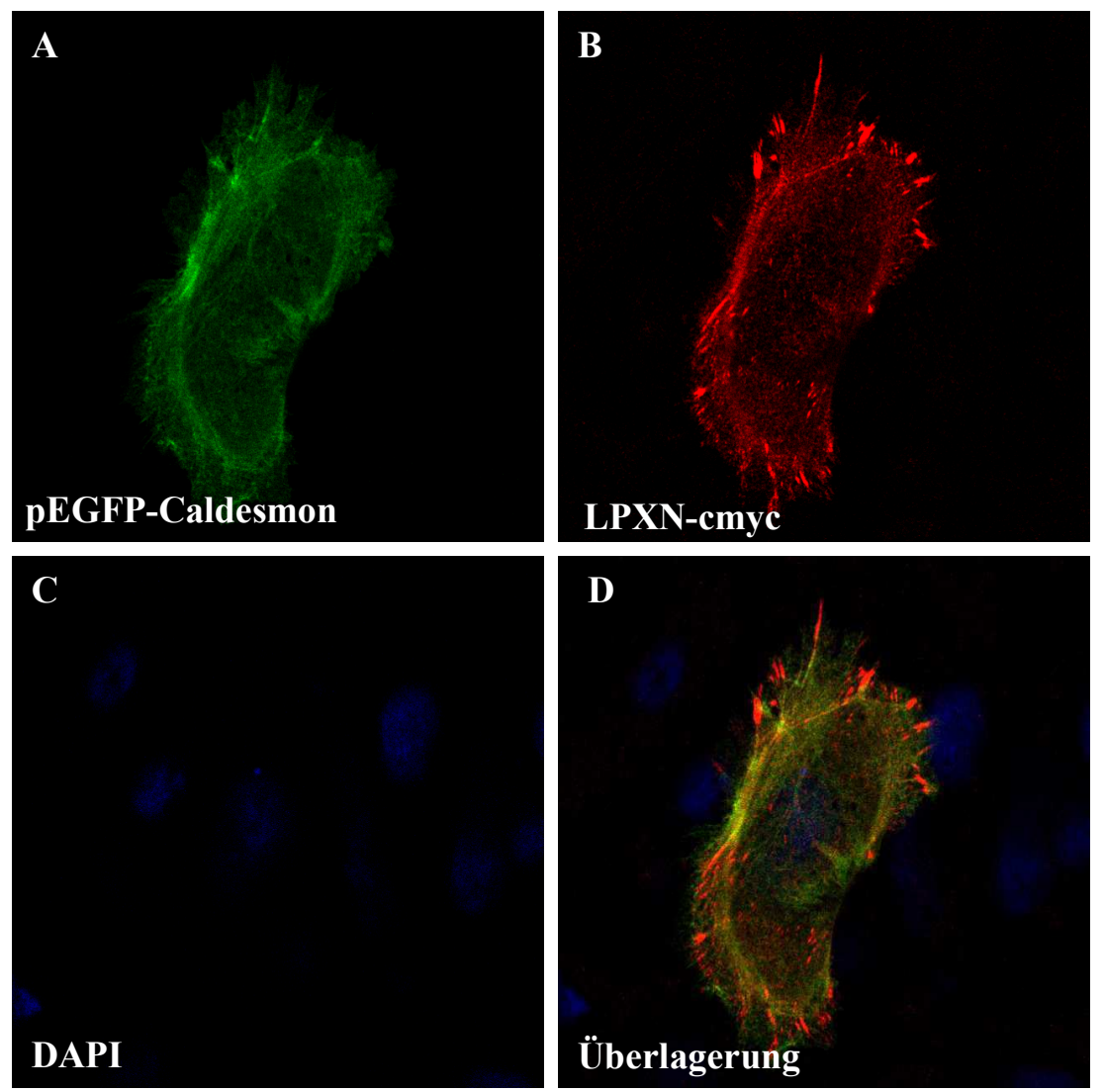

Abb. 3.32: Kolokalisation von LPXN und Caldesmon in den PCa-Zellen PC-3. Mittels Immunzytochemie konnte eine subzelluläre Kolokalisation von LPXN und Caldesmon in den PC-3-Zellen festgestellt werden. Dafür wurden die Zellen mit den Plasmiden zur Überexpression von EGFP-Caldesmon und LPXN-cmyc kotransfiziert, auf einem Glasobjektträger ausplattiert und nach $24 \mathrm{~h}$ fixiert. LPXN-cmyc wurde mit einem cmyc-spezifischen Antikörper detektiert. A. Die Überlagerung der kotransfizierten Zellen zeigt eine Lokalisation sowohl von Caldesmon als auch von LPXN an den Enden der F-Aktin-Filamente, den focal adhesion sites. Die Färbung der Zellkerne erfolgte mit DAPI. Die Bilder wurden mit einem konfokalen Laserscanning-Mikroskop mit einer 600 fachen Vergrößerung aufgenommen.

\subsubsection{Interaktionsnachweis von LPXN und Caldesmon durch ein GST- Pulldown-Experiment}

Ein Experiment, um die Protein-Protein-Wechselwirkungen zwischen LPXN und Caldesmon nachzuweisen, stellt der GST-Pulldown dar. Dafür wurde LPXN zunächst als Gluthation-STransferase (GST)-Fusionsprotein in E.coli exprimiert und aufgereinigt (Material und Methoden, 2.27.2). Um zu untersuchen, mit welchem Bereich von LPXN die Interaktion mit 
Caldesmon stattfindet, wurden GST-Konstrukte generiert, die einerseits nur die LIM-Domäne (GST-LPXN-LIM) von LPXN und andererseits nur die LD-Motive (GST-LPXN-LD) von LPXN (Material und Methoden 2.8.7) enthielten. Gleichzeitig wurden PC-3-Zellen zur Überexpression von Caldesmon mit pEGFP-Caldesmon transfiziert. Nach der Aufreinigung des GST-LPXN Fusionsproteins und der Isolierung des Gesamtproteins der transfizierten PC3-Zellen wurden diese zusammen inkubiert. Durch die bestehende Interaktion von LPXN und Caldesmon konnte der gesamte (GST-LPXN)-(EGFP-Caldesmon)-Komplex anschließend an die Gluthation-Sepharose binden. Nicht gebundenes Protein wurde durch nachfolgende Waschschritte entfernt. Die Elution der Komplexe von der Gluthation-Sepharose erfolgte mittels reduziertem Gluthation. Nach der Isolierung des gebundenen Proteins wurde eine Western Blot-Analyse mit einem Caldesmon-spezifischen Antikörper und zur Überprüfung der erfolgreichen Aufreinigung mit einem GST-spezifischen Antikörper durchgeführt. In einem Kontrollansatz wurde das Protein der transfizierten PC-3-Zellen mit GST-Protein inkubiert. Wie in Abbildung 3.33 dargestellt, konnte eine Interaktion von Caldesmon mit LPXN (GST-LPXN), genauer mit der LD-Domäne von LPXN (GST-LPXN-LD), nachgewiesen werden.

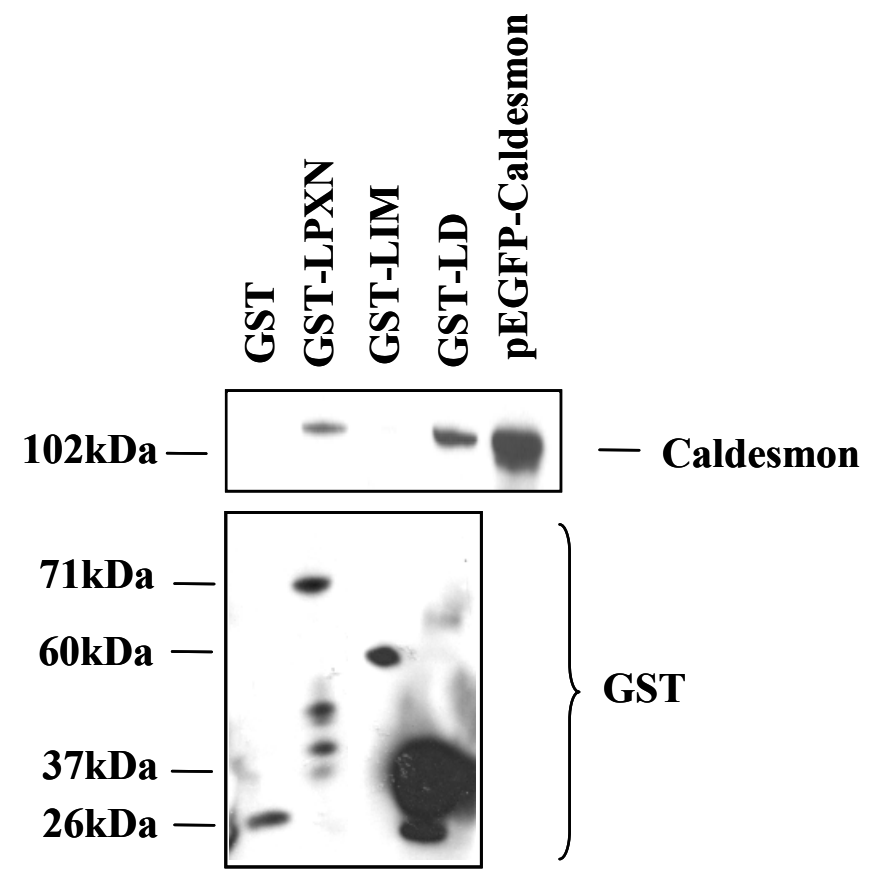

Abb. 3.33: GST-Pulldown zur Bestätigung der Interaktion von LPXN und Caldesmon. PC-3-Zellen wurden mit einem pEGFP-Caldesmon-Plasmid transfiziert und nach 48 h Gesamt-Protein isoliert. Anschließend wurden mit den in Bakterien überexprimierten Fusionsproteinen (GST-LPXN, GST-LPXN-LIM, GST-LPXN-LD, GST) und dem Gesamt-Protein der Zellen ein GST-Pulldown durchgeführt. Nach Aufreinigung der Proteine wurde zur 
Überprüfung der Interaktion von LPXN und Caldesmon eine Western Blot-Analyse mit einem Caldesmonspezifischen Antikörper durchgeführt. Für das gesamte LPXN (GST-LPXN) sowie die LD-Domäne von LPXN (GST-LD) konnte für Caldesmon eine Interaktion mit LPXN bestätigt werden. In der Negativkontrolle (GST) wurde keine Bande in der für EGFP-Caldesmon erwarteten Größe (102 kDa) detektiert. Als Positivkontrolle der Western Blot-Analyse und als Überprüfung der erfolgreichen Überexpression von EGFP-Caldesmon in PC-3Zellen wurde zusätzlich der Input (EGFP-Caldesmon) aufgetragen. Die Überprüfung der aufgereinigten GSTFusionsproteine erfolgte durch Hybridisierung der Membran mit einem GST-Antikörper.

\subsubsection{Analysen zur Funktion von Caldesmon}

\subsubsection{Herunterregulierung der Expression von Caldesmon in PCa- Zelllinien mittels RNA-Interferenz}

Die Funktion von Caldesmon in den PCa-Zelllinien wurde durch die Herunterregulierung der Expression untersucht. Dazu wurden PC-3-Zellen mit zwei verschiedenen Caldesmonspezifischen Duplex-siRNA-Oligonukleotiden transfiziert (siCaldA und siCaldB). Als Kontrolle wurden die Zellen mit einem Duplex-siRNA-Oligonukleotid transfiziert, welches spezifisch gegen das Luciferase-Gen gerichtet ist (Material und Methoden 2.22.2). $72 \mathrm{~h}$ nach der Transfektion wurden Gesamt-RNA bzw. Gesamt-Protein isoliert. Die RNA wurde mittels reverser Transkriptase in cDNA umgeschrieben und anschließend für eine quantitative real time PCR-Analyse eingesetzt. $50 \mu \mathrm{g}$ des isolierten Gesamt-Proteins wurden für eine Western Blot-Analyse eingesetzt. Aus der Abbildung 3.34 ergibt sich, dass sowohl auf RNA- als auch auf Protein-Ebene eine spezifische Herunterregulierung der Caldesmon-Expression durch die siRNA-Oligonukleotide erfolgt. In der quantitativen real time PCR-Analyse konnte eine Reduktion der Caldesmon-Expression um 60\% (siCaldA) bzw. 85\% (siCaldB) ermittelt werden.

$\mathbf{A}$

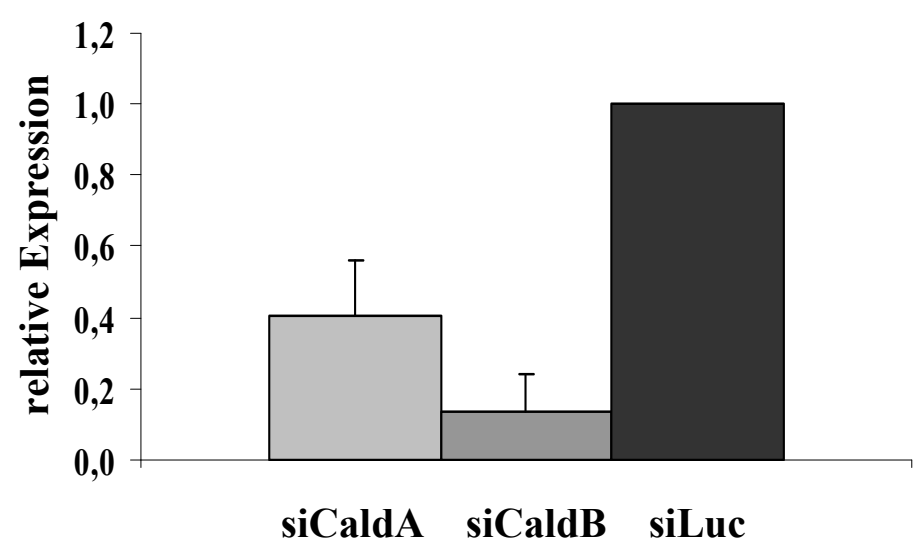




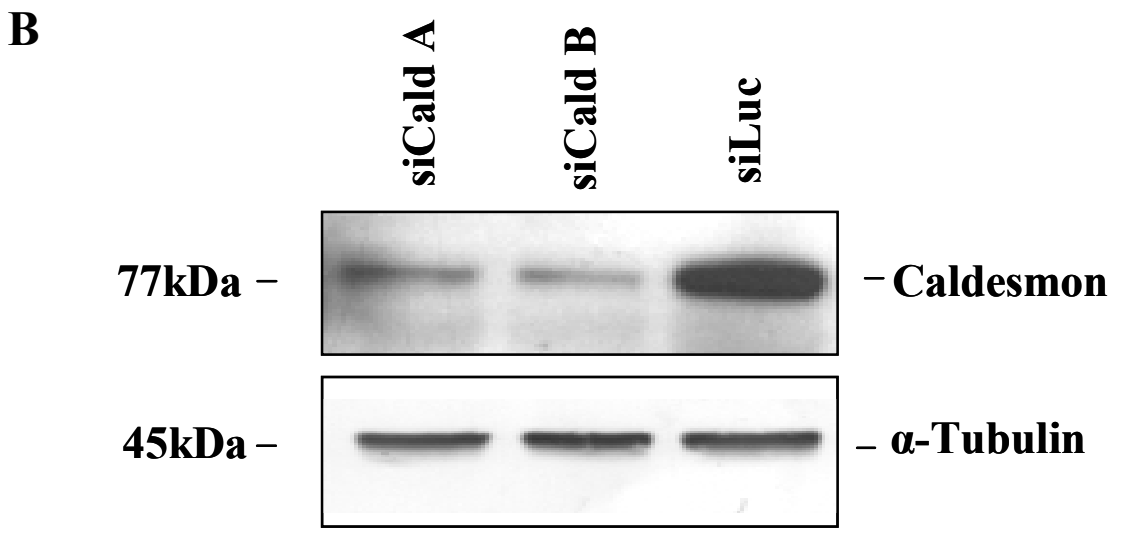

Abb. 3.34 Quantitative real time PCR-Analyse und Western Blot-Analyse zur Bestätigung der herunterregulierten Caldesmon-Expression in PC-3-Zellen nach Transfektion mit spezifischer siRNA. Zur Herunterregulierung der Caldesmon-Expression wurden PC-3-Zellen mit Caldesmon-spezifischer siRNA (siCaldA, siCaldB) und als Kontrolle gegen das Luciferase-Gen transfiziert. A. Die quantitative real time PCRAnalyse bestätigt einen knockdown der Caldesmon-Expression durch die siRNA um 60\% (siCaldA) bzw. 85\% (siCaldB). Dabei wurde jeweils die relative Expression von Caldesmon, abgeglichen gegen ein HousekeepingGen ermittelt. B. Auf Proteinebene konnte ebenfalls eine spezifische Herunterregulierung der CaldesmonExpression nach Transfektion der Zellen mit spezifischer siRNA demonstriert werden. Zur Kontrolle der aufgetragenen Proteinmenge wurde die Western Blot-Membran mit einem $\alpha$-Tubulin-spezifischen Antikörper hybridisiert.

\subsubsection{Verstärkte Zellmigration von PC-3- und DU 145-PCa-Zellen nach Herunterregulierung der Caldesmon-Expression}

Da Caldesmon an den Stressfasern des Zytoskeletts lokalisiert ist und ein bedeutender Faktor in der Organisation und Stabilisation des Mikrofilament-Netzwerkes darstellt, stellte sich die Frage, ob Caldesmon, ebenso wie LPXN, in die Migrationsfähigkeit der PCa-Zellen involviert ist. Zur Beantwortung dieser Frage wurde ein Migrationsassay durchgeführt. Dazu wurden PC-3-Zellen zunächst mit Caldesmon-spezifischer siRNA und als Kontrolle mit Luciferase-spezifischer siRNA transfiziert. Nach $48 \mathrm{~h}$ wurden 80000 Zellen in einer Transwell-Migrations-Kammer ausplattiert und anschließend für weitere $24 \mathrm{~h}$ inkubiert. Während dieser Zeit konnten die migrierenden Zellen auf die andere Seite der PET-Membran gelangen. Nach der Inkubationszeit wurden die in der Kammer verbliebenen Zellen entfernt und die Zellen auf der Unterseite der Membran fixiert und angefärbt. Danach wurde die Membran vorsichtig aus der Kammer geschnitten und auf einem Objektträger eingedeckelt. 
Unter einem Mikroskop wurden Zellen in 5 Sichtfeldern in 200facher Vergrößerung ausgezählt (Material und Methoden, 2.21). Es wurden mindestens drei unabhängige Experimente durchgeführt. Wie in Abbildung $3.35 \mathrm{zu}$ erkennen, weisen sowohl die PC-3- als auch die DU 145-PCa-Zellen nach Herunterregulierung der Caldesmon-Expression im Vergleich zu den Kontrollzellen eine erhöhte Migrationsfähigkeit auf $(A+B)$.

A

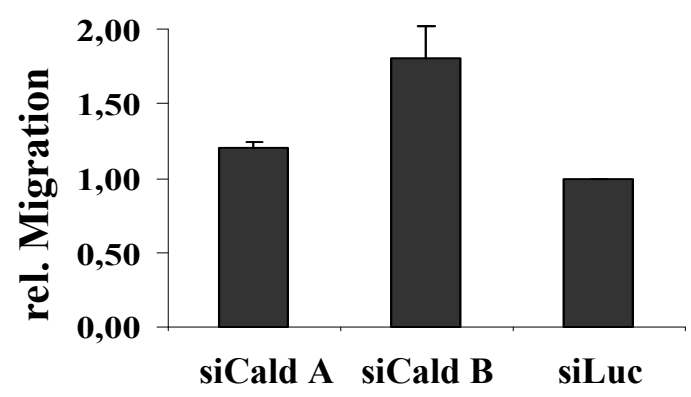

B

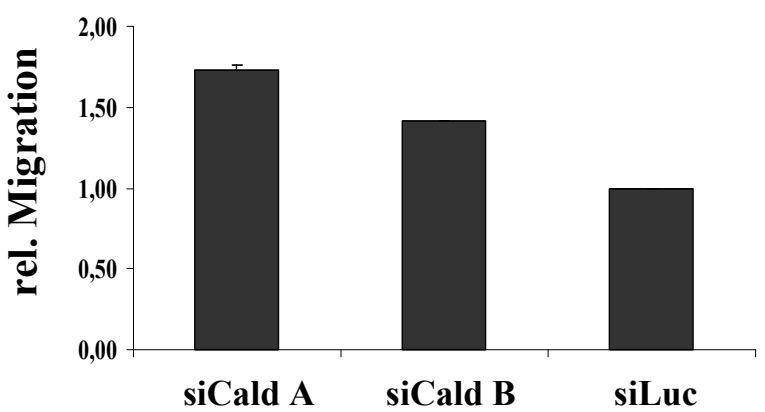

PC-3

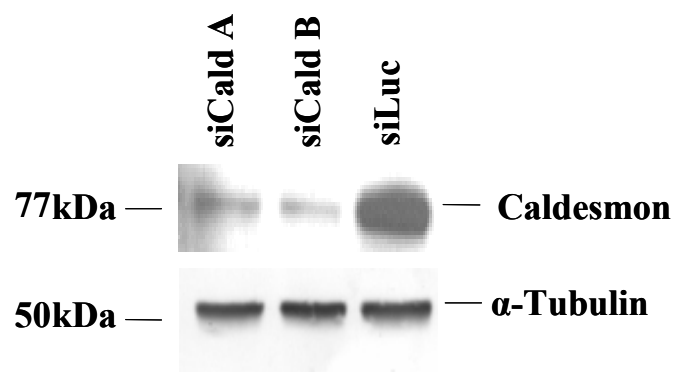

DU 145

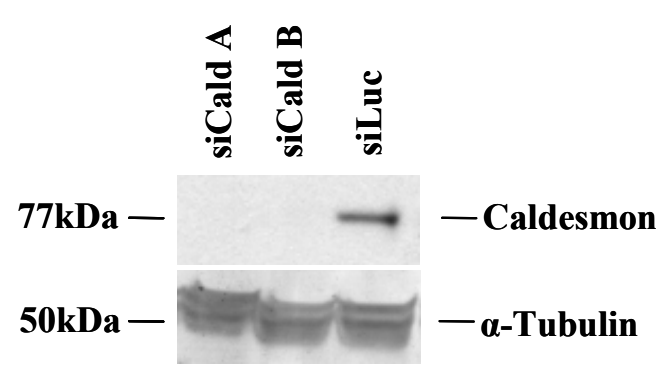

Abb. 3.35: Migrationsassay zur Bestimmung der Migrationsfähigkeit von PC-3- und DU 145-PCa-Zellen nach Herunterregulierung der Caldesmon-Expression. Die Migrationsfähigkeit von PC-3- und DU 145Zellen wurde durch einen Transwell-Migrationsassay überprüft. Dafür wurde die Expression von Caldesmon in den PCa-Zellen mittels siRNA herunterreguliert (siCaldA, siCaldB). Als Kontrolle wurden die Zellen mit Luciferase-spezifischer siRNA transfiziert (siLuc). Die Migrationsfähigkeit der Zellen wurde dadurch bestimmt, wie viele Zellen während einer Inkubationszeit von $24 \mathrm{~h}$ durch eine PET-Membran hindurchwandern konnten. Das Auszählen von fünf verschiedenen Sichtfeldern unter dem Mikroskop ergab das mittlere Migrationsverhalten der Zellen. Die Versuche wurden jeweils als Triplett durchgeführt und der Mittelwert einschließlich der Standardabweichung grafisch dargestellt. Zur Überprüfung der erfolgreichen Herunterregulierung der Caldesmon-Expression in den PC-3- und DU 145-PCa-Zellen wurde eine Western BlotAnalyse durchgeführt. Dazu wurde zur Detektion von Caldesmon ein spezifischer Caldesmon-Antikörper, zur Überprüfung der aufgetragenen Proteinmenge ein Antikörper gegen $\alpha$-Tubulin verwendet. 


\subsubsection{Caldesmon hat keinen Einfluss auf die Proliferation von PCa- Zellen}

Eine weitere Eigenschaft von Caldesmon ist die Regulation des Zellzyklus durch eine Beschleunigung des Eintritts in die M-Phase [Kordowska et al., 2005]. Um zu überprüfen, ob Caldesmon in die Proliferation von PC-3- und DU 145-PCa-Zellen involviert ist, wurde ein Proliferationsassay durchgeführt, bei dem die Zunahme der Lebendzellzahl während einer Zeitspanne von $72 \mathrm{~h}$ gemessen wurde (siehe Material und Methoden 2.19). Die Expression von Caldesmon in den Zelllinien PC-3 und DU 145 wurde für diese Analyse herunterreguliert und anschließend wurde im Abstand von $24 \mathrm{~h}$ die Umsetzung eines Tetrazolium-Gemischs durch die metabolisch aktiven Zellen bei $490 \mathrm{~nm}$ gemessen. Es konnte kein signifikanter Unterschied im Proliferations-Verhalten der Caldesmon siRNA-transfizierten Zellen im Vergleich zu den Kontrollzellen beobachtet werden. Sowohl in PC-3- als auch in DU 145Zellen nimmt Caldesmon keinen Einfluss auf die Proliferation (Abb. 3.36).

PC-3

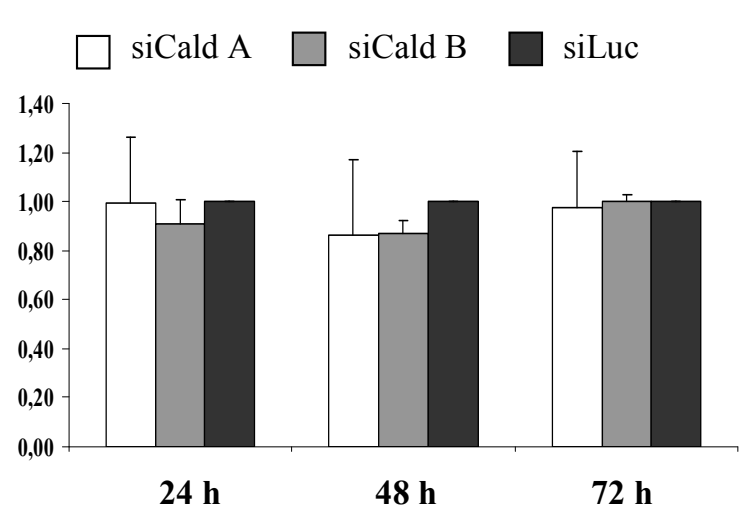

DU 145

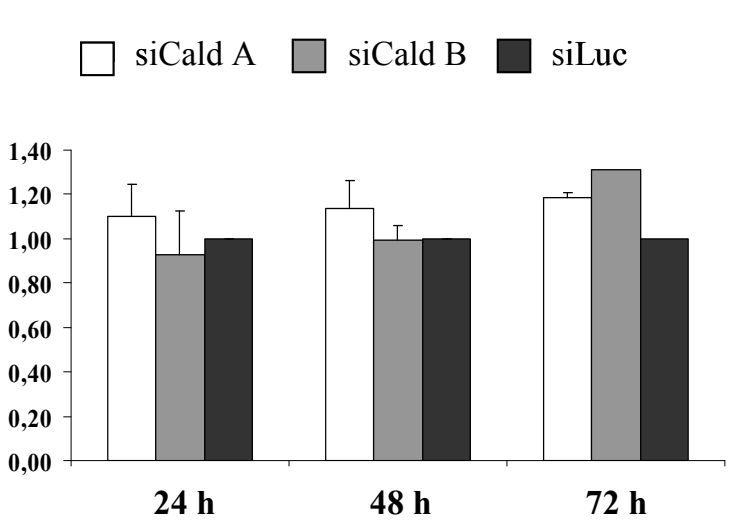

Fig. 3.36: Caldesmon nimmt keinen Einfluss auf die Proliferation der PCa-Zelllinien PC-3 und DU 145. PC-3- und DU 145-Zellen wurden mit siRNA gegen Caldesmon (siCaldA und siCaldB) und als Kontrolle gegen Luciferase (siLuc) transfiziert. Anschließend wurden die transfizierten Zellen für die Proliferationsmessung in 96-Well-Platten ausplattiert. Die Proliferation der Zellen wurde im Abstand von 24 h mit einem MTS-Assay bestimmt. In beiden Zelllinien resultiert die Herrunterregulierung der Caldesmon-Expression in keiner sichtbaren Veränderung des Proliferationsverhaltens. 


\subsubsection{Analysen zur Expression von Caldesmon in Abhängigkeit der LPXN-Expression}

Die Expressionsstärke von LPXN und Caldesmon in den PCa-Zelllinien korreliert sowohl auf RNA- als auch auf Proteinebene (siehe 3.4.1 und Kaulfuß et al., 2008). Daher besteht die Möglichkeit, dass eine Form der Interaktion zwischen den beiden Proteinen die gegenseitige oder einseitige Regulation der Expression ist. Um dies zu untersuchen, wurde in den PC-3 PCa-Zellen die Expression von LPXN mittels siRNA herunterreguliert. Kontrollzellen wurden gleichzeitig mit Luciferase-siRNA transfiziert. Nach $72 \mathrm{~h}$ wurde aus den Zellen Gesamt-Protein isoliert und $50 \mu \mathrm{g}$ für eine Western Blot-Analyse eingesetzt. Die Analyse der Caldesmon-Expression in diesen Zellen wurde mit einem Caldesmon-spezifischen Antikörper durchgeführt. In Abbildung 3.37 ist deutlich zu erkennen, dass sich die Expressionsstärke von Caldesmon nicht durch eine herunterregulierte LPXN-Expression verändert.

Weiterhin wurde eine Western Blot-Analyse mit Proteinen der LPXN-überexprimierenden Primärzellklone (83A und 72A) aus den doppelt transgenen LPXN/TRAMP-Mäusen durchgeführt. Als Kontrolle dienten die Proteine der Primärzellklone aus den einfach transgenen TRAMP-Mäusen (27F und 45F). Diese Western Blot-Analyse bestätigt ebenfalls, dass die Expression von Caldesmon nicht in Abhängigkeit zur LPXN-Expression reguliert wird. Auch nach Überexpression von LPXN ist keine Veränderung des Expressionslevels von Caldesmon zu erkennen. Beide Western Blot-Analysen wurden dreimal wiederholt (Abb. 3.37).

$\mathbf{A}$

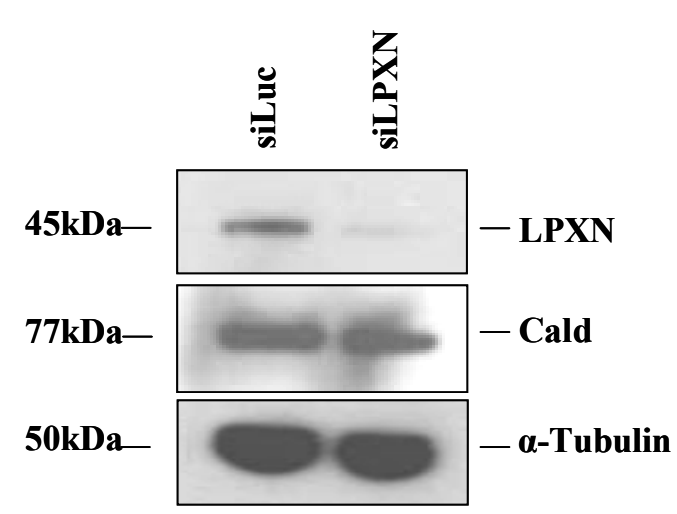

B

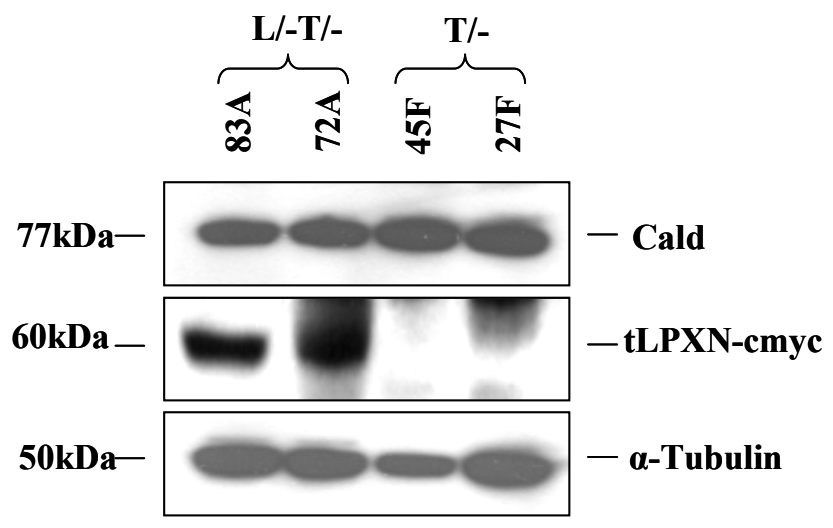

Abb. 3.37: LPXN hat keinen Einfluss auf die Expressionsstärke von Caldesmon. PC-3-PCa-Zellen wurden zur Herunterregulierung der LPXN-Expression mit spezifischer siRNA transfiziert. A. Nach $72 \mathrm{~h}$ wurde Gesamt-Protein isoliert und $50 \mu \mathrm{g}$ für die Western Blot-Analyse eingesetzt. Mit einem Caldesmon-Antikörper 
konnte bei $77 \mathrm{kDa}$ eine spezifische Bande detektiert werden. Die verminderte LPXN-Expression führte nicht zu einer deregulierten Caldesmon-Expession. Zum Nachweis der aufgetragenen Proteinmenge wurde ein Antikörper gegen $\alpha$-Tubulin verwendet. Die Herunterregulierung der LPXN-Expression konnte durch Hybridisierung der Membran mit einem LPXN-Antikörper bestätigt werden. B. Die Expression von Caldesmon wurde zusätzlich in den LPXN-überexprimierenden Primärzellen der doppelt transgenen Mäuse (T/-L/-, 83A und 72A) im Vergleich zu den einfach transgenen Mäusen (T/-, 45F und 27F) untersucht. Der verwendete Caldesmon-Antikörper detektiert keinen Unterschied im Expressionslevel von Caldesmon in Abhängigkeit zur LPXN-Expression. Zur Detektion des transgenen tLPXN-cmyc wurde ein LPXN-Antikörper verwendet. Die aufgetragene Proteinmenge wurde mit einem $\alpha$-Tubulin-spezifischen Antikörper kontrolliert.

\subsubsection{Analysen zur Phosphorylierung von Caldesmon in Abhängigkeit zur LPXN-Expression}

LPXN ist ein Adapterprotein und bildet somit eine Plattform, von der verschiedene Signalwege ausgehen können. LPXN ist z.B. in der Lage, Kinasen zu rekrutieren, welche wiederum Caldesmon phosphorylieren könnten. Es ist bereits beschrieben worden, dass Caldesmon ein Substrat der CDC2-Kinase sowie von ERK1/2 MAPK [Li et al., 2009; Hai et al., 2005] ist und dass Caldesmon durch die Phosphorylierung in einen inaktiven Zustand übergeht. Dass bedeutet, dass phosphoryliertes Caldesmon von den Aktin-Filamenten dissoziiert, das Zytoskelett destabilisiert wird und die Zellen z.B. eine größere Migrationsfähigkeit entwickeln.

Um zu untersuchen, ob der Phosphorylierungsstatus von Caldesmon abhängig ist von der Expressionsstärke von LPXN, wurden PC-3-PCa-Zellen mit LPXN- und als Kontrolle mit Luciferase-spezifischer siRNA transfiziert. Nach $48 \mathrm{~h}$ wurde die Zellen durch 24stündigen Serumentzug synchronisiert und durch erneute Serumgabe für vier Stunden zum Wachstum angeregt. Anschließend wurde Gesamt-Protein aus den Zellen isoliert und $50 \mu \mathrm{g}$ für eine Western Blot-Analyse eingesetzt. Die Membran wurde mit einem Antikörper hybridisiert, der spezifisch nur die phosphorylierte Form von Caldesmon erkennt. Um zu überprüfen, ob die Gesamt-Proteinmenge von Caldesmon in beiden Proben nicht voneinander abweicht, wurde die Membran zusätzlich mit einem Antikörper inkubiert, der sowohl die phosphorylierte als auch die nicht-phosphorylierte Form von Caldesmon detektiert. Wie in Abbildung $3.38 \mathrm{zu}$ erkennen ist, nimmt die Proteinmenge an phosphoryliertem Caldesmon nach LPXN 
knockdown (siLPXN) im Vergleich zu den Kontrollen (siLuc) stark ab. Gleichzeitig bleibt die Menge des insgesamt exprimierten Caldesmon in beiden Zellen konstant.

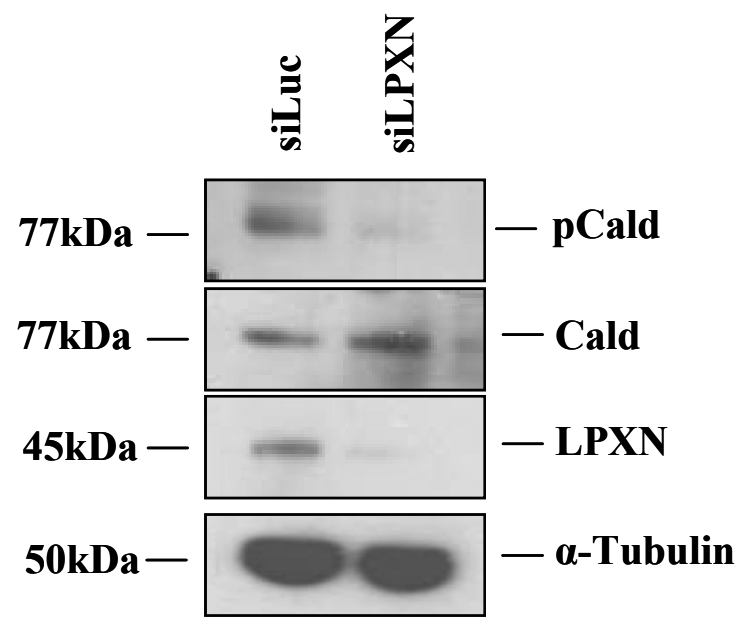

Abb. 3.38: Western Blot-Analyse zur Phosphorylierung und Expression von Caldesmon in PC-3-PCaZellen nach Herunterregulierung der LPXN-Expression. PC-3-PCa-Zellen wurden mit spezifischer LPXNbzw. Luciferase-siRNA transfiziert, nach insgesamt $72 \mathrm{~h}$ Gesamt-Protein isoliert und $50 \mu \mathrm{g}$ für die Western Blot-Analyse eingesetzt. Zunächst wurde ein Antikörper eingesetzt, der nur die phosphorylierte Form von Caldesmon erkennt (pCald). Anschließend wurde ein Antikörper verwendet, der sowohl die phosphorylierte als auch die unphosphorylierte Form von Caldesmon detektiert. Zur Überprüfung der erfolgreichen Herunterregulierung der LPXN-Expression wurde ein Antikörper gegen LPXN eingesetzt. Die aufgetragene Proteinmenge wurde mit einem $\alpha$-Tubulin-spezifischen Antikörper überprüft. Es ist deutlich zu erkennen, dass nach dem knockdown der LPXN-Expression der Phosphorylierungsgrad von Caldesmon stark abnimmt. 


\section{Hypothese: LPXN beeinflusst die Zelladhäsion}

\subsection{LPXN beeinflusst die Zelladhäsion und die Zytoskelett-Organisation}

Die Migration und Invasion von PCa-Zellen wird maßgeblich von den adhäsiven Eigenschaften der Zelle zur extrazellulären Matrix (ECM) bestimmt. Zelloberflächenrezeptoren sind dafür verantwortlich, die extrazellulären Signale einzufangen und diese an das Zytoskelett weiterzugeben. Da LPXN ein Adapterprotein ist, könnte es ein wichtiges Bindeglied zwischen den Zelloberflächenrezeptoren und den intrazellulären Signalwegen darstellen und somit die adhäsiven Eigenschaften einer Zelle mitbestimmen.

\subsubsection{Analyse der Zelladhäsion und -organisation nach LPXN-Herunter- regulierung in vitro}

\subsubsection{Verringerte Zelladhäsion und Zellzahl nach Herunterregulierung der LPXN-Expression}

Zur Bestimmung des Einflusses von LPXN auf die adhäsiven Eigenschaften der Zellen wurde ein Zelladhäsions-Assay durchgeführt (Material und Methoden 2.20). Dafür wurden PC-3 PCa-Zellen mit LPXN-spezifischer siRNA und als Kontrolle mit Luciferase-spezifischer siRNA transfiziert. Jeweils zwei Wells eines Glasobjektträgers wurden für $2 \mathrm{~h}$ mit dem Matrixmoleküle Fibronektin beschichtet, während zwei Wells unbeschichtet blieben. Die transfizierten Zellen wurden darauf ausplattiert und nach $1 \mathrm{~h}$ bzw. $2 \mathrm{~h}$ wurden die adhärenten Zellen fixiert. Mittels Immunzytochemie wurde das Zytoskelett visualisiert und die Zellen auf ihre Anzahl und Größe hin analysiert. Wie in Abbildung 3.39 zu erkennen ist, konnten von den Zellen mit herunterregulierter LPXN-Expression weniger Zellen auf Fibronektin beschichteten Objekträgern adhärieren als von den Kontrollzellen (siLuc). Weiterhin konnte beobachtet werden, dass die Zellen nach LPXN knockdown eine geringere Zelloberfläche aufweisen als die Kontrollzellen. Während das Zytoskelett der hier abgebildeten PC-3Kontrollzellen nach $2 \mathrm{~h}$ bereits weit ausgebreitet ist und einen festen Kontakt zur Matrix 
aufgebaut hat, sind die Zellen mit LPXN knockdown noch rund und ohne weitere ZellFortsätze.

FITC-Phalloidin
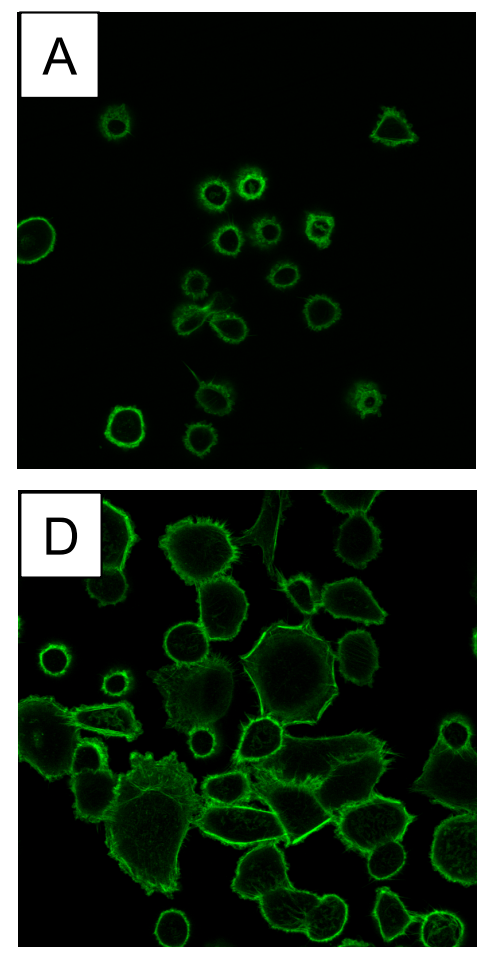

DAPI
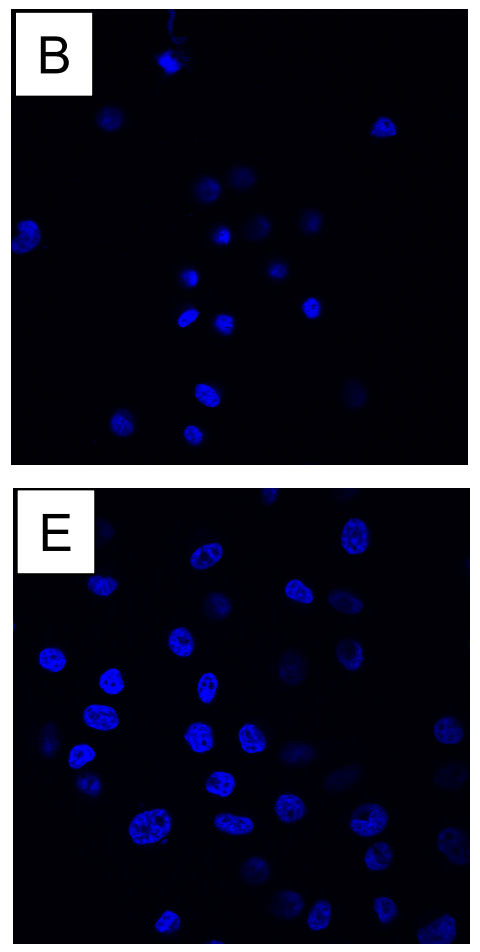

Überlagerung

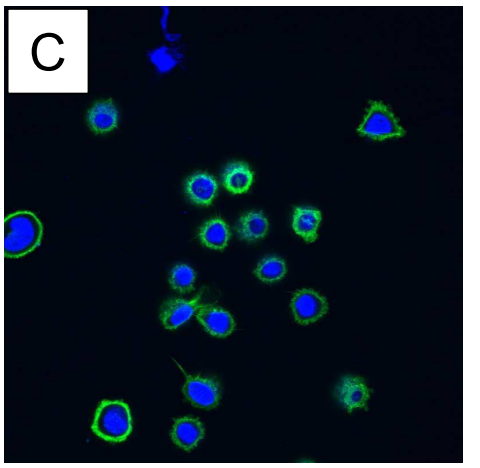

$\operatorname{siLPXN}$

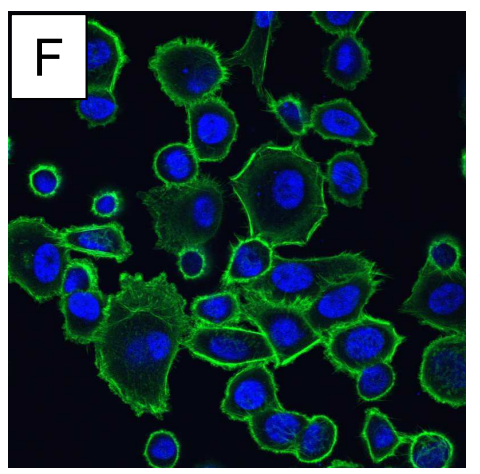

siLuc

Abb. 3.39: Immunzytochemie zur Untersuchung der adhäsiven Eigenschaften von PC-3Prostatakarzinomzellen nach Herunterregulierung der LPXN-Expression. PC-3-Zellen wurden mit LPXN(siLPXN) und Luciferase-spezifischer (si.Luc) siRNA transfiziert und nach $72 \mathrm{~h}$ für $2 \mathrm{~h}$ auf Fibronektinbeschichteten Glasobjektträgern ausplattiert. Nach der Fixierung wurden die Zellen zur Visualisierung des Zytoskeletts mit FITC-gekoppeltem Phalloidin behandelt, das die F-Aktin-Fasern anfärbt (FITC-Phalloidin) (A + D). Die Kerne wurden mit DAPI sichtbar gemacht $(B+E)$. Die Herunterregulierung der LPXN-Expression äußert sich in einer geringeren Anzahl adhärenter Zellen sowie einer verminderten Zelloberfläche der adhärenten Zellen ( $\mathrm{C}$ und F). Alle Bilder wurden mit einem konfokalen Laserscanning-Mikroskop in 600facher Vergrößerung aufgenommen.

Als Kontrolle wurden die transfizierten Zellen (siLPXN und siLuc) nach dem Ausplattieren für einen längeren Zeitraum ( $24 \mathrm{~h})$ inkubiert. In Abbildung 3.40 wird deutlich, dass sich die adhärenten Zellen sowohl in der Größe als auch in der Anzahl nach 24 h nicht mehr voneinander unterscheiden. 
FITC-Phalloidin
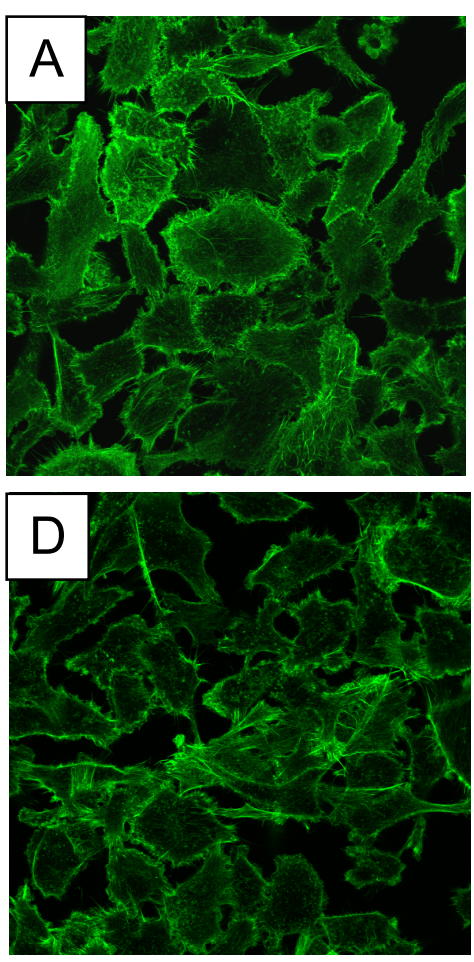

DAPI
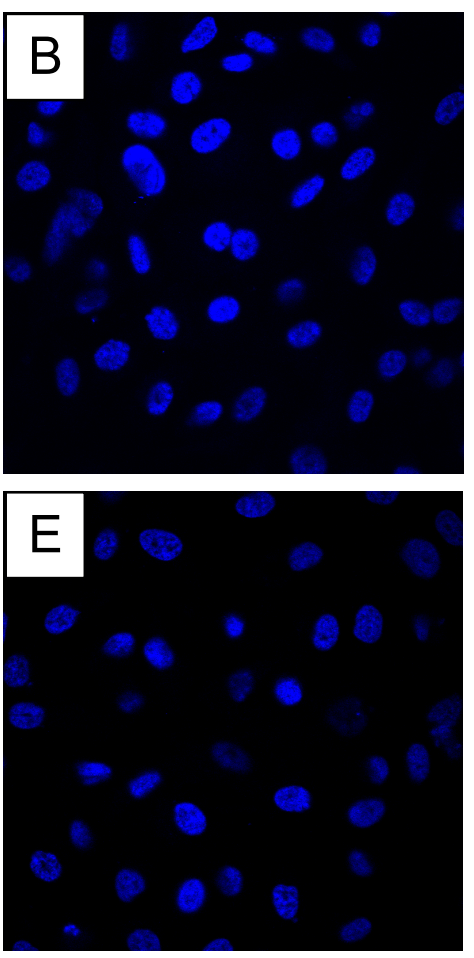

Überlagerung

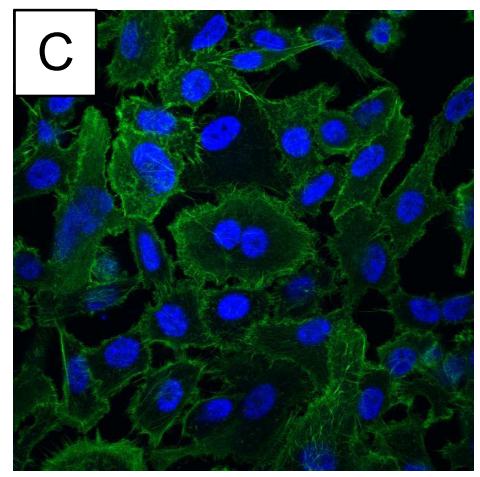

siLPXN

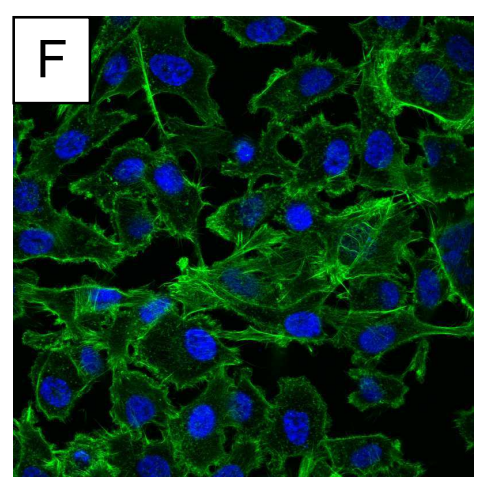

siLuc

Abb. 3.40: Immunzytochemie zur Analyse der adhäsiven Eigenschaften von PC-3-Zellen mit herunterregulierter LPXN-Expression. PC-3-Zellen wurden für $72 \mathrm{~h}$ mit LPXN- (siLPXN) und Luciferase(siLuc) spezifischer siRNA transfiziert und anschließend für $24 \mathrm{~h}$ auf einem Objektträger ausplattiert. Nach der Fixierung wurde das Zytoskelett mit FITC-Phalloidin visualisiert (A und D) und die Kerne mit DAPI gefärbt (B und E). Nach 24 h können keine Unterschiede in der Zellzahl bzw. Zellgröße der adhärenten Zellen (siLPXN vs. siLuc) beobachtet werden. Alle Aufnahmen wurden mit einem konfokalem Lasescanning-Mikroskop mit einer 600fachen Vergrößerung aufgenommen.

Zur Untersuchung der adhäsiven Eigenschaften der Zellen auf verschieden beschichteten Glasobjektträgern wurden diese für jeweils $2 \mathrm{~h}$ auf den Matrixmolekülen Fibronektin, Rattenschwanz-Collagen (Collagen), Bovines Serum-Albumin (BSA) und Gelantine inkubiert. Zwei Wells eines Glasobjektträgers blieben unbeschichtet. Anschließend wurden LPXN- und Luciferase-siRNA transfizierte PC-3- und DU 145-Zellen ausplattiert und die adhärenten Zellen nach $2 \mathrm{~h}$ fixiert. Das Zytoskelett wurde mit FITC-Phalloidin sichtbar gemacht und unter einem Fluoreszenz-Mikroskop analysiert. Jeweils fünf Sichtfelder der fünf verschiedenen Beschichtungen der LPXN- bzw. Luciferase-siRNA-transfizierten Zellen wurden ausgezählt und jeweils die Zelloberfläche aller Zellen ermittelt. Die Versuche wurden als Triplett durchgeführt und der Mittelwert \pm Standardabweichung berechnet. Die Anzahl bzw. die durchschnittliche Oberfläche der Luciferase-transfizierten Zellen der jeweiligen Beschichtung wurden gleich 1 gesetzt und dazu jeweils die Anzahl bzw. Oberfläche der 
LPXN siRNA-transfizierten Zellen in Relation gebracht. In der Abbildung $3.41 \mathrm{~A}$ ist zu erkennen, dass die relative Oberfläche der Zellen mit LPXN knockdown auf Fibronektinbeschichteten Objekträgern den größten Unterschied im Vergleich zu den Kontrollzellen zeigt. Weiterhin ist in Abbildung $3.41 \mathrm{~B}$ deutlich $\mathrm{zu}$ sehen, dass auf allen Beschichtungsmaterialien nach Herunterregulierung der LPXN-Expression eine verminderte Zellzahl adhärenter Zellen zu verzeichnen ist. Durch den Verlust der LPXN-Expression verlieren die Zellen demnach die Adhäsionseigenschaften zu der ECM, was sowohl zu einer reduzierten Zellzahl als auch einer reduzierten Zelloberfläche führt.

Zusätzlich konnte mit Hilfe von Invasionskammern, die mit den ECM-Komponenten Fibronektin, Collagen I, Collagen IV und Laminin beschichtet waren, demonstriert werden, dass nach Herunterregulierung der LPXN-Expression die Invasionsfähigkeit der Zellen am stärksten in den Fibronektin-beschichteten Kammern reduziert ist [Daten nicht gezeigt; Kaulfuß et al., 2009].

A
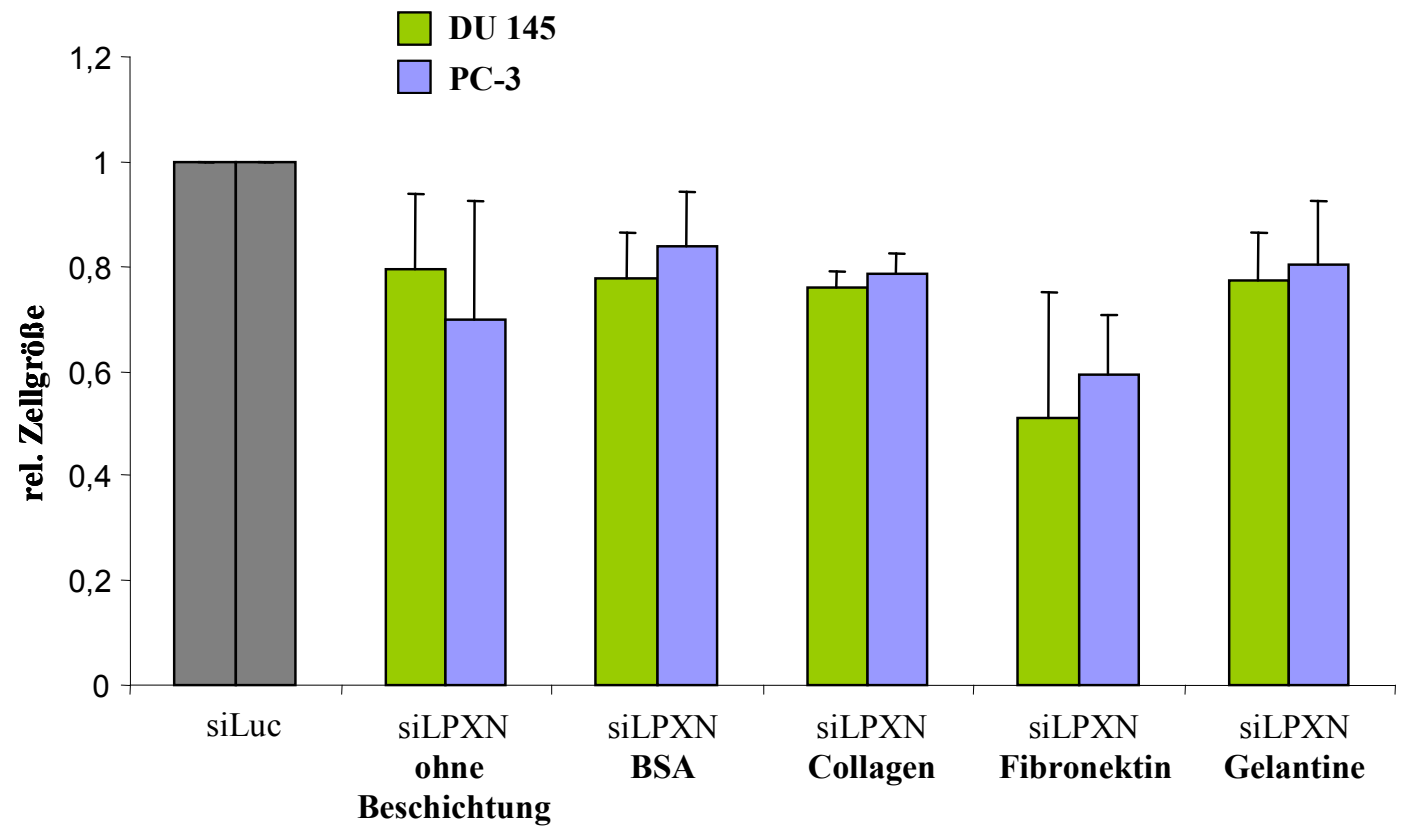
B

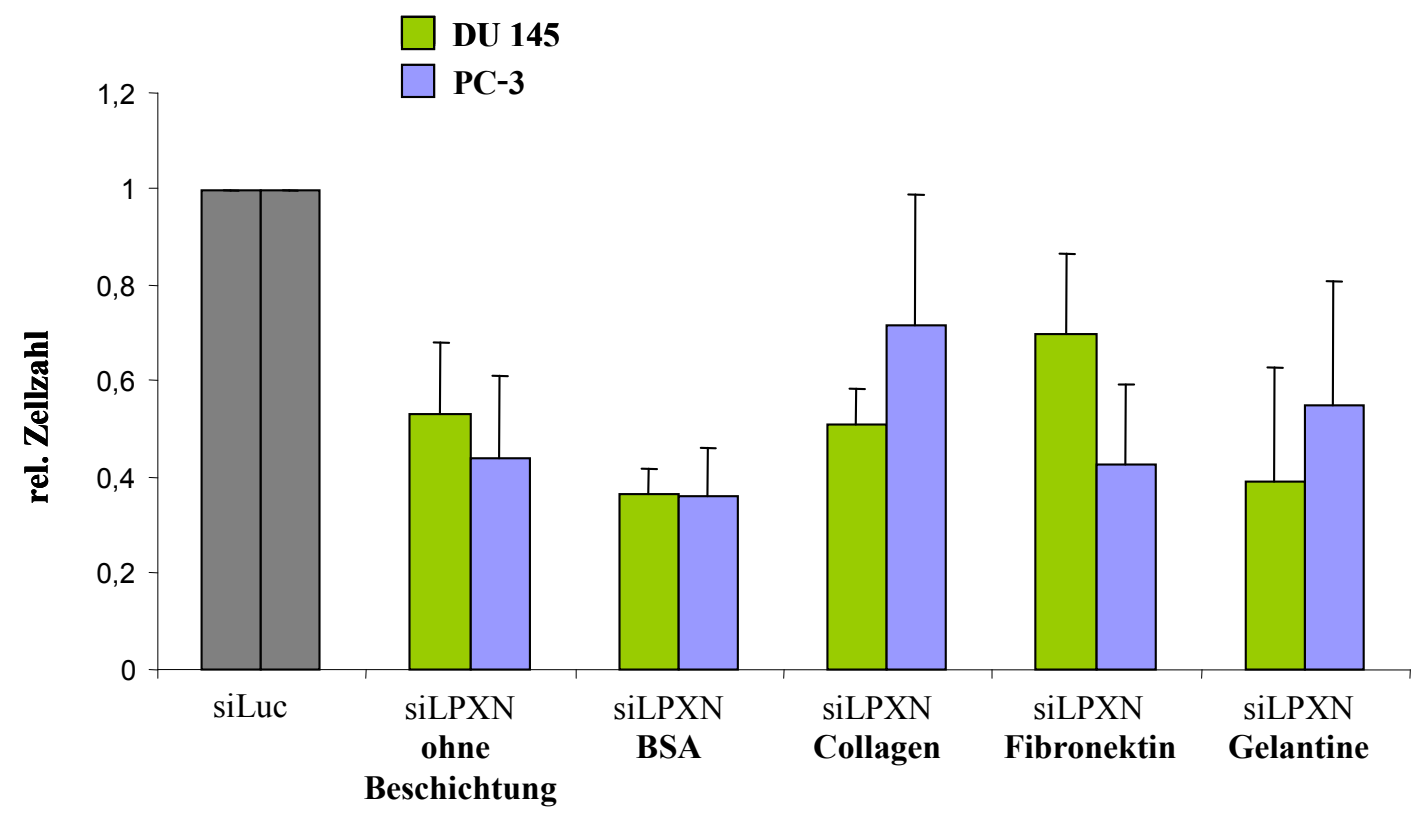

Abb. 3.41: Verlust der adhäsiven Eigenschaften von PC-3- und DU 145-PCa-Zellen nach Herunterregulierung der LPXN-Expression. LPXN-siRNA- und Luciferase-siRNA-transfizierte PC-3- und DU 145-Zellen wurden auf Glasobjektträgern ausplattiert, welche zuvor mit Bovinem Serum-Albumin (BSA), Rattenschwanz-Collagen (Collagen), Fibronektin und Gelantine beschichtet wurden bzw. ohne Beschichtung blieben. Nach $2 \mathrm{~h}$ wurden die nicht adhärenten Zellen vorsichtig abgenommen und die restlichen Zellen fixiert. Anschließend konnten die Zellen unter einem Floureszenz-Mikroskop auf Zelloberfläche (A) und Anzahl (B) analysiert werden. Dabei wurden jeweils fünf Sichtfelder der fünf verschiedenen Beschichtungen der LPXNbzw. Luciferase-siRNA-transfizierten Zellen fotografiert und jeweils die Anzahl und Oberfläche der Zellen ermittelt. Die Anzahl bzw. die durchschnittliche Oberfläche der Luciferase-transfizierten Zellen der jeweiligen Beschichtung wurde gleich 1 gesetzt und dazu jeweils die Anzahl bzw. Oberfläche der LPXN-siRNAtransfizierten Zellen in Relation gebracht. Alle Versuche wurden als Triplett durchgeführt und der Mittelwert \pm Standardabweichung ermittelt.

\subsubsection{Verringerte Bildung von focal adhesion sites nach Herunter- regulierung der LPXN-Expression}

Focal adhesion sites spielen bei der Zellmigration und Zelladhäsion eine bedeutende Rolle. Durch den Auf- und Abbau der focal adhesion sites entsteht eine dynamische Strukur, durch die die Zelle in der Lage ist, sich zu bewegen. Ob die Expressionsstärke des focal adhesion proteins LPXN allein dazu beitragen kann, dass die Bildung der focal adhesion sites während 
der Zelladhäsion beeinflusst wird, wurde in einer immunzytochemischen Analyse untersucht. Dafür wurden LPXN- und Luciferase-transfizierte DU 145-PCa-Zellen auf Fibronektinbeschichteten Glasobjektträgern ausplattiert und nach einer Inkubationszeit von $2 \mathrm{~h}$ fixiert. Anschließend wurden die focal adhesion sites mit einem Antikörper gegen phospho-Tyrosin angefärbt. DU 145-Zellen, die mit LPXN-spezifischer siRNA transfiziert wurden, zeigten im Vergleich zu den Luciferase-siRNA-transfizierten Zellen deutlich definiertere und stärkere focal adhesions sites (Abb. 3.42).

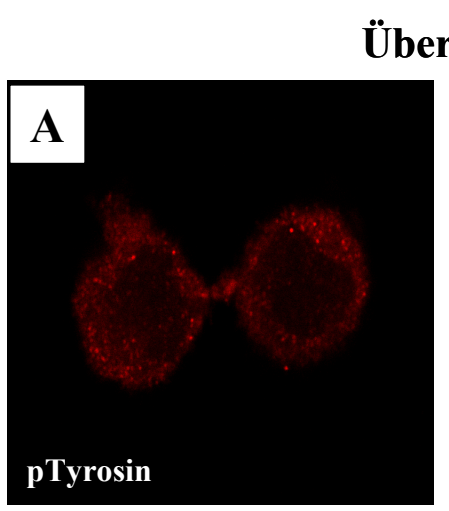

\section{rsicht}
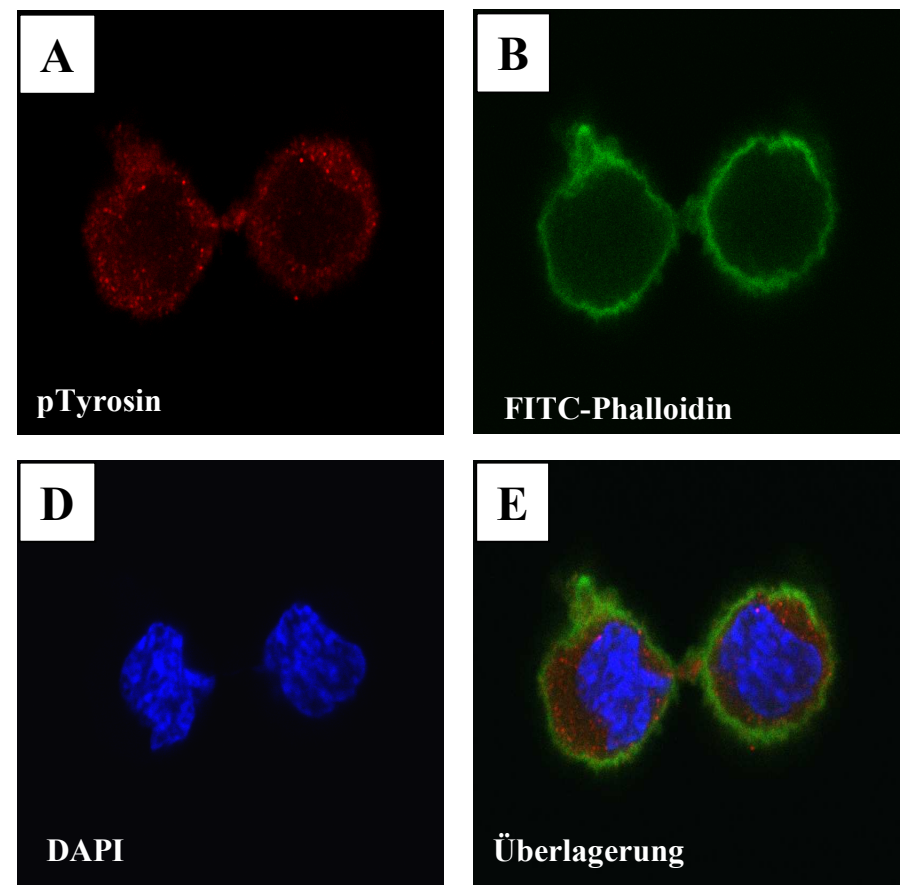

FITC-Phalloidin

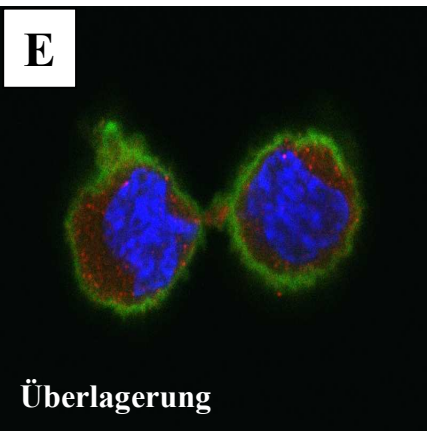

\section{Detailansicht}

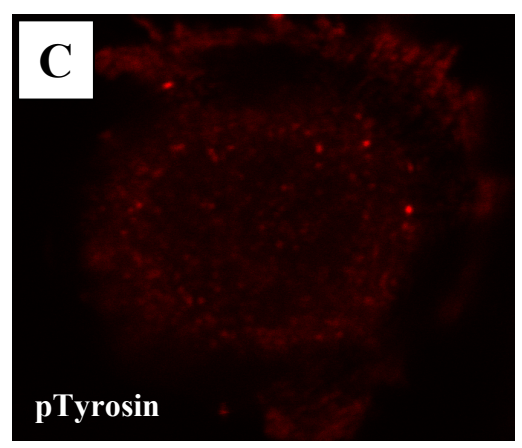

SiLPXN

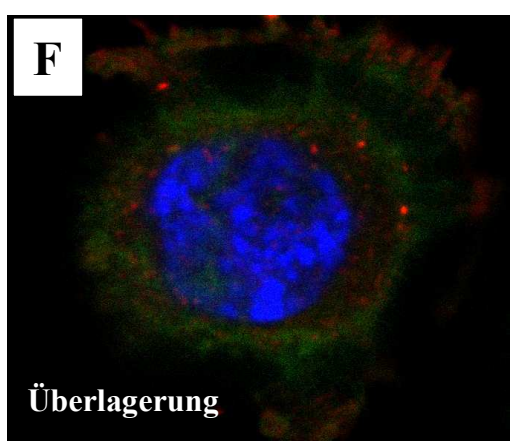




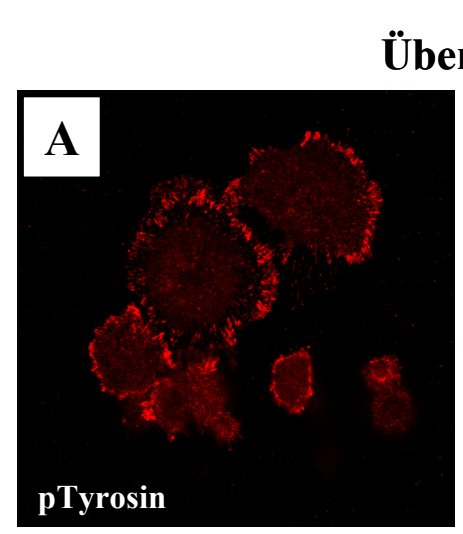

\section{Übersicht}
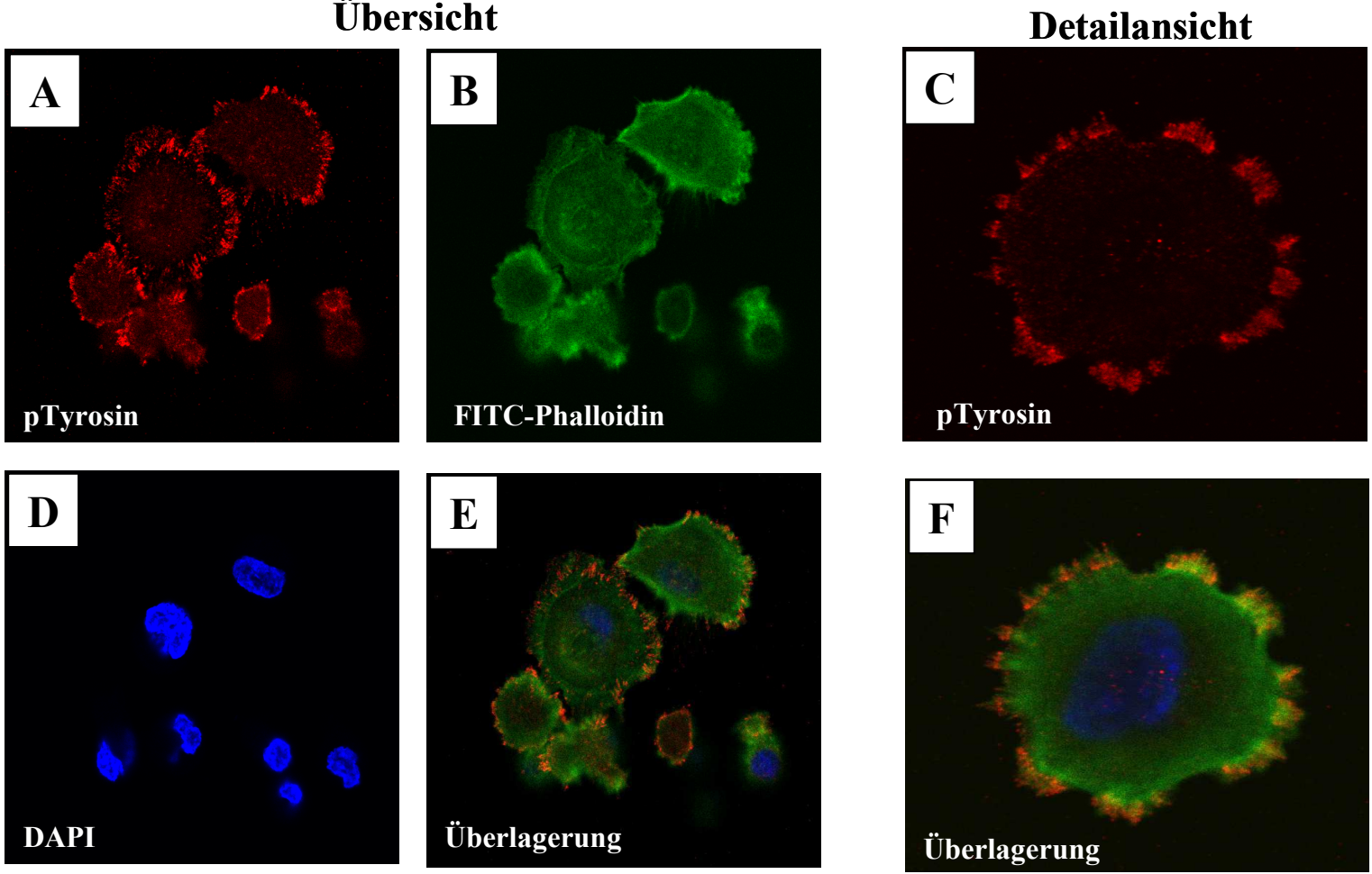

siLuc

Abb. 3.42: Immunzytochemie zur Analyse der focal adhesion sites nach Herunterregulierung der LPXNExpression. DU 145 PCa-Zellen wurden mit spezifischer siRNA gegen LPXN (siLPXN) und als Kontrolle gegen Luciferase (siLuc) transfiziert. Nach $72 \mathrm{~h}$ wurden die Zellen für $2 \mathrm{~h}$ auf einem Glasobjektträger ausplattiert und anschließend fixiert. Zur Detektion der focal adhesion sites wurde ein Antikörper gegen pTyrosin (A und C) verwendet, das Zytoskelett wurde mit FITC-Phalloidin (B) visualisiert und der Zellkern mit DAPI angefärbt (D). Die Detailansicht der Zellen (C und F) zeigt deutlich, dass die Herunterregulierung der LPXN-Expression in den DU 145-Zellen in einem Verlust der focal adhesion sites resultiert. Bei den Luciferasetransfizierten Zellen hingegen konnten große, definierte focal adhesion sites detektiert werden. Alle Aufnahmen wurden mit einem konfokalen Laserscanning-Mikroskop mit einer 600fachen Vergrößerung aufgenommen.

\subsubsection{3 „Blebbing“ der Zellen nach Herunterregulierung der LPXN- Expression}

Beim näheren Betrachten der Morphologie der LPXN- und Luciferase-transfizierten PCaZellen fällt auf, dass die Zelle nach Herunterregulierung der LPXN-Expression und einer Adhäsionszeit von $2 \mathrm{~h}$ unregelmäßige Ausbuchtungen der Plasmamembran formt. Dieses als „blebbing“ bezeichnete Phänomen ist bei den Kontrollzellen nicht zu erkennen (Abb. 3.43). 

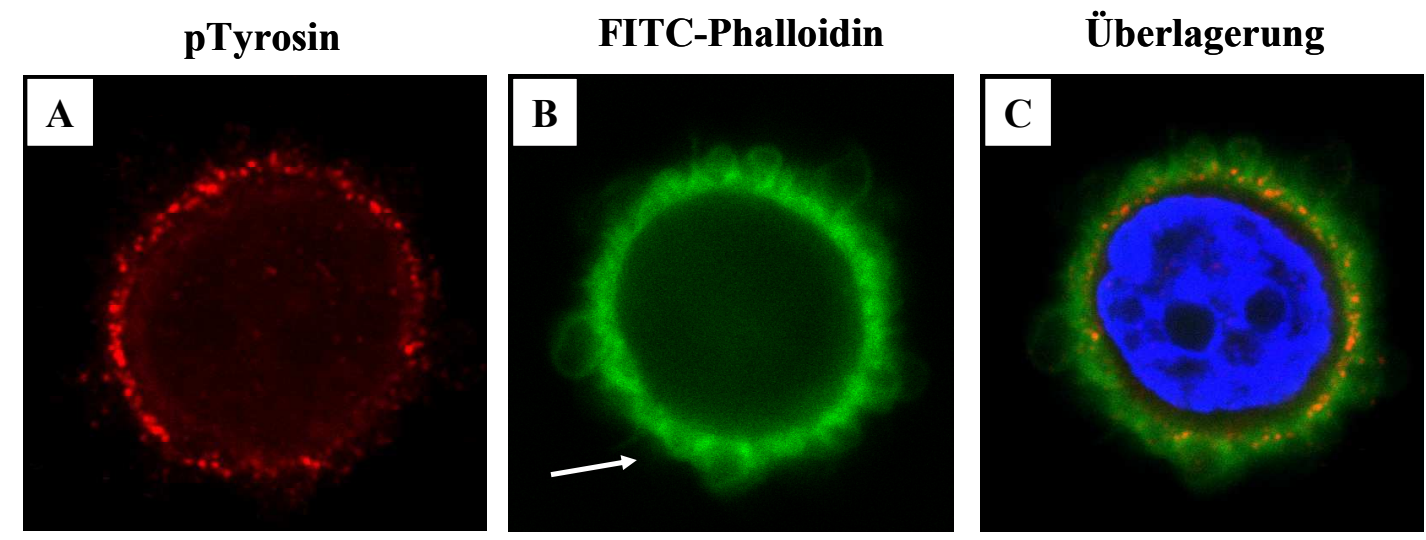

siLuc
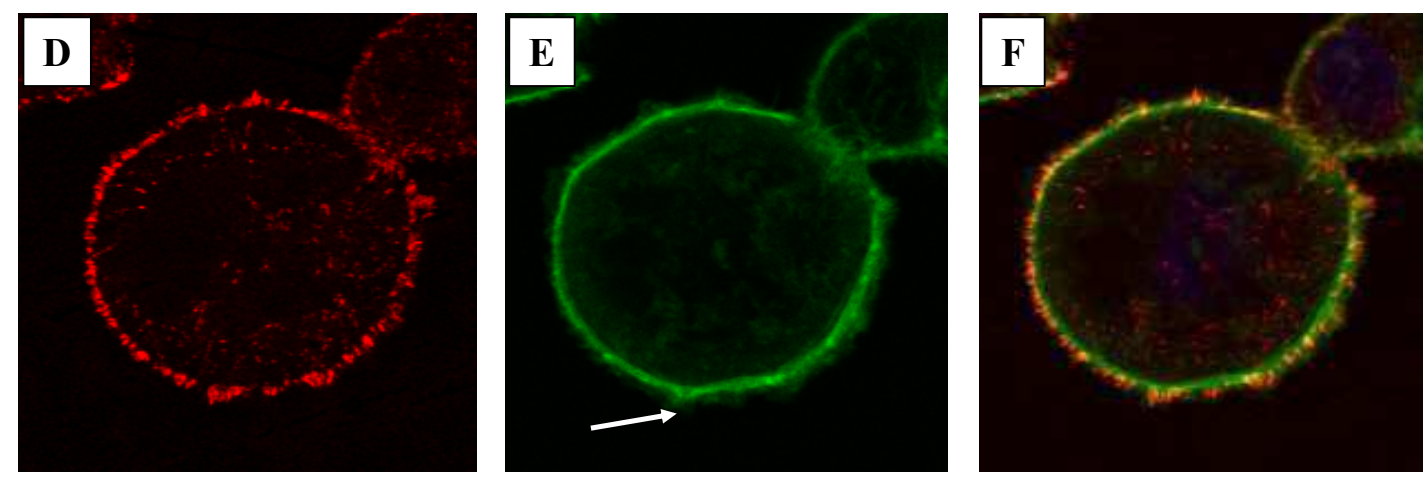

$\operatorname{siLPXN}$

Abb. 3.43: Morphologie von PC-3-Zellen nach Herunterregulierung der LPXN-Expression. LPXN siRNAtransfizierte und Luc siRNA-transfizierte PC-3-PCa-Zellen wurden für $2 \mathrm{~h}$ auf Glasobjektträgern ausplattiert, fixiert und anschließend mit einem phospho-Tyrosin-Antikörper behandelt (A und D). Das Zytoskelett wurde mit FITC-Phalloidin visualisiert (B und E) und der Kern mit DAPI angefärbt. Die Plasmamembran der LPXN siRNA-transfizierten Zellen (siLPXN) zeigt im Vergleich zu den Luc siRNA-transfizierten Zellen (siLuc) deutliche Ausbuchtungen der Plasmamembran (Pfeil B und E). Alle Bilder wurden mit einem konfokalen Laserscanning-Mikroskop bei 600 facher Vergrößerung aufgenommen und anschließend weiter vergrößert.

\subsubsection{Analyse der Zelladhäsion und -organisation bei LPXN-Über- expression ex vivo}

\subsubsection{Erhöhte Zelladhäsion nach Überexpression von LPXN ex vivo}

$\mathrm{Da}$ die Adhäsionseigenschaften der PCa-Zellen nach Herunterregulierung der LPXNExpression stark abnehmen, wurde in einem weiteren Versuch analysiert, ob die in vitroErgebnisse auch am Beispiel des Mausmodells bestätigt werden können. Dafür wurde ein Adhäsionsassay mit den aus den LPXN/TRAMP-Prostatatumoren isolierten Primärzellen 
(Zellklon 83A) und als Kontrolle mit den aus den TRAMP-Prostatatumoren isolierten Primärzellen (Zellklon 27F) durchgeführt. Die Zellen wurden jeweils auf Fibronektinbeschichteten und unbeschichteten Glasobjektträgern für $2 \mathrm{~h}$ ausplattiert und anschließend fixiert. Durch Färbung FITC-gekoppelten Phalloidin wurden die Zellen visualisiert. Die Überexpression von LPXN in den Primärzellen 83A L/-T/- bewirkt im Vergleich zu den Primärzellen 27F T/- eine verstärkte Zelladhäsion, welche sich in einer erhöhten Zellzahl und einer vergrößerten Zelloberfläche äußert (Abb. 3.44).

FITC-Phalloidin
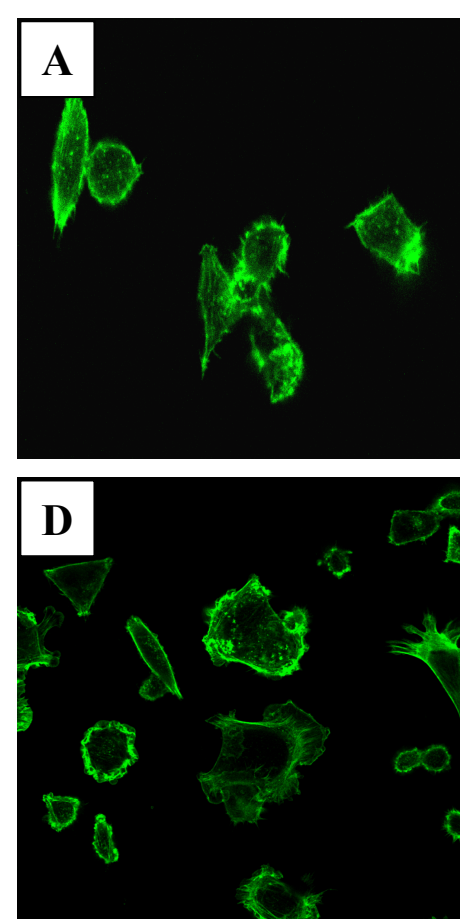

DAPI
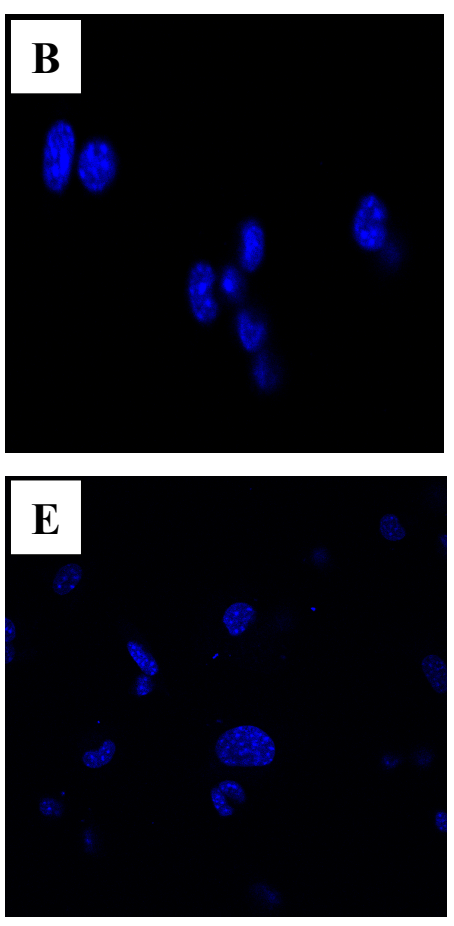

Überlagerung

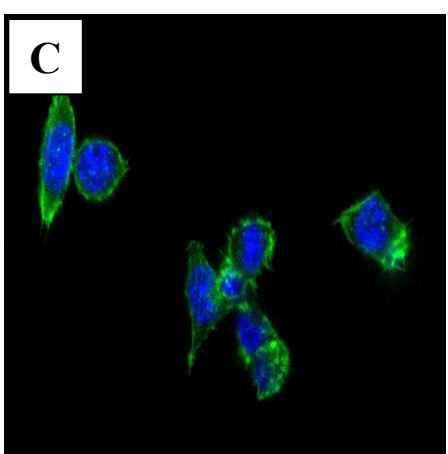

27F T/-

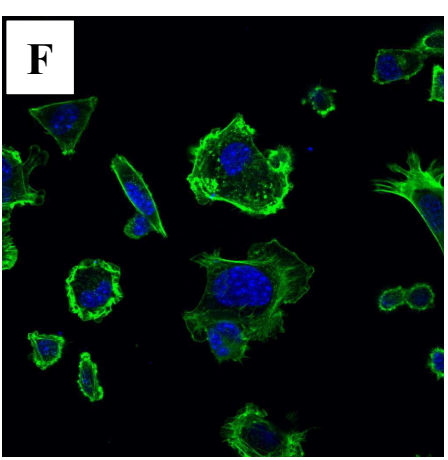

83A L/-T/-

Abb. 3.44 Immunzytochemie zur Analyse der adhäsiven Eigenschaften von LPXN-überexprimierenden

Primärzellen. Die Primärzellklone 27F (T/-) und 83A (L/-T/-) wurden für $2 \mathrm{~h}$ auf Fibronektin-beschichteten Glasobjektträgern ausplattiert. Nach der Fixierung wurde das Zytoskelett mit FITC-Phalloidin visualisiert und die Kerne mit DAPI gefärbt. 


\subsubsection{Verstärkte Bildung von focal adhesion sites nach LPXN- Überexpression}

Im vorherigen Abschnitt konnte gezeigt werden, dass die PCa-Zellen nach Herunterregulierung der LPXN-Expression ihre Adhäsionsfähigkeit zur ECM verlieren und dass es zu einer verringerten Bildung der focal adhesion sites kommt. Um die Stärke der focal adhesion sites bei Überexpression von LPXN zu untersuchen, wurden die aus den doppelt (L/-T/-) und einfach (L/-) transgenen Mäusen isolierten Primärzellen verwendet. Diese wurden für $4 \mathrm{~h}$ auf Fibonektin-beschichteten Glasobjektträger ausplattiert, fixiert und anschließend immunhistochemisch analysiert. Mit einem phospho-Tyrosin Antikörper wurden die focal adhesion sites visualisiert. Die Abbildung 3.45 lässt deutlich erkennen, dass die LPXN-überexprimierenden Primärzellen 83A starke und ausgeprägte focal adhesion sites aufweisen, während in den Primärzellen 27F, welche aus den einfach transgenen Mäusen hervorgingen, kleinere und nicht sehr definierte focal adhesion sites detektiert werden konnten.

Sowohl nach Herunterregulierung der LPXN-Expression in den PCa-Zellen DU 145 als auch nach Überexpression von LPXN in den Primärzellen 83A korreliert die Stärke der focal adhesion sites direkt mit der LPXN-Expression.

\section{Detailansicht}
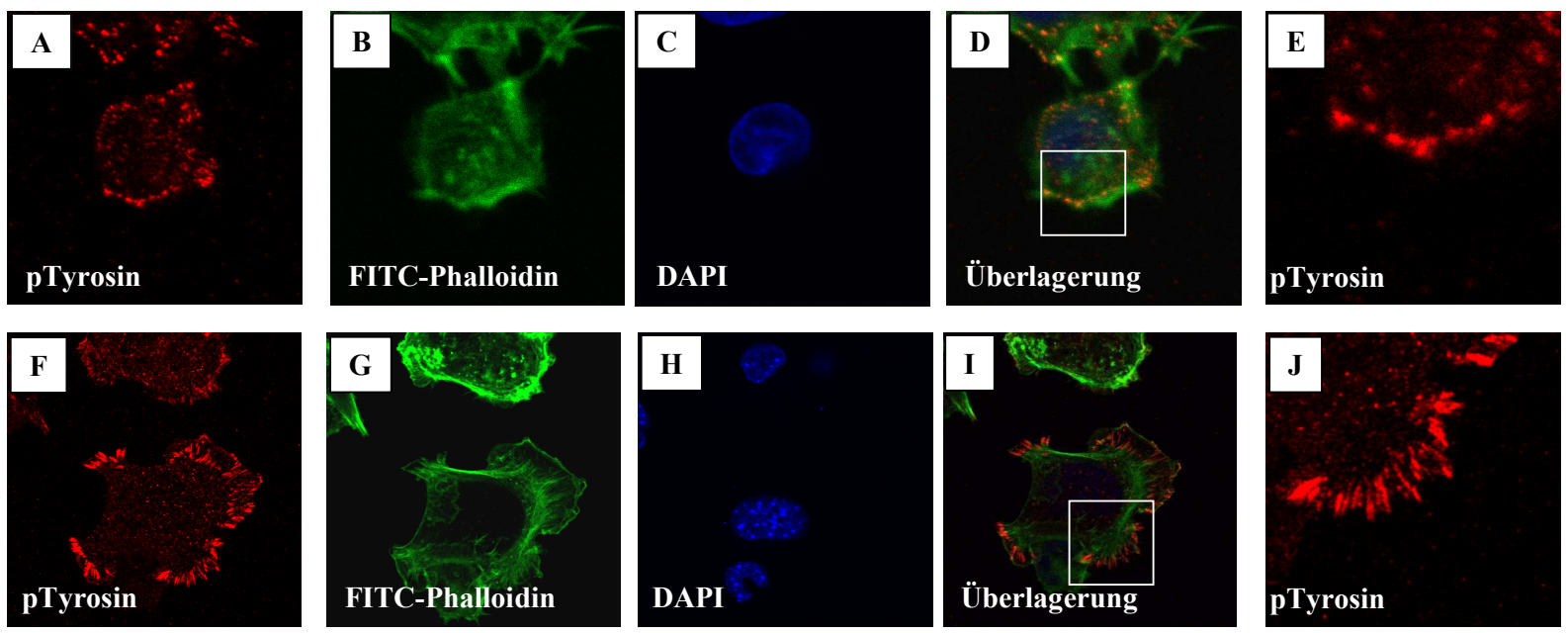

Abb. 3.45: Immunzytochemie zur Analyse der focal adhesion sites nach LPXN-Überexpression in Primärzellen aus Prostatatumoren. Die Primärzellklone 27F (einfach transgen T/-) und 83A (doppelt transgen L/-T/-) wurden für $4 \mathrm{~h}$ auf einem Fibronektin-beschichteten Glasobjektträger inkubiert und anschließend fixiert. Zur Detektion der focal adhesion sites wurde ein Antikörper gegen phosphoryliertes Tyrosin (pTyrosin) verwendet (A und F), das Zytoskelett wurde mit FITC-Phalloidin visualisiert (B und G) und der Zellkern mit 
DAPI angefärbt (C und H). Die Detailansicht (E und J) verdeutlicht, dass nach Überexpression von LPXN (83A L/-T/-) stärkere und definiertere focal adhesion sites detektiert werden konnten im Vergleich zu den Kontrollzellen (27F T/-). Für sämtliche Aufnahmen wurde ein konfokales Laserscanning-Mikroskop verwendet. Die Bilder wurden in 600 facher Vergrößerung aufgenommen, die Detailansichten wurden anschließend weiter vergrößert.

\subsubsection{GST-Pulldown zur Analyse der Aktivität der Rho-GTPasen RhoA und Rac}

Die Familie der Rho-GTPasen sind essentielle Regulatoren bei der Organisation des Zytoskeletts und damit bei der Zelladhäsion und -migration [Ridley et al., 2003; Jaffe und Hall, 2005]. Die Rho-GTPase RhoA z.B. ist für die Ausbildung von focal adhesion sites und für die Kontraktion von Stressfasern verantwortlich. Rac hingegen ist an der Formation von Lamellipodien beteiligt, die Aktinfortsätze am mobilen Teil der Zelle darstellen [Ridley und Hall, 1992; Ridley et al., 1992; Nobes und Hall, 1995].

Um zu überprüfen, ob durch die Herunterregulierung der LPXN-Expression eine Deregulation der Aktivierung/Deaktivierung der Rho-GTPasen RhoA und Rac bei der Zelladhäsion stattfindet, wurde die Aktivität der beiden GTPasen mittels eines GST-Pulldowns ermittelt. Die verwendeten Effektoren TRBD (Rhotekin-binding domain) und RBD (Rac-bindingdomain) können nur von RhoA bzw. Rac gebunden werden, wenn diese aktiviert sind (Material und Methoden 2.27.3).

\subsubsection{Aufreinigung der GST-Fusionsproteine}

Die GST-Fusionsproteine GST-TRBD, GST-RBD und GST wurden in E.coli überexprimiert und anschließend wurde Gesamt-Protein isoliert. Die Aufreinigung der Proteine erfolgte mit Gluthation-Sepharose, an die nur die GST-Fusionsproteine binden können. Die Durchflüsse, die Waschschritte und die Eluate der Proteinaufreinigung wurden auf einem SDS-Gel aufgetrennt und anschließend mit Coomassie Brillant Blue gefärbt (Abb. 3.46) (Material und Methoden 2.15.6.). Wie zu erkennen ist, konnten die GST-Fusionsproteine aus dem GesamtProtein isoliert werden. 


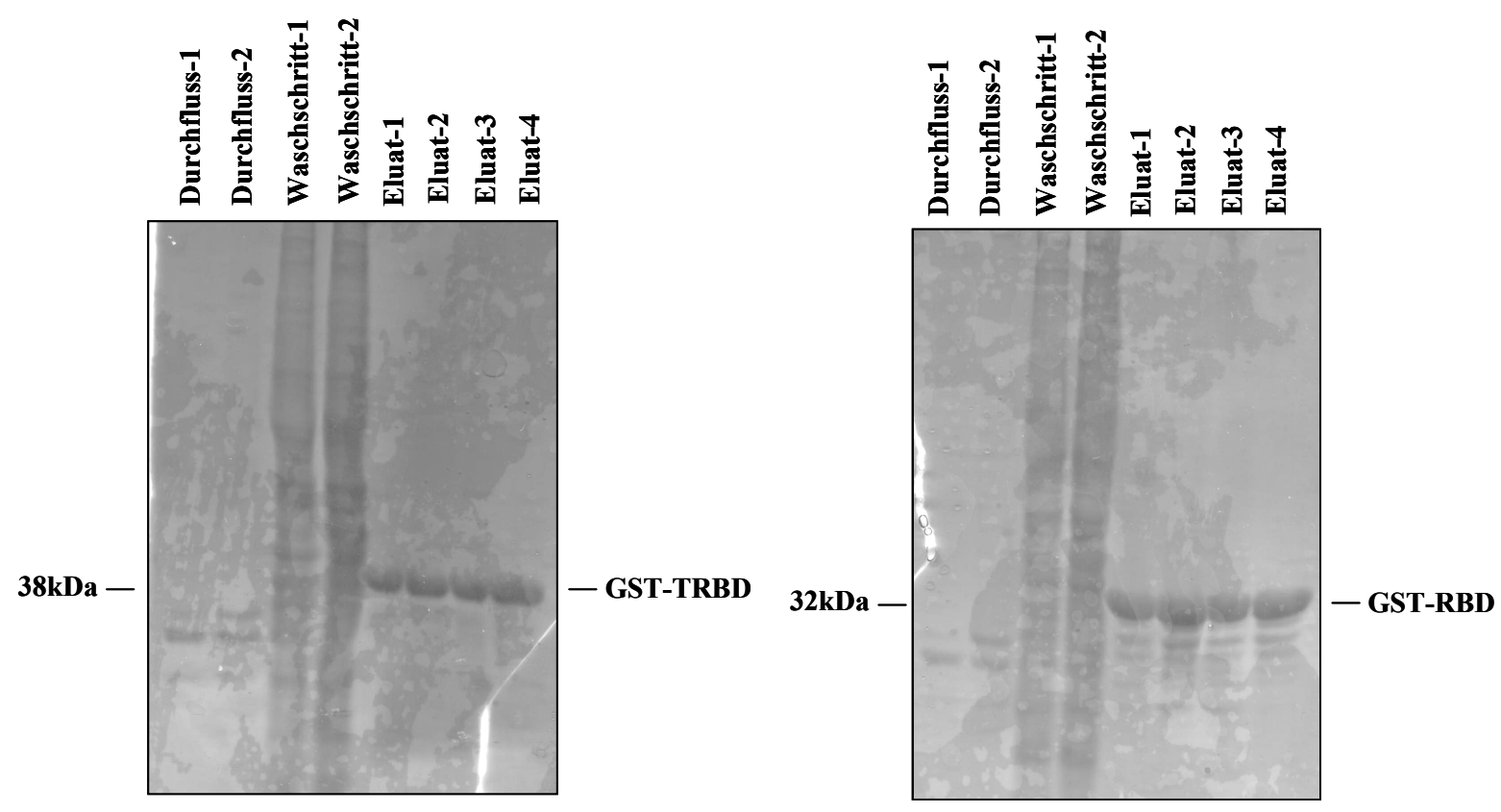

Abb. 3.46: Coomassie-Färbung eines SDS-Gels zur Überprüfung der Aufreinigung von GSTFusionsproteinen. Die GST-Fusionsproteine GST-TRBD (38 kDa) und GST-RBD (32 kDa) wurden in E.coli überexprimiert und anschließend mit Gluthation-Sepharose aufgereinigt. Die Durchflüsse 1/2, die Waschschritte1/2 und die Eluate1-4 der GST-TRBD und GST-RBD-Aufreinigung wurden auf einem SDS-Gel aufgetrennt und mit Coomassie Brillant Blue gefärbt.

\subsubsection{GST-Pulldown mit den aufgereinigten GST-Fusionsproteinen}

PC-3-Zellen wurden mit LPXN- und als Kontrolle mit Luciferase-siRNA transfiziert und nach $72 \mathrm{~h}$ Gesamt-Protein isoliert. Dieses wurde mit den zuvor aufgereinigten und konzentrierten GST-Proteinen (GST-TRBD, GST-RBD, GST) inkubiert und über Gluthation-Sepharose aufgereingt. Durch eine anschließende Western Blot-Analyse mit einem RhoA- bzw. Racspezifischen Antikörper konnte die Menge an aktivem RhoA bzw. Rac in den LPXN- und Luciferase-siRNA-transfizierten Zellen ermittelt werden. Wie in Abbildung $3.46 \mathrm{zu}$ erkennen ist, konnte in den Kontrollzellen (siLuc) im Vergleich zu den Zellen mit herunterregulierter LPXN-Expression (siLPXN) vermehrt aktives RhoA nachgewiesen werden (Abb. 3.47 A). Im Gegensatz dazu konnte in den Kontrollzellen (siLuc) im Vergleich zu den Zellen mit herunterregulierter LPXN-Expression (siLPXN) weniger aktives Rac detektiert werden (Abb. 3.47 B). Als Positivkontrolle diente Protein von PC-3-Zellen, welches vor der Durchführung des GST-Pulldowns mit GTP aktiviert wurde (positiv) (Material und 
Methoden, 2.27.4). Als Negativkontrolle wurde das Gesamt-Protein nur mit GST-Protein inkubiert, welches nicht an ein Effektorprotein gebunden war (negativ).

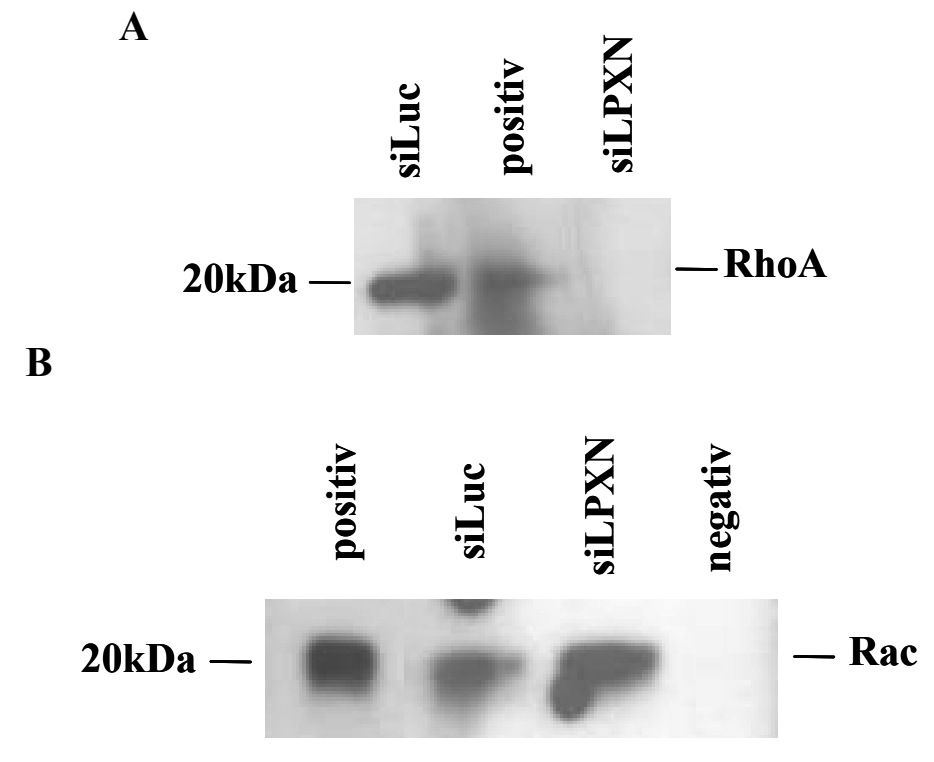

Abb. 3.47: GST-Pulldown zur Analyse des aktiven RhoA und Rac in PC-3-Zellen mit herunterregulierter LPXN-Expression. Von PC-3-Zellen mit herunterregulierter LPXN-Expression und von Kontrollzellen wurde nach vierstündiger Adhäsion Gesamt-Protein isoliert. Anschließend wurde mit dem Protein und dem RhoAEffektorprotein TRBD bzw. mit dem Rac-Effektorprotein RBD ein GST-Pulldown durchgeführt. A. Die anschließende Western Blot-Analyse mit einem RhoA-spezifischen Antikörper zeigt eine verstärkte Aktivierung von RhoA in den Kontrollzellen (TRBD siLuc) im Vergleich zu den Zellen mit herunterregulierter LPXNExpression (TRBD siLPXN). B. Eine Western Blot-Analyse mit einem Rac-spezifischen Antikörper demonstriert hingegen eine verstärkte Aktivierung von Rac in Zellen mit herunterregulierter LPXN-Expression (RBD siLPXN) im Vergleich zu den Kontrollzellen (TRBD siLuc). 


\section{Hypothese: LPXN ist in Signalwege integriert, welche die Zellprogression beeinflussen}

\subsection{Analysen zum Einfluss von LPXN auf die Phosphorylierung und Expression weiterer Gene}

Es konnte bereits gezeigt werden, dass LPXN an der Migration, Invasion und Adhäsion von PCa-Zellen beteiligt ist. Es kann aber davon ausgegangen werden, dass LPXN als Adapterprotein die Zelleigenschaften zwar vermittelt, aber diese nicht alleine ausführen kann. Daher stellt sich die Frage, welche Gene bzw. Proteine durch LPXN aktiviert oder deaktiviert werden, damit die zu beobachteten Effekte eintreten.

\subsubsection{Durchführung eines Antikörper-Arrays}

Zur Identifizierung von LPXN-vermittelten Signalwegen wurde von der Firma Kinexus ein Antikörper-Array durchgeführt. Dafür wurde zunächst die Expression von LPXN in der PCaZelllinie PC-3 mittels spezifischer siRNA (siLPXN) für $72 \mathrm{~h}$ herunterreguliert. Als Kontrolle wurde eine siRNA gegen Luciferase (siLuc) verwendet. Anschließend wurde Gesamt-Protein isoliert und die erfolgreiche Herunterregulierung der LPXN-Expression mittels Western BlotAnalyse überprüft (Abb. 3.48). Die Proteine von drei verschiedenen Transfektionen wurden überprüft, gepoolt und an die Firma Kinexus verschickt. Dort erfolgte die fluoreszierende Markierung des Gesamt-Proteins und anschließender Hybridisierung mit der Array-Membran (Material und Methoden 2.26).

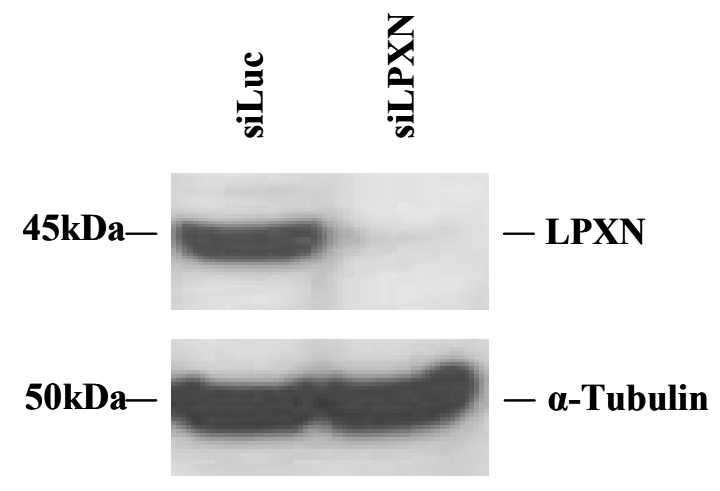


Abb. 3.48: Westen Blot-Analyse zur Überprüfung der LPXN-Expression nach Transfektion der Zellen mit spezifischer siRNA. Die Expression von LPXN in PC-3 PCa-Zellen wurde in drei verschiedenen Ansätzen für $72 \mathrm{~h}$ herunterreguliert. Anschließend wurde jede Transfektion mittels Western Blot-Analyse auf eine herunterregulierte LPXN-Expression hin überprüft und dann gepoolt. Mit einem LPXN-spezifischen Antikörper konnte eine LPXN-Bande bei $45 \mathrm{kDa}$ nur in den Luciferase-transfizierten Kontrollzellen detektiert werden. Ein Antikörper gegen $\alpha$-Tubulin wurde für die Überprüfung der aufgetragenen Proteinmenge eingesetzt.

Nach der Auswertung der Ergebnisse konnten 18 Proteine identifiziert werden, welche mindestens um den Faktor 1,5 hoch- bzw. herunterreguliert wurden. Bei zehn Proteinen änderte sich die Expressionsstärke (Tab. 3.2) und bei acht Proteinen der Phosphorylierungsstatus (Tab. 3.3) nach Herunterregulierung der LPXN-Expression.

Tab 3.2: Ergebnisse des Antikörper-Arrays für PC-3 PCa-Zellen nach Herunterregulierung der LPXNExpression (siLPXN vs. siLuc). Aufgeführt sind ausschließlich die Proteine, bei denen eine Veränderung in der Expressionsstärke erfolgte.

\begin{tabular}{|l|c|l|c|}
\hline \multicolumn{1}{|c|}{ Symbol } & $\begin{array}{c}\text { Phosphorylierungs } \\
\text {-Stelle }\end{array}$ & \multicolumn{1}{|c|}{ Protein (kompletter Name) } & $\begin{array}{c}\text { fold change } \\
\text { siLPXN/siLuc }\end{array}$ \\
\hline KDEL receptor 1 & Pan-spezifisch & ER lumen protein retaining receptor 1 & 2,39 \\
\hline Cyclin D1 & Pan-spezifisch & Cyclin D1 (PRAD1) & 2,16 \\
\hline Hsp90 & Pan-spezifisch & Heat shock 90 kDa protein alpha/beta & 2,12 \\
\hline Hsp90 & Pan-spezifisch & Heat shock 90 kDa protein alpha/beta & 2,10 \\
\hline PKCb1 & Pan-spezifisch & Protein-serine kinase C beta 1 & 2,04 \\
\hline p21 CDKI1 & Pan-spezifisch & cyclin-dependent kinase inhibitor 1 (MDA6) & 0,55 \\
\hline CDK1 (CDC2) & Pan-spezifisch & Cyclin-dependent protein-serine kinase 1 & 0,53 \\
\hline PKBb (Akt2) & Pan-spezifisch & Protein-serine kinase B beta & 0,51 \\
\hline Yes & Pan-spezifisch & $\begin{array}{l}\text { Yamaguchi sarcoma proto-oncogene- } \\
\text { encoded tyrosine kinase }\end{array}$ \\
\hline TAK1 & Pan-spezifisch & TGF-beta-activated protein-serine kinase 1 & 0,49 \\
\hline GSK3a & Pan-spezifisch & Glycogen synthase-serine kinase 3 alpha & 0,47 \\
\hline
\end{tabular}


Tab. 3.3. Ergebnisse des Antikörper-Arrays für PC-3 PCa-Zellen nach Herunterregulierung der LPXNExpression (siLPXN vs. siLuc). Aufgeführt sind ausschließlich die Proteine, bei denen eine Veränderung im Phosphorylierungsstatus erfolgte.

\begin{tabular}{|l|c|l|c|}
\hline \multicolumn{1}{|c|}{ Symbol } & $\begin{array}{c}\text { Phosphorylierungs- } \\
\text { Stelle }\end{array}$ & \multicolumn{1}{|c|}{ Protein (kompletter Name) } & $\begin{array}{c}\text { fold change } \\
\text { siLPXN/siLuc }\end{array}$ \\
\hline HSP27 & S82 & $\begin{array}{l}\text { Heat shock 27 kDa protein beta 1 } \\
\text { (HspB1) }\end{array}$ & 3,32 \\
\hline CaMK2a & T286 & $\begin{array}{l}\text { Calcium/calmodulin-dependent } \\
\text { protein-serine kinase 2 alpha }\end{array}$ & 2,41 \\
\hline EGFR & Y1197 & $\begin{array}{l}\text { Epidermal growth factor receptor- } \\
\text { tyrosine kinase }\end{array}$ & 1,86 \\
\hline 4E-BP1 & T45 & $\begin{array}{l}\text { Eukaryotic translation initiation } \\
\text { factor 4E binding protein 1 } \\
\text { (PHAS1) }\end{array}$ & 1,82 \\
\hline EGFR & T678 & $\begin{array}{l}\text { Epidermal growth factor receptor- } \\
\text { tyrosine kinase }\end{array}$ & 1,76 \\
\hline CDK1/2 & Y15 & $\begin{array}{l}\text { Cyclin-dependent protein-serine } \\
\text { kinase 1/2 }\end{array}$ & 1,75 \\
\hline PKCd & S645 & Protein-serine kinase C delta & 1,73 \\
\hline $\begin{array}{l}\text { GRK2 } \\
\text { (BARK1) }\end{array}$ & S670 & $\begin{array}{l}\text { G protein-coupled receptor-serine } \\
\text { kinase 2 }\end{array}$ & 0,55 \\
\hline
\end{tabular}

\subsection{2 Überprüfung der Daten des Antikörper-Arrays}

Zur Überprüfung der deregulierten Expression der gelb-markierten Proteine nach Herunterregulierung der LPXN-Expression wurde eine quantitative real time PCR-Analyse durchgeführt. Dafür wurden PC-3 Pka-Zellen zunächst mit LPXN-spezifischer und als Kontrolle mit Luciferase-spezifischer siRNA transfiziert. Nach 72 h wurde Gesamt-RNA isoliert und diese mittels reverser Transkriptase in cDNA umgeschrieben. Für die Gene GSK3 $\alpha$, KDELR1 und CDC2 konnte keine Bestätigung der Daten des Antikörper-Arrays auf RNA-Ebene erzielt werden. Für die Kinasen TAK1 und Yes hingegen ist auch in der quantitativen real time PCR-Analyse eine deutliche Herunterregulierung der Expression nach LPXN knockdown in den PC-3-Zellen nach $48 \mathrm{~h}$ und $72 \mathrm{~h}$ zu verzeichnen (Abb. 3.49). 


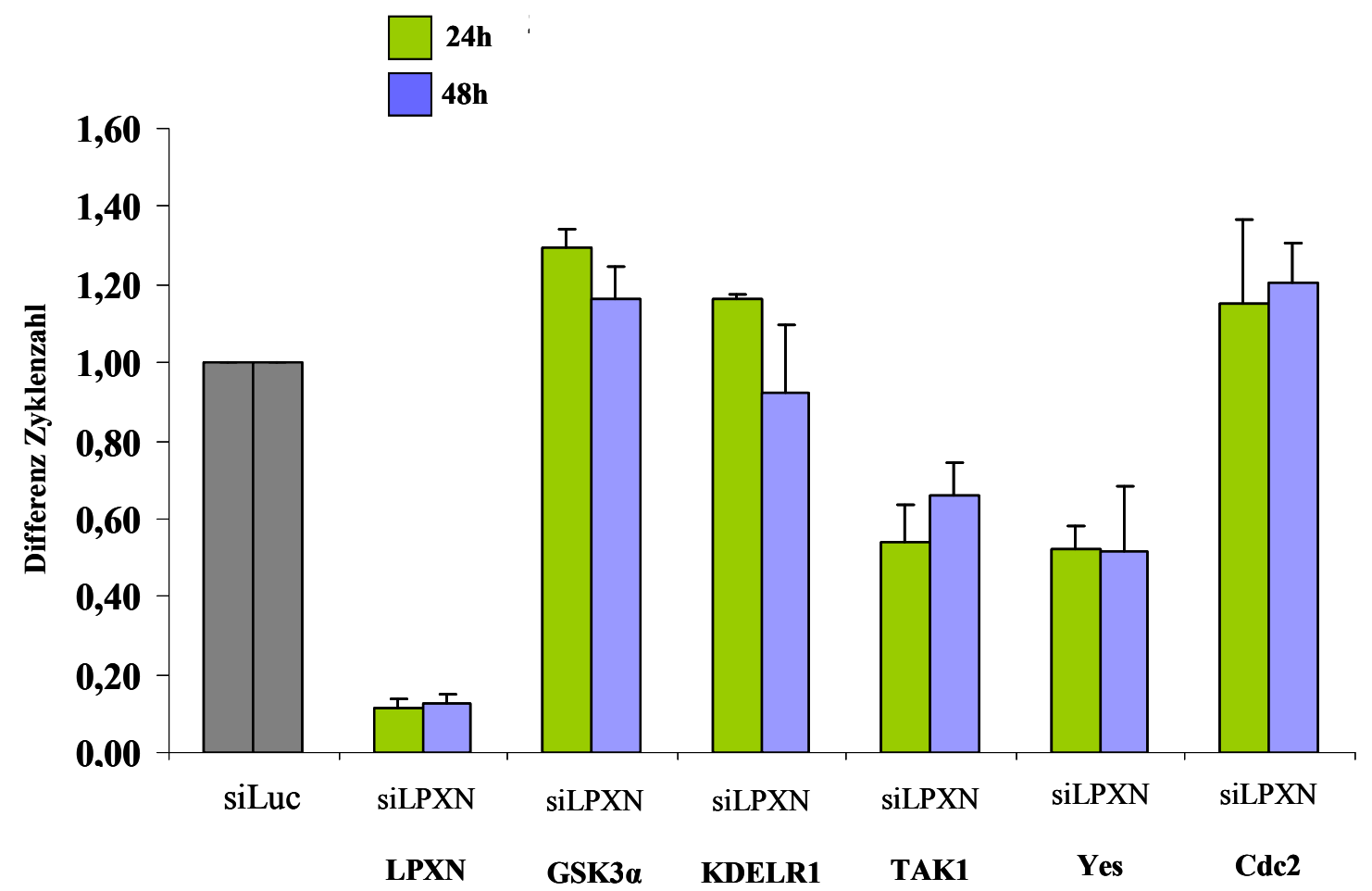

Abb. 3.49: Ergebnisse der quantitativen real time PCR-Analyse zur Überprüfung der Antikörper-Array Daten. PC-3-PCa-Zellen wurden für $48 \mathrm{~h}$ bzw. $72 \mathrm{~h}$ mit LPXN-spezifischer (siLPXN) und als Kontrolle mit Luciferase-spezifischer (siLuc) siRNA transfiziert. Anschließend wurde Gesamt-RNA isoliert und cDNA synthetisiert. Die Expression der in der Tabelle 1 gelb hinterlegten Gene wurde mittels quantitativer real time PCR-Analyse mit spezifischen Primern überprüft. Zur Normalisierung der Werte wurde der Mittelwert der housekeeping Gene TBP und PBGD verwendet. Dargestellt ist die Genexpression in den LPXN-siRNA transfizierten Zellen jeweils in Relation zur Expression in den Luciferase-siRNA transfizierten Zellen, welche hier gleich 1 gesetzt wurde (siLuc). Dabei ist der Wert der Mittelwert von drei unabhängig voneinander durchgeführten Versuchen. Für TAK1 und Yes konnte die im Array ermittelte verminderte Expression in den Zellen mit LPXN knockdown bestätigt werden, wohingegen GSK3 $\alpha$, KDELR1 und CDC2 keine veränderte Expression auf RNA-Ebene zeigen.

TAK1 gehört zur Familie der Serin/Threonin-MAPK-Proteinkinasen und wird durch TGF $\beta$ aktiviert. Der TGF $\beta$-Rezeptor ist an vielen intrazellulären Signalwegen wie z.B. Proliferation und Differenzierung aber auch Zellmigration und Invasion beteiligt (Jennings und Pietenpol, 1998).

Um zunächst die herunterregulierte TAK1-Expression nach LPXN knockdown auf Proteinebene $\mathrm{zu}$ bestätigen, wurde ein Antikörper gegen TAK1 erworben. Wie in Abbildung $3.50 \mathrm{zu}$ erkennen, konnte der Expressionsverlust von TAK1 mittels Western Blot bestätigt werden. 


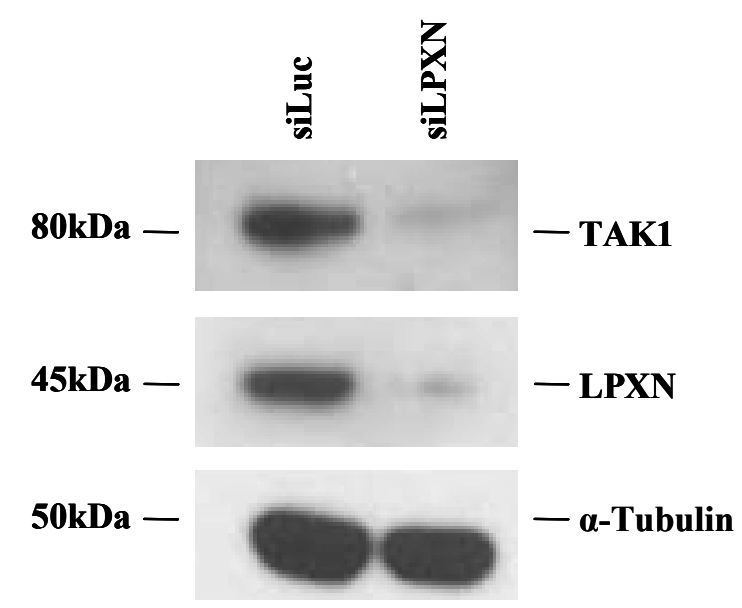

\begin{abstract}
Abb. 3.50: Westen Blot-Analyse zum Expressionsverlust von TAK1 nach Herunterregulierung der LPXN-
Expression. PC-3-PCa-Zellen wurden mit LPXN-spezifischer siRNA und als Kontrolle mit Luciferasespezifischer siRNA transfiziert. Nach $72 \mathrm{~h}$ wurde Gesamt-Protein isoliert und $50 \mu \mathrm{g}$ für die Western BlotAnalyse eingesetzt. Zur Detektion von TAK1 wurde ein TAK1-Antikörper verwendet, der bei $80 \mathrm{kDa}$ eine spezifische Bande detektiert. Die Herunterregulierung der LPXN-Expression wurde mit einem LPXNspezifischen Antikörper überprüft. Die aufgetragene Proteinmenge wurde mit einem $\alpha$-Tubulin-Antikörper nachgewiesen. Die Western Blot-Analyse wurde mit Proteinen aus verschiedenen Transfektionen dreimal wiederholt.
\end{abstract}

\title{
3.6.3 Analyse der TAK1-vermittelten Signalwege
}

Aus der Literatur ist bekannt, dass TAK1 die MAPK JNK und p38 phosphoryliert und damit aktiviert. Durch diese Phosphorylierung kann der Transkriptionsfaktor ATF-2 transaktiviert werden, welcher wiederum Zielgene aktiviert, die in Zellmigration und Tumorigenese involviert sind [Gupta et al., 1995; Livingston at al, 1997; van Dam et al., 1997). Zwei dieser Zielgene sind Maspin und Presenilin. Für Maspin konnte bereits gezeigt werden, dass es die Zellinvasion und Motilität von PCa-Zellen inhibiert [Sheng et al., 1996].

Um zu untersuchen, ob LPXN diesen Signalweg via TAK1 beeinflusst, wurde zunächst der Phosphorylierungsstatus von JNK, MKK3/6 und p38 in Zellen mit herunterregulierter LPXNExpression und als Kontrolle mit herunterregulierter Luciferase-Expression auf Proteinebene überprüft. Die Western Blot-Analysen, welche mit Antikörpern gegen JNK, MKK3/6 und p38 durchgeführt wurden, die nur jeweils die phosphorylierte Form erkennen, bestätigt, dass nur der Phosphorylierungsgrad von JNK nach Herunterregulierung der LPXN-Expression (siLPXN) abnimmt (Abb. 3.51). Bei MKK3/6 und p38 ist im Phosphorylierungsstatus nach 
Herunterregulierung der LPXN-Expression kein Unterschied zu erkennen. Dies deutet darauf hin, dass dieser Arm des TAK1-Signalweges nicht durch LPXN reguliert wird.

A

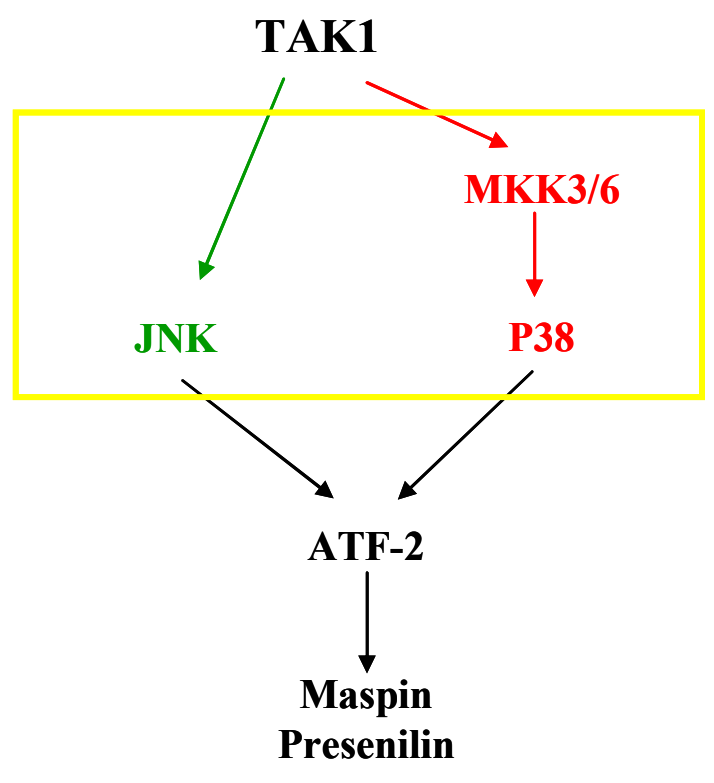

B
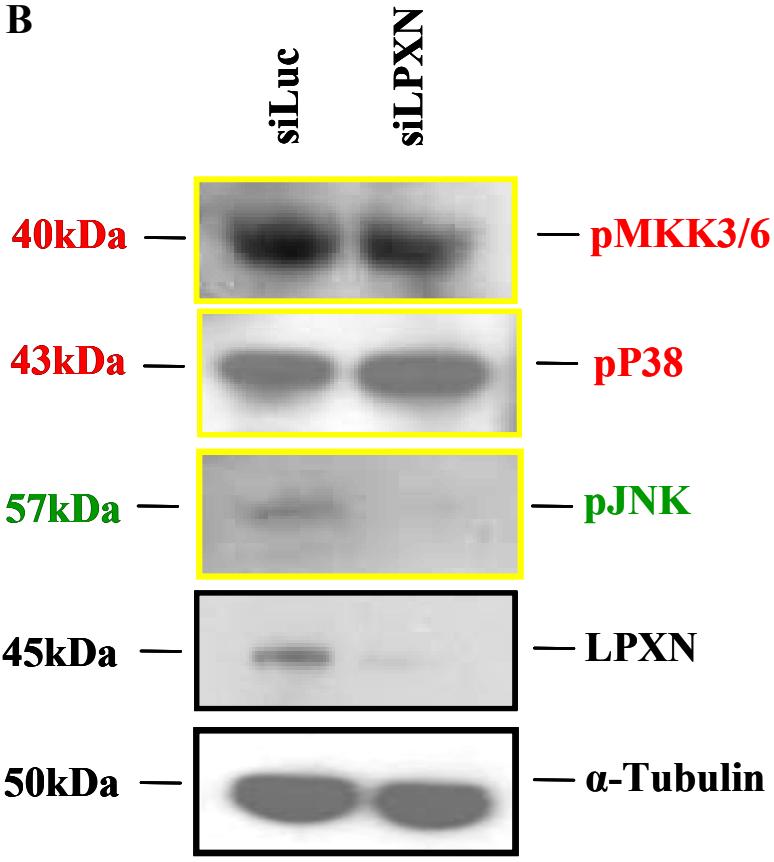

Abb. 3.51: Western Blot-Analyse zur Phosphorylierung von MKK3/6, p38 und JNK in PC-3-Zellen mit herunterregulierter LPXN-Expression. A. TAK1 phosphoryliert und aktiviert die Proteine MAPK MKK3/6, p38 und JNK. JNK und p38 können im phosphorylierten Zustand den Transkriptionsfaktor ATF-2 aktivieren, wodurch die Zielgene Maspin und Presenilin angeschaltet werden. B. Zur Überprüfung, ob LPXN den TAKSignalweg beeinflusst, wurde eine Western Blot-Analyse durchgeführt. PC-3-Zellen wurden mit LPXN-siRNA (siLPXN) und als Kontrolle mit Luciferase-siRNA (siLuc) transfiziert. Die Western Blot-Analyse wurde mit 50 $\mu \mathrm{g}$ Gesamt-Protein und MKK3/6, p38 und JNK-spezifischen Antikörpern durchgeführt, welche jeweils ausschließlich die phosphorylierte Form erkennen. Zur Überprüfung der aufgetragenen Proteinmenge wurde ein Antikörper gegen $\alpha$-Tubulin verwendet.

Um den weiteren TAK1-JNK-ATF2-Maspin/Presenilin Signalweg zu verfolgen, wurde erneut die Expression von LPXN in PC-3 PCa-Zellen herunterreguliert (siLPXN). Anschließend wurde Gesamt-RNA isoliert und eine quantitative real time PCR-Analyse mit Maspin- und Presenilin-spezifischen Primern durchgeführt (Material und Methoden 2.13.3). Als Kontrolle wurden die PC-3-Zellen mit siRNA gegen Luciferase herunterreguliert (siLuc). Wie in Abbildung $3.51 \mathrm{zu}$ erkennen ist, nimmt die relative Expression von Maspin (siLPXN Maspin) und Presenilin (siLPXN Presenilin) nach LPXN knockdown im Vergleich zu den 
Kontrollzellen um 40\% bzw. 30\% ab. Die Versuche wurden jeweils als Triplett durchgeführt und der Mittelwert einschließlich Standardabweichung in der Abbildung 3.52 dargestellt.

A

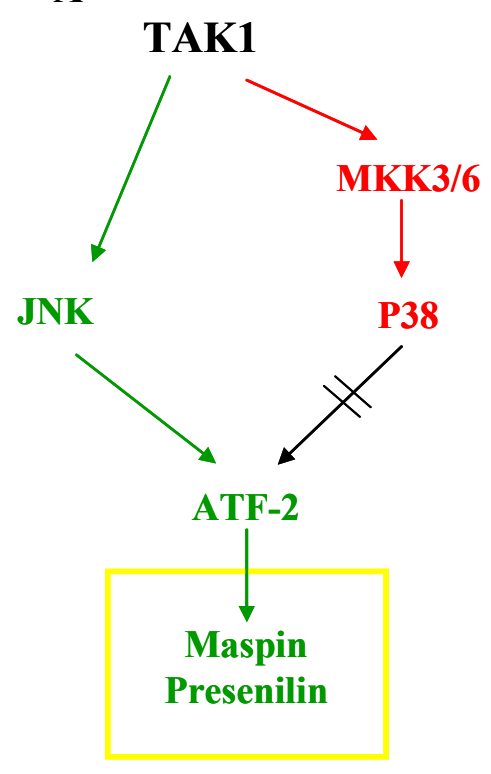

B

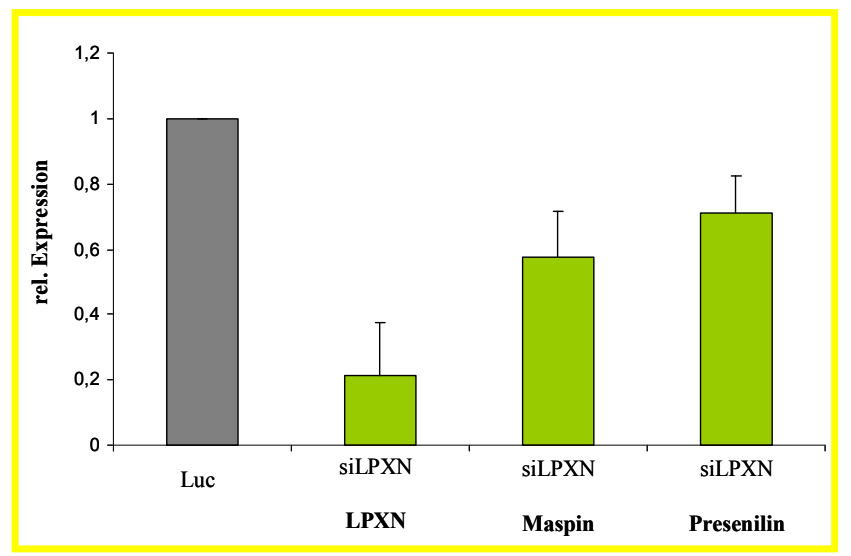

Abb. 3.52: Quantitative real time PCR-Analyse zur Expression der ATF-2 Zielgene Maspin und Presenilin nach Herunterregulierung der LPXN-Expression. A. Dargestellt ist der TAK1-vermittelter Signalweg, welcher durch LPXN reguliert wird. B. Die Expression von LPXN und als Kontrolle von Luciferase wurde in PC-3 PCa-Zellen herunterreguliert, nach $72 \mathrm{~h}$ Gesamt-RNA isoliert und diese mittels reverser Transkriptase in cDNA umgeschrieben. Für die quantitative real time PCR-Analyse wurden Primer verwendet, die spezifisch die ATF-2 Zielgene Maspin und Presenilin sowie LPXN amplifizieren. Zur Normalisierung der Werte wurde der Mittelwert der housekeeping Gene TBP und PBGD verwendet. Dargestellt ist die Genexpression (LPXN, Maspin und Presenilin) in den LPXN-transfizierten Zellen jeweils in Relation zur Expression in den Luciferasetransfizierten Zellen, welche hier gleich 1 gesetzt wurden (siLuc). Die Werte ergeben sich aus den Mittelwerten von drei verschiedenen Transfektionen, welche jeweils zweimal in der quantitativen real time PCR getestet wurden.

Ob eine Expressionsänderung des ATF-2-Zielgens Presenilin auch nach Überexpression von LPXN zu beobachten ist, wurde in den Primärzellen 83A (L/-T/-) und 27F (T/-) untersucht. Dafür wurde von den LPXN-überexprimierenden Primärzellen 83A (L/-T/-) und als Kontrolle von $27 \mathrm{~F}$ (T/-) RNA isoliert und cDNA synthetisiert. Anschließend wurde eine quantitative real time PCR-Analyse mit Presenilin-spezifischen Primern für murines Presenilin durchgeführt. In den Primärzellen 83A (L/-T/-) kann durch die Überexpression von LPXN eine deutliche Expressionszunahme von Presenilin im Vergleich zu den Kontrollzellen 27F 
(T/-) beobachtet werden. Die in Abbildung 3.53 angegebene relative Expression ergibt sich aus dem Mittelwert der Analyse von drei verschiedenen Experimenten.

A

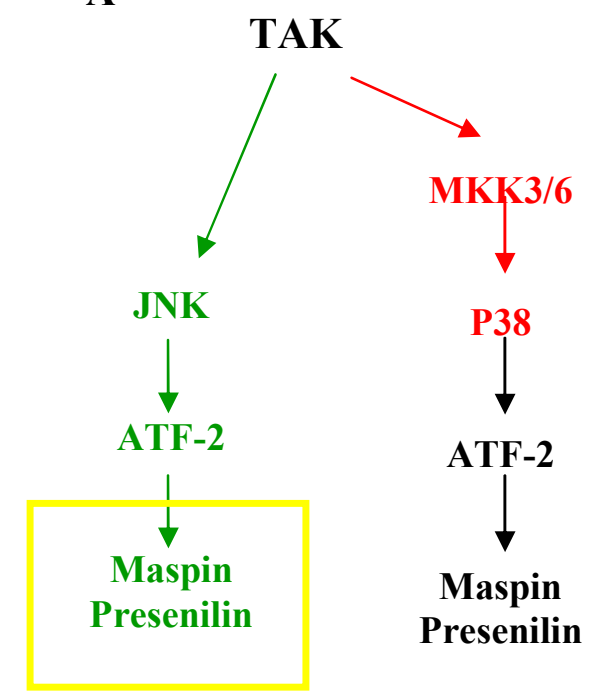

B

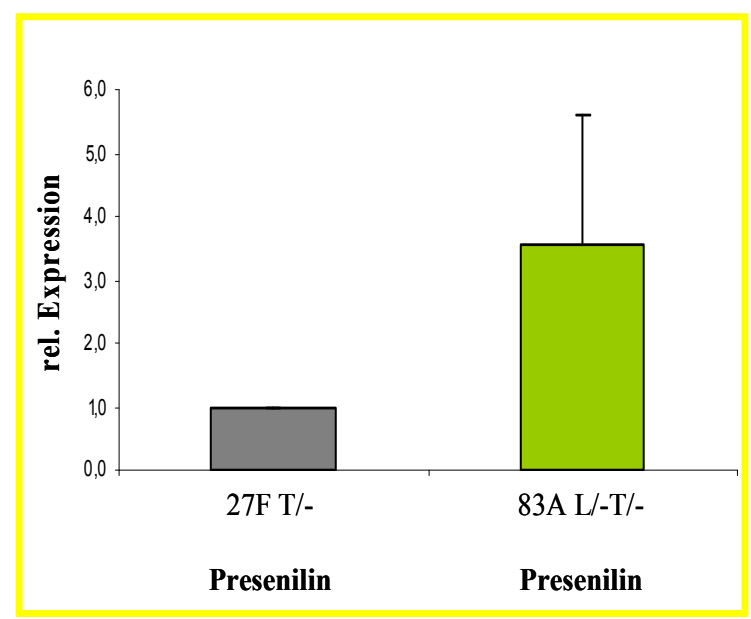

Abb. 3.53: Quantitative real time PCR zur Expression des ATF-2 Zielgens Presenilin in LPXNüberexprimierenden Primärzellen. A. TAK1-vermittelter Signalweg, welcher durch LPXN reguliert wird. B. Von den Primärzellen 83A (L/-T/-) und 27F (T/-) wurde Gesamt-RNA isoliert und diese mittels reverser Transkriptase in cDNA umgeschrieben. Die quantitative real time PCR-Analyse mit spezifischen Primern gegen murines Presenilin demonstriert eine verstärkte Expression von Presenilin in den LPXN-überexprimierenden Primärzellen 83A (L/-T/-) im Vergleich zu den Kontrollzellen 27F (T/-). Die Werte ergeben sich aus dem Mittelwert von drei unabhängig voneinander durchgeführten Versuchen. Die Expression von Presenilin in den LPXN-überexprimierenden Zellen 83A wurde zu derjenigen der Kontrollzellen (Bezugswert gleich 1) ins Verhältnis gesetzt.

\subsubsection{Analyse der SRC-vermittelten Signalwege}

Eine weitere Gruppe möglicher Kandidatenproteine, auf deren Aktivität LPXN Einfluss nehmen könnte, stellt die Familie der SRC-Kinasen dar. Es konnte bereits beschrieben werden, dass LPXN mit der SRC-Kinase c-SRC in Osteoklasten einen Komplex formt [Sahu et al., 2007].

Zur Überprüfung, ob LPXN die Phosphorylierung der Mitglieder der SRC-Familie beeinflussen kann, wurden PC-3 PCa-Zellen mit LPXN-spezifischer siRNA und als Kontrolle mit Luciferase-spezifischer siRNA transfiziert. Anschließend wurde den Zellen für $24 \mathrm{~h}$ das 
Serum entzogen und durch erneute Serumgabe für $4 \mathrm{~h}$ das Wachstum angeregt, bevor Gesamt-Protein isoliert wurde. Die Analyse des Aktivitätsstatus der Mitglieder der SRCFamilie erfolgte mit Hilfe eines Phosphorylierungs-spezifischen Antikörpers gegen Serin 416. Wie in Abbildung $3.54 \mathrm{zu}$ erkennen ist, konnte nach Herunterregulierung der LPXNExpression (siLPXN) im Vergleich zu den Kontrollen ein deutlicher Verlust im Phosphorylierungsstatus der Mitglieder der SRC-Familie nachgewiesen werden. Als Kontrolle wurde zusätzlich ein Antikörper verwendet, der sowohl die phosphorylierte als auch die unphosphorylierte Form der Mitglieder der SRC-Familie detektiert.

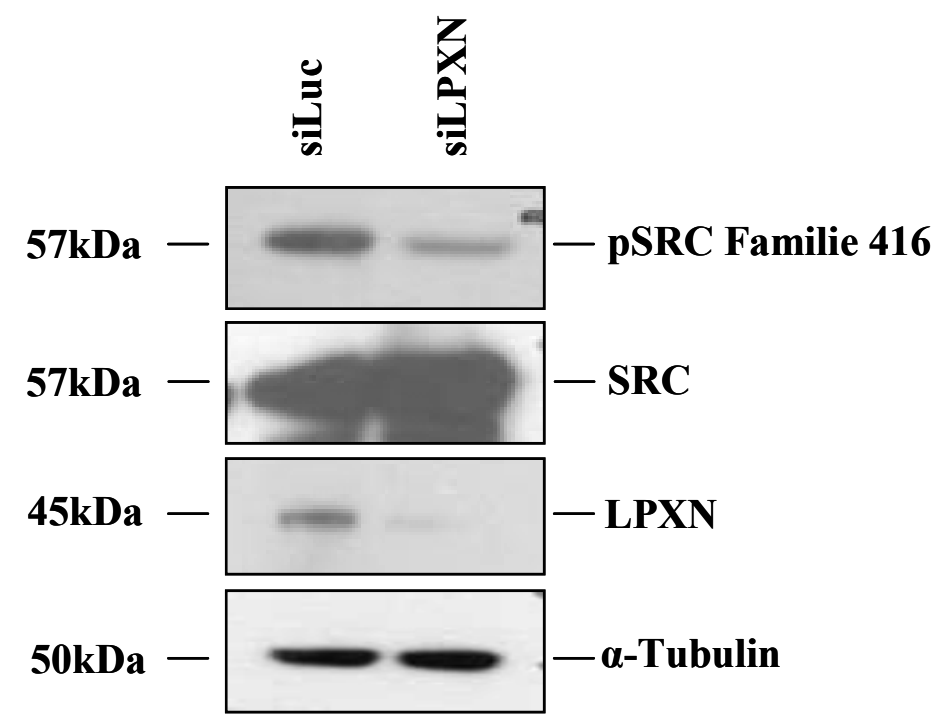

\begin{abstract}
Abb. 3.54: Western Blot-Analyse zum Phosphorylierungsstatus der Mitglieder der SRC-Familie in Zellen mit herunterregulierter LPXN-Expression. PC-3 PCa-Zellen wurden mit LPXN-spezifischer siRNA (siLPXN) bzw. als Kontrolle mit Luciferase-spezifischer siRNA (siLuc) transfiziert. Nach $72 \mathrm{~h}$ wurde GesamtProtein isoliert und $50 \mu \mathrm{g}$ für die Western Blot-Analyse eingesetzt. Zunächst wurde ein Antiköper verwendet, der spezifisch bei einer Größe von $57 \mathrm{kDa}$ die phosphorylierte Form der SRC-Kinasen an der Phosporylierungsstelle Serin 416 erkennt. Zur Darstellung der Gesamt- SRC-Proteinmenge wurde ein Antikörper gegen die phosphorylierte sowie die unphosphorylierte Form von SRC verwendet. Ein Antikörper gegen LPXN bestätigt den knockdown der LPXN-Expression in den LPXN-siRNA-transfizierten Zellen. Ein Antikörper gegen $\alpha$-Tubulin diente zur Kontrolle der aufgetragenen Proteinmenge.
\end{abstract}




\section{Diskussion}

\subsection{Zusammenfassung der Ergebnisse}

In der vorliegenden Arbeit konnte das focal adhesion-Protein Leupaxin (LPXN) als ein in die Progression von Prostatakarzinomen $(\mathrm{PCa})$ involviertes Protein charakterisiert werden. In vivo-Studien an doppelt transgenen LPXN/TRAMP-Mäusen bestätigen, dass LPXN das Wachstum von bestehenden TRAMP-Tumoren sowie von Fernmetastasen stark beschleunigt, wobei der Initiationszeitpunkt der Tumorbildung durch die Überexpression von LPXN nicht beeinflusst wird. Eine durch LPXN vermittelte verstärkte Tumorprogression konnte ebenfalls in LPXN/TRAMP-Mäusen beobachtet werden, welche zuvor durch eine Kastration einem Androgenentzug unterzogen wurden. Die mittlere Überlebensdauer der kastrierten LPXN/TRAMP-Mäuse lag bei 18,7 Wochen, während die Kontrollmäuse ein durchschnittliches Alter von 20,6 Wochen erreichten. Nach Etablierung von jeweils zwei Primärzelllinien aus den PCa der LPXN/TRAMP- und TRAMP-Mäuse konnte gezeigt werden, dass sowohl die Migrations- als auch die Invasionsfähigkeit der LPXN/TRAMPZellen durch die Überexpression von LPXN im Vergleich zu den Kontrollprimärzellen dreibzw. zweifach erhöht ist.

Die Ergebnisse der in vivo-Studien führten zu der Frage, wie LPXN die Progression von PCa beeinflussen kann. In vorangegangenen Arbeiten wurde beschrieben, dass eine verminderte LPXN-Expression die Expression von p120CTN erhöht [Kaulfuß, 2006]. In der vorliegenden Arbeit konnte gezeigt werden, dass auch nach Überexpression von LPXN mittels TATTransduktion eine negative Korrelation der Expression von p120CTN und LPXN in den PCaZelllinien PC-3 und DU 145 zu erkennen ist. Expressionsanalysen mittels Western Blot an Tumormaterial aus den LPXN/TRAMP- und TRAMP-Mäusen sowie an den isolierten murinen PCa-Primärzellen bestätigten ebenfalls die Abhängigkeit zwischen der p120CTNund der LPXN-Expression. Um den Einfluss von LPXN und p120CTN auf das Migrationsund Invasionsverhalten von PCa-Zellen zu untersuchen, wurde die Expression beider Gene in PC-3- und DU 145-Zellen mittels siRNA herunterreguliert. Dabei konnte gezeigt werden, dass eine verminderte Expression von p120CTN in einer erhöhten Migrations- und Invasionsfähigkeit der Zellen resultiert. Die verminderte Expression von LPXN reduziert hingegen die Migrations- und Invasionsfähigkeit der Zellen [Kaulfuß et al., 2008]. Die simultane Herunterregulierung der LPXN- und p120CTN-Expression resultierte in einer 
Aufhebung der Einzel-Effekte. Weiterhin veränderte sich durch die Herunterregulierung der p120CTN- und LPXN-Expression die subzelluläre Lokalisation des p120CTNInteraktionspartners $\beta$-Catenin. $\beta$-Catenin ist nach dem knockdown von p120CTN im Kern, nach dem knockdown von LPXN an der Membran und nach dem knockdown von p120CTN und LPXN sowohl im Kern als auch an der Membran von PC-3-Zellen lokalisiert. Eine Expressionsanalyse des $\beta$-Catenin Zielgens MMP-7 in PCa-Zellen mittels quantitativer real time-PCR konnte zeigen, dass ein knockdown von p120CTN in einer erhöhten Expression von MMP-7 und ein knockdown von LPXN in einer verminderten Expression von MMP-7 resultiert.

Mit Hilfe eines whole genome Microarrays an Prostatatumormaterial von LPXN/TRAMPund TRAMP-Mäusen sollten Gene identifiziert werden, die durch die Expression von LPXN während der Tumorprogression dereguliert werden. Dabei konnte eine um den Faktor 0,84 herunterregulierte Expression der Cystathionine-beta-Synthase (Cbs) und eine um den Faktor 1,65 hochregulierte Expression von HOP homeobox (Hopx) im Tumormaterial der LPXN/TRAMP-Mäuse im Vergleich zu den Kontrollmäusen beobachtet werden. Dieses Ergebnis konnte ebenfalls mittels quantitativer real time-PCR bestätigt werden.

In vorangegangenen Studien wurde Caldesmon als Interaktionspartner von LPXN identifiziert [Beckemeyer, 2007] und stellt somit ein Kandidatenprotein bei der LPXN-vermittelten Progression von PCa dar. Die Expressionsanalyse in den etablierten PCa-Zelllinien LNCaP, PC-3 und DU 145 ergab sowohl auf RNA- als auch auf Proteinebene eine stark erhöhte Expression von Caldesmon in den androgen-unabhängigen und invasiven PC-3-Zellen. Subzellulär ist Caldesmon an den F-Aktin-Fasern lokalisiert, wobei zusätzlich eine Kolokalisation von Caldesmon und LPXN an den focal adhesion sites beobachtet werden konnte. Nach Herunterregulierung der Caldesmon-Expression konnte in PC-3- und DU 145Zellen eine erhöhte Migrations- und Invasionsfähigkeit, jedoch keine veränderte Proliferation der Zellen nachgewiesen werden. Die Interaktion zwischen LPXN und Caldesmon wurde mittels GST-Pulldown bestätigt, wobei der Interaktionsbereich auf die LIM-Domänen von LPXN eingeschränkt werden konnte. Weiterhin konnte demonstriert werden, dass nach Herunterregulierung der LPXN-Expression die Expression von Caldesmon nicht verändert wird, aber die Menge an phosphoryliertem und damit inaktivem Caldesmon abnimmt, was zu einer Reduktion der Migration der PCa-Zellen führt.

Weitergehende Untersuchungen konnten zeigen, dass LPXN auch einen Einfluss auf die Adhäsion und Ausbreitung von PCa-Zellen ausübt. So zeigten PC-3- und DU 145-Zellen mit herunterregulierter LPXN-Expression eine verminderte Adhärenz $1 \mathrm{~h}$ bzw. $2 \mathrm{~h}$ nach 
Ausplattieren auf verschieden beschichteten Untergründen im Vergleich zu den Kontrolltransfizierten Zellen. Des Weiteren konnte mittels Immunzytochemie eine reduzierte Ausbreitung der LPXN knockdown Zellen beobachtet werden. Die LPXNüberexprimierenden murinen PCa-Primärzellen (LPXN/TRAMP) hingegen adhärierten stärker als die entsprechenden TRAMP-Kontrollprimärzellen. Da bei der für die Adhärenz und Ausbreitung von Zellen notwendigen Umstrukturierung des Zytoskeletts vor allem die Familie der kleinen Rho-GTPasen einen große Rolle spielen, wurde mittels GST-PulldownAssays die Aktivitäten von RhoA und Rac1 in PC-3-Zellen mit LPXN knockdown bestimmt. So konnte gezeigt werden, dass bei verminderter LPXN-Expression eine verringerte RhoAund eine verstärkte Rac1-Aktivität zu verzeichnen ist.

Um $\mathrm{zu}$ untersuchen, in welche weiteren Signalwege LPXN involviert ist, wurde ein Antikörper-Array an PC-3-Zellen mit herunterregulierter LPXN-Expression im Vergleich zu Kontrollzellen durchgeführt. Die Kinasen TAK1 und Yes konnten dabei als herunterregulierte Gene nach LPXN knockdown identifiziert werden. Die weitere Analyse der TAK1vermittelten Signalwege ergab, dass sich abhängig von der LPXN-Expression auch der Phosphorylierungsstatus der downstream von TAK1 stehenden Kinase JNK ändert. Der Phosphorylierungsstatus der downstream von TAK1 stehenden Kinasen MKK3/6 und p38 änderte sich hingegen nicht. Die Involvierung von LPXN in den TAK1-JNK-ATF-2Signalweg konnte durch eine quantitative real-time PCR bestätigt werden. Die ATF-2Zielgene Maspin und Presenilin1 waren nach Herunterregulierung der LPXN-Expression in PC-3-Zellen vermindert exprimiert, wohingegen in den LPXN-überexprimierenden Primärzellen (LPXN/TRAMP) eine verstärkte Expression von Presenilin1 nachgewiesen werden konnte.

Die Analyse des Phosphorylierungsstatus der Kinasen der SRC-Familie ergab weiterhin einen Einfluss von LPXN auf deren Aktivität. Bei verminderter LPXN-Expression war der Phosphorylierungsstatus der Mitglieder der SRC-Familie in PC-3-Zellen im Vergleich zu Kontrollzellen reduziert. 


\subsection{Zur Bedeutung von LPXN in der Progression von Prostatakarzinomen}

Viele humane Tumore entstehen durch verschiedene genetische und epigenetische Veränderungen, durch die die Proliferation und Homöostase der Zellen gestört werden. Hanahan und Weinberg [2000] postulierten, dass sich maligne Zellen durch den Erwerb der Autonomie der Wachstumssignale, der Unempfindlichkeit gegenüber Wachstumsinhibierenden Signalen, des Umgehens des programmierten Zelltodes (Apoptose) und des unbegrenzten Replikationspotentials entwickeln. Erlangt eine Zelle durch Mutationen diese Eigenschaften, ist sie in der Lage, eine Population an Zellen mit den gleichen physiologischen Dispositionen aufzubauen, wodurch eine primäre Tumormasse entsteht. Um sich zu einer größeren Tumormasse zu entwickeln, muss diese die Fähigkeit der fortwährenden Angiogenese erlangen [Bouck et al., 1996; Hanahan und Folkman, 1996; Hanahan und Weinberg, 2000]. Während der weiteren Entwicklung der meisten humanen Tumore entstehen Zellen, die sich von der primären Tumormasse lösen, in das umliegende Gewebe invadieren, durch die Blutbahn an entfernte Orte gelangen und dort Metastasen bilden. Die Metastasenbildung ist der Grund für 90\% der Krebs-verursachten Todesfälle [Sporn, 1996; Hanahan und Weinberg, 2000].

Das humane PCa folgt durch die Akkumulation von genetischen und epigenetischen Veränderungen in seiner Progression ebenfalls einem kanonischen Muster: Entstehung der Prostata intraepithelialen Neoplasie (PIN), lokal begrenzter Tumor, Invasion der malignen Zellen in das Stroma, Infiltration von Samenblase, Blasenhals, Sphincter extemus und Rektum und Bildung von Metastasen zumeist in Lymphknoten und Knochen. Der Verlust der Expression oder das Auftreten von Mutationen in Tumorsuppressorgenen oder Transkriptionsfaktoren wie z.B. AR, Phosphatase und Tensin homolog (PTEN), Protein 53 (p53) und NK3 homeobox 1 (NKX3.1) konnten im fortgeschrittenen Stadium des PCa beobachtet werden [Hollstein et al., 1998; Abate-Shen und Shen, 2000; Song et al., 2009]. Trotzdem gibt es noch immer unzureichende Kenntnisse über spezifische Gene und Signalwege, die in die Progression der PIN zum invasiven und metastasierenden PCa involviert sind.

In vorangegangenen Arbeiten konnte Leupaxin als differentiell exprimiertes Gen im humanen PCa identifiziert werden [Kaulfuß, 2006]. Durch in vivo-Experimente an transgenen Mäusen konnte jedoch gezeigt werden, dass LPXN keinen Einfluss auf die Initiation des PCa ausübt [Kaulfuß, 2006]. Für diese Untersuchungen wurde eine Expressionskassette verwendet, die 
426 Basenpaare (bp) des Probasin-Promotors der Ratte und 28 bp der 5 untranslatierten Region enthält, was dazu führt, dass das CAT (Chloramphenicol-Acetyltransferase) -Gen prostataspezifisch exprimiert wird. Das Transgen wird nach dem Entwicklungsstand und hormonell durch Androgene reguliert, wobei sich die Expression hauptsächlich auf die ventralen, dorsalen und lateralen Lappen der Prostata beschränkt [Greenberg, 1994]. In der transgenen LPXN-Maus wurde hinter den beschriebenen Probasin-Minimalpromotor der offene Leserahmen des humanen LPXN und zusätzlich zur Unterscheidung des endogenen, murinen LPXN ein 6facher cmyc-Tag kloniert [Herr, 2005]. Es wurden zwei unabhängige transgene Maus-Linien auf FVB-Hintergrund generiert. Wie erwartet, führt die Verwendung des Probasin-Promotors zur Expression von LPXN ausschließlich in den dorsalen und ventralen Lappen der Prostata, wobei Mauslinie \#19 eine schwache und Mauslinie \#20 eine starke Expression des transgenen LPXN aufweist. Histopathologische Untersuchungen der Mäuse bis zu einem Alter von zwei Jahren bestätigen, dass durch die Überexpression von LPXN keine morphologischen Veränderungen in Form von malignen Läsionen in der Prostata entstehen [Kaulfuß et al., 2009]. Dennoch konnten voneinander unabhängige in vitro-Studien beweisen, dass LPXN Eigenschaften wie Migrations- und Invasionsfähigkeit von PCa-Zellen beeinflusst [Sahu et al., 2007; Kaulfuß et al., 2008].

Die Annahme, dass LPXN die Progression von PCa fördert, konnte durch die Verpaarung der LPXN-Mäuse mit TRAMP-Mäusen bestätigt werden. In der TRAMP-Maus, welche auf einem C57Bl/6-Hintergrund generiert wurde, steht das SV40 (Simian Virus 40 Antigen) large T- und small t-Antigen [Greenberg et al., 1995] ebenfalls unter der Kontrolle des ProbasinMinimalpromotors. Da das SV40-Antigen mit den Produkten der Retinoblastom- und p53Tumorsuppressorgene interagiert und deren Wirkungsweise inaktiviert, entwickelt sich in 100\% dieser Mäuse im Alter von 24 bis 30 Wochen ein PCa mit Fernmetastasen [Linzer et al., 1979; Lane et al., 1979; DeCaprio et al., 1988]. Durch eine Kastration und dem daraus resultierenden Androgenentzug kommt es bei 80\% der TRAMP-Mäuse zu einer Androgenunabhängigen Entwicklung des PCa. Die Initiation und Progression des PCa sowie die Bildung von Fernmetastasen in Lymphknoten, Lunge und Knochen in der TRAMP-Maus weist dabei starke Homologien zum humanen PCa auf [Gingrich et al., 1996; Gingrich und Greenberg, 1996; Gingrich et al., 1997]. Aufgrund dieser Eigenschaften eignet sich das TRAMP-Mausmodel hervorragend für in vivo-Studien über den Einfluss von Genen auf die Progression von bereits initiierten PCa.

Durch die Analyse der F1-Generation, die aus der Verpaarung von transgenen LPXN-Mäusen mit den TRAMP-Mäusen stammt, konnte bestätigt werden, dass LPXN an der Progression 
von PCa beteiligt ist. Im Alter zwischen 18 und 26 Wochen entwickelt die Mehrheit der untersuchten doppelt transgenen LPXN/TRAMP-Mäuse bereits ein schlecht differenziertes PCa mit Fernmetastasen in Leber, Lunge oder Lymphknoten, während zum gleichen Zeitpunkt die Mehrheit der einfach transgenen TRAMP-Kontrollmäuse nur eine morphologische Veränderung der Prostata in Form der PIN aufweist. Der Initiationszeitpunkt des PCa bleibt in allen untersuchten Mäusen unverändert. Dies bestätigt wiederum, dass die Initiation des PCa ausschließlich durch die Überexpression des SV40 T/t-Antigens ausgelöst wird und dass LPXN keinen Einfluss auf die Initiation von PCa ausübt. Kontroverse Ergebnisse wurden dazu von Dai et al. [2009] veröffentlicht. Es wurde beobachtet, dass die stabile Transfektion von NIH3T3-Zellen mit pEGFP-N1-LPXN und die anschließende subkutane Injektion der Zellen in BALB/c-Nacktmäuse in einer Tumorbildung nach 28 Tagen resultieren.

Die Entwicklung und das Wachstum von PCa sind wesentlich von der Funktion von Androgenen abhängig. Einerseits sichern die Androgene in der gesunden Prostata das Überleben der Epithelzellen und andererseits vermitteln sie den ersten Schritt in der Entstehung maligner Prostatazellen [De Marzo et al., 1998]. Solange wie der lokale Prostatatumor keine Fernmetastasen gebildet hat, können Patienten durch Operation oder Strahlentherapie behandelt werden. Bei fortgeschrittenen Tumoren hingegen wird bei einer Vielzahl von Patienten eine androgen-unterdrückende Therapie angewendet. Bereits 1972 wurde diese Methode zur Behandlung von aggressiven PCa von Huggins und Hodges beschrieben [1972]. Dabei werden vor allem Medikamente verwendet, die als Antiandrogene wirken, sowie LH-RH- (luteinizing-hormone-releasing-hormone) Analoga (z.B. Leuprorelin). Obwohl diese Therapieform zunächst das Tumorwachstum inhibiert, tritt nach 12 bis 24 Monaten ein androgen-unabhängiges Rezidiv auf, welches durch ein noch aggressiveres Verhalten der PCa-Zellen und durch die Bildung von Metastasen gekennzeichnet ist, was letztendlich zum Tod des Patienten führt. Die postulierten Mechanismen zur Erklärung der Hormonresistenz umfassen im Wesentlichen drei Ansätze.

Der erste Ansatz beschreibt die verstärkte Aktivierung des AR durch Punktmutationen oder Amplifikationen auf genomischer Ebene, welche in 20 bis 30\% der androgen-unabhängigen Prostatatumore auftreten [Gaddipati et al., 1994]. Die Mehrheit der Mutationen treten in der Ligandenbindungsdomäne des AR auf und bewirken, dass Liganden wie z.B. Östrogen oder Hydrocortison am AR binden und eine Aktivierung bewirken können [Veldscholte et al., 1990; Matias et al., 2002]. 
Eine zweite Möglichkeit stellt die Liganden-unabhängige Aktivierung des AR dar. Ein möglicher Mechanismus der Liganden-unabhängigen Aktivierung des AR beschreibt die Phosphorylierung und damit Aktivierung der AR-Koaktivatoren, was zu einer erhöhten Transkriptionsaktivität des AR führt [Ueda et al. 2002; Edwards et al., 2005b]. Ueda et al. [2002] konnten zeigen, dass Interleukin-6 (IL-6) in Abwesenheit der Androgene den AR aktivieren kann und, dass die Phosphorylierung des AR-Koaktivators SRC durch die mitogenactivated protein kinase (MAPK) für die liganden-unabhängige Aktivierung des AR durch IL6 erforderlich ist. Dieselbe Arbeitsgruppe konnte weiterhin zeigen, dass die Expression des Prostata spezifischen Antigens (PSA) in PCa-Zellen durch die Liganden-unabhängige Aktivierung des AR durch IL-6 induziert werden kann [Ueda et al., 2002]. Ebenfalls kann eine veränderte Balance zwischen Koaktivatoren und Korepressoren die AR-Aktivität beeinflussen [Gregory et al., 2001; Mestayer et al., 2003].

Eine dritte Möglichkeit der Hormonresistenz basiert auf dem Konzept, dass die Wachstumsund Überlebens-fördernden Funktionen des AR durch alternative Signalwege umgangen werden, so dass der AR für die Tumorprogression nicht länger von Bedeutung ist. Ein Beispiel dafür stellt das anti-apoptotische Gen BCL-2 dar, welches durch das Umgehen der Apoptose als Onkogen wirkt. McDonnell et al. [1992] konnten immunhistochemisch zeigen, dass in 13 von 19 androgen-abhängigen PCa keine BCL-2-Expression zu detektieren ist, während in allen untersuchten androgen-unabhängigen PCa eine diffuse, starke Färbung von BCL-2 nachgewiesen werden konnte. Diese Beobachtung konnte auch durch andere Arbeitsgruppen bestätigt werden, die eine direkte Korrelation der Bcl-2-Expression mit der Progression des PCa vom androgen-abhängigen zum androgen-unabhängigen Stadium nachweisen konnten [Raffo et al., 1995; Catz und Johnson, 2003].

Trotz zahlreicher Studien zur Aufklärung der zugrundeliegenden Mechanismen bei der Entwicklung des androgen-abhängigen PCa zum androgen-unabhängigen Rezidiv, bleibt letzteres für die Humanmedizin ein schwerwiegendes Problem. In vivo kann das androgenunabhängige Wachstum des PCa in TRAMP-Mäusen durch eine Kastration imitiert werden. Untersuchungen mehrerer Arbeitsgruppen ergaben, dass durch die Komplexität und Heterogenität der Primärtumore der Androgenentzug jedoch in den TRAMP-Mäusen, ähnlich dem humanen Karzinom, unterschiedliche Auswirkungen hat: die Mehrheit der Tumore verlangsamen zunächst ihr Wachstum, während der Androgenentzug auf einige Tumore keinen Einfluss hat [Gingrich et al., 1997; Johnson et al., 2005]. In den Tumoren, welche positiv auf den Androgenentzug ansprechen, konnte zehn Wochen nach der Kastration eine erhöhte Expression von Bcl-2 und Grp78 und eine reduzierte Expression von BAX, BCL-xl, 
SV40 T-Antigen und c-myc beobachtet werden. Weiterhin zeigten diese Tumore zunächst eine Reduktion der proliferierenden Zellen im Vergleich zu nicht-kastrierten Mäusen. 20 Wochen nach der Kastration konnte jedoch ein Anstieg in der Größe des Primärtumors sowie die Entstehung von Fernmetastasen beobachtet werden [Tang et al., 2008].

Die Analyse des Einflusses von LPXN auf das Progressionsverhalten von androgenunabhängigen $\mathrm{PCa}$ in vivo ergab ein signifikant schnelleres Prostatatumorwachstum in kastrierten LPXN/TRAMP-Mäusen im Vergleich zu einfach transgenen TRAMP-Mäusen. Während die einfach transgenen TRAMP-Mäuse nach Androgenentzug ein durchschnittliches Überlebensalter von 20,6 Wochen erreichten, konnte bei den doppelt transgenen LPXN/TRAMP-Mäusen nach Androgenentzug nur ein durchschnittliches Überlebensalter von 18,7 Wochen beobachtet werden. In 80\% der Mäuse waren zum Zeitpunkt der Präparation Fernmetastasen in Lymphknoten, Leber, Lunge und Niere zu verzeichnen. Zum selben Zeitpunkt (20,6 bzw. 18,7 Wochen) konnte in den nicht-kastrierten Mäusen der jeweiligen Versuchstiergruppe (TRAMP bzw. LPXN/TRAMP) nur in 11\% bzw. 56\% ein vergleichbares Karzinom und nur in $0 \%$ bzw. 7\% Metastasen detektiert werden.

Zur Beantwortung der Frage, wie LPXN das androgen-unabhängige Prostatatumorwachstum beschleunigen kann, gibt es drei Ansätze. Zum einen konnte bereits in vorangegangenen Arbeiten gezeigt werden, dass LPXN mit dem AR interagiert [Kaulfuss et al., 2008]. Da diese Interaktion jedoch nur in Anwesenheit des Liganden DHT beobachtet werden konnte, müsste der AR die Fähigkeit erlangt haben, die Liganden-Spezifität zu ändern, um auch in Abwesenheit der Androgene durch z.B. Antiandrogene oder Östrogene aktiviert zu werden.

Für das Paxillin-Familienmitglied ARA55 konnte die Fähigkeit der Änderung der LigandenSpezifität bereits gezeigt werden [Fujimoto et al., 1999]. Außerdem konnte beobachtet werden, dass in Anwesenheit von ARA55 die Aktivität des AR auch bei niedrigen Konzentrationen von Androgenen erhöht wird. Weiterhin wurde in zwei von sechs Patienten ein erhöhtes Expressionslevel von ARA55 in den androgen-unabhängigen Tumorbereichen im Vergleich $\mathrm{zu}$ den androgen-abhängigen Tumorbereichen nachgewiesen [Fujimoto et al., 2007].

Eine zweite mögliche Erklärung stellt die direkte Regulation der Transkription von Zielgenen des AR dar. Kaulfuss et al. [2008] konnten zeigen, dass LPXN sowohl im Kern als auch im Zytoplasma von PCa-Zellen lokalisiert und die transkriptionelle Aktivität des AR erhöht. Shi et al. [2008] demonstrierten, dass im androgen-unabhängigen PCa sowohl der AR als auch die Mitglieder der p160-kDa Kernrezeptor-Koaktivatoren stark exprimiert werden, und dass diese die androgen-unabhängige Aktivierung des AR erhöhen. 
Weiterhin könnte die Aktivierung des AR im androgen-unabhängigen Stadium des PCa durch Kinasen und Cytokine erfolgen. Die Funktionalität des AR ist durch dessen Phosphorylierungsstatus determiniert [Wang et al., 1999]. Daher besteht die Möglichkeit, dass die Induktion der transkriptionellen Aktivität durch die Faktoren, die die Phosphorylierung des AR vermitteln, ausgelöst wird. Für die Serin-Threonin-Kinase AKT konnte gezeigt werden, dass durch die Phosphorylierung des AR an der Stelle Ser 213 und Ser 791 die AR-Aktivität reduziert wird. Mutationen, durch die das Serin 213 durch ein Alanin ausgetauscht wird, resultieren in einer Resistenz der AKT-vermittelten Suppression der AR-Aktivität in DU 145-Zellen [Lin et al., 2001; Lin et al., 2003]. Für das Cytokin IL-6 konnte gezeigt werden, dass es zum Einen in DU 145-Zellen AR-verantwortliche Reportergene aktivieren kann [Hobisch et al., 1998] und zum Anderen, dass es im Serum von Patienten mit einem androgen-unabhängigen PCa erhöht ist und gleichzeitig mit dem PSA (prostate specific antigen)-Level im Serum korreliert [Adler et al., 1999; Drachenberg et al., 1999; Wise et al., 2000]. Interessanterweise konnte im Rahmen dieser Arbeit mittels quantitativer real time-PCR nach Herunterregulierung der LPXN-Expression in PC-3- und DU 145-Zellen ebenfalls eine verringerte Expression von IL-6 nachgewiesen werden (Ergebnisse nicht gezeigt). Es ist daher möglich, dass LPXN im androgen-unabhängigen PCa indirekt über die Regulation der IL-6-Expression Einfluss auf die Transkription von ARZielgenen nimmt (Abb. 4.1).

A

\section{$\underline{\text { Androgen-abhängiges Wachstum }}$}

I

II

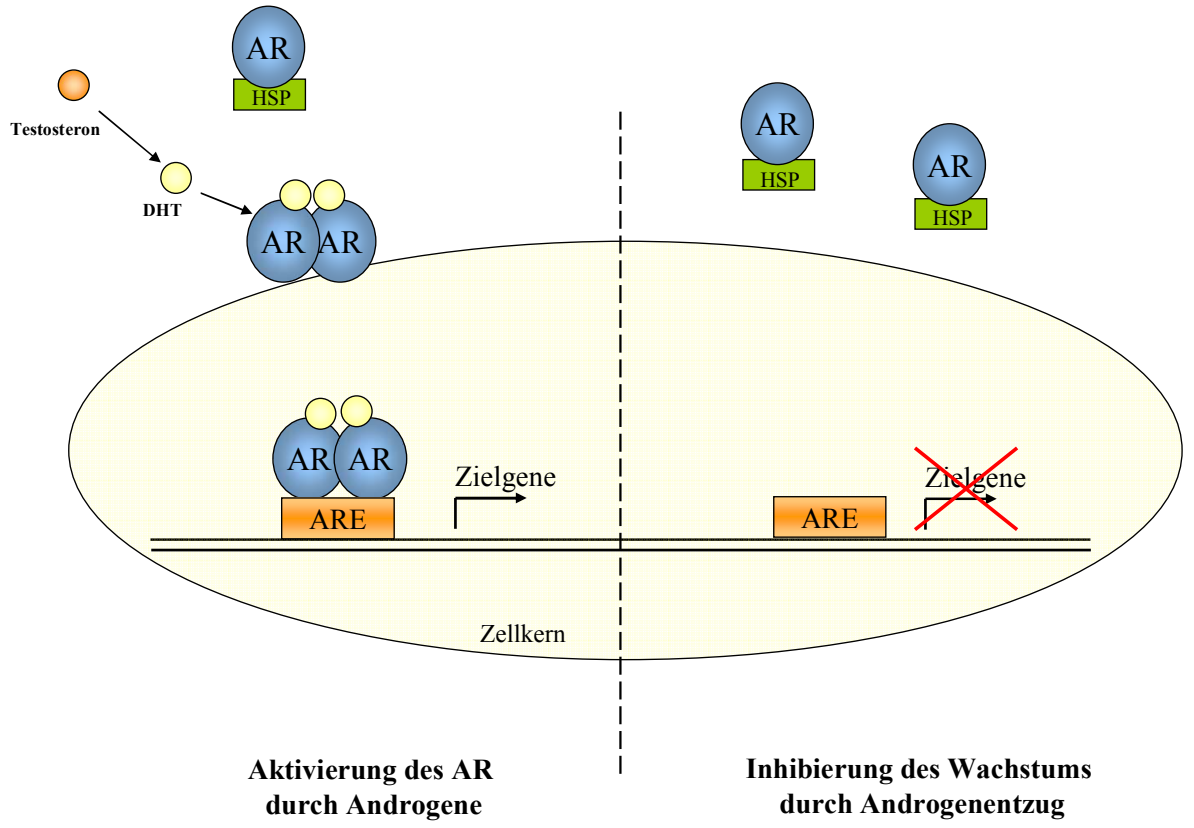




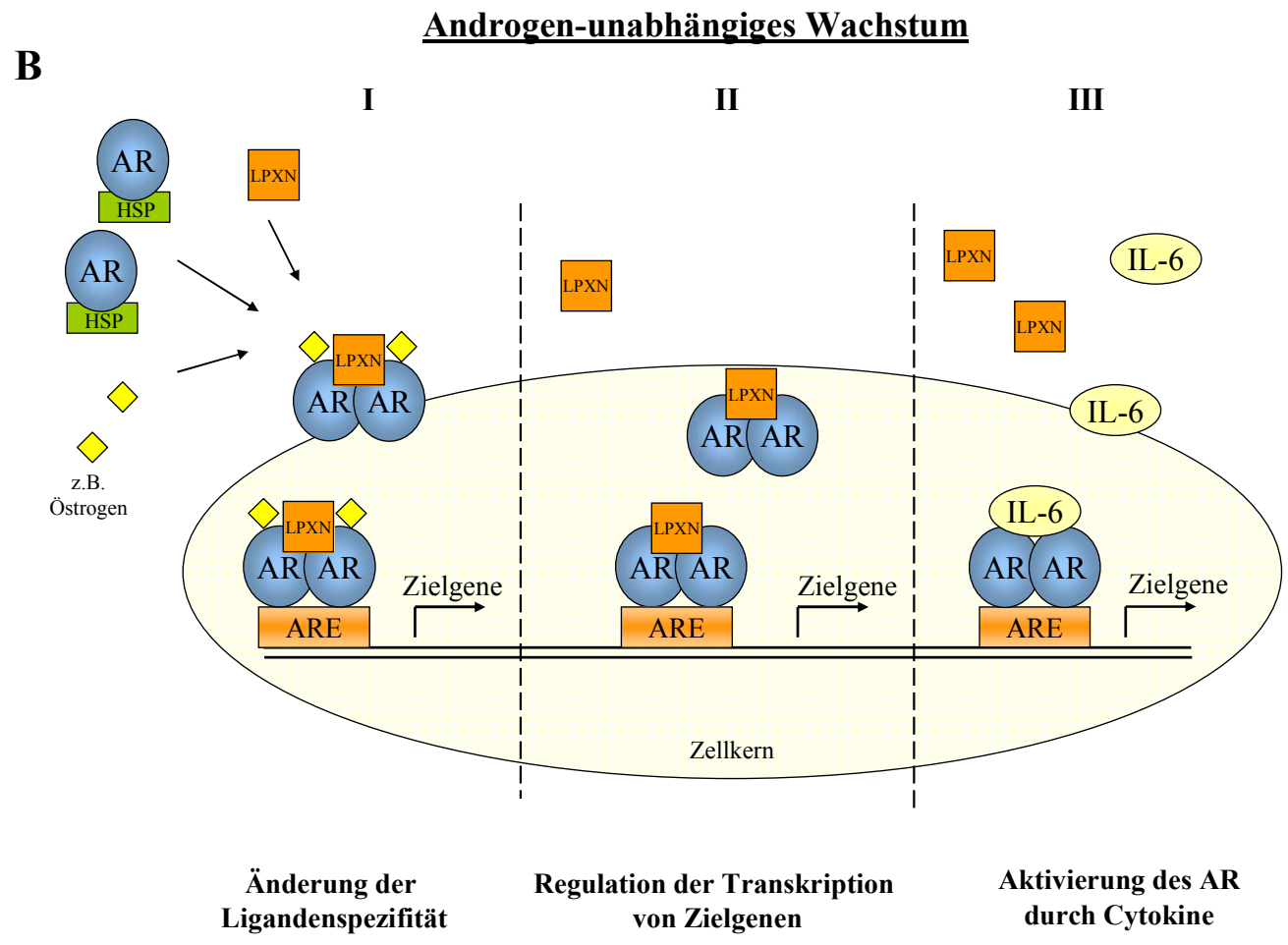

Abb. 4.1: Grafische Darstellung zum Einfluss des AR und von LPXN auf das Androgen-abhängige und unabhängige Wachstum von PCa. A: Androgen-abhängiges Wachstum: I: Im normalen Prostatagewebe vermittelt der AR, aktiviert durch Androgene, das Wachstum der Zellen. II: Der Entzug der Androgene führt zunächst zur Inhibierung des Wachstums. B: Androgen-unabhängiges Wachstum: Die Änderung der Ligandenspezifität (I), die Regulation der Transkription von Zielgenen (II) und die Aktivierung des AR durch z.B. Cytokine (III) sind potentielle Mechanismen, durch die LPXN das androgen-unabhängige Wachstum des PCa fördern könnte.

\subsection{Molekulare Mechanismen der Tumorprogression}

Die Tumorigenese im Menschen ist ein vielfältiger Prozess mit genetischen Veränderungen, durch die eine Transformation von normalen Zellen zu malignen Tumorzellen und im späteren Stadium zu hoch-invasiven und metastasierenden Zellen erfolgt. Auf molekularer Ebene werden als verantwortliche Gene für die Tumorinvasion und Metastasierung, welche wichtige Aspekte der Tumorprogression beschreiben, vor allem Zelladhäsionsmoleküle (z.B. Integrine), Matrix-Metalloproteinasen und ihre Inhibitoren sowie Wachstumsfaktoren diskutiert. 


\subsubsection{Zelladhäsionsmoleküle in der Tumorprogression}

Die Zelladhäsion spielt bei Wachstum, Migration und Differenzierung von Zellen eine bedeutende Rolle. Zelladhäsionsmoleküle (CAMs) sind an der Zell-Zell-Interaktion sowie der Zell-Matrix-Interaktion beteiligt [Cohen et al., 1997]. Bis zum jetzigen Zeitpunkt konnten 50 CAMs identifiziert werden, die aufgrund ihrer Proteinstruktur in vier Gruppen eingeteilt werden: die Immunoglobulin (Ig)- Superfamilie, Integrine, Selektine und die CadherinFamilie [Okegawa et al., 2002]. Die Ig-Superfamilie ist die größte Familie der CAMs und umfasst Zelloberflächen- sowie lösliche Proteine, die bei Erkennungs- und Bindungsprozessen in der Zelle eine wichtige Rolle spielen. Sie beinhalten z.B. einige Antigen-Rezeptoren, Cytokine und Wachstumsfaktor-Rezeptoren. Integrine beschreiben vor allem die Transmembranproteine, die für die Zell-Zell-Verbindung und die Signalübertragung zwischen den Zellen verantwortlich sind. Die Gruppe der Selektine umfasst die Zelloberflächenproteine P-, E- und L-Selektin. Die Mitglieder der Cadherin-Familie lokalisieren in der Zelle an speziellen Zell-Zell-Adhäsionsstellen, an denen sie mit dem Zytoskelett der Zelle in Verbindung stehen. Sie fungieren als Tumorsuppressorgene [Hedrick et al., 1993]. Defekte in der Expression oder der Funktion von Cadherinen werden mit der Tumorprogression in Korrelation gebracht [Behrens et al. 1989]. Die klassischen Cadherine sind E (epithelial)-, N (neural)- und P (placental)- Cadherin. Das bedeutendste und am intensivsten untersuchte Cadherin stellt das E-Cadherin dar. Es vermittelt den ZellZellkontakt und fungiert als wichtiger Suppressor der Zellinvasion und Metastasierung von epithelialen Tumoren [Birchmeier und Behrens, 1994; Becker et al., 1994; Berx et al., 2001]. Es konnte gezeigt werden, dass während der Progression von duktalen Brusttumoren E-Cadherin als dynamisch und reversibel exprimiert beobachtet werden [Kowalski et al., 2003]. Derksen et al. [2006] konnten zeigen, dass der konditionale Verlust der E-CadherinExpression in Mäusen mit p53-Defizienz im Brustepithel die Tumorinvasion und -progression fördert. Der alleinige Verlust der E-Cadherin-Expression im Mausmodell reicht hingegen nicht aus um ein Tumorwachstum zu iniitieren [Tinkle et al., 2004; Tunggal et al., 2005; Derksen et al., 2006].

Da die Cadherine nicht über eine intrinsische Enzymaktivität verfügen, assoziieren sie mit ihrer zytoplasmatischen Domäne mit einer Gruppe von intrazellulären Proteinen, den Cateninen, welche die Cadherine an die Aktin-Filamente binden und so den SignalTransduktions-Mechanismus vermitteln [Ozawa et al., 1998; Bryant und Stow, 2004; Mege et al., 2006]. Diese Assoziation der Catenine zu den Cadherinen ist ein bedeutender 
Schritt der intakten Zelladhäsion. Eine Änderung der Catenin-Expression oder -Lokalisation kann zur Störung der Zell-Zell-Adhäsion und somit zu aggressiveren und invasiveren Eigenschaften der Tumorzellen führen. Zu den wichtigsten Vertretern der Catenine gehören $\beta$-Catenin, welches direkt an das distale Ende der zytoplasmatischen Domäne der Cadherine bindet, $\alpha$-Catenin, welches indirekt durch die Bindung an $\beta$-Catenin mit den Cadherinen verbunden ist und p120-Catenin (p120CTN), welches mit der proximalen Region der zytoplasmatischen Domäne der Cadherine assoziiert ist.

In den letzten zwei Jahrzehnten konnte über die Funktionen von $\beta$-Catenin in humanen Tumoren zahlreiche Erkenntnisse gewonnen werden. Es konnte z.B. gezeigt werden, dass in ca. 90\% der kolorektalen Tumore Mutationen bei den Mitgliedern des Wnt- $\beta$-Catenin Signalweges auftreten. [Bienz et al., 2000; Vogelstein et al., 2004]. Mutationen, durch die der Wnt- $\beta$-Catenin Signalweg aktiviert wird, fördern die Stabilisierung des freien $\beta$-Catenins und die Akkumulation von $\beta$-Catenin im Kern. Im Kern bindet $\beta$-Catenin an den N-terminalen Bereich von TCF/LEF (T-cell-factor/ lymphoid enhancer factor), welche zusammen einen Transkriptionskomplex bilden. Dieser Transkriptionskomplex reguliert die Transkription der Wnt- $\beta$-Catenin Zielgene, was in einer Veränderung der Zellproliferation, Zellpolarität und Zellmigration resultiert [Behrens et al., 1996; van de Wetering et al., 1997]. Gleichzeitig konnte durch verschiedene Arbeitsgruppen gezeigt werden, dass der Verlust der Cadherine und der daraus resultierende ansteigende Pool des freien, cytoplasmatischen $\beta$-Catenins nicht ausreichen, um den $\beta$-Catenin-Signalweg einzuschalten. So zeigen Krebszelllinien, welche kein E-Cadherin exprimieren, keine erhöhte Expression von $\beta$-Catenin-Zielgenen [Caca et al., 1999; van de Wetering et al., 2001]. Unter normalen Bedingungen wird das freie, cytoplasmatische $\beta$-Catenin durch die schnelle Degradation auf einem konstanten Level gehalten. Nur wenn zusätzlich zum Verlust des E-Cadherins die Degradations-Maschinerie defekt ist, resultiert dies in einem Anstieg von $\beta$-Catenin im Kern und zur Expression von Zielgenen [Sadot et al., 1998; Herzig et al., 2007] (Abb. 4.2). 


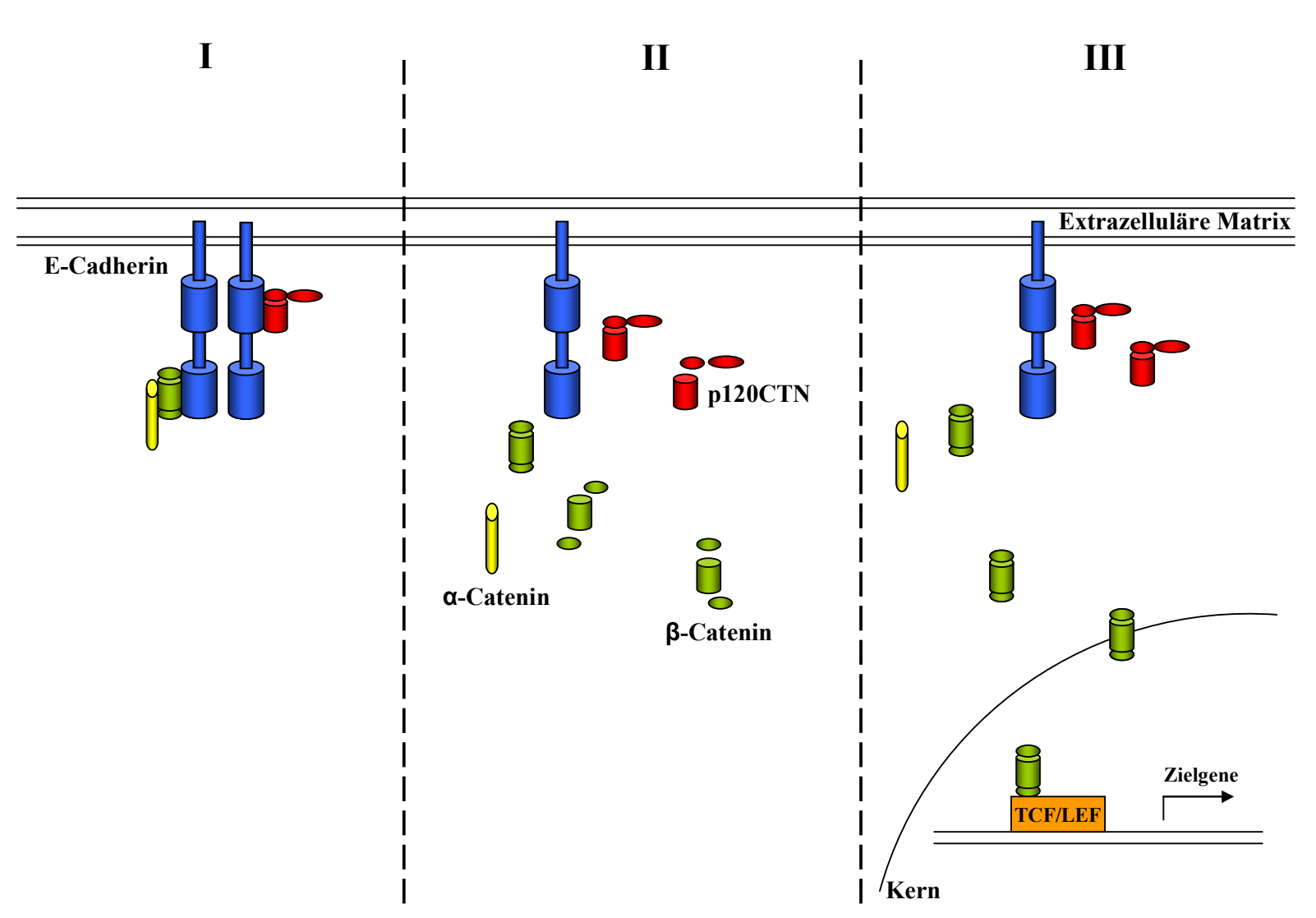

Zelladhäsion

Degradation

Expression von Zielgenen

Abb. 4.2: Schematische Darstellung zur Wirkungsweise der Zelladhäsionsmoleküle. I: Unter normalen Bedingungen sind $\alpha$-Catenin, $\beta$-Catenin, E-Cadherin und p120CTN in Komplexen an die Membran gebunden. II: Beim Verlust der E-Cadherin-Expression kommt es zur Lockerung der Komplexbildung, wodurch die einzelnen Moleküle vom Komplex dissoziieren und degradiert werden. III: Nur wenn zusätzlich zur E-CadherinExpression die Degradations-Maschinerie defekt ist, kann $\beta$-Catenin in den Kern wandern und die Expression von Zielgenen fördern, wodurch das Zellverhalten, wie z.B. Migration, Invasion und Proliferation reguliert werden.

Das Catenin p120CTN gehört zur p120-Proteinfamilie und wurde ursprünglich als Substrat der SRC-Kinase sowie anderer Rezeptor-Tyrosinkinasen identifiziert [Reynolds et al., 1989; Downing und Reynolds, 1991]. Die Mitglieder der p120-Proteinfamilie haben eine charakteristische Organisation ihrer Armadillo-Repeat-Domäne gemeinsam. Die Interaktion zwischen den Mitgliedern der p120-Proteinfamilie und der Cadherine wird über deren Armadillo-Repeat-Domäne vermittelt. Molekulare Analysen zeigten, dass p120CTN zum Einen für den Transport der Cadherine zur Zellmembran und zum Anderen für die Stabilität der Cadherine an der Zellmembran verantwortlich ist. Bei verminderter oder gestörter p120CTN-Expression konnte beobachtet werden, dass es zur Lockerung der Komplexbildung 
der Adhäsionsmoleküle an der Zelloberfläche kommt, wodurch die Anordnung der Cadherine verloren geht und diese degradiert werden [Davis et al., 2003; Xiao et al., 2005; Maeda et al., 2006]. Im Tumorgewebe von Blase [Syrigos et al., 1998], Brust [Nakopoulou et al., 2002], Prostata [Kallakury et al., 2001a, b], Lunge [Bremnes et al., 2002] und Pankreas [Karayiannakis et al., 1999] konnte für p120CTN eine abnormale Expression detektiert werden, wobei der Verlust, auch in Korrelation mit dem Verlust der E-Cadherin- und $\beta$-Catenin-Expression, immer mit einer schlechten Prognose assoziiert ist.

Weiterhin konnte p120CTN als Regulator der Zellmigration und -proliferation durch die Regulation der Aktivitäten der RhoGTPasen identifiziert werden [Anastasiadis et al., 2007]. Die RhoGTPasen regulieren verschiedene zelluläre Funktionen, wie z.B. ZytoskelettOrganisation, Adhäsion und Polarität [Fukata et al., 2003; Etienne-Manneville, 2004]. Dabei sind sie speziell für die Ausbildung von verschiedenen Aktinfortsätzen, wie z.B. Filopodien, Lamellipodien, Invadopodien und Podosomen verantwortlich, durch die Zellmigration, -invasion und -adhäsion vermittelt werden.

Es wird postuliert, dass p120CTN zum Einen gebunden an den Zell-Zell-Adhäsionskomplex vorliegen kann, wodurch es die Zelladhäsion beeinflusst, und zum Anderen in einem zytoplasmatischen Pool, wodurch es die Aktivität der Regulatoren der RhoGTPasen kontrolliert [Thoreson et al., 2000]. Noren et al. [2000] konnten demonstrieren, dass p120CTN mit dem Guaninnukleotid-Austauschfaktor (GEF) Vav2 interagiert, wodurch die Aktivität der GTPasen und damit die Veränderung des Zytoskeletts beeinflusst werden. Weiterhin konnte gezeigt werden, dass die Überexpression von p120CTN die Aktivitäten der RhoGTPasen Cdc42 und Rac1 stimuliert und die Aktivität von RhoA inhibiert. Dies könnte in einer verstärkten Zellmigration resultieren (Abb. 4.3). 


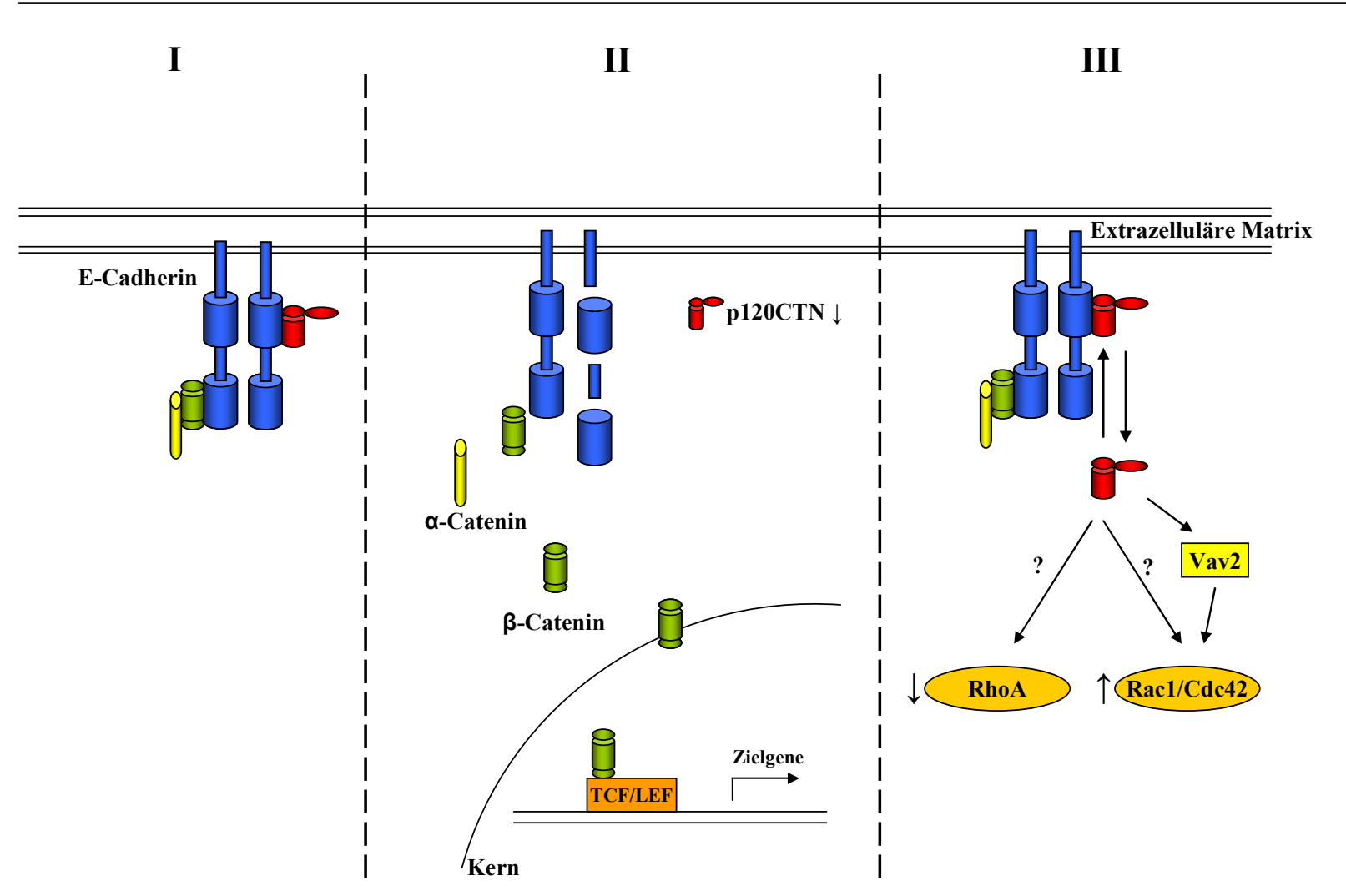

Zelladhäsion

Expression von Zielgenen

Regulation der RhoGTPasen

\begin{abstract}
Abb. 4.3: Schematische Darstellung zur Wirkungsweise der Zelladhäsionsmoleküle in Abhängigkeit von der p120CTN-Expression. I: Unter normalen Bedingungen sind $\alpha$-Catenin, $\beta$-Catenin, E-Cadherin und p120CTN in Komplexen an der Membran gebunden. II: Durch den Verlust der p120CTN-Expression könnte der Zell-Zell-Adhäsionskomplex gelockert werden, wodurch sich $\beta$-Catenin löst und in den Kern translozieren kann. Im Kern könnte $\beta$-Catenin durch die Bindung an TCF/LEF die Expression von Zielgenen und dadurch Zellmigration, -invasion und -proliferation fördern. III: (mod. nach Noren et al., 2000) Nicht gebunden an den Zell-Zell-Adhäsionskomplex könnte p120CTN die Regulatoren der RhoGTPasen RhoA, Rac1 und Cdc42 beeinflussen, wodurch Zelleigenschaften wie Zellmigration vermittelt werden könnten.
\end{abstract}

\title{
4.3.2 Matrix-Metalloproteinasen in der Tumorprogression
}

Bevor Tumorzellen während der Progression in die Blutbahn gelangen und sich schließlich an verschiedensten Stellen wieder anheften, um Metastasen zu bilden, müssen sie sich vom Primärtumor ablösen und die Extrazelluläre Matrix (ECM) überwinden. Die Fähigkeit der Fortbewegung ist eine koordiniertes Zusammenspiel zwischen den CAMs, die das Ablösen und Anheften der Zellen kontrollieren, und der Veränderung der ECM durch MatrixMetalloproteinasen (MMPs) [Holly et al., 2000; Hornebeck et al., 2002]. MMPs bilden eine 
Familie von Zink-abhängigen Endopeptidasen mit spezifischer und selektiver Aktivität gegen viele Komponenten der ECM [Liotta und Stetler-Stevenson, 1990]. Sie werden in Collagenasen (MMP-1, -8, -13), Gelantinasen (MMP-2, -9), Stromelysine (MMP-3, -10, -11), Matrilysine (MMP-7, -26), Membran-spezifische MMPs (MMP-14, -15, -16, -17, -24, -25) und andere MMPs (MMP-12, -19, -20, -21, 23, -27, -28) eingeteilt. Die Gruppierung basiert auf der Domänen-Struktur und der Substrat-Präferenz [Murphy et al., 2008]. MMPs werden als Zymogene abgesondert und müssen anschließend extrazellulär aktiviert werden. Diese extrazelluläre Aktivierung kann durch bereits aktivierte MMPs oder durch verschiedene Serin-Proteinasen initiiert werden [Woessner und Nagase, 2000].

MMPs sind nicht nur in der Lage, verschiedene Komponenten der ECM wie Collagen, Elastin und Gelantine zu degradieren [Lemaitre et al., 2006; VanSaun et al., 2006], sondern sie haben ebenfalls das Potential Zelloberflächen- sowie perizelluläre Proteine zu spalten, wodurch sie das Verhalten der Zellen auf verschiedene Weise beeinflussen können (Abb. 4.4). MMP-3 und MMP-7 können z.B. das CAM E-Cadherin spalten, wodurch der komplette Zelladhäsionskomplex gestört wird und Zellinvasion sowie -migration gefördert werden [Lochter et al., 1997; Noe et al., 2001]. In fast allen Krebsarten konnte eine signifikant positive Korrelationen zwischen der MMP-Expression und einer hohen Malignität der Zellen, sowie verschiedenen Indikatoren, welche auf eine schlechte Prognose des Patienten hinweisen, gefunden werden [Giambernardi et al., 1998; Sternlicht und Bergers, 2000].

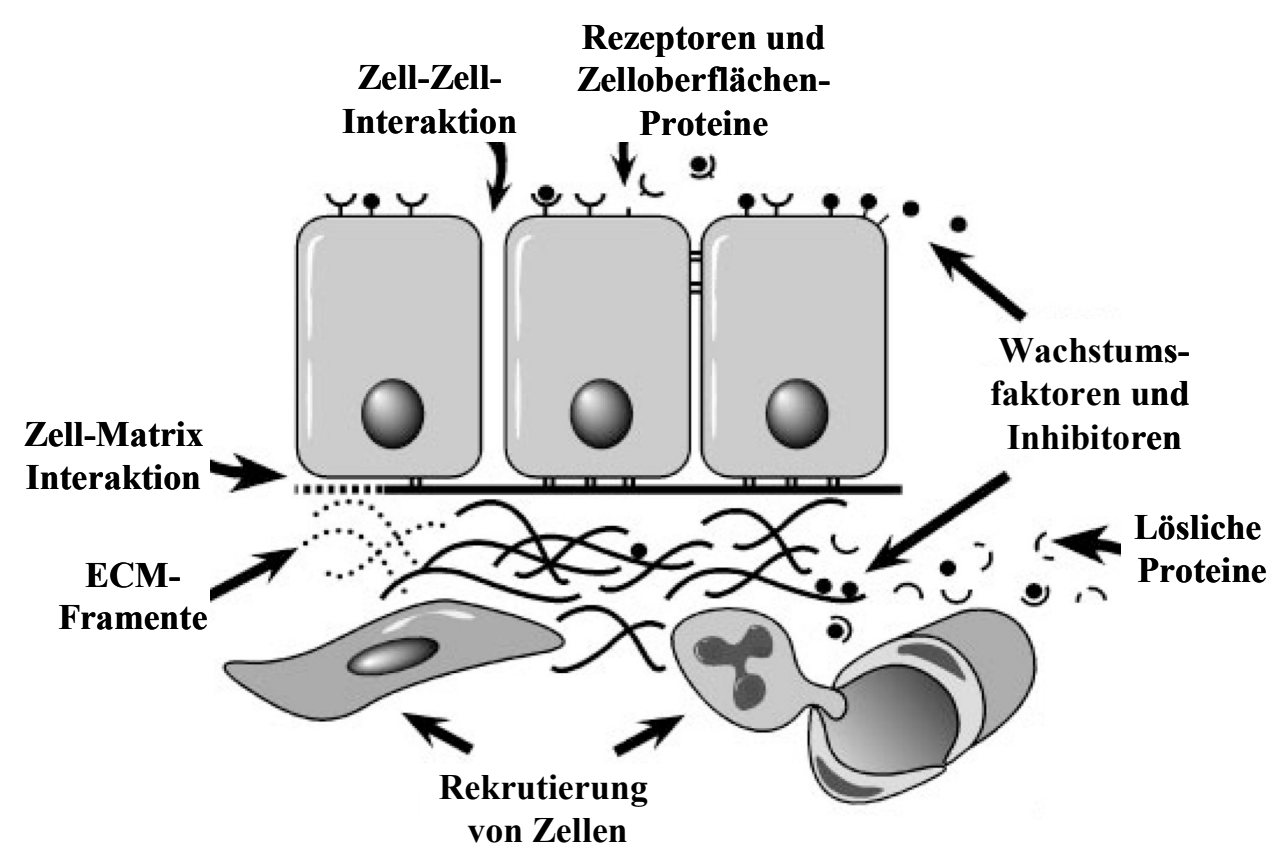


Abb. 4.4: Potentielle Mechanismen bzw. Angriffspunkte der Matrix-Metalloproteinasen (mod. nach Sternlicht und Werb, 2001). Matrix-Metalloproteinasen (MMPs) sind nicht nur in der Lage, Fragmente der ECM zu degradieren und die angegebenen Proteine zu spalten, sondern beeinflussen ebenfalls Zell-ZellInteraktionen, Zell-Matrix-Interaktionen und die Rekrutierung von Zellen.

MMPs werden sowohl auf der Ebene der Genexpression als auch auf der Ebene der ProteinAktivierung reguliert. Die transkriptionelle Regulation der MMP-Gene erfolgt durch AP-1 in der proximalen Promotorregion [Fini et al., 1998] und wird durch verschiedene extrazelluläre Stimuli induziert. Diese extrazellulären Stimuli sind z.B. Cytokine (Interleukin-4 und -6), Wachstumsfaktoren (EGF, TGF- $\alpha$, bFGF, TGF- $\beta-1)$, Zell-Zell- oder Zell-MatrixInteraktionen [Sundareshan et al., 1999; Duivenvoorden et al., 1999; Mira et al., 1999].

Die Regulation der MMPs auf der Ebene der Protein-Aktivierung wird vor allem den Invadopodien zugeschrieben [Chen et al., 1985; Weaver et al., 2006]. Invadopodien stellen Aktin-reiche Strukturen an der basalen Seite der migrierenden Zelle dar, durch die der direkte Kontakt zu der ECM vermittelt wird und an denen die MMPs akkumulieren. Durch den Aufund Abbau der Invadopodien werden die Aktin-Anordung, Signalwege, Zelladhäsion und die Sekretion der Proteinasen beeinflusst und die ECM-Anordnung reguliert [Weaver et al., 2006; Linder et al., 2007].

Die Dynamik der Invadopodien, und damit die Sekretion der MMPs, werden wiederum durch Proteine reguliert, die an den Aktinfilamenten lokalisieren. Yoshio et al. [2007] konnten zeigen, dass das Aktin- und Calmodulin-bindende Protein Caldesmon einen Regulator der Invadopodien-Formation darstellt. Durch alternatives splicing von Caldesmon entstehen fünf verschiedene Isoformen [Hayashi et al., 1992]. Während Isoform 1 (h-Cald) als in Muskelzellen vorkommende Isoform beschrieben wird (90-150 kDa), treten die Isoformen 2-5 (1-Cald) mit einem geringeren Molekulargewicht $(60-80 \mathrm{kDa})$ in Nichtmuskelzellen auf. In transformierten Zellen und Tumorzellen konnte beobachtet werden, dass die Formation der Invadopodien und der verwandten Podosomen ansteigt, wenn Caldesmon schwach exprimiert wird. Dagegen wird die Bildung der Invadopodien und Podosomen inhibiert, wenn Caldesmon überexprimiert wird [Yoshio et al., 2007]. Da an den Invadopodien, wie bereits oben erwähnt, Proteine sezerniert werden, durch die die Komponenten der ECM degradiert werden können, stellen diese eine Schlüsselfunktion in der Zellinvasion dar.

Die Überexpression von Caldesmon konnte in einen direkten Zusammenhang mit der Abnahme der Degradation der ECM und der Inhibierung der Invasionsfähigkeit der Zellen gebracht werden [Yoshio et al. 2007]. Eine Herunterregulierung der Caldesmon-Expression in der Brustkrebszelllinie MDA-MB-435 und der Darmkrebszelllinie HCA7 resultiert hingegen 
in einer verstärkten Invadopodien-Formation und einer daraus resultierenden erhöhten Degradation der ECM sowie Invasionsfähigkeit der Zellen.

Verschiedene Arbeitsgruppen konnten demonstrieren, dass die Phosphorylierung von Caldesmon durch z.B. die CDC2-Kinase zur Inaktivierung des Proteins führt, wodurch Caldesmon von den Mikrofilamenten dissoziiert, die Inhibierung der ATPase-Aktivität aufgehoben wird und die Invadopodien neu gebildet werden [Foster et al., 2004; Kordowska et al., 2005; Li et al., 2009]. Die bekannten Phosphorylierungsstellen für die Serin-Kinasen ERK und CDC2 sind Ser 497 und Ser 527 in der C-terminalen Region von Caldesmon (1-Cald) (Abb. 4.5). Eine Korrelation zwischen der Expression/Phosphorylierung von Caldesmon und der Expression/Sekretion der MMPs wurde bis dato nicht nachgewiesen.

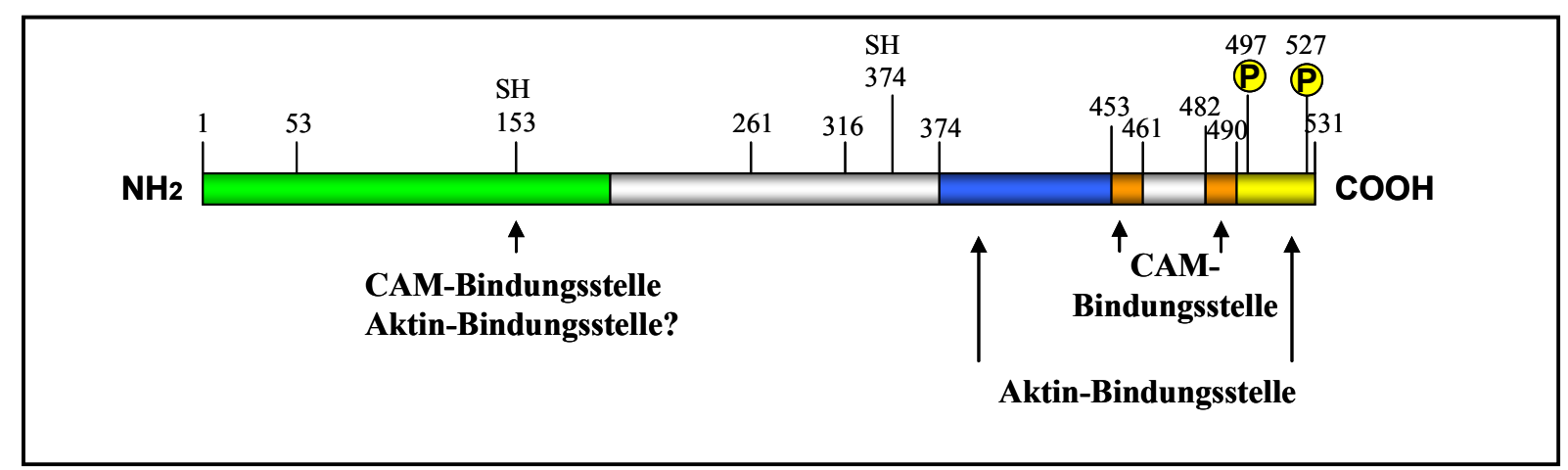

Abb. 4.5: Domänenstruktur des humanen 1-Caldesmon mit Bindungsstellen für Aktin und Calmodulin. Die Phosphorylierungsstellen Ser 497 und Ser 527 sind bekannt für die Serin-Kinasen ERK und CDC2 (mod. nach Kordowska et al., 2006)

\subsubsection{Wachstumsfaktoren in der Tumorprogression}

Die Progression von normalen Zellen zu malignen, invasiven und metastasierenden Zellen erfordert neben der veränderten Expression von CAMs und MMPs die Umgehung der wachstumsinhibierenden Signale. In einer proliferierenden Zelle bindet z.B. der EGF mit hoher Affinität an den Transmembranrezeptor (EGFR) an der Zelloberfläche und stimuliert so die intrinsische Tyrosin-Kinase-Aktivität des Rezepors. Die Tyrosin-Kinase-Aktivität initiiert wiederum eine Signal-Transduktions-Kaskade, die in einer Reihe von biochemischen Veränderungen in der Zelle resultiert. Viele Onkogene besitzen die Fähigkeit, die Wachstumssignale nachzuahmen, um so die Zellproliferation $\mathrm{zu}$ beschleunigen. In einer normalen Zelle sind antiproliferierende Signale für die Homöostase der Zelle verantwortlich. 
Viele dieser wachstumsinhibierenden Signale kontrollieren den Übergang der Zelle von der G1-Phase in den Wachstumszyklus [Hanahan und Weinberg, 2000]. Auf molekularer Ebene werden viele wachstumsinhibierenden Signale über das Retinoblastomprotein $(\mathrm{pRb})$ und dessen zwei Verwandte p107 und p130 vermittelt. Phosphoryliertes pRb stört die Zellproliferation durch die Inhibierung des E2F-Transkriptionsfaktors, welcher die Transkription von Genen kontrolliert, die für den Übergang der G1-Phase in die S-Phase von Bedeutung sind [Weinberg, 1995]. TGF- $\beta$ (transforming growth factor- $\beta$ ) ist eines der am besten untersuchten Signalmoleküle, das in normalen Zellen dafür verantwortlich ist, dass $\mathrm{pRb}$ nicht phosphoryliert und damit inaktiviert wird. Derynck et al. [2007] haben zusammengefasst, dass in Tumorzellen von Brust, Darm, Lunge, Pankreas und Prostata [Levy et al., 2006] generell mehr TGF- $\beta$ exprimiert wird als in den entsprechenden normalen Zellen und dass TGF- $\beta$ seine wachstumsinhibierende Funktion im fortgeschrittenden Tumor verliert, wodurch Wachstum, Invasion und Metastasierung der Zellen induziert werden.

In vielen normalen epithelialen, endothelialen und hämatopoetischen Zellen vermittelt TGF- $\beta$ die Arretierung der Zellen in der G1-Phase auch durch die Aktivierung der Inhibitoren der Cyclin-abhängigen Kinasen (CDK) p16 ${ }^{\mathrm{INK} 4 \mathrm{~A}}, \mathrm{p} 15^{\mathrm{INK} 4 \mathrm{~B}}, \mathrm{p} 21^{\mathrm{CIP} 1}$ und p27 Kip1 [Massague, 2006] und die Inhibierung der Transkriptionsfaktoren Myc, Id1 und Id2. In den meisten Tumorzellen verhindern Mutationen in den downstream Effektoren des TGF- $\beta$-Signalweges, z.B. Smad, dass die CDK-Inhibitoren aktiviert, bzw. die Transkriptionsfaktoren inhibiert werden [Massague, 2006]. Neben dem Smad-Signalweg werden ebenfalls andere Signalwege durch den TGF- $\beta$-Rezeptor aktiviert, wie z.B. PI3K/AKT, Rho/Rac GTPasen, Ras/MAPK und TAK1/MEKK1/JNK und p38 (Abb. 4.6) [Derynck und Zhang, 2003; Moustakas und Heldin, 2005].

TAK1 (TGF- $\beta$-activated kinase 1) konnte 1995 von Yamaguchi et al. als Mitglied der TGFaktivierenden MAPK Kinase Kinase (MKKK) identifiziert werden. Die Aktivierung des TAK1-Proteins erfolgt durch die Phosphorylierung von zwei Threonin-Resten (Thr-184 und Thr-187) und einem Serin-Rest (Ser-192) [Kishimoto et al., 2000]. Shibuya et al. [1996] konnten zeigen, dass TAK1 mit dem TAK1-bindenden Protein 1 (TAB1) interagiert, welches die Aktivität von TAK1 reguliert.

In mesangialen Zellen der Maus konnte beobachtet werden, dass die Blockade des TAK1Signals durch dominant negative TAK1-Mutanten in einer Inhibierung der TGF- $\beta$-induzierten Aktivierung von MKK3 und p38 resultiert [Kim et al., 2007]. Neil und Schiemann [2008] zeigten einen direkten Einfluss von TAK1 auf die Invasionsfähigkeit von Mammakarzinomzellen. 
Weiterhin konnte gezeigt werden, dass TAK1 mit den IкB-Kinase-Komplexen interagiert und diese auch aktiviert (z.B. IKK $\alpha$, IKK $\beta$ und IKK $\gamma / \mathrm{NEMO}$ ), wodurch die Aktivierung des Transkriptionsfaktors NF-кB vermittelt wird [Sakurai et al., 1999; Sakurai et al., 2002]. Eine Untersuchung an den hoch-invasiven MDA-MB-231- und an den wenig-invasiven MCF-7Brustkrebszellen ergab, dass der Toll-like receptor 2 (TLR2) in den MDA-MB-231-Zellen bis zu 10x höher exprimiert wird als in den MCF-7-Zellen. Es konnte gezeigt werden, dass durch die TLR2-Aktivierung die Aktivität von NFkB sowie die Phosphorylierung von TAK1 und

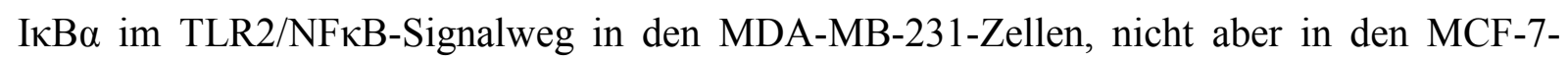
Zellen, erhöht sind. Weiterhin konnte ein Anstieg des IL-6-, TGFß-, VEGF- und MMP-9Levels durch die TLR2-Aktivierung beobachtet werden [Xie et al., 2009].

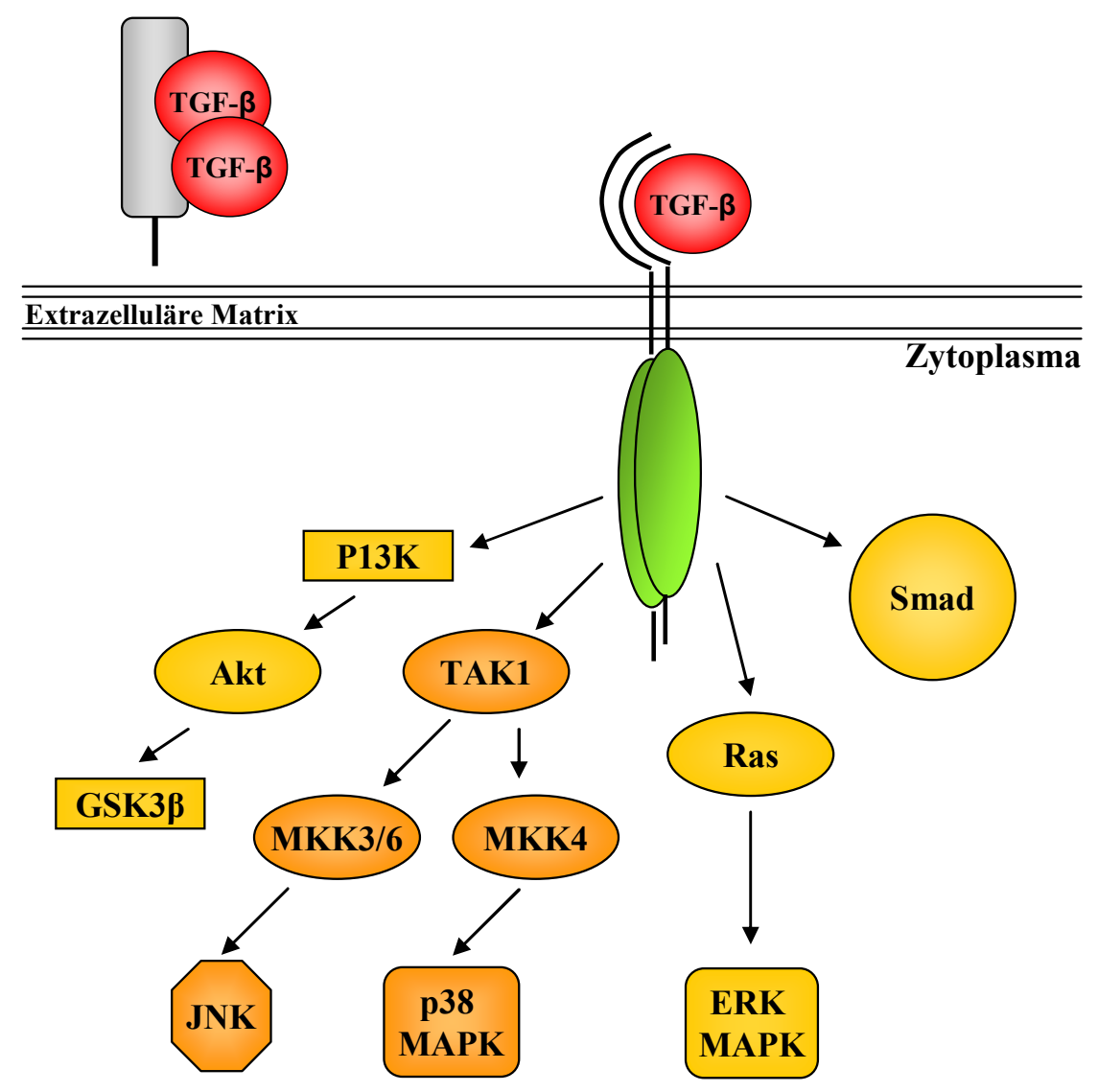

Abb. 4.6: Signalwege, die durch die Aktivierung des TGF- $\beta$-Rezeptors aktiviert werden. Mutationen in den downstream-Effektoren des TGF- $\beta$-Signalweges führen zur Aktivierung von Inhibitoren und damit zur Umgehung der wachstumsinhibierenden Signale während der Tumorprogression. 


\subsection{LPXN im Netzwerk der progressionsrelevanten Moleküle}

Im vorangegangenen Abschnitt wurden verschiedene Proteinfamilien, von denen bekannt ist, dass sie in die Tumorprogression involviert sind, beschrieben. Wie aber verhält sich LPXN in dem molekularen Netzwerk, welches die Tumorprogression beeinflusst? Hat LPXN einen direkten Einfluss auf Tumorinvasion und Metastasierung oder agiert es über Vermittler, deren Aktivitäten wesentlich von der Expression von LPXN abhängen, durch die die Progression beschleunigt wird?

In den vorliegenden in vitro-Studien an murinen Primärtumorzellen, die aus doppelt transgenen LPXN/TRAMP- und einfach transgenen TRAMP-Tumoren isoliert wurden, konnte gezeigt werden, dass LPXN die Migrations- und Invasionsfähigkeit der Zellen beschleunigt. Adapterproteine, wie LPXN, können direkt Zelladhäsionsmoleküle (z.B. Integrine und Cadherine), zytoskelettale Proteine, Kinasen oder Phosphatasen rekrutieren und mit diesen interagieren, wodurch eine Verbindung zwischen der ECM und dem Aktin-Zytoskelett aufgebaut wird.

\subsubsection{LPXN-vermittelte Progression durch Zelladhäsionsmoleküle}

In den vorliegenden in vitro-Studien konnte durch immunzytochemische Analysen an PC-3und DU 145-Zellen gezeigt werden, dass eine Herunterregulierung der LPXN-Expression in einer Lokalisation von $\beta$-Catenin ausschließlich an der Zytoplasmamembran und in einer reduzierten Expression des $\beta$-Catenin Zielgens MMP-7 resultiert. Diese Zellen zeigen zusätzlich eine deutlich verminderte Aggressivität, d.h. Migrations- und Invasionsfähigkeit. Die Herunterregulierung der Expression des Zelladhäsionsmoleküls p120CTN resultiert hingegen in einer Lokalisation von $\beta$-Catenin im Kern und in einer verstärkten Expression von MMP-7, sowie in einer höheren Aggressivität der Zellen. Es ist davon auszugehen, dass LPXN keinen direkten Einfluss auf die Lokalisation von $\beta$-Catenin in der Zelle ausübt. Daher besteht die Möglichkeit, dass LPXN ausschließlich über die Regulation der p120CTNExpression diesen Signalweg beeinflusst. Analysen des humanen p120CTN-Promotors, welcher putative Steroidhormonrezeptor-Bindungsstellen aufweist, von denen bekannt ist, dass LPXN diese aktivieren kann, blieben bisher jedoch ohne Ergebnis. Möglicherweise verläuft auch diese Regulation nicht direkt über LPXN, sondern über weitere 
Transkriptionsfaktoren, welche durch LPXN vermittelt, einen negativen Einfluss auf die Transkription von p120CTN ausüben.

Zusätzlich zur veränderten Expression könnte LPXN die Aktivität von p120CTN auch über die Phosphorylierung, z.B. der SRC-Kinase beeinflussen: zum Einen ist bekannt, dass SRC ein Interaktionspartner von LPXN darstellt [Sahu et al., 2007], und zum Anderen, dass p120CTN ein Substrat von SRC ist [Mariner et al., 2001]. Diese Hypothese wird gestützt durch die Ergebnisse der Western Blot-Analyse, durch die gezeigt werden konnte, dass nach Herunterregulierung der LPXN-Expression in PC-3-Zellen die phosphorylierte Form der Mitglieder der SRC-Familie weniger stark exprimiert werden als in Kontrollzellen. Eine Überexpression von LPXN könnte demnach in einer verstärkten Phosphorylierung der Mitglieder der SRC-Familie und somit in einer verstärkten Phosphorylierung von p120CTN resultieren, wodurch die Cadherin-Catenin-Komplexe an der Zellmembran gelockert und degradiert werden. $\beta$-Catenin könnte in den Kern wandern und die Transkription von Zielgenen regulieren, die die Zellmigration fördern (Abb. 4.7).

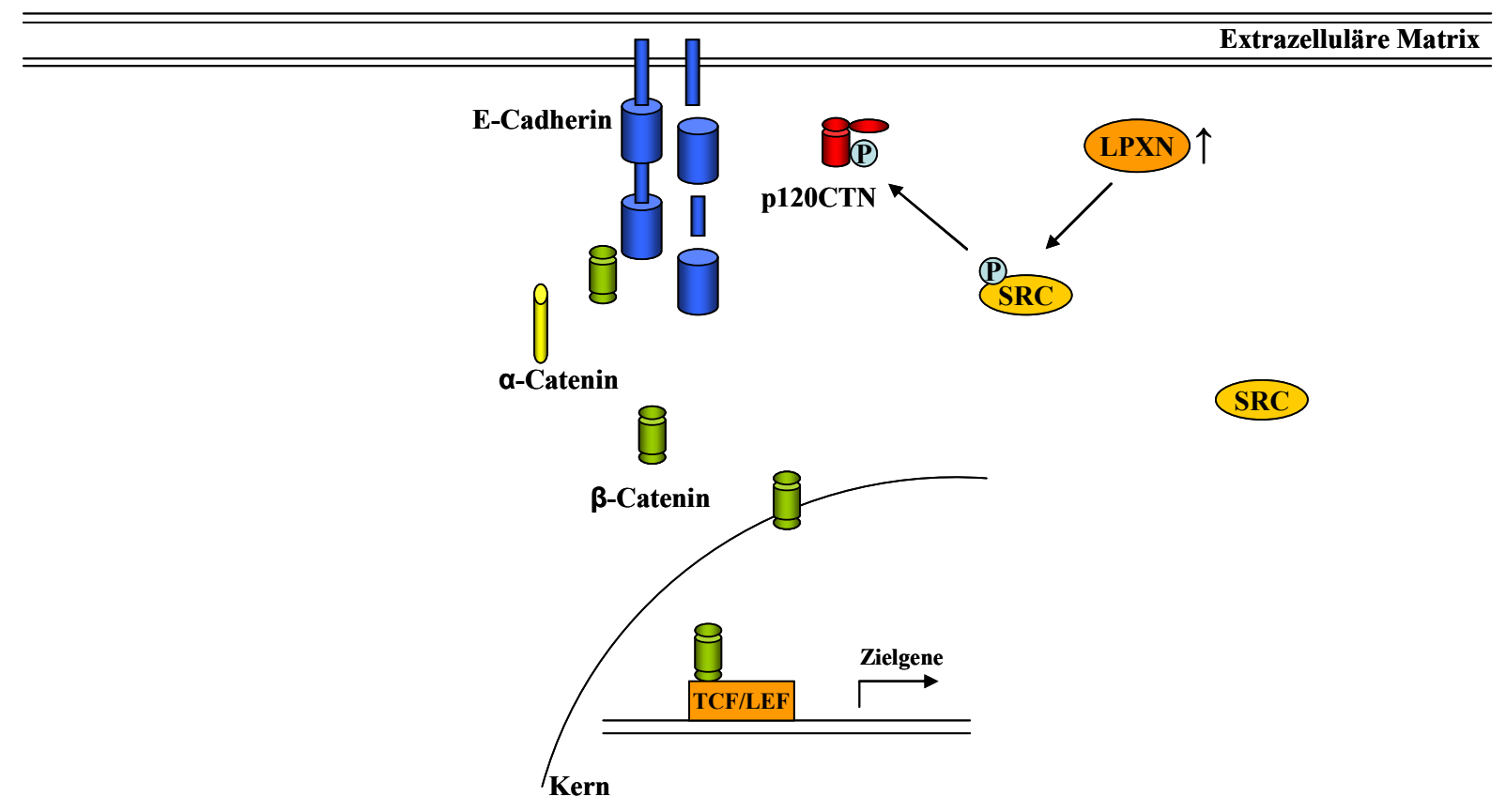

Expression von Zielgenen

Abb. 4.7: Indirekte Regulation der Lokalisation von $\boldsymbol{\beta}$-Catenin durch LPXN. Durch eine verstärkte Expression von LPXN könnte die SRC-Kinase vermehrt phosphoryliert werden, wodurch die Phosphorylierung von p120CTN stattfindet. Dies könnte in einer Lockerung des Cadherin-Catenin-Komplexes resultieren, wodurch $\beta$-Catenin in den Kern wandern könnte und dort die Transkription von Zielgenen, die in Zellmigration und Zellinvasion involviert sind, fördern. 
In den vorgelegten in vitro-Studien konnte auch gezeigt werden, dass die Expression von LPXN negativ mit der Expression von p120CTN korreliert. Mittels Western Blot-Analyse konnte diese Korrelation sowohl an etablierten PCa-Zelllinien, welche durch das TATTransduktion-System LPXN verstärkt repräsentieren, als auch an Prostatagewebe von LPXN/TRAMP-Mäusen sowie den daraus isolierten Primärtumorzellen nachgewiesen werden. Eine verminderte oder abnormale Expression von p120CTN in verschiedenen Tumorentitäten konnte bereits von verschiedenen Arbeitsgruppen beobachtet werden [Kallakury et al., 2001a; Chetty et al., 2008; Perez-Moreno et al., 2008; Liu et al., 2009]. Weiterhin wurde gezeigt, dass ein konditionaler knockout von p120CTN in der Bauchspeicheldrüse oder in der Haut von Mäusen zu einer Hyperproliferation der Zellen führt [Davis und Reynolds, 2006; Perez-Moreno et al., 2006]. Einen Ansatz zur Erklärung, wie eine erhöhte LPXN-Expression und eine verminderte p120CTN-Expression den Effekt der verstärkten Tumorprogression beeinflussen können, stellen die RhoGTPasen dar.

Wie bereits in 4.3.1 erwähnt, ist p120CTN in der Lage die Aktivität der Regulatoren der RhoGTPasen zu kontrollieren [Thoreson et al., 2000] (Abb. 4.3), wobei eine verstärkte p120CTN-Expression in einer Aktivierung von Rac1 und einer Inhibierung von RhoA resultiert. Es konnte gezeigt werden, dass p120CTN die Aktivität von RhoA inhibiert, indem es die Dissoziation des GDP von inaktivem RhoA supprimiert [Anastasiadis et al., 2000; Castano et al., 2007; Yanagisawa et al., 2008] oder indem es den negativen Regulator p190RhoGAP rekrutiert [Wildenberg et al., 2006]. Durch einen im Rahmen dieser Arbeit durchgeführten GST-Pulldown, bei dem die Aktivitäten von RhoA und Rac1 in Abhängigkeit von der LPXN-Expression analysiert wurden, konnte in PC-3-Zellen bei verminderter LPXNExpression ebenfalls eine Aktivierung von Rac1 und eine Inhibierung von RhoA beobachtet werden. Im Rahmen der biologischen Dissertation von Frau Dr. Kaulfuß wurde bereits 2006 gezeigt, dass eine negative Korrelation der LPXN- und p120CTN-Expression auch nach Herunterregulierung der LPXN-Expression besteht.

Es besteht daher die Möglichkeit, dass durch die verstärkte Expression von LPXN im fortgeschrittenen Stadium des PCa die Expression von p120CTN herunterreguliert wird. Unabhängig voneinander könnten die verstärkte LPXN-Expression und die verminderte p120CTN-Expression die Aktivitäten der RhoGTPasen Rac1, Cdc42 und RhoA kontrollieren, wodurch der Aufbau von Lamellipodien gefördert wird. Lamellipodien sind ausgedehnte, flache Fortsätze an der vorderen Seite der migrierenden Zelle, die mit einem großen Netzwerk an Aktin-Filamenten durchsetzt sind. Durch sie wird die Migrationsfähigkeit der Zelle bestimmt. 
Neben dem Einfluss von LPXN auf die o.g. Signalwege, durch die Zellmigration und Zellinvasion während der Progression von Tumorzellen beeinflusst werden, konnte im Rahmen der vorliegenden Arbeit gezeigt werden, dass LPXN die Zell-Matrix-Adhäsion beeinflusst. PC-3- und DU 145-Zellen, die eine verminderte LPXN-Expression aufweisen, zeigen im Zelladhäsions-Assay ein deutlich vermindertes Adhäsionspotential auf verschieden beschichteten Untergründen. Sowohl die Zellzahl als auch die Zellgröße der am Boden adhärierenden Zellen unterscheiden sich nach $1 \mathrm{~h}$ Adhäsionszeit in LPXN-defizienten Zellen im Vergleich zu Kontrollzellen um bis zu 50\%. Neben einer verringerten Größe der focal adhesion sites konnten in Zellen mit LPXN knockdown weiterhin sog. „,blebs“ beobachtet werden. „Blebs“ stellen Blasen in der Plasmamembran dar, die durch extrazelluläre Stimuli oder andere Signale hervorgerufen werden und einem strengen, hoch-dynamischen Zyklus folgen, der schätzungsweise 1 min andauert: eine schnelle Ausdehnung der Plasmamembran, eine kurze statische Phase und eine langsame Retraktion der Blasen bis zur Ausgangsmorphologie der Plasmamembran [Cunningham, 1995; Charras et al., 2005]. Für MDA-MB-435-Mammakarzinomzellen konnte gezeigt werden, dass sie ihren Phänotyp verändern und Blasen bilden, wenn diese mit Matrigel in Berührung kommen [Kitzing et al., 2007]. Fackler und Grosse [2008] haben zusammengefasst, dass eine verminderte ZellMatrix-Adhäsion oder -Interaktion mit einem ansteigenden hydrostatischen Druck in der Zelle korreliert, wodurch die Blasenbildung der Plasmamembran kontrolliert wird. Verschiedene Experimente zur Induktion der Blasenbildung bei nicht-invasiven Zellen ergaben, dass diese die Fähigkeit in 3D-Matrizes zu invadieren erhöhen [Gadea et al., 2007; Tournaviti et al., 2007]. Die Blasenbildung wird daher als Fluchtmechanismus beschrieben, durch den die Zelle die Proteolyse der ECM umgeht [Sahai und Marshall, 2003; Friedl, 2004]. Es besteht daher die Möglichkeit, dass die LPXN-defizienten PCa-Zellen durch die Blasenbildung versuchen, die geringere Aktivierung der o.g. Signalwege zu umgehen. Normalerweise bilden invasive Zellen bei Kontakt mit einem ECM-Substrat, wie z.B. Fibronektin, Gelatine oder Collagen, Invadopodien aus, durch die der Kontakt zum Substrat hergestellt, die Sekretion von Proteasen aktiviert wird und ein lokaler Abbau der ECM stattfindet [Yamaguchi et al., 2006; Linder, 2007]. Da die Aktin-Polymerisation eine entscheidende Rolle bei der Bildung der Invadopodien spielt, die über Oberflächenrezeptoren, wie Integrine und Wachstumsfaktoren gesteuert wird [Yamaguchi et al., 2005], besteht die Möglichkeit, dass durch den Verlust der LPXN-Expression diese Signaltransduktion gestört wird. Für LPXN konnte bereits gezeigt werden, dass es mit Integrin $\alpha 4$ interagiert, wobei der genaue Mechanismus noch nicht bekannt ist [Liu et al., 2002]. Es wäre daher möglich, dass LPXN in den adhärierenden und 
invasiven Zellen ausgehend von den Signalen der Integrine, Regulatoren rekrutiert, mit diesen interagiert und dadurch das Verhalten der Zelle verändert.

Durch einen im Rahmen dieser Arbeit durchgeführten Invasionsassay mit verschiedenen Komponenten der ECM (Fibronektin, Collagen I, Collagen IV und Laminin) konnte gezeigt werden, dass LPXN-defiziente PCa-Zellen eine um bis zu 80\% verringerte Invasionsfähigkeit aufweisen (Ergebnisse nicht gezeigt) [Kaulfuß et al., 2009].

Im Zelladhäsions-Assay konnte weiterhin beobachtet werden, dass nach einer Adhäsionszeit von $24 \mathrm{~h}$ die Blasenbildung der Zellen mit LPXN knockdown nicht mehr zu erkennen ist. Dies bestätigt die Annahme, dass durch die Beschichtung der Objektträger, in denen die ZellAdhäsions-Assays durchgeführt wurden, mit verschiedenen Komponenten der ECM (Collagen, Fibronektin, Gelatine, BSA) eine dünne 3D-Matrix entsteht, die die Zellen versuchen zu proteolysieren. Durch die Expression von LPXN könnten die oben beschriebene Bildung der Invadopodien und der Abbau der ECM viel effektiver stattfinden als in den LPXN-defizienten Zellen (Abb. 4.8). Interessant wäre zu untersuchen, ob ein Unterschied in der Zytoskelett-Struktur oder der Zellzahl nach $8 \mathrm{~h}$ noch zu erkennen ist. Weiterhin könnte eine Messung der Anzahl der Invadopodien Aufschluss darüber geben, ob LPXN tatsächlich einen direkten Einfluss auf die Ausbildung der Aktinstrukturen hat. Durch den Adhäsionsassay konnten weiterhin die oben beschriebenen Effekte auch auf Objektträgern beobachtet werden, die vorher nicht zusätzlich mit den Komponenten der ECM beschichtet wurden. Dies unterstützt die Hypothese, dass durch die verminderte LPXN-Expression nicht nur die Expression der MMPs verringert ist, sondern dass bereits der Signaltransduktionsapparat und die Bildung der Invadopodien, die die Zell-Matrix-Adhäsion vermitteln, gestört sind. 


\section{1 h Adhäsion}
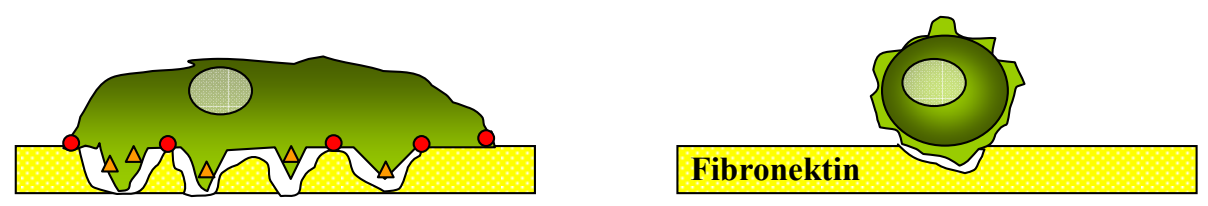

○ LPXN

$\triangle$ MMPs

\section{4 h Adhäsion}

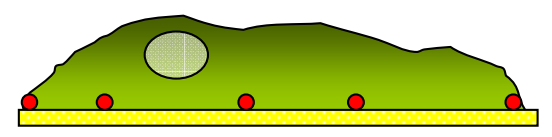

LPXN $\uparrow$

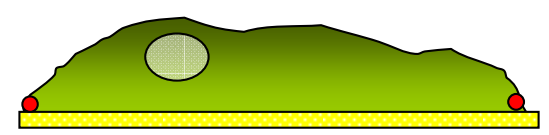

$\mathbf{L P X N} \downarrow$

Abb. 4.8: Möglicher Mechanismus der LPXN-vermittelten Adhäsion auf Fibronektin-beschichteten Objektträgern. Durch die Expression von LPXN könnten der Kontakt der Zelle mit der ECM und der Abbau der ECM nach $1 \mathrm{~h}$ Adhäsionszeit sehr viel effektiver funktionieren als in Zellen mit herunterregulierter LPXNExpression. Diese Zellen umgehen den Verlust der LPXN-vermittelten Signaltransduktion durch die Blasenbildung. Nach einer Adhäsionszeit von 24 h unterscheiden sich die Zellen mit herunterregulierter LPXNExpression in ihrer Größe und im Zytoskelett nicht mehr von den Kontrollzellen (LPXN $\uparrow$ ).

\subsubsection{LPXN-vermittelte Progression durch Caldesmon}

Die durch LPXN-vermittelte verstärkte Progression von PCa-Zellen könnte auch durch das Aktin-bindende Protein Caldesmon reguliert werden. Caldesmon konnte 2007 als Interaktionspartner von LPXN identifiziert werden [Beckemeyer, 2007]. Durch einen Migrationsassay mit PC-3- und DU 145-Zellen konnte eine Involvierung von Caldesmon in die Migrationsfähigkeit von PCa-Zellen bestätigt werden. Nach Herunterregulierung der Caldesmon-Expression war im Vergleich zu Kontrollzellen eine erhöhte Migrationsfähigkeit der Zellen zu beobachten. Weiterhin konnte in der vorliegenden Arbeit gezeigt werden, dass in PC-3-Zellen eine durch RNAi induzierte herunterregulierte LPXN-Expression in einer verminderten Serin-Phosphorylierung von Caldesmon an der Aminosäureposition 789 (h-Cald, entspricht Aminosäureposition 527 in 1-Cald) resultiert. Wie bereits unter 4.3.2 beschrieben, führt die Phosphorylierung von Caldesmon zur Inaktivierung des Proteins, 
wodurch Caldesmon von den Mikrofilamenten dissoziiert und die Lamellipodien neu gebildet werden können [Foster et al., 2004; Kordowska et al., 2006; Li et al., 2009]. Es besteht daher die Möglichkeit, dass in Zellen mit einer geringen LPXN-Expression auch eine geringere Phosphorylierung von Caldesmon stattfindet. Die geringe Phosphorylierung äußert sich in einer starken Affinität von Caldesmon zu den Aktin-Filamenten und zu einer Inhibierung der Aktomyosin ATPase-Aktivität [Ngai und Walsh, 1984; Huber et al., 1998], wodurch die Zelle nicht mehr in der Lage ist, neue Lamellipodien zu bilden und zu migrieren.

In einer LPXN-überexprimierenden Zelle könnte Caldesmon hingegen stark phosphoryliert werden. Dadurch wird Caldesmon inaktiviert, dissoziiert von den Aktin-Filamenten und stabilisiert die Bildung der Lamellipodien (Abb. 4.9). Es kommt zu einer verstärkten Migrationsfähigkeit der Zelle. Ob eine verstärkte Expression von LPXN in PCa tatsächlich in einer verstärkten Phosphorylierung von Caldesmon resultiert, wird z.Zt. in unserer Arbeitsgruppe überprüft.

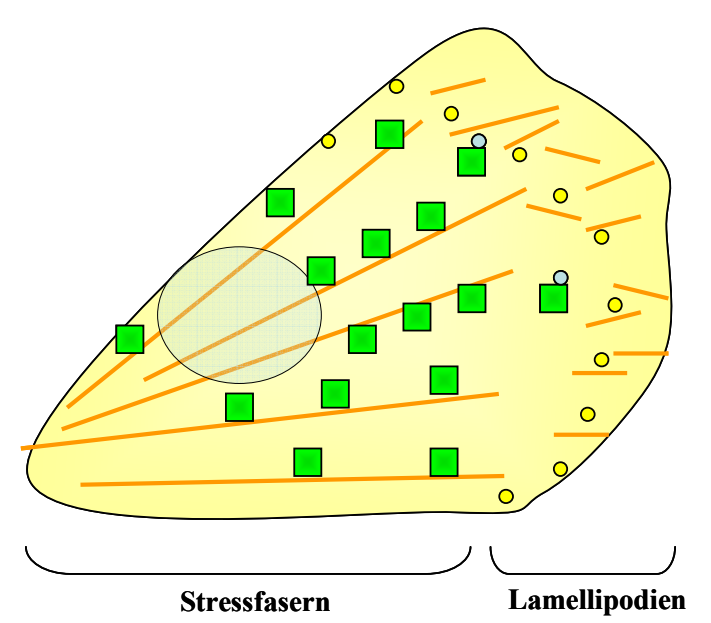

Stressfasern
Lamellipodien

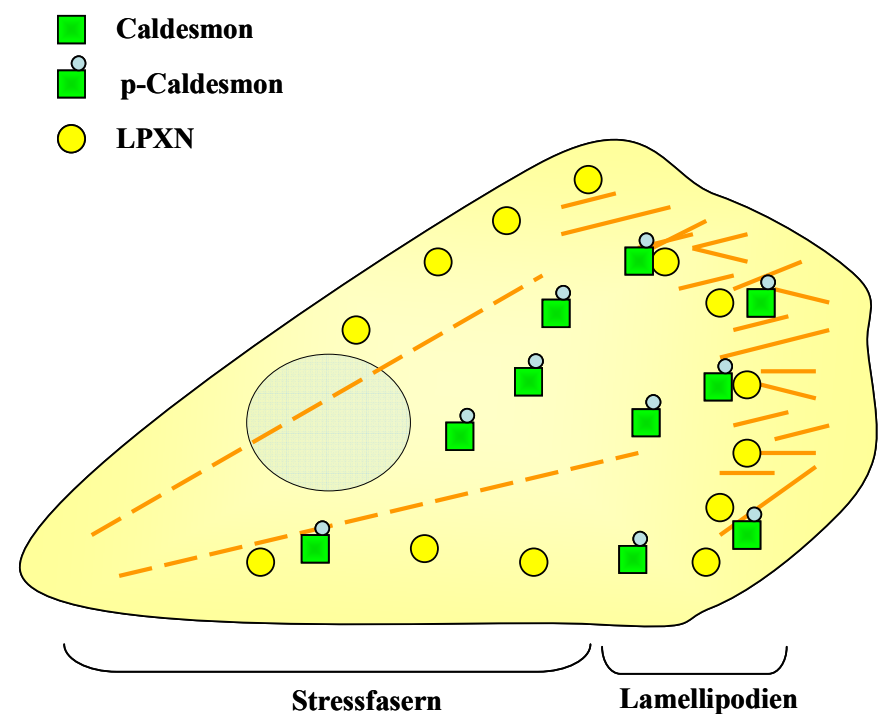

verstärkte Migration
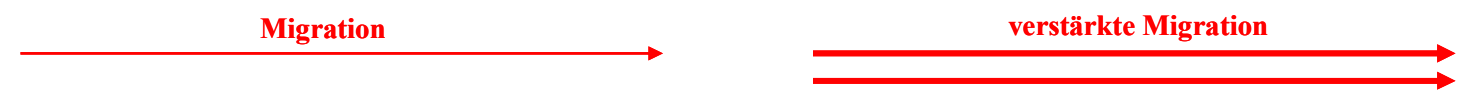

Abb. 4.9: Einfluss des Phosphorylierungsstatus von Caldesmon auf das Verhalten von Karzinomzellen. Durch die Expression von LPXN wird die Migrationsfähigkeit von PCa-Zellen erhöht. In einer Zelle mit geringer LPXN-Expression kann das Aktin-bindende Protein Caldesmon an den Stressfasern lokalisieren, wodurch die Aktivität der Aktomyosin ATPase inhibiert wird. Eine starke Expression von LPXN resultiert in den Zellen in einer verstärkten Interaktion von LPXN und Caldesmon und in einer verstärkten Phosphorylierung von Caldesmon, wodurch es inhibiert wird und von den Aktinfasern dissoziiert. Dadurch wird die Bildung von Lamellipodien begünstigt und die Zelle kann migrieren. 
Wie bereits unter 4.3.2 erläutert, steht die Bildung der Invadopodien im direkten Zusammenhang mit der Sekretion der Matrix-Metalloproteinasen [Bowden et al., 2001; Linder et al., 2007; Gimona et al., 2008]. Yoshio et al [2007] konnten zeigen, dass die Überexpression von Caldesmon in einer reduzierten Degradation der ECM und der Inhibierung der Invasionsfähigkeit der Zellen resultiert. Es bleibt also zu prüfen, ob durch die LPXN-vermittelte Phosphorylierung von Caldesmon die Bildung der Invadopodien ansteigt, wodurch die Sekretion der MMPs ausgelöst wird. LPXN wäre dann nicht nur über den p120CTN- $\beta$-Catenin-MMP-7-Signalweg, sondern auch über den pCald-MMP-Signalweg in der Degradation der ECM und somit an der Migration und Invasion von Karzinomzellen beteiligt (Abb. 4.10).

Weiterhin bleibt zu prüfen, welche Kinasen für die LPXN-vermittelte Phosphorylierung von Caldesmon verantwortlich sind. Ein im Rahmen dieser Arbeit durchgeführter Western Blot zur Identifizierung von Kinasen, welche die Aminosäure Serin an der Position 789 phosphorylieren können, blieb bisher ohne Ergebnis. In Nicht-Muskelzellen konnte bisher die Phosphorylierung von Caldesmon an dieser Stelle nur durch die Cdc2-Kinase [Yamashiro et al., 1990, 1991] und durch ERK [Adam et al., 1992; D'Angelo et al., 1999] gezeigt werden, wobei die Phosphorylierung durch die Cdc2-Kinase eine größeren Effekt auf Caldesmon und die Aktin-Interaktion ausübt [Huang et al., 2003; Foster et al., 2004]. Im Rahmen der biologischen Dissertation von Frau Dr. Kaulfuß [2006] wurden Untersuchungen zum Phosphorylierungsstatus von ERK in PCa-Zellen mit herunterregulierter LPXN-Expression durchgeführt. Dabei konnte nur in den nicht-invasiven LNCaP-Zellen, nicht aber in den invasiven PC-3- und DU 145-Zellen, eine geringere Aktivität von ERK nach LPXN knockdown festgestellt werden. Chew und Lam [2007] konnten auch in B-Zellen keinen Einfluss von LPXN auf die Aktivität von ERK demonstrieren.

Weitere mögliche Kandidaten stellen die c-Jun NH2-terminale Serinkinase JNK und die MAP-Kinase TAK1 dar. Für JNK konnte mittels Western Blot gezeigt werden, dass der Phosphorylierungsstatus nach Herunterregulierung der LPXN-Expression vermindert ist. Für TAK1 konnte bis zum jetzigen Zeitpunkt sowohl auf RNA- als auch auf Proteinebene gezeigt werden, dass die Expression nach Herunterregulierung der LPXN-Expression reduziert ist. Der Einfluss von JNK und TAK1 auf den Phosphorylierungsstatus von Caldesmon wurde bis dato nicht untersucht. 


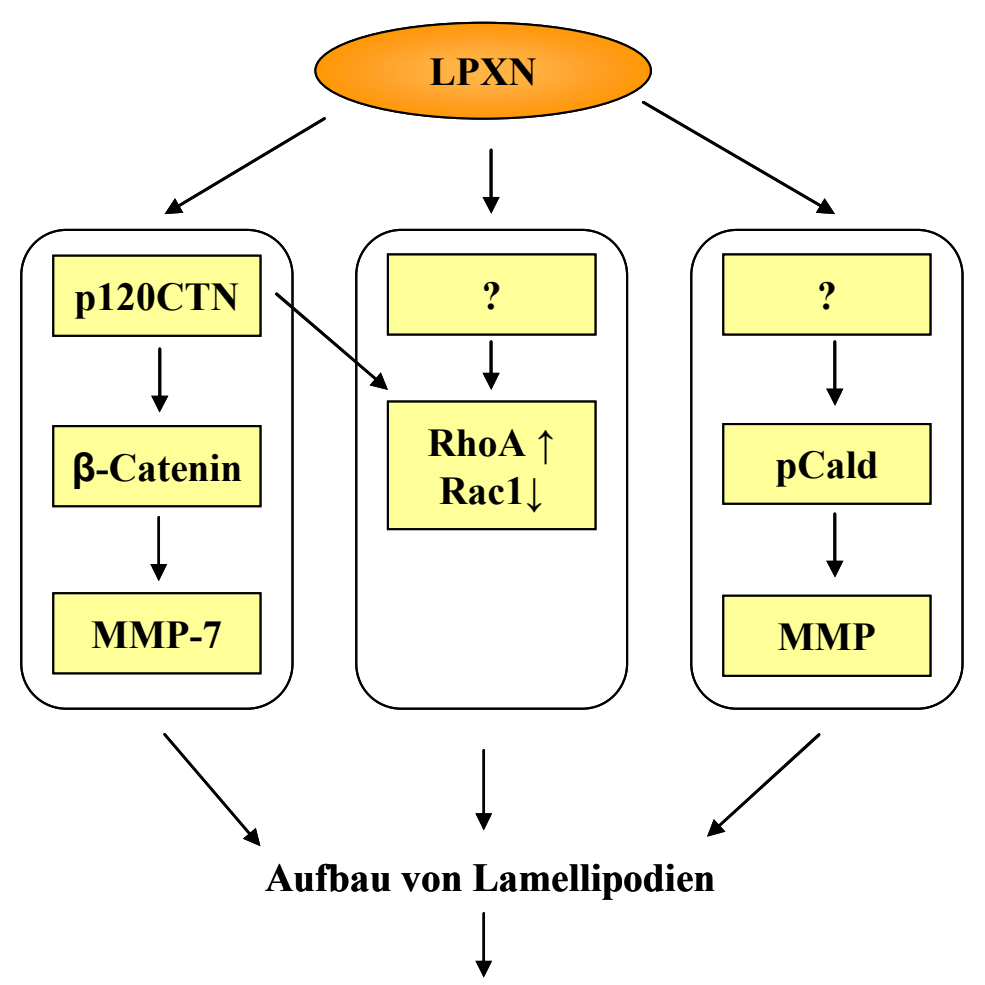

Zellmigration / Zellinvasion

\begin{abstract}
Abb. 4.10: Schematische Darstellung der Signalwege, durch die LPXN die Zellmigration und Zellinvasion beeinflussen könnte. Das Adapterprotein LPXN ist in der Lage durch die Veränderung der Expression, Aktivierung oder Phosphorylierung Signalwege anzuschalten. Für den p120CTN- $\beta$-Catenin-MMP-7-Signalweg, die Aktivierung von RhoA bzw. Inaktivierung von Rac1 und die Phosphorylierung von Caldesmon konnte der Einfluss von LPXN bereits gezeigt werden. Dadurch wird der Aufbau von Lamellipodien begünstigt, wodurch die Zellmigration und Zellinvasion gefördert werden.
\end{abstract}

\title{
4.4.3 Weitere LPXN-vermittelte Signalwege
}

Im Rahmen der vorliegenden Arbeit konnte in einem Antikörper-Array eine herunterregulierte Expression der MAPKKK TAK1 in PC-3 Zellen mit LPXN knockdown nachgewiesen werden. Weiterführende Analysen mittels quantitativer real time PCR und Western Blot-Analyse konnten bestätigen, dass LPXN in den TAK1-JNK-ATF2-Presenilin1Signalweg involviert ist. Es konnte z.B., wie bereits unter 4.4.2 erwähnt, gezeigt werden, dass bei herunterregulierter LPXN-Expression die Menge an phosphoryliertem JNK abnimmt. JNKs gehören zu der Familie der Serin/Threonin-MAP-Kinasen. Die Phosphorylierung eines konservierten Thr-X-Tyr-Motifs durch die MAPKK führt zur Aktivierung von JNK 
[Davis, 2000]. Altan und Fenteany [2004] konnten in Säugerzellen zeigen, dass die Inhibierung des JNK-Signalweges die Migrationsfähigkeit der Zellen und die Bildung der Lamellipodien reduziert. Es besteht also die Möglichkeit, dass die LPXN-vermittelte verstärkte Progression des PCa auch durch die Aktivierung von JNK stattfindet. Ob eine erhöhte Expression von LPXN aber tatsächlich auch in einer Aktivierung von JNK resultiert und ob dadurch die Migrationsfähigkeit der Zellen spezifisch beeinflusst wird, wurde bis dato nicht geprüft. Weiterhin konnte gezeigt werden, dass aktiviertes JNK $\beta$-Catenin phosphorylieren kann, wodurch die Zell-Zell-Adhäsion zerstört werden könnte [Lee et al., 2009]. Der Einfluss von LPXN auf die subzelluläre Lokalisation von $\beta$-Catenin könnte demnach nicht nur über die Expression von p120CTN, sondern auch über die Phosphorylierung von JNK stattfinden.

Für die Expression von Presenilin1 konnte mittels quantitativer real time PCR eine Korrelation mit der Expressionsstärke von LPXN sowohl in LPXN-defizienten PCa-Zellen als auch in LPXN-überexprimierenden Primärzellen gefunden werden. Presenilin1 wurde ursprünglich als ein Protein beschrieben, welches in die Pathogenese von Alzheimer involviert ist [Tanzi, 2008]. Baki et al. [2001] konnten zeigen, dass Presenilin1 an der Plasmamembran mit dem Cadherin/Catenin-Zelladhäsionskomplex interagiert und die Assoziation von E-Cadherin und $\beta$-Catenin stabilisiert. In Wildtyp- und Presenilin1 knockout Zellen konnte beobachtet werden, dass ein Anstieg des Presenilin1-Levels die p120CTN/ E-Cadherin-Bindung inhibiert, wohingegen ein Anstieg des p120CTN-Levels die Presenilin1/E-Cadherin-Bindung inhibiert. Ob dieser Effekt auch direkt durch die Expression von LPXN reguliert werden kann, bleibt zu untersuchen.

Im Rahmen dieser Arbeit wurde zur Identifizierung von weiteren durch LPXN deregulierten Signalwegen ein whole genome Microarray mit Prostatatumormaterial von LPXN/TRAMPund TRAMP-Mäusen durchgeführt. Dabei wurden Hopx und Cbs als LPXN-vermittelte deregulierte Gene identifiziert. Yamaguchi et al. [2009] beschreiben Hopx als Suppressor von Zervixkarzinomen. In dieser Studie konnte auf RNA- und Proteinebene gezeigt werden, dass die Mehrheit von 28 untersuchten Tumoren im Vergleich zum Normalgewebe eine reduzierte Hopx-Expression aufweist. Weiterhin konnte gezeigt werden, dass die Methylierung der Hopx-Promotorregion ein Marker für die Aggressivität des Tumors ist [Yamaguchi et al., 2009; Ooki et al., 2010]. In dem von uns durchgeführten whole genome Microarray konnte die Expression von Hopx jedoch als ein um den Faktor 1,65 hochreguliertes Gen in den doppelt transgenen LPXN/TRAMP-Tumoren identifiziert werden. Dabei ist zu beachten, dass sich der Wert aus dem Mittelwert der Genexpression der Tumore 
von drei doppelt transgenen LPXN/TRAMP-Mäusen im Vergleich zu drei einfach transgenen TRAMP-Mäusen ergab. Weiterhin lag die Wahrscheinlichkeit für ein falsch positives Ergebnis bei 71,54\%. Für die Überprüfung der Array-Daten durch eine quantitative real timePCR wurden dieselben cDNAs verwendet wie für den Array. Um die Expression von Hopx eindeutig in Korrelation mit der LPXN-Expression im Tumorgewebe zu bringen, müsste weiteres Gewebematerial analysiert werden. Eine zusätzliche Schwäche des Arrays besteht darin, dass zwar die Tumorgröße (100-150 $\mathrm{mm}^{3}$ ) und die Histopathologie (schlecht differenzierter Tumor) von allen untersuchten Tumoren identisch waren, dennoch das genaue Progressionsstadium nicht zu erkennen war. Zur Optimierung des Arrays ist in unserer Arbeitsgruppe geplant, mittels Mikrodissektion nur die jeweiligen Anfangsstadien (PIN und gut differenziertes Tumorgewebe) des PCa von beiden Versuchstiergruppen zu analysieren. Die Expression der Cystathionin beta-synthase (Cbs) wurde in dem Microarray als um den Faktor 0,84 herunterreguliertes Gen in den doppelt transgenen LPXN/TRAMP-Tumoren im Vergleich zu den einfach transgenen LPXN-Tumoren identifiziert. Expressionsstudien an Lebertumoren konnten darlegen, dass eine reduzierte Cbs-Expression signifikant mit dem Tumorgrad und der Überlebenswahrscheinlichkeit des Patienten korreliert [Kim et al., 2009].

\subsection{Perspektiven}

In der vorliegenden Arbeit konnte LPXN eindeutig als ein Protein identifiziert werden, welches die Progression von sowohl androgen-abhängigen als auch androgen-unabhängigen PCa beschleunigt. Die gewonnenen in vitro-Daten konnten darlegen, dass LPXN in verschiedene, miteinander vernetzte Signalwege involviert ist, durch die Zelladhäsion, Zellmigration und Zellinvasion beschleunigt werden. Dennoch ist davon auszugehen, dass LPXN noch weitere Gene, z.B. Tumorsuppressorgene, Wachstumsfaktoren und Cytokine während der Entwicklung zum aggressiven, metastasierenden PCa beeinflusst. Diese gilt es zu identifizieren, um gezielt Aussagen über die Funktion von LPXN als putativen Progressionsmarker $\mathrm{zu}$ formulieren. Die bestehenden LPXN/TRAMP-Mäuse stellen ein hervorragendes Modell zur Untersuchung von deregulierten Genen während der Progression des PCa dar. Eine Optimierung des bereits durchgeführten whole genome Microarrays, die Analyse nur der jeweiligen Anfangsstadien (PIN oder gut differenziertes Tumorgewebe) des PCa von beiden Versuchstiergruppen mittels Mikrodissektion (siehe auch 4.4.3), könnten weitere Hinweise auf Gene geben, die in vivo das aggressive Verhalten der Zellen 
beeinflussen. Außerdem bieten die aus den murinen Tumoren isolierten Primärzellen für die weiteren Analysen von LPXN ein gutes in vitro-Modell. Alle Erkenntnisse zur Charakterisierung der LPXN-vermittelten Signalwege, die aus den durchgeführten Arrays gewonnen werden konnten, können in den Primärzellen bestätigt und verifiziert werden, da sie eine ideale Verbindung zwischen dem Mausmodell und dem in vitro-Modell darstellen. Eine Charakterisierung der Chromosomen der Primärzellen der LPXN/TRAMP- und TRAMP-PCa ergab ein diffuses Bild an chromosomalen Veränderungen, einschließlich von Robertson'schen Translokationen, Verlust oder Zugewinn von (Geschlechts-)Chromosomen und großen Deletionen/Duplikationen (Ergebnisse nicht gezeigt). Auch humane maligne Tumoren sind genetisch instabil und weisen daher häufig chromosomale Störungen auf. Die Zahl der chromosomalen Veränderungen nimmt im Verlauf der Tumorprogression zu. Je ausgeprägter die Chromosomenaberationen in einem humanen PCa sind, desto höher ist der Malignitätsgrad [Koss, 2005]. Durch die Isolierung und die Chromosomenanalyse weiterer muriner Primärzellen aus den LPXN/TRAMP- und TRAMP-Mäusen der gleichen Passage könnte ein Zusammenhang zwischen der LPXN-Überexpression und der Akkumulation von bestimmten chromosomalen Veränderungen gefunden werden. Daraus könnten dann evtl. Rückschlüsse auf deregulierte Onkogene und/oder Tumorsuppressorgene gezogen werden. Für das Protoonkogen $M y c$ konnte z.B. gezeigt werden, dass es auf dem langen Arm des Chromosoms 8 lokalisiert ist und somatische Amplifikationen dieses DNA-Abschnitts zu den häufigsten Ereignissen im Prostatatumor gehören [van Duin et al., 2005].

Mit diesem Wissen könnten dann auch therapierelevante in vivo-Untersuchungen vorgenommen werden, die z.B. den Einfluss der LPXN-Hemmung auf die Progression von bestehenden $\mathrm{PCa}$ analysieren. Eine Injektion von isolierten humanen Primärzellen unter die Haut von Nacktmäusen und die anschließende Herunterregulierung der LPXN-Expression mittels siRNA in den PCa-Xenografts könnten Hinweise auf Therapiemöglichkeiten geben. Bei einem positiven Ansprechen der PCa-Zellen auf die LPXN-siRNA und die damit verbundene Reduktion des $\mathrm{PCa}$, wäre es weiterhin interessant, den genauen Zeitpunkt des Ansprechens festzustellen. Es ist bekannt, dass LPXN nicht an der Initiation des PCa beteiligt ist. $\mathrm{Ob}$ durch eine Reduktion der LPXN-Expression jedoch bereits der lokale Primärtumor eingegrenzt werden kann oder ob nur der Übergang vom lokalen PCa zum invasiven und metastasierenden PCa inhibiert werden kann, bleibt zu untersuchen.

Eine weitere Möglichkeit wäre die durch LPXN deregulierten Gene, die im Rahmen dieser Arbeit identifiziert werden konnten, auf Therapieansätze zu prüfen. Z.B. konnten Hinweise für einen Zusammenhang von LPXN und den Signalwegen, die durch $\beta$-Catenin und den 
SRC-Kinasen vermittelt werden, gefunden werden. Lu et al. [2009] konnten zeigen, dass der Wnt/ $\beta$-Catenin-Signalweg durch den Inhibitor PKF118-310 in den PCa-Zellen PC-3 und DU 145 inhibiert werden kann. Weiterhin konnten Yu et al. [2009] demonstrieren, dass 44\% der untersuchten PCa-Patienten, die mit Dasatanib, dem Inhibitor der SRC-Kinasen, behandelt wurden, bereits nach 12 Wochen keine weitere Progression des Tumors mehr aufwiesen.

Im Rahmen dieser Arbeit konnte ebenfalls gezeigt werden, dass LPXN an der Progression von androgen-unabhängigen Tumoren beteiligt ist. Kaulfuß et al. konnten bereits 2008 sowohl eine Interaktion als auch eine Transaktivierung des AR durch LPXN beobachten. Obwohl es schon mehrere Erkenntnisse über das androgen-unabhängige, zum Tode des Patienten führende Wachstum von PCa gibt, konnten bisher keine wirklich hilfreichen Therapieansätze für Patienten entwickelt werden. Daher erscheint es sinnvoll, umfangreichere Daten, sowie follow up-Daten über die Expression von LPXN im humanen PCa zu sammeln und $\mathrm{zu}$ analysieren. Eine (Über-)expression von LPXN in Biopsie-Material von sowohl androgen-abhängigen als auch androgen-unabhängigen Tumoren könnte darauf hindeuten, dass sich ein Tumor besonders aggressiv und progressiv verhalten wird, woraufhin der Patient mit einer intensiven Therapie behandelt werden muss. Dafür wäre jedoch die Gegenüberstellung von einer genügend großen Anzahl von Patienten mit einem schlechten Verlauf der Krankheit (Metastasierung, Rezidiv, Tod) und einem milden Verlauf der Krankheit (Heilung, Überleben) notwendig. Anschließend könnte die Frage beantwortet werden, ob und zu welchem Zeitpunkt die Expression von LPXN in den Tumoren erhöht ist und welche morphologischen sowie pathologischen Veränderungen daraus resultieren.

Die parallele Untersuchung der LPXN-abhängigen Expression von anti-apoptotischen Genen wie z.B. BCL-2, welche bereits in einen Zusammenhang mit der Entwicklung von androgenunabhängigen PCa gestellt wurden, stellt einen Ansatz für die weitere Analyse dar. In der Komplexität des PCa erscheint es dennoch utopisch, LPXN als ein Gen zu charakterisieren, welches auf den gesamten Tumorverlauf Einfluss nimmt. Vielmehr ist es das Ziel, die einzelnen Funktionen von LPXN in der Gesamtheit des PCa zu identifizieren, um so up- und downstream-stehende Gene zu ermitteln, durch die Therapieverfahren entwickelt werden könnten.

Die in dem Antikörper-Array ermittelten deregulierten Gene nach Herunterregulierung der LPXN-Expression umfassen interessante Kinasen, wie z.B. TAK1 und Yes und Rezeptoren, wie z.B. den EGFR. Weiterhin konnte beobachtet werden, dass die Expression des Cytokins IL-6 nach LPXN knockdown herunterreguliert ist (Ergebnisse nicht gezeigt). Viele neuere Arbeiten verschiedener Arbeitsgruppen konnten eine pathogene Rolle für TAK1, Yes und IL- 
6 in der Progression von PCa bestätigen [Cavaretta et al., 2007; Neil und Schiemann, 2008; Malinowska et al., 2009; Santer et al., 2010; Wang et al., 2010]. Diese Gene bieten daher gute Möglichkeiten, weitere Signalwege, in die LPXN involviert ist, sowie Ansatzpunkte, für eine relevante Therapie für Patienten mit einem PCa zu identifizieren. 


\section{Zusammenfassung}

Leupaxin (LPXN) stellt ein zytoskelettales Adapterprotein der Paxillin-Protein-Familie dar, dessen Expression direkt mit dem Gleason Score von humanen PCa korreliert [Kaulfuß et al., 2008]. In der vorliegenden Arbeit wurde LPXN durch in vivo-Experimente bei doppelt transgenen LPXN/TRAMP-Mäusen als ein Protein identifiziert, welches das Wachstum von bestehenden TRAMP-Tumoren sowie von Fernmetastasen beschleunigt. Parallel dazu durchgeführte in vitro-Studien an Primärzellen, welche aus den Tumoren der LPXN/TRAMP-Tumoren isoliert wurden, haben ergeben, dass durch die Überexpression von LPXN sowohl die Migrations- als auch die Invasionsfähigkeit der LPXN/TRAMP-Zellen im Vergleich zu Kontrollzellen drei- bzw. zweifach erhöht ist. Um die Frage zu beantworten, wie LPXN die Progression von PCa beeinflusst, wurde der Zusammenhang zwischen der LPXNExpression und der Expression des Zelladhäsionsmoleküls p120CTN näher untersucht. Sowohl in vivo als auch in vitro resultiert eine Überexpression von LPXN in einer reduzierten Expression von p120CTN. Studien an den etablierten humanen PCa-Zelllinien PC-3 und DU 145 zeigten außerdem, dass diese nach Herunterregulierung der p120CTN-Expression eine erhöhte Migrations- und Invasionsfähigkeit im Vergleich zu Kontrollzellen aufweisen. Eine Herunterregulierung der LPXN-Expression resultierte hingegen in einer verminderten Migrations- und Invasionsfähigkeit der Zellen. Die simultane Herunterregulierung der LPXNund p120CTN-Expression resultierte in einer Aufhebung der Einzel-Effekte. Da bekannt ist, dass p120CTN für die Stabilität des Cadherin-Catenin-Komplexes an der Zellmembran verantwortlich ist [Maeda et al., 2006], wurde die subzelluläre Lokalisation von $\beta$-Catenin und die Expression des $\beta$-Catenin-Zielgens MMP-7 in PC-3-Zellen nach Herunterregulierung der LPXN- und p120CTN-Expression untersucht. Der knockdown der LPXN-Expression resultierte in einer Lokalisation von $\beta$-Catenin an der Zellmembran sowie in einer Reduktion der MMP-7-Expression, während der knockdown der p120CTN-Expression eine Lokalisation von

$\beta$-Catenin im Kern und eine erhöhte MMP-7-Expression zur Folge hatte. Der simultane knockdown der LPXN- und p120CTN-Expression ergab wiederum eine Aufhebung der Einzel-Effekte. Somit konnte p120CTN als Vermittler der LPXN-induzierten Zellmigration und Zellinvasion charakterisiert werden.

Zur Identifizierung von weiteren LPXN-vermittelten Signalwegen, durch die die verstärkte Progression der LPXN-überexprimierenden PCa erklärt werden könnte, wurde zum Einen ein 
whole genome Microarray an Prostatamaterial von LPXN/TRAMP- und TRAMP-Mäusen und zum Anderen ein Antikörper-Array an PC-3-Zellen mit herunterregulierter LPXN-Expression durchgeführt. Die Auswertung des whole genome Microarrays ergab eine herunterregulierte Expression der Cystathione-beta-Synthase (Cbs) und eine hochregulierte Expression von HOP homeobox (Hopx) im Tumormaterial von LPXN/TRAMP-Mäusen im Vergleich zu Kontrollmäusen. Durch den Antikörper-Array wurden die Kinasen TAK1 und Yes als herunterregulierte Gene nach LPXN-knockdown identifiziert. Die weitere Analyse der TAK1vermittelten Signalwege ergab, dass in PC-3-Zellen abhängig von der Stärke der LPXNExpression auch der Phosphorylierungsstatus der downstream von TAK1 stehenden Kinase JNK zunimmt. Die daraufhin durchgeführte Expressionsanalyse der TAK1-JNK-ATF-2Zielgene Maspin und Presenilin1 ergab in PCa-Zellen mit herunterregulierter LPXNExpression eine signifikante Herunterregulierung der Maspin- und Presenilin1-Expression. Eine Analyse des Phosphorylierungsstatus der Kinasen der SRC-Familie ergab weiterhin, dass eine verminderte LPXN-Expression auch eine reduzierte Phosphorylierung und damit eine reduzierte Aktivität dieser Kinasen zur Folge hat.

Weiterhin wurde im Rahmen dieser Arbeit die Interaktion von LPXN und dem Aktinbindenen Protein Caldesmon, welches bereits mit der Invasionsfähigkeit von Karzinomzellen in Verbindung gebracht wurde [Yoshio et al., 2007], verifiziert und weiter analysiert. In PC-3-Zellen wurde subzellulär eine Lokalisation von Caldesmon an den F-Aktin-Fasern sowie eine Kolokalisation von LPXN und Caldesmon an den focal adhesion sites beobachtet. Nach Herunterregulierung der Caldesmon-Expression wurde in PC-3- und DU 145-Zellen eine erhöhte Migrations- und Invasionsfähigkeit, jedoch keine veränderte Proliferation der Zellen nachgewiesen. Die LPXN-Expression nimmt keinen Einfluss auf die Expression von Caldesmon, sondern ausschließlich auf dessen Phosphorylierungsstatus. Eine verminderte LPXN-Expression korrelierte mit einer verringerten Phosphorylierung von Caldesmon, was zu einer Reduktion der Migrationsfähigkeit der PCa-Zellen führte.

Da die Progression von Karzinomen weitgehend von den adhäsiven Eigenschaften der Zellen abhängt, wurde weiterhin im Rahmen dieser Arbeit untersucht, welchen Einfluss LPXN auf das Adhäsionsverhalten der PCa-Zellen ausübt. Die etablierten PCa-Zelllinien PC-3 und DU 145 mit herunterregulierter LPXN-Expression sowie die murinen LPXN/TRAMPPrimärzellen zeigten im Vergleich zu Kontrollzellen in Abhängigkeit der LPXN-Expression eine veränderte Adhäsionsfähigkeit sowie Ausbreitung. Da bei der für die Adhärenz und Ausbreitung der Zellen notwendigen Umstrukturierung des Zytoskeletts vor allem die Familie der kleinen Rho-GTPasen eine Rolle spielen, wurden die Aktivitäten von RhoA und Rac1 in 
PC-3-Zellen mit verminderter LPXN-Expression bestimmt. Es konnte gezeigt werden, dass bei verminderter LPXN-Expression eine verringerte RhoA- und eine verstärkte Rac1Aktivität zu verzeichnen ist.

Zusammenfassend konnte im Rahmen dieser Arbeit LPXN als ein Protein identifiziert werden, welches die Progression von PCa verstärkt. Verschiedene ermittelte LPXNabhängige Signalwege geben Erkärungen für diese verstärkte Progression sowie Hinweise auf mögliche Therapieansätze für Patienten mit einem PCa. 


\section{Literaturverzeichnis}

Abate-Shen C and Shen MM (2000). "Molecular genetics of prostate cancer." Genes Dev 14(19): $2410-2434$

Adachi Y, Yamamoto H, Itoh F, Hinoda Y, Okada Y, Imai K (1999). "Contribution of matrilysin (MMP-7) to the metastatic pathway of human colorectal cancers." Gut 45: 252258

Adam LP, Gapinski CJ, Hathaway DR (1992). "Phosphorylation sequences in h-caldesmon from phorbol ester-stimulated canine aortas." FEBS Lett 302(3): 223-226

Adler HL, McCurdy MA, Kattan MW, Timme TL, Scardino PT, Thompson TC (1999). "Elevated levels of circulating interleukin-6 and transforming growth factor-beta1 in patients with metastatic prostatic carcinoma." J Urol 161(1): 182-187

Altan ZM and Fenteany $G$ (2004). "c-Jun N-terminal kinase regulates lamellipodial protrusion and cell sheet migration during epithelial wound closure by a gene expressionindependent mechanism.” Biochem Biophys Res Commun 322(1): 56-67

Altschul SF, Gish W, Miller W, Myers EW, Lipman DJ (1990). "Basic local aligment search tool." J Mol Biol 215(3): 403-410

Anastasiadis PZ, Moon SY, Thorensen MA, Mariner DJ, Crawford HC, Zheng Y, Reynolds AB (2000). “Inhibition of RhoA by p120 catenin.” Nat Cell Biol 2: 637-644

Anastasiadis PZ (2007). "p120-ctn: A nexus for contextual signaling via Rho GTPases." Biochim Biophys Acta 1773(1): 34-46

Baki L, Marambaud P, Efthimiopoulos S, Georgakopoulos A, Wen P, Cui W, Shioi J, Koo E, Ozawa M, Friedrich VL Jr, Robakis NK (2001). "Presenilin-1 binds cytoplasmic epithelial cadherin, inhibits cadherin/p120 association, and regulates stability and function of the cadherin/catenin adhesion complex." Proc Natl Acad Sci USA 98(5): 2381-2386 
Beckemeyer S (2007). “Analysen von Leupaxin und seiner Interaktionspartner auf das Progressionsverhalten von Prostatakarzinomzellen" Institut für Humangenetik, GeorgAugust-Universität, Göttingen.

Becker KF, Atkinson MJ, Reich U, Becker I, Nekarda H, Siewert JR, Höfler H (1994). "E-Cadherin gene mutation provide clues to diffuse type gastric carcinomas." Cancer Res. 54: $3845-3852$

Becker-Hapak M, McAllister SS, Dowdy SF (2001). "TAT-mediated protein transduction into mammalian cells." Methods 24(3): 247-56

Behrens J, Mareel MM, Van Roy FM, Birchmeier W (1989). "Dissecting tumor cell invasion: epithelial cells acquire invasive properties after the loss of uvomorulin-mediated cell-cell adhesion.“ J Cell Biol 108: 2435-2447

Behrens J, von Kries JP, Kühl M, Bruhn L, Wedlich D, Grosschedl R, Birchmeier W (1996). "Functional interaction of beta-catenin with the transcription factor LEF-1." Nature 382(6592): 638-642

Berx G and Van Roy F (2001). "The E-Cadherin/catenin complex: an important gatekeeper in breast cancer tumorigenesis and malignant progression." Breast cancer Res 3: 289-293

Bienz M and Clevers H (2000). "Linking colorectal cancer to Wnt signaling." Cell 103: 311320

Birchmeier W and Behrens J (1994). "Cadherin expression in carcinomas: role in the formation of cell junctions and the prevention of invasivness." Biochim Biophys Acta 1198: $11-26$

Bogenrieder T and Herlyn M (2003). "Axis of evil: Molecular mechanisms of cancer metastasis." Oncogene 22: 6524-6536

Bolon I, Devouassoux M, Robert C, Moro D, Brambilla C, Brambilla E (1997). "Expression of urokinase-type plasminogen activator, stromelysin 1, stromelysin 3, and matrilysin genes in lung carcinomas." Am J Pathol 150: 1619-1629 
Bouck N, Stellmach V, Hsu SC (1996). „How tumors become angiogenic.” Adv Cancer Res 69: 135-174 Review

Bowden ET, Coopman PJ, Mueller SC (2001). "Invadopodia: unique methods for measurement of extracellular matrix degradation in vitro." Methods Cell Biol 63: 613-627

Bradford MM (1976). "A rapid and sensitive method for the quantitation of microgram quantities of protein utilizing the principle of protein-dye binding." Anal Biochem 72: 248254

Brembeck FH, Rosario M, Birchmeier W (2006). "Balancing cell adhesion and Wnt signaling, the key role of $\beta$-catenin." Curr Opin In Genetics \& Development 16: 51-59

Bremnes RM, Veve R, Gabrielson E, Hirsch FR, Baron A, Bemis L, Gemmill RM, Drabkin HA, Franklin WA (2002). "High-throughput tissue microarray analysis used to evaluate biology and prognostic significance of the E-cadherin pathway in non-small-cell lung cancer." J Clin Oncol 20(10): 2417-2412

Brown MC, Curtis MS, Turner CE (1998). "Paxillin LD motifs may define a new family of protein recognition domains." Nat Struct Biol. 5: 677-678

Brown MC, Perrotta JA, Turner CE (1998b). "Identification of LIM3 as the principal determinant of paxillin focal adhesion localization and characterization of a novel motif on paxillin directing vinculin and focal adhesion kinase binding.“ Mol Biol Cell 9: 1803-1816

Brown S, Coghill ID, McGrath MJ, Robinson PA (2001). "Role of LIM domains in mediating signaling protein interactions.“ IUBMB Life 51(6): 359-364 Review.

Bryant DM and Stow JL (2004). “The ins and outs of E-cadherin trafficking." Trends Cell Biol 14: 427-434

Caca K, Kolligs FT, Ji X, Hayes M, Qian J, Yahanda A, Rimm DL, Costa J, Fearon ER (1999). "Beta- and gamma-catenin mutations, but not E-cadherin inactivation, underlie T-cell factor/lymphoid enhancer factor transcriptionalderegulation in gastric and pancreatic cancer." Cell Growth Differ 10: 369-376 
Castano J, Solanas G, Casagolda D ,Raurell I, Villagrasa P, Bustelo XR, Garcia de Herreros A, Dunach M (2007). "Specifi c phosphorylation of p120-catenin regulatory domain differently modulates its binding to RhoA." Mol Cell Biol 27: 1745-1757

Catz SD and Johnson JL (2003). "BCL-2 in prostate cancer: a minireview." Apoptosis 8(1): 29-37

Cavarretta IT, Neuwirt H, Untergasser G, Moser PL, Zaki MH, Steiner H, Rumpold H, Fuchs D, Hobisch A, Nemeth JA et al. (2007). "The antiapoptotic effect of IL-6 autocrine loop in a cellular model of advanced prostate cancer is mediated by Mcl-1." Oncogene 26: 2822-2832

Charras GT, Yarrow JC, Horton MA, Mahadevan L, Mitchison TJ (2005). "Nonequilibration of hydrostatic pressure in blebbing cells." Nature 435: 365-369

Chen CD, Welsbie DS, Tran C, Baek SH, Chen R, Vessella R, Rosenfeld MG and Sawyers CL (2004). "Molecular determinants of resistance to antiandrogen therapy." Nat Med 10: 33-39

Chen WT, Chen JM, Parsons SJ, Parsons JT (1985). „Local degradation of fibronectin at sites of expression of the transforming gene product pp60src." Nature 316: 156-158

Chetty R, Jain D, Serra S (2008). “p120 catenin reduction and cytoplasmic relocalization leads to dysregulation of E-cadherin in solid pseudopapillary tumors of the pancreas." Am J Clin Pathol 130(1): 71-76

Chew V and Lam K-P (2007). "Leupaxin negatively regulates B cell receptor signaling." J Biol Chem 282(37): 27181-27191

Cogoni C and Macino G (2000). "Post-transcriptional gene silencing across kingdoms." Curr Opin Genet Dev 10(6): 638-643

Cohen MB, Grieblin TL, Ahghotu CA, Rokhlin OW, Ross JS (1997). “Cellular adhesion molecules in urologic malignancies." Amer J Clin Path 107(1): 56-63

Cunningham CC (1995). “Actin polymerization and intracellular solvent $\mathrm{fl}$ ow in cell surface blebbing." J Cell Biol 129: 1589-1599 
D'Angelo G, Graceffa P, Wang CA, Wrangle J, Adam LP (1999). "Mammal-specific, ERK-dependent, caldesmon phosphorylation in smooth muscle. Quantitation using novel antiphosphopeptide antibodies." J Biol Chem 274(42): 30115-30121

Dai HP, Xue YQ, Zhou JW, Li AP, Wu YF, Pan JL, Wang Y, Zhang J (2009). "LPXN, a member of the paxillin superfamily, is fused to RUNX1 in an acute myeloid leukemia patient with a $\mathrm{t}(11 ; 21)(\mathrm{q} 12 ; \mathrm{q} 22)$ translocation. “ Genes Chromosomes Cancer 48(12): 1027-1036

Davis RJ (2000). “Signal transduction by the JNK group of MAP kinases.” Cell 103(2): 239252 Review

Davis MA, Ireton RC, Reynolds AB (2003). “A core function for p120-catenin in cadherin turnover" J Cell Biol 163: 525-534

Davis MA and Reynolds AB (2006). "Blocked acinar development, E-cadherin reduction, and intraepithelial neoplasia upon ablation of p120-catenin in the mouse salivary gland. Dev Cell 10: 21-31

DeCaprio JA, Ludlow JW, Figge J, Shew JY, Huang CM, Lee WH, Marsilio E, Paucha E, Livingston DM (1988). "SV40 large timor antigen forms a specific complex with the product of the retinoblastoma susceptibility gene." Cell 17: 275-283

De Marzo AM, Nelson WG, Meeker AK, Coffey DS (1998). "Stem cell features of benign and malignant prostate epithelial cells." J Urol 160(6 Pt 2): 2381-2392

Derynck R and Akhurst RJ (2007). "Differentiation plasticity regulated by TGF-beta family proteins in development and disease." Nat Cell Biol 9(9): 1000-1004

Derynck R and Zhang YE (2003). "Smad-dependent and Smad-independent pathways in TGF-beta family signalling." Nature 425(6958): 577-584

Derksen PW, Liu X, Saridin F, van der Gulden H, Zevenhoven J, Evers B, van Beijnum JR, Griffioen AW, Vink J, Krimpenfort P et al. (2006). "Somatic inactivation of Ecadherin and p53 in mice leads to metastatic lobular mammary carcinoma through induction of anoikis resistance and angiogenesis." Cancer Cell 10(5): 437-449 
Downing JR and Reynolds AB (1991). "PDGF, CSF-1, and EGF induce tyrosine phosphorylation of p120, a pp60src transformation-associated substrate" Oncogene 6(4): 607613

Drachenberg DE, Elgamal AA, Rowbotham R, Peterson M, Murphy GP (1999). "Circulating levels of interleukin-6 in patients with hormone refractory prostate cancer." Prostate 41(2): 127-133

Duivenvoorden WC, Hirte HW, Singh G. (1999). „Transforming growth factor betal acts as an inducer of matrix metalloproteinase expression and activity in human bonemetastasizing cancer cells." Clin Exp Metastasis 17: 27-34

Edwards J and Bartlett JM (2005a). "The androgen receptor and signal-transduction pathways in hormone-refractory prostate cancer. Part 1: Modifications to the androgen receptor.” BJU Int 95(9): 1320-1326

Edwards J and Bartlett JM (2005b). "The androgen receptor and signal-transduction pathways in hormone-refractory prostate cancer. Part 2: Androgen-receptor cofactors and bypass pathways.” BJU Int 95(9): 1320-1326

Elbashir SM, Harborth J, Lendeckel W, Yalcin A, Weber K, Tuschl T (2001a). "Duplexes of 21-nucleotide RNAs mediate RNA interference in cultured mammalian cells." Nature 411(6836): 494-498

Elbashir SM, Lendeckel W, Tuschl T (2001b). "RNA interference is mediated by 21- and 22-nucleotide RNAs." Genes Dev 15(2): 188-200

Etienne-Manneville S (2004). “Cdc42--the centre of polarity.” J Cell Sci. 117(Pt 8): 12911300

Fackler OT and Grosse R (2008). "Cell motility through plasma membrane blebbing." J Cell Biol 181(6): 879-884

Fini ME, Cook JR, Mohan R, Brinckerhoff CE (1998). "Regulation of matrix metalloproteinase gene expression.” Academic Press 300-356 
Friedl P (2004). "Prespecification and plasticity: shifting mechanisms of cell migration." Curr Opin Cell Biol 16(1): 14-23

Fujimoto N, Yeh S, Kang HY, Inui S, Chang HC, Mizokami A, Chang C (1999). "Cloning and characterization of androgen receptor coactivator, ARA55, in human prostate." J Biol Chem 274(12): 8316-8321

Fujimoto N, Miyamoto H, Mizokami A, Harada S, Nomura M, Ueta Y, Sasagui T, Matsumoto T (2007). "Prostate cancer cells increase androgen sensitivity by increase in nuclear androgen receptor and androgen receptor coactivators; a possible mechanism of hormone-resistance of prostate cancer cells." Cancer Invest. 25(1): 32-37

Foster DB, Huang R, Hatch V, Craig R, Graceffa P, Lehman W, Wang CLA (2004). "Modes of caldesmon binding to actin: sites of caldesmon contact and modulation of interactions by phosphorylation.” J Biol Chem 279(51): 53387-53394

Fujimoto N, Yeh S, Kang HY, Inui S, Chang HC, Mizokami A, Chang CJ (1999). "Cloning and characterization of androgen receptor coactivator, ARA55, in human prostate." Biol Chem 274(12): 8316-8321

Fukata M, Nakagawa M, Kaibuchi K (2003). „Roles of Rho-family GTPases in cell polarisation and directional migration." Curr Opin Cell Biol 15(5): 590-597 Review

Gaddipati JP, McLeod DG, Heidenberg HB, Sesterhenn IA, Finger MJ, Moul JW, Srivastava S (1994). "Frequent detection of codon 877 mutation in the androgen receptor gene in advanced prostate cancers." Cancer Res 54: 2861-2864

Gadea G, de Toledo M, Anguille C, Roux P (2007). "Loss of p53 promotes RhoA-ROCKdependent cell migration and invasion in 3D matrices." J Cell Biol 178(1): 23-30

Gershoni JM and Palade GE (1982). "Electrophoretic transfer of proteins from sodium dodecyl sulfate-polyacrylamide gels to a positively charged membrane filter." Anal Biochem 124(2): 396-405

Gershoni JM and Palade GE (1983). "Protein blotting: priciples and applications." Anal Biochem 131(1): 1-15 
Giambernardi TA, Grant GM, Taylor GP, Hay RJ, Maher VM, McCormick JJ, Klebe RJ (1998). "Overview of matrix metalloproteinase expression in cultured human cells." Matrix Biol 16(8): 483-496

Gingrich JR, Barrios RJ, Morton RA, Boyce BF, DeMayo FJ, Finegold MJ, Angelopoulou R, Rosen JM, Greenberg NM (1996). "Metastatic prostate cancer in a transgenic mouse." Cancer Res 56(18): 4096-4102

Gingrich JR, Greenberg NM (1996). “A transgenic mouse prostate cancer model.” Toxicol Pathol 24(4): 502-504

Gingrich JR, Barrios RJ, Kattan MW, Mahm HS, Finegold MJ, Greenberg NM (1997). “Androgen-independentprostate cancer progression in the TRAMP model." Cancer Res 57: $4687-4691$

Gimona M, Buccione R, Courtneidge SA, Linder S (2008). “Assembly and biological role of podosomes and invadopodia." Curr Opin Cell Biol 20: 235-241

Greenberg NM, DeMayo FJ, Sheppard PC, Barrios R, Lebovitz R, Finegold M, Angelopoulou R, Dodd JG, Duckworth ML, Rosen JM et al. (1994). "The rat probasin gene promoter directs hormonally and developmentally regulated expression of a heterologous gene specifically to the prostate in transgenic mice." Mol Endocrinol 8(2): 230239

Greenberg NM, F DeMayo, MJ Finegold, D Medina, WD Tilley, JO Aspinall, GR Cunha, AA Donjacour, RJ Matusik, Rosen JM (1995). "Prostate cancer in a transgenic mouse." Proc Natl Acad Sci U S A 92(8): 3439-3443

Gregory CW, He B, Johnson RT, Ford OH, Mohler JL, French FS, Wilson EM (2001). "A mechanism for androgen receptor-mediated prostate cancer recurrence after androgen deprivation therapy" Cancer Res 61(11): 4315-4319

Grossmann ME, Huang H, Tindall DJ (2001). "Androgen receptor signaling in androgenrefractory prostate cancer." J Nat Canc Inst 93: 1687-1697 
Gupta S, Campbell D, De'rijard B, Davis RJ (1995). “Transcription factor ATF2 regulation by the JNK signal transduction pathway." Science 267: 389-393

Gupta A, Lee BS, Khadeer MA, Tang Z, Chellaiah M, Abu-Amer Y, Goldknopf J, Hruska KA (2003). "Leupaxin is a critical adaptor protein in the adhesion zone of the osteoclast" J Bone Miner Res. 18: 669-685

Hai CM and Gu Z (2006). "Caldesmon phosphorylation in actin cytoskeletal remodeling." Eur J Cell Biol 85(3-4): 305-309

Hammond SM, Caudy AA, Hannon GJ (2001). "Post-transcriptional gene silencing by double-stranded RNA." Nat Rev Genet 2(2): 110-119

Han G, Buchanan G, Ittmann M, Harris JM, Yu X, Demayo FJ, Tilley W, Greenberg NM (2005). "Mutation of the androgen receptor causes oncogenic transformation of the prostate." Proc Natl Acad Sci 102: 1151-1156

Hanahan D (1983). "Studies on transformation of Escherichia coli with plasmids." $J \mathrm{Mol}$ Biol 166(4): 557-580

Hanahan D and Weinberg RA (2000). "The hallmarks of cancer." Cell 100(1): 57-70.

Hanahan D and Folkman J (1996). "Patterns and emerging mechanisms of the angiogenic switch during tumorigenesis." Cell. 86(3): 353-364 Review

Hayashi K, Yano H, Hashida T, Takeuchi R, Takeda O, Asada K, Takahashi E, Kato I, Sobue K (1992). "Genomic structure of the human caldesmon gene." Proc Natl Acad Sci USA 89(24): 12122-12126

Hedrick L, Cho K, Vogelein B (1993). "Cell adhesion as tumor suppressors." Trends Cell Biol 3: 36-39

Heppner KJ, Matrisian LM, Jensen RA, Rodgers WH (1996). "Expression of most matrix metalloproteinase family members in breast cancer represents a tumor-induced host response." Am J Pathol 149: 273-282 
Herr A-M (2005). "Analysen zur Expression und Funktion des Leupaxin Gens in humanen Karzinomen." Institut für Humangenetik, Georg-August-Universität, Göttingen.

Herzig M, Savarese F, Novatchkova M, Semb H, Christofori G (2007). "Tumor progression induced by the loss of E-cadherin independent of beta-catenin/Tcf-mediated Wnt signaling." Oncogene 26: 2290-2298

Heinlein CA and Chang C (2004). “Androgen receptor in prostate cancer." Endocr Rev 25: 276-308

Hildebrand JD, Schaller MD, Parsons JT (1995). "Paxillin, a tyrosine phosphorylated focal adhesion-associated protein binds to the carboxyl terminal domain of focal adhesion kinase" Mol Biol Cell 6(6): 637-647

Hobisch A, Eder IE, Putz T, Horninger W, Bartsch G, Klocker H, Culig Z (1998). "Interleukin-6 regulates prostate-specific protein expression in prostate carcinoma cells by activation of the androgen receptor." Cancer Res 58(20): 4640-4645

Hollstein M, Moeckel G, Hergenhahn M, Spiegelhalder B, Keil M, Werle-Schneider G, Bartsch H, Brickmann J (1998). „On the origins of tumor mutations in cancer genes: insights from the p53 gene." Mutat Res 405: 145-54

Holly SP, Larson MK, Parise LV (2000). "Multiple roles of integrins in cell motility." Exp Cell Res 261(1): 69-74 Review

Hornebeck W, Emonard H, Monboisse JC, Bellon G (2002). "Matrix-directed regulation of pericellular proteolysis and tumor progression." Semin Cancer Biol 12(3): 231-241 Review

Horoszewics JS, Leong SS, Kawinski E, Karr JP, Rosenthal H, Chu TM, Mirand EA, Murphy GP (1983). "LNCaP model of human prostatic carcinoma" Cancer Res 43(4): 18091818

Huang R, Li L, Guo H, Wang CL (2003). „Caldesmon binding to actin is regulated by calmodulin and phosphorylation via different mechanisms.” Biochemistry 42(9): 2513-2523 
Huber PA, Gao Y, Fraser ID, Copeland O, EL-Mezgueldi M, Slatter DA, Keane NE, Marston SB, Levine BA (1998). "Structure-activity studies of the regulatory interaction of the 10 kilodalton $\mathrm{C}$-terminal fragment of caldesmon with actin and the effect of mutation of caldesmon residues." Biochemistry 37(8): 2314-2326

Huggins C and Hodges CV (1972). "Studies on prostatic cancer. I. The effect of castration, of estrogen and androgen injection on serum phosphatases in metastatic carcinoma of the prostate." CA Cancer J Clin 22(4): 232-240

Hutvagner G and PD Zamore (2002). "RNAi: nature abhors a double-strand." Curr Opin Genet Dev 12(2): 225-32

Ichikawa Y, Ishikawa T, Momiyama N, Kamiyama M, Sakurada H, Matsuyama R, Hasegawa S, Chishima T, Hamaguchi Y, Fujii S (2006). "Matrilysin (MMP-7) degrades VE-cadherin and accelerates accumulation of beta-catenin in the nucleus of human umbilical vein endothelial cells." Oncol Rep 15(2): 311-315

Jaffe AB and Hall A (2005). "Rho GTPases: biochemistry and biology." Annu Rev Cell Dev Biol 21: 247-269

Jaggi M, Johansson SL, Baker JJ, Smith LM, Galich A, Balaji KC (2005). “Aberrant expression of E-cadherin and beta-catenin in human prostate cancer." Urol Oncol 23(6): 402406

Jennings MT and Pietenpol JA (1998). "The role of transforming growth factor $\beta$ in glioma progression.” J Neurooncol 36: 123-140

Johnson MA, Iversen P, Schwier P, Corn AL, Sandusky G, Graff J, Neubauer BL (2005). "Castration triggers growth of previously static androgen-independentlesions in the transgenic adenocarcinoma ofthe mouse prostate (TRAMP) model.” Prostate 62: 322-338

Kaighn ME, Narayan KS, Ohnuki Y, Lechner JF, Jones LW (1979). "Establishment and characterization of a human prostatic carcinoma cell line (PC-3)." Invest Urol 17(1): 16-23 
Kallakury BV, Sheehan CE, Winn-Deen E, Oliver J, Fisher HA, Kaufman RP, Ross JS (2001). "Decreased expression of catenins (alpha and beta), p120 CTN, and E-cadherin cell adhesion proteins and E-cadherin gene promoter methylation in prostatic adenocarcinomas." Cancer 92(11): 2786-95

Kallakury BV, Sheehan CE, Ross JS (2001 b). "Co-downregulation of cell adhesion proteins alpha- and beta-catenins, p120CTN, E-cadherin, and CD44 in prostatic adenocarcinomas." Hum Pathol 32(8): 849-558

Karayiannakis AJ, Syrigos KN, Efstathiou J, Valizadeh A, Noda M, Playford RJ, Kmiot W, Pignatelli MJ (1999). "Expression of catenins and E-cadherin during epithelial restitution in inflammatory bowel disease." Pathol 185(4): 413-418

Karelina TV, Goldberg GI, Eisen AZ (1994). "Matrilysin (PUMP) correlates with dermal invasion during appendageal development and cutaneous neoplasia." J Invest Dermatol 103: $482-487$

Kaulfuß S (2006). “Zur Funktion von Leupaxin beim Karzinom der Prostata.” Institut für Humangenetik, Georg-August-Universität, Göttingen

Kaulfuß S, von Hardenberg S, Schweyer S, Herr AM, Laccone F, Wolf S, Burfeind P (2009). "Leupaxin acts as a mediator in prostate carcinoma progression through deregulation of p120catenin expression." Oncogene 28(45): 3971-3982

Kim SI, Kwak JH, Zachariah M, He Y, Wang L, Choi ME (2007). "TGF-beta-activated kinase 1 and TAK1-binding protein 1 cooperate to mediate TGF-beta1-induced MKK3-p38 MAPK activation and stimulation of type I collagen." Am J Physiol Renal Physiol 292(5): $1471-1478$

Kim J, Hong SJ, Park JH, Park SY, Kim SW, Cho EY, Do IG, Joh JW, Kim DS (2009). "Expression of cystathionine beta-synthase is downregulated in hepatocellular carcinoma and associated with poor prognosis." Oncol Rep 21(6): 1449-1454

Kishimoto K, Matsumoto K, Ninomiya-Tsuji J (2000). “TAK1 mitogen-activated protein kinase kinase kinase is activated by autophosphorylation within its activation loop." $J$ Biol Chem 275: 7359-7364 
Kitzing TM, Sahadevan AS, Brandt DT, Knieling H, Hannemann S, Fackler OT, Grosshans J, Grosse R (2007). "Positive feedback between Dia1, LARG, and RhoA regulates cell morphology and invasion." Genes Dev 21: 1478-1483

Kordowska J, Huang R, Wang CL (2006). "Phosphorylation of caldesmon during smooth muscle contraction and cell migration or proliferation." J Biomed Sci 13(2): 159-172

Kordowska J, Hetrick T, Adam LP, Wang CL (2006). "Phosphorylated 1-caldesmon is involved in disassembly of actin stress fibers and postmitotic spreading." Exp Cell Res 312(2): $95-110$

Kosa JL, Michelsen JW, Louis HA, Olsen J I, Davis DR, Beckerle MC, Winge DR (1994). "Common metal ion coordination in LIM domain proteins." Biochemistry 33: 468477

Koss LG (2005). “Localized prostate cancer and DNA ploidy.” JAMA 294(10): 1207-1208

Kowalski PJ, Rubin MA, Kleer CG (2003). "E-Cadherin expression in primary carcinomas of the breast and its distant metastases." Breast Cancer Res 5: 217-222

Lane DP and Crawford LV (1979). "T-antigen is bound to host proteins in SV-40 transformed cells." Nature 278: 261-263

Laemmli UK (1970). "Cleavage of structural proteins during the assembly of the head of bacteriphage T4." Nature 227(5259): 680-685

Lee MH, Koria P, Qu J, Andreadis ST (2009). "JNK phosphorylates beta-catenin and regulates adherens junctions." FASEB J 23(11): 3874-3883

Lemaître $\mathbf{V}$ and D'Armiento $\mathbf{J}$ (2006). "Matrix metalloproteinases in development and disease." Birth Defects Res C Embryo Today 78(1): 1-10

Levy L and Hill CS (2006). "Alterations in components of the TGFbeta superfamily signaling pathways in human cancer." Cytokine Growth Factor Rev 17: 41-58 
Lin HK, Yeh S, Kang HY, Chang C (2001). “Akt suppresses androgen-induced apoptosis by phosphorylating and inhibiting androgen receptor." Proc Natl Acad Sci USA 98: 72007205

Lin HK, Hu YC, Yang L, Altuwaijri S, Chen YT, Kang HY, Chang C (2003). "Suppression versus induction of androgen receptor functions by the phosphatidylinositol 3kinase/Akt pathway in prostate cancer LNCaP cells with different passage numbers." J Biol Chem 278: 50902-50907

Li Y, Reznichenko M, Tribe RM, Hess PE, Taggart M, Kim H, DeGnore JP, Gangopadhyay S, Morgan KG (2009). "Stretch activates human myometrium via ERK, caldesmon and focal adhesion signaling." PLoS One 4(10): e7489

Linder S (2007). "The matrix corroded: podosomes and invadopodia in extracellular matrix degradation." Trends Cell Biol 17: 107-117

Linzer DIH and Levine AJ (1979). "Characterization of a 54 kDalton cellular SV40 tumor antigen present in SV40-transformed cells and uninfected embryonal carcinoma cells." Cell 17: $43-52$.

Liotta LA and Stetler-Stevenson WG (1990). "Metalloproteinases and cancer invasion." Cancer Biol 1: 99-106

Lipsky BP, Beals CR, Staunton DE (1998). "Leupaxin is a novel LIM domain protein that forms a complex with PYK2." J Biol Chem 273(19): 11709-11713

Liu S, Kiosses WB, Rose DM, Slepak M, Salgia R, Griffin JD, Turner CE, Schwartz MA, Ginsberg MH (2002). "A fragment of paxillin binds the alpha 4 integrin cytoplasmic domain (tail) and selectively inhibits alpha 4-mediated cell migration." J Biol Chem 277(23): 20887-20894

Liu Y, Li QC, Miao Y, Xu HT, Dai SD, Wei Q, Dong QZ, Dong XJ, Zhao Y, Zhao C, Wang EH (2009). “Ablation of p120-catenin enhances invasion and metastasis of human lung cancer cells." Cancer Sci 100(3): 441-448 
Livingstone C, Patel G, Jones N (1997). "ATF-2 contains a phosphorylation-dependent transcriptional activation domain.” EMBO J 14: 1785-1797

Lochter A, Galosy S, Muschler J, Freedman N, Werb Z, Bissell MJ (1997). "Matrix metalloproteinase stromelysin- 1 triggers a cascade of molecular alterations that leads to stable epithelial-tomesenchymal conversion and a premalignant phenotype in mammary epithelial cells." J Cell Biol 139: 1861-1872

Lu W, Tinsley HN, Keeton A, Qu Z, Piazza GA, Li Y (2009). "Suppression of Wnt/betacatenin signaling inhibits prostate cancer cell proliferation.” Eur J Pharmacol 602(1): 8-14

Maeda M, Johnson E, Mandal SH, Lawson KR, Keim SA, Svoboda RA, Caplan S, Wahl JK III, Wheelock MJ, Johnson KR (2006). "Expression of inappropriate cadherins by epithelial tumor cells promotes endocytosis and degradation of E-cadherin via competition for p120(ctn)." Oncogene 25: 4595-4604

Malinowska K, Neuwirt H, Cavarretta IT, Bektic J, Steiner H, Dietrich H, Moser PL, Fuchs D, Hobisch A, Culig Z (2009). "Interleukin-6 stimulation of growth of prostate cancer in vitro and in vivo through activation of the androgen receptor." Endocrine-Related Cancer 16: $155-169$

Maniatis T and Efstratiadis A (1980). "Fractionation of low molecular weight DNA or RNA in polyacrylamide gels containing 98\% formamide or 7 M urea." Methods Enzymol 65(1): 299-305

Mariner DJ, Anastasiadis P, Keilhack H, Böhmer FD, Wang J, Reynolds AB (2001). "Identification of Src phosphorylation sites in the catenin p120ctn." J Biol Chem 276(30): 28006-28013

Massague J (2006). “The logic of TGF-beta signalling.” Febs Journal 273: 2-12

Matias PM, Carrondo MA, Coelho R, Thomaz M, Zhao XY, Wegg A, Crusius K, Egner U, Donner P (2002). "Structural basis for the glucocorticoid response in a mutant human androgen receptor (AR(ccr)) derived from an androgen-independent prostate cancer." J Med Chem 45(7): 1439-1446 
McDonnell TJ, Troncoso P, Brisbay SM, Logothetis C, Chung LW, Hsieh JT, Tu SM, Campbell ML (1992). "Expression of the protooncogene bcl-2 in the prostate and its association with emergence of androgen-independent prostate cancer." Cancer Res 52(24): 6940-6944

Mege RM, Gavard J, Lambert M. (2006). "Regulation of cell-cell junctions by the cytoskeleton." Curr Opin Cell Biol 18: 541-548

Mestayer C, Blanchere M, Jaubert F, Dufour B, Mowszowics I (2003). "Expression of androgen receptor coactivators in normal and cancer prostate tissues and cultured cell lines." Prostate 56(3): 192-200

Michelsen JW, Sewell AK, Louis HA, Olsen JI, Davis DR, Winge DR, Beckerle MC (1994). "Mutational analysis of the metal sites in an LIM domain." J Biol Chem 269: 1110811113

Mickey DD, Stone KR, Wunderli H, Mickey GH, Vollmer RT, Paulson DF (1977). „Heterotransplantation of a human prostatic adenocarcinoma cell line in nude mice. “ Cancer Res 37(11): 4049-4058

Mira E, Manes S, Lacalle RA, Marquez G, Martinez AC (1999). "Insulin-like growth factor I-triggered cell migration and invasion are mediated by matrix metalloproteinase-9." Endocrinology 140: 1657-1664

Moustakas A and Heldin CH (2005). "Non-Smad TGF-beta signals." J Cell Sci 118(Pt 16): 3573-3584

Murphy $G$ and Nagase $H$ (2008). "Progress in matrix metalloproteinase research." Mol Aspects Med 29(5): 290-308

Nakopoulou L, Zervas A, Gakiopoulou-Givalou H, Constantinides C, Doumanis G, Davaris P, Dimopoulos C (2000). "Prognostic value of E-cadherin, beta-catenin, p120ctn in patients with transitional cell bladder cancer." Anticancer Res 20(6B): 4571-4578 
Neil JR and Schiemann WP (2008). “Altered TAB1:I kappaB kinase interaction promotes transforming growth factor beta-mediated nuclear factor-kappaB activation during breast cancer progression." Cancer Res 68(5): 1462-1470

Ngai PK and Walsh MP (1984). "Inhibition of smooth muscle actin-activated myosin Mg2+-ATPase activity by caldesmon.” J Biol Chem 259(22): 13656-13659

Nobes C and Hall A (1995). "Rho, Rac, and Cdc42 GTPases regulate the assembly of multimolecular focal complexes associated with actin stress fibers, lamellipodia, and filopodia." Cell. 81: 53-62

Noe V, Fingleton B, Jacobs K, Crawford HC, Vermeulen S, Steelant W, Bruyneel E, Matrisian LM, Mareel M (2001). "Release of an invasion promoter Ecadherin fragment by matrilysin and stromelysin-1." J Cell Sci 114: 111-118

Noren NK, Liu BP, Burridge K, Kreft B (2000). "p120 catenin regulates the actin cytoskeleton via Rho family GTPases.” J Cell Biol 150(3): 567-580

Ohnuki Y, Marnell Mm, Babcock MS, Lechner JF, Kaighn ME (1980). "Chromosomal analysis of human prostatic adenocarcinoma cell lines.” Cancer Res 40(3): 524-534

Okegawa T, Li Y, Pong RC, Hsieh JT (2002). "Cell adhesion proteins as tumor suppressors." J Urol 167(4): 1836-1843

Ooki A, Yamashita K, Kikuchi S, Sakuramoto S, Katada N, Kokubo K, Kobayashi H, Kim MS, Sidransky D, Watanabe M (2010). "Potential utility of HOP homeobox gene promoter methylation as a marker of tumor aggressiveness in gastric cancer." Oncogene [Epub ahead of print]

Ozawa M, Baribault H, Kemler R (1989). "The cytoplasmic domain of the cell adhesion molecule uvomorulin associates with three independent proteins structurally related in different species.” EMBO J 8: 1711-1717

Pajouh MS, Nagle RB, Breathnach R, Finch JS, Brawer MK, Bowden GT (1991). "Expression of metalloproteinase genes in human prostate cancer." J Cancer Res Clin Oncol 117: $144-150$ 
Peifer M (1993). “Cancer, catenins, and cuticle pattern: a complex connection. Science 262(5140): 1667-1668

Perez-Alvarado GC, Miles C, Michelsen, JW, Louis HA, Winge, DR, Beckerle MC, Summers MF (1994). "Structure of the carboxy-terminal LIM domain from the cysteine rich protein CRP.“ Nat Struct Bio. 1: 388-398

Perez-Moreno M, Davis MA, Wong E, Pasolli HA, Reynolds AB, Fuchs E (2006). "p120catenin mediates infl ammatory responses in the skin." Cell 124: 631-644

Perez-Moreno M, Song W, Pasolli HA, Williams SE, Fuchs E (2008). "Loss of p120 catenin and links to mitotic alterations, inflammation, and skin cancer." Proc Natl Acad Sci USA 105(40): 15399-15404

Raffo AJ, Perlman H, Chen MW, Day ML, Streitman JS, Buttyan R. (1995). "Overexpression of bcl-2 protects prostate cancer cells from apoptosis in vitro and confers resistance to androgen depletion in vivo." Cancer Res 55(19): 4438-4445

Reynolds AB, Roesel DJ, Kanner SB, Parsons JT (1989). „Transformation-specific tyrosine phosphorylation of a novel cellular protein in chicken cells expressing oncogenic variants of the avian cellular src gene.” Mol Cell Biol 9(2): 629-638

Reynolds AB, Daniel J, McCrea PD, Wheelock MJ, Wu J, Zhang Z (1994). "Identification of a new catenin: the tyrosine kinase substrate p120cas associates with Ecadherin complexes." Mol Cell Biol 14(12): 8333-8342

Ridley AJ and Hall A (1992). "The small GTP-binding protein rho regulates the assembly of focal adhesions and actin stress fibers in response to growth factors." Cell 70: 389-399

Ridley AJ, Paterson HF, Johnston CL, Diekman D, Hall A (1992). "The small GTPbinding protein rac regulates growth factor-induced membrane ruffling." Cell 70: 401-410

Sadot E, Simcha I, Shtutman M, Ben-Ze'ev A, Geiger B (1998). "Inhibition of betacatenin-mediated transactivation by cadherin derivatives.” Proc Natl Acad Sci 95: 1533915344. 
Sahai E and Marshall CJ (2003). "Differing modes of tumour cell invasion have distinct requirements for Rho/ROCK signalling and extracellular proteolysis." Nat Cell Biol 5(8): 711-719

Sahu SN, Khadeer MA, Robertson BW, Núñez SM, Bai G, Gupta A (2007). “Association of leupaxin with Src in osteoclasts." Am J Physiol Cell Physiol 292(1): C581-590

Sahu SN, Nunez S, Bai G, Gupta A (2007). "Interaction of Pyk2 and PTP-PEST with leupaxin in prostate cancer cells.“ Am J Physiol Cell Physiol. Prostate 62(4): 322-338

Saiki RK, Scharf S, Faloona F, Mullis KB, Horn GT, Erlich HA, Arnheim N (1985). "Enzymatic amplification of beta-globin genomic sequences and restriction site analysis for diagnostic of sickle cell anemia." Science 230(4732): 1350-1354

Sakurai H, Miyoshi H, Toriumi W, Sugita T (1999). "Functional interactions of TGF- $\beta$ -

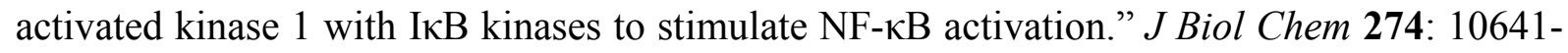
10648

Sakurai H, Nishi A, Sato N, Mizukami J, Miyoshi H, Sugita T (2002). "TAK1-TAB1 fusion protein: a novel constitutively active mitogen-activated protein kinase kinase kinase that stimulates AP-1 and NF-кB signaling pathways." Biochem Biophys Res Commun 297: $1277-1281$

Sambrook J, Fritsch EF, Maniatis T (1989). "Molecular cloning: a laboratory manual.“ New York, USA, Cold Spring Habour.

Santer FR, Malinowska K, Culig Z, Cavarretta IT (2010). "Interleukin-6 trans-signalling differentially regulates proliferation, migration, adhesion and maspin expression in human prostate cancer cells." Endocr Relat Cancer 17(1): 241-253

Sharp PA (2001). "RNA interference-2001." Genes Dev 15(5): 485-490

Sheng S, Carey J, Seftor EA, Dias L, Hendrix MJ, Sager R (1996). "Maspin acts at the cell membrane to inhibit invasion and motility of mammary and prostatic cancer cells." Proc Natl Acad Sci U S A 93(21): 11669 - 11674 
Shi XB, Xue L, Zou JX, Gandour-Edwards R, Chen H, deVere White RW (2008). "Prolonged androgen receptor loading onto chromatin and the efficient recruitment of p160 coactivators contribute to androgen-independent growth of prostate cancer cells." Prostate 68(16): 1816-1826

Shibuya H, Yamaguchi K, Shirakabe K, Tonegawa A, Gotoh Y, Ueno N, Irie K, Nishida E, Matsumoto K (1996). "TAB1: an activator of the TAK1 MAPKKK in TGF-signal transduction." Science 272: 1179-1182

Shields JM, Rogers-Graham K, Der CJ (2002). „Loss of transgelin in breast and colon tumors and in RIE-1 cells by Ras deregulation of gene expression through Raf-independent pathways.” J Biol Chem 277(12): 9790 - 9799

Sobue K and Sellers JR (1991). "Caldesmon, a novel regulatory protein in smooth muscle and nonmuscle actomyosin systems." J Biol Che 266(19): 12115-12118

Song H, Zhang B, Watson MA, Humphrey PA, Lim H, Milbrandt J (2009). "Loss of Nkx3.1 leads to the activation of discrete downstream target genes during prostate tumorigenesis." Oncogene 28(37): 3307-3319

Sporn MB (1996). “The war on cancer.” Lancet 347(9012): 1377-1381 Review

Stanbrough M, Leav I, Kwan PW, Bubley GJ, Balk SP (2001). "Prostatic intraepithelial neoplasia in mice expressing an androgen receptor transgene in prostate epithelium." Proc Natl Acad Sci 98: 10823-10828

Sternlicht MD and Bergers G (2000). "Matrix metalloproteinases as emerging targets in anticancer therapy: status and prospects.” Emerging Ther Targets 4: 609-633

Stone KR, Mickey DD, Wunderli H, Mickey GH, Paulson DF (1978). "Isolation of a human prostate carcinoma cell line (DU 145)." Int J Cancer 21(3): 274-281

Studier FW and Moffatt BA (1986). "Use of bacteriophage T7 RNA polymerase to direct selective high-level expression of cloned genes." J Mol Biol 189(1): 113-130

Sundareshan P, Nagle RB, Bowden GT (1999). "EGF induces the expression of matrilysin in the human prostate adenocarcinoma cell line LNCaP." Prostate 40: 159-166 
Sundberg-Smith LJ, DiMichele LA, Sayers RL, Mack CP, Taylor JM (2008). „The LIM protein leupaxin is enriched in smooth muscle and functions as an serum response factor cofactor to induce smooth muscle cell gene transcription." Circ Res 102: 1502-1511

Syrigos KN, Karayiannakis A, Syrigou EI, Harrington K, Pignatelli M (1998). "Abnormal expression of p120 correlates with poor survival in patients with bladder cancer." Eur J Cancer 34(13): 2037-2040

Tang Y, Wang L, Goloubeva O, Khan MA, Zhang B, Hussain A (2008). "Divergent effects of castration on prostate cancer in TRAMP mice: possible implications for therapy." Clin Cancer Res 14(10): 2936-2943

Tanzi RE (2008). "Novel therapeutics for Alzheimer's disease.” Neurotherapeutics 5(3): 377380

Thoreson MA, Anastasiadis PZ, Daniel JM, Ireton RC, Wheelock MJ, Johnson KR, Hummingbird DK, Reynolds AB (2000). "Selective uncoupling of p120ctn from E-cadherin disrupts strong adhesion." J Cell Biol 148: 189-201

Tinkle CL, Lechler T, Pasolli HA, Fuchs E (2004). "Conditional targeting of E-cadherin in skin: insights into hyperproliferative and degenerative responses." Proc Natl Acad Sci USA 101: $552-557$

Tournaviti S, Hannemann S, Terjung S, Kitzing TM, Stegmayer C, Ritzerfeld J, Walther P, Grosse R, Nickel W, Fackler OT (2007). "SH4-domain-induced plasma membrane dynamization promotes bleb-associated cell motility." J Cell Sci 120(Pt 21): 38203829

Tremblay L, Hauck W, Aprikian AG, Begin LR, Chapdelaine A, Chevalier S (1996). "Focal adhesion kinase (pp125FAK) expression, activation and association with paxillin and p50CSK in human metastatic prostate carcinoma" Int J Cancer 68(2): 164-171

Tunggal JA, Helfrich I, Schmitz A, Schwarz H, Gunzel D, Fromm M, Kemler R, Krieg T, Niessen CM (2005). „E-cadherin is essential for in vivo epidermal barrier function by regulating tight junctions.” EMBO J 24: 1146-1156 
Tuschl, T (2001). "RNA interference and small interfering RNAs." Chembiochem 2(4): 239245

Ueda T, Mawji NR, Bruchovsky N, Sadar MD (2002). "Ligand-independent activation of the androgen receptor by interleukin- 6 and the role of steroid receptor coactivator- 1 in prostate cancer cells." J Biol Chem 277(41): 38087-38094

Ueda T, Bruchovsky N, Sadar MD (2002). “Activation of the androgen receptor N-terminal domain by interleukin-6 via MAPK and STAT3 signal transduction pathways." J Biol Chem 277(9): 7076-7085

van Dam H, Wilhelm D, Herr I, Steffen A, Herrlich P, Angel P (1997). "ATF-2 is preferentially activated by stress-activated protein kinases to mediate c-jun induction in response to genotoxic agents.” EMBO J 14: 31798-31811

van de Wetering M, Barker N, Harkes IC, van der Heyden M, Dijk NJ, Hollestelle A, Klijn JG, Clevers H, Schutte M (2001). „Mutant Ecadherin breast cancer cells do not display constitutive Wnt signaling.” Cancer Res 61: 278-284

van Duin M, van Marion R, Vissers K, Watson JE, van Weerden WM, Schröder FH, Hop WC, van der Kwast TH, Collins C, van Dekken H (2005). “ High-resolution array comparative genomic hybridization of chromosome arm 8q: evaluation of genetic progression markers for prostate cancer." Genes Chromosom Cancer 44: 438-449

VanSaun MN and Matrisian LM (2006). "Matrix metalloproteinases and cellular motility in development and disease." Birth Defects Res C Embryo Today 78(1): 69-79

Veldscholte J, Ris-Stalpers C, Kuiper GG, Jenster G, Berrevoets C, Claassen E, van Rooij HC, Trapman J, Brinkmann AO, Mulder E (1990). "A mutation in the ligand binding domain of the androgen receptor of human LNCaP cells affects steroid binding characteristics and response to anti-androgens.” Biochem Biophys Res Commun 173(2): 534540

Vogelstein B and Kinzler KW (2004). "Cancer genes and the pathways they control." Nat Med 10(8): 789-799 
Wang FQ, So J, Reierstad S, Fishman DA (2005). "Matrilysin (MMP-7) promotes invasion of ovarian cancer cells by activation of progelatinase." Int J Cancer 114: 19-31

Wang LG, Liu XM, Kreis W, Budman DR (1999). "Phosphorylation/dephosphorylation of androgen receptor as a determinant of androgen agonistic or antagonistic activity." Biochem Biophys Res Commun 259(1): 21-28

Wang Y, Dong Q, Zhang Q, Li Z, Wang E, Qiu X (2010). “Overexpression of yesassociated protein contributes to progression and poor prognosis of non-small-cell lung cancer." Cancer Sci [Epub ahead of print]

Weaver AM (2006). "Invadopodia: specialized cell structures for cancer invasion." Clin Exp Metastasis 23: 97-105

Weinberg RA (1995). “The retinoblastoma protein and cell cycle control." Cell 81: 323-330

Wildenberg GA, Dohn MR, Carnahan RH, Davis MA, Lobdell NA, Settleman J, Reynolds AB (2006). "p120-catenin and p190RhoGAP regulate cell-cell adhesion by coordinating antagonism between Rac and Rho." Cell 127: 1027-1039

Wise GJ, Marella VK, Talluri G, Shirazian D (2000). "Cytokine variations in patients with hormone treated prostate cancer." J Urol 164(3 Pt 1): 722-725

Woessner JF and Nagase H (2000). "Matrix Metalloproteinases and TIMPs." New York: Oxford Univ

Xie W, Wang Y, Huang Y, Yang H, Wang J, Hu Z (2009). "Toll-like receptor 2 mediates invasion via activating NF-kappaB in MDA-MB-231 breast cancer cells." Biochem Biophys Res Commun 379(4): 1027-1032

Xiao K, Garner J, Buckley KM, Vincent PA, Chiasson CM, Dejana E, Faundez V, Kowalczyk AP (2005). "p120-Catenin regulates clathrin-dependent endocytosis of VEcadherin.” Mol Biol Cell 16: 5141-5151

Yamaguchi K, Shirakabe K, Shibuya H, Irie K, Oishi I, Ueno N, Taniguchi T, Nishida E, Matsumoto K (1995). "Identification of a member of the MAPKKK family as a potential mediator of TGF-beta signal transduction." Science 270: 2008-2011 
Yamaguchi H, Lorenz M, Kempiak S, Sarmiento C, Coniglio S, Symons M, Segall J, Eddy R, Miki H, Takenawa T, Condeelis J (2005). "Molecular mechanisms of invadopodium formation: the role of the N-WASP-Arp2/3 complex pathway and cofilin." J Cell Biol 168(3): 441-452

Yamaguchi H, Pixley F, Condeelis $\mathbf{J}$ (2006). "Invadopodia and podosomes in tumor invasion.” Eur J Cell Biol 85: 213-218

Yamaguchi S, Asanoma K, Takao T, Kato K, Wake N (2009). "Homeobox gene HOPX is epigenetically silenced in human uterine endometrial cancer and suppresses estrogenstimulated proliferation of cancer cells by inhibiting serum response factor." Int $J$ Cancer 124(11): 2577-2588

Yamashiro S, Yamakita Y, Ishikawa R, Matsumura F (1990). "Mitosis-specific phosphorylation causes $83 \mathrm{~K}$ non-muscle caldesmon to dissociate from microfilaments." Nature 344(6267): 675-678

Yamashiro S, Yamakita Y, Hosoya H, Matsumura F (1991). "Phosphorylation of nonmuscle caldesmon by p34cdc2 kinase during mitosis." Nature 349(6305): 169-172

Yanagisawa M, Huveldt D, Kreinest P, Lohse CM, Cheville JC, Parker AS, Copland JA, Anastasiadis PZ (2008). "A p120 catenin isoform switch affects Rho activity, induces tumor cell invasion and predicts metastatic disease." J Biol Chem 283: 18344-18354

Yokouchi K, Numaguchi Y, Kubota R, Ishii M, Imai H, Murakami R, Ogawa Y, Kondo T, Okumura K, Ingber DE, Murohara T (2006). "l-Caldesmon regulates proliferation and migration of vascular smooth muscle cells and inhibits neointimal formation after angioplasty" Arterioscler Thromb Vasc Biol 26(10): 2231-2237

Yoshio T, Morita T, Kimura Y, Tsujii M, Hayashi N, Sobue K (2007). "Caldesmon suppresses cancer cell invasion by regulating podosome/invadopodium formation." FEBS Lett 581(20): 3777-3782

Yu EY, Wilding G, Posadas E, Gross M, Culine S, Massard C, Morris MJ, Hudes G, Calabrò F, Cheng $\mathbf{S}$ et al. (2009). "Phase II study of dasatinib in patients with metastatic castration-resistant prostate cancer." Clin Cancer Res 15(23): 7421-7428 


\section{Lebenslauf}

\section{Persönliche Daten:}

Name:

Geburtsdatum:

Geburtsort:

Staatsangehörigkeit:

\section{Bildungsweg:}

$$
\begin{aligned}
& 1982-1992 \\
& 1992-2001 \\
& 2001-2002
\end{aligned}
$$

$2002-2006$

$2004-2005$

$2006-2007$

$2007-2010$
Sandra Gräfin von Hardenberg, geb. Beckemeyer 23.04.1982

Minden

deutsch
Besuch der Grundschule Kutenhausen

Besuch des städtischen Gymnasiums in Petershagen

Studium der Biologie und Mathematik auf gymnasiales

Lehramt an der Carl-von-Ossietzky-Universität in

Oldenburg

Studium der Biologie an der Georg-August-Universität in Göttingen

Erasmus Austausch-Studium an der Universität in Lund, Schweden

Diplomarbeit am Institut für Humangenetik der GeorgAugust-Universität in Göttingen

Experimentelle Arbeiten zur Dissertation am Institut für Humangenetik der Georg-August-Universität in

Göttingen 


\section{Danksagung}

Ich möchte mich bei Herrn Prof. Dr. Dr. W. Engel für die Bereitschaft, diese Arbeit zu betreuen, seine fortwährende Diskussionsbereitschaft und seine Anregungen bedanken.

Bei Frau Prof. Dr. S. Hoyer-Fender möchte ich mich für die Übernahme des Korreferat sowie das Interesse und die konstruktive Kritik bedanken.

Bei meiner Betreuerin Frau Dr. Silke Kaulfuß möchte ich mich für die interessante Aufgabenstellung sowie für das unglaubliche Interesse und das Engagement am Fortgang dieser Arbeit bedanken. Weiterhin möchte ich mich für die Diskussionsbereitschaft und das Annehmen von neuen Ideen, die ständige Hilfsbereitschaft bei der Planung der Experimente und die gründliche Durchsicht sowie Korrektur der Manuskripte bedanken.

Herrn Prof. Dr. Burfeind danke ich für die freundschaftliche Laboratmosphäre, die Hilfsbereitschaft, das Interesse an der Arbeit und das Korrekturlesen der Abstracts, Poster und des Papers.

Bei Herrn PD Dr. S. Schweyer möchte ich mich für die Zusammenarbeit bei der Auswertung der histopathologischen Befunde der Mäuseschnitte bedanken.

Stefan Wolf und Jutta Schröder möchte ich für die Pflege und das sorgfältige Überwachen der transgenen Mäuse sowie die Unterstützung bei der Präparation und Kastration der Mäuse bedanken.

Ein ganz lieber Dank gilt vor allem Rovena, Daria, Henning, Jose, Nicole, Sascha, Christoffer, Maren und Hilka für die freundschaftliche, hilfsbereite, unterstützende und lustige Atmosphäre im Labor. Britta danke ich sehr für wertvolle Unterstützung, besonders mit den Primärzellen, in einer wichtigen Phase der Arbeit. Vielen Dank dafür!

Bei allen Mitarbeitern des Instituts für Humangenetik bedanke ich mich für das freundliche Miteinander.

Mein herzlichster Dank gilt meinem Wichard für sein Interesse, seine Unterstützung und sein uneingeschränktes Vertrauen sowie meinen Eltern für Ihre Unterstützung bei jeglichen Problemen und die Möglichkeit meine Ausbildung nach meinen Vorstellungen zu gestalten. 